Miriam Gallegos Navas (Coordinadora)

\title{
La inclusión de las TIC EN LA EDUCACIÓN DE PERSONAS CON DISCAPACIDAD
}

RELATOS DE EXPERIENCIAS

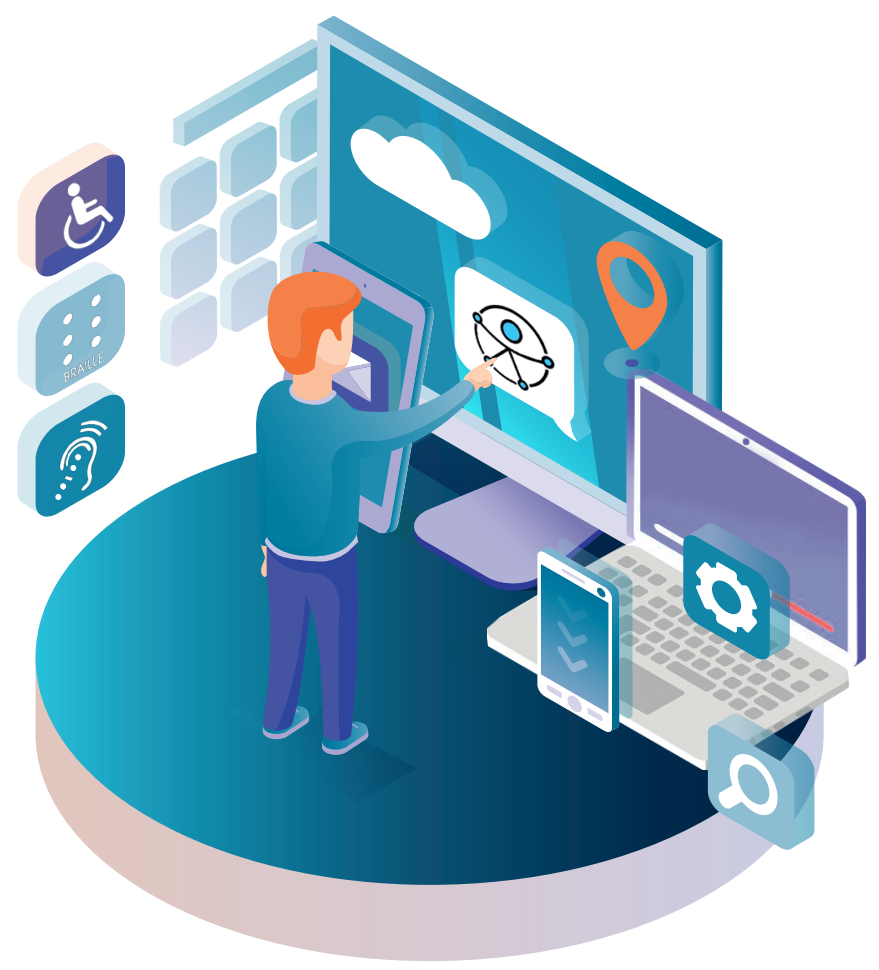




\section{La inclusión de las TIC en la educación de personas con discapacidad Relatos de experiencias}





\author{
Miriam Gallegos Navas \\ Coordinadora
}

\title{
La inclusión de las TIC en la educación de personas con discapacidad Relatos de experiencias
}
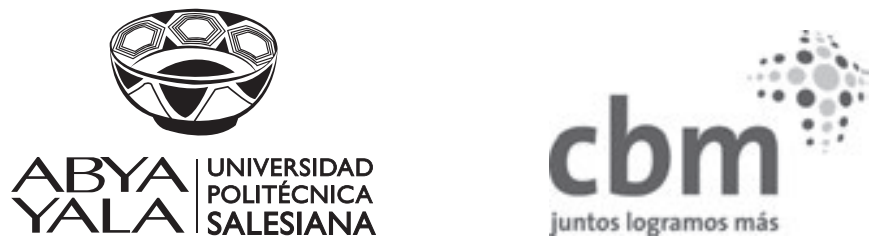

2018 


\section{LA INCLUSIÓN DE LAS TIC EN LA EDUCACIÓN DE PERSONAS CON DISCAPACIDAD}

\section{Relatos de experiencias}

(c) Miriam Gallegos Navas (Coordinadora)

1ra edición: $\quad$ Universidad Politécnica Salesiana

Av. Turuhuayco 3-69 y Calle Vieja

Cuenca-Ecuador

Casilla: 2074

P.B.X. $(+593$ 7) 2050000

Fax: $(+5937) 4088958$

e-mail: rpublicas@ups.edu.ec

www.ups.edu.ec

CARRERA DE EDUCACIÓN

MAESTRÍA DE EDUCACIÓN ESPECIAL

Grupo de Investigación de Educación Inclusiva (GEI)

Revisores: $\quad$ Miriam Bernarda Gallego Condoy, Jessica Jazmín Rivadeneira Peñafiel, Alberto Rusbel Duchi Bastidas.

Colaboradores: $\quad$ Jessica Jazmín Rivadeneira Peñafiel, Washington Ramiro Rubio Rubio, Fulvio Elívar Cabrera Jiménez, Mishel Pallo Ushiña.

Con el apoyo de CBM Internacional

Derechos de autor: 055217

ISBN:

978-9978-10-331-9

Edición, diseño, $\quad$ Editorial Universitaria Abya-Yala diagramación Quito-Ecuador e impresión

Tiraje: 300 ejemplares

Impreso en Quito-Ecuador, diciembre de 2018

Publicación arbitrada de la Universidad Politécnica Salesiana 


\section{Índice}

Índice de Figuras ...............................................................................

Índice de Tablas ................................................................................. 12

Presentación ................................................................................................. 13

Introducción ............................................................................................ 17

Viaje al centro de las TIC inclusivas ..................................................... 29

Experiencias de buenas prácticas............................................................ 47

1. Reciclaje de tecnologías de consumo como apoyo

a las personas con baja visión

Franklin Aguayo, Miriam Gallegos

2. Aplicaciones informáticas para el aprendizaje

de inglés en universitarios con discapacidad visual

Cristian Castañeda, Miriam Gallegos

3. Las TIC en tres instituciones educativas de Quito

Alberto Duchi

4. Pantalla digital MIMIO en el área de comunicación

con estudiantes con discapacidad intelectual de segundo de básica

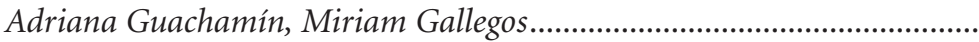

5. ¿Estudiantes aburridos o propuesta pedagógica poco motivadora? Experiencia de inclusión significativa de las TIC

en los procesos de enseñanza y aprendizaje

Evelina Mariel Lamberti.

6. La incorporación de las TIC en el aprendizaje.

Mejoramiento de la calidad de vida (testimonio)

Pablo Laverde, Miriam Gallego, Jessica Rivadeneira 


\section{6}

7. Proyecto "Sígueme" una iniciativa para apoyar

a estudiantes con Trastornos del Espectro Autista

Giovanna Bedoya, Miriam Gallegos

8. Fortalecimiento de las funciones cognitivas

en adultos mayores con discapacidad

Yolanda Ortiz, Miriam Gallegos.

9. MIMIO: herramienta de interaprendizaje

en personas con discapacidad intelectual

Daniel Salas, Miriam Gallegos

10. La familia asume el uso de las TIC como apoyo al aprendizaje

Silvania Salazar, Miriam Gallegos

11. Apoyos para garantizar el acceso al aprendizaje

de los estudiantes con discapacidad en el nivel superior

Miriam Gallego, Mauricio Suárez, Andrés Jaramillo..

12. Desarrollo de funciones básicas mediante un diseño de intermediación cognitiva Gloria Sánchez, Miriam Gallegos...

13. ¡Mis manos enseñan, tus ojos aprenden! Fotografía y producción de video en la educación de personas sordas Jaime Sarmiento..

14. La teoría del Neuroaprendizaje a través de las TIC en personas que asisten al servicio de rehabilitación Juan Carlos Guachamin, Miriam Gallegos

Conclusiones

Bibliografía

Informantes 


\section{Índice de Figuras}

Figura 1. Beneficio del uso de las TIC en la educación

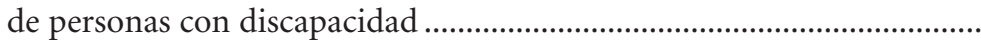

Figura 2. El costo beneficio del uso de las TIC

en la educación de estudiantes con discapacidad

Figura 3. Acceso a internet en las instituciones educativas ....................... 23

Figura 4. ¿Es usuario de las TIC en su vida profesional?............................. 24

Figura 5. Uso de programas informáticos por parte de los docentes...... 24

Figura 6. Capacitación de los docentes........................................................ 25

Figura 7. Formación de mensajes a través de pictogramas ....................... 37

Figura 8 . Videojuegos que favorecen el movimiento ocular ..................... 42

Figura 9. Software Super Visión .................................................................... 49

Figura 10. Uso de software en una Tablet.................................................. 50

Figura 11. Menú de Configuración del software........................................ 50

Figura 12. Ejemplo de utilización del software ............................................ 51

Figura 13. Uso de gafas electrónicas bifocales.......................................... 51

Figura 14. Recursos y materiales con adaptación ......................................... 56

Figura 15. Docentes del Grupo de Educación Inclusiva GEI..................... 61

Figura 16. Estudiantes del grupo GAOS que apoyaron en Emaús ........... 64

Figura 17. Estudiantes del grupo GAOS que apoyaron en Insfidim ....... 65

Figura 18. Estudiantes del grupo GAOS

que apoyaron en la escuela Santa Teresita ...................................................... 65 


\section{8}

Figura 19. Capacitación en la escuela

Santa Teresita del valle de Fe y Alegría

Figura 20. Capacitación en Instituto

Fiscal de Discapacidad Motriz INSFIDIM ..................................................... 68

Figura 21. Capacitación en la Emaús............................................................... 68

Figura 22. Participación docente las tareas participativas

Escuela Santa Teresita del Valle de Fe y Alegría ....

Figura 23. Participación docente en las tareas participativas,

Escuela Emaús.

Figura 24. Palabras de bienvenida y agradecimiento

del Coordinador del grupo GAOS

Figura 25. Palabras de agradecimiento del grupo GEI.

$\begin{array}{ll}\text { Figura 26. Palabras de agradecimiento de los estudiantes, grupo GAOS... } & 71\end{array}$

Figura 27. Entrega de certificados de participación..................................... 72

Figura 28. Grupo de docentes participantes .............................................. $\quad 72$

Figura 29. Grupo de docentes y estudiantes capacitadores........................ 73

Figura 30. Pantalla Mimio ................................................................................ 78

Figura 31. Utilitarios Pantalla Mimio .......................................................... 78

Figura 32. Software Sebran.......................................................................... 79

Figura 33. Software Mini Sebran ............................................................... $\quad 80$

Figura 34. Ejemplo de Software de Proyecto Aprender ............................... 81

Figura 35. Estudiantes trabajando con la pantalla Interactiva Mimio .... 82

Figura 36. Tiempo promedio de adquisición de la lecto escritura básica y operaciones matemáticas de suma y resta ............................................... 84

Figura 37. Agrado por acudir a cada asignatura/10 .................................... 84

Figura 38. Fabián, descubriendo y conociendo diversos seres vivos con la aplicación AURASMA . 
Figura 39. Jeremías resolviendo una evaluación de Geometría en EDILIM

Figura 40. Lucas programando al robot DASH con la aplicación GO!... 90 Figura 41. Estimulación multisensorial por el robot DOT con la aplicación GO!

Figura 42. Jeremías, escribiendo créditos en una fotonovela, utilizando Microsoft Publisher

Figura 43. Candela, participando en las Olimpiadas de Informática, Instancia provincial llevada a cabo en la ciudad de Córdoba, Argentina ..

Figura 44. Pablo Laverde, "Programador Matemático". 103

Figura 45. Apoyo incondicional de la madre 105

Figura 46. Gusto por la Literatura 106

Figura 47. Discursos presidenciales

Figura 48. Inicios en la Universidad

Figura 49. Actividades de relajación

Figura 50. Captar atención

Figura 51. Motivar a mirar y topar la pantalla

Figura 52. Manejo de pantalla

Figura 53. Favorecer la relación y adquisición de conocimientos

Figura 54. Evaluación Inicial Atención visual

Figura 55. Evaluación Final Atención visual

Figura 56. Evaluación Inicial Adquisición de conocimientos

Figura 57. Evaluación Final Adquisición de conocimientos

Figura 58. Evaluación Inicial Conducta

Figura 59. Evaluación Final Conducta.

Figura 60. Evaluación Inicial Adquisición de lenguaje 
Figura 62. Algunas técnicas de gamificación

Figura 63. Estudiante haciendo uso de ratón.

Figura 64. Estudiante usando su tablero de comunicación en el sistema Pikto Plus

Figura 65. Utilización de Pictogram Room

Figura 66. Estudiante trabajando con Pictogram Room

Figura 67. Estudiantes recibiendo aromaterapia, estimulación visual, auditiva, vestibular, y propioceptiva

Figura 68. Uso de herramientas didácticas.

Figura 69. Estudiantes de EINA

Figura 70. Estudiantes en Educación Física de EINA

Figura 71. Estudiantes de EINA utilizando el lápiz digital de la pantalla MIMIO

Figura 72. Jorge Sebastián de 2 años empieza su proceso de formación ...

Figura 73. Fundación EINA

Figura 74. Jorge Sebastián con los juegos interactivos

Figura 75. Escuela El Parvulario de la Fundación EINA

Figura 76. Clase de computación

Figura 77. Defensa de tesis

Figura 78. Incorporación y presentación de su trabajo académico......

Figura 79. Uso de información digital en su entrevista de trabajo.

Figura 80. Uso de la tiflobiblioteca

Figura 81. "Víctor Reader".

Figura 82. Ciclo de aprendizaje del programa Jaws.....

Figura 83. Uso del Software Jaws

Figura 84. Lectores de pantalla.

Figura 85. Usuarios de la Tiflobiblioteca 
Figura 86. Actividades del proceso de formación ........................................ 162

Figura 87. Panel "Simón Dice” ..................................................................... 166

Figura 88. Panel del lenguaje................................................................ 168

Figura 89. Recursos utilizados............................................................... 170

Figura 90. Trabajo sostenido en Fe y Alegría............................................... 174

Figura 91. Formación en fotografía en Fe y Alegría .................................. 176

Figura 92. Formación en producción audiovisual en Fe y Alegría ........... 177

Figura 93. Metodología de la propuesta ................................................... 178

Figura 94. Plan terapéutico individual ....................................................... 183

Figura 95. Bouncy Balls ........................................................................... 184

Figura 96. Ejemplos de uso del software ................................................... 185

Figura 97. Dispositivos adaptados ............................................................ 185

Figura 98. Sofía usando El visor 3D (segundo mes)................................. 186

Figura 99. VR. Ocean Aquarium 3D-Aplicando la música bineural ....... 187

Figura 100. Recursos utilizados en experiencia según el neuroaprendizaje .......................................................................... 190 


\section{Índice de Tablas}

Tabla 1. Uso de redes sociales como mecanismo de comunicación ......... 26

Tabla 2. Resumen de fases ................................................................................ 45

Tabla 3. Unidades y temas propuestos.......................................................... 62

Tabla 4. Logros obtenidos......................................................................... 82

Tabla 5. Beneficiarios del proyecto............................................................. 117

Tabla 6. Recursos utilizados Proyecto Sígueme........................................... 122

Tabla 7. Uso de la tecnología ........................................................................ 129

Tabla 8. Recursos de las aulas multisensoriales........................................... 137

Tabla 9. Resultados del diagnóstico inicial .............................................. 187

Tabla 10. Cuadro resumen de logros

con relación al Coeficiente Intelectual........................................................ 188

Tabla 11. Cuadro resumen .................................................................... 188 


\section{Presentación}

Decía Freud que las palabras y la magia fueron al principio una misma cosa. ¿Será por eso que muchos seguimos buscando en los libros ese halo luminoso y mágico que nos ayude a conectarnos con otras experiencias y a encontrar nuevas ideas?

Si es usted uno de esos buscadores, este libro le gustará. Sus autores nos ofrecen sus conocimientos y esfuerzo profesional para proponernos un amplio espectro de buenas prácticas con TIC (Tecnologías de la Información y la Comunicación). Han organizado de forma eficiente metodologías, recursos y valores para que visualicemos que la escuela debe ser para todos.

Sus experiencias son amplias y variadas. Mientras que unas son sofisticadas propuestas, como aprovechar el celular o la tableta para mostrarnos nuevas posibilidades de realidad aumentada, otras, más sencillas tecnológicamente y no por ello menos válidas, combinan el uso de software con tecnología de bajo costo (paneles táctiles, difusores de aroma,...). Su finalidad es la misma: que las personas mejoren sus competencias comunicativas y de aprendizaje a través de las interacciones con otras personas y el apoyo de recursos digitales multimodales y multisensoriales.

El libro induce al lector a un viaje reflexivo. Ofrece propuestas sobre el nuevo papel del docente en una escuela cada vez más heterogénea en la que los tradicionales libros de texto conviven naturalmente con los contenidos digitales e interactivos. Una escuela inclusiva en la que, tanto el alumnado en general como el etiquetado con Necesidades Específicas de Apoyo Educativo (NEAE) en particular, aspiran a participar en una educación distinta a la de sus antecesores. Esperan aprender 
escuchando, viendo y, sobre todo, "haciendo". Anhelan una metodología que combine diferentes recursos en un ambiente abierto, creativo y colaborativo. Las propuestas memorísticas y repetitivas ya no son el punto de partida; pasan a otro plano. La autora de una de las experiencias mostradas en el libro la titula, con mucho acierto, en forma de reto: “¿Estudiantes aburridos o propuesta pedagógica poco motivadora?”

La familia y la comunidad son consideradas por los autores como elementos potenciadores de la persona. R. Rosenthal, psicólogo de Harvard, demostró que las expectativas de los adultos sobre la capacidad de aprendizaje de un joven le influyen enormemente en su desempeño académico. Este llamado efecto Pygmalion es la cara opuesta de la denominada incompetencia aprendida, potenciada por otra forma de entender la escuela de algunos adultos que, a través de su trato con niños y jóvenes con NEAE, les fomentan la creencia de que sus esfuerzos por aprender fracasarán inevitablemente y, si no sucede así y tienen éxito, tienden a atribuirlo a la suerte o a algo externo a ellos mismos. Los autores del libro están lejos de esta idea y nos ofrecen prácticas exitosas reforzadas por testimonios personales que son ejemplos de superación, esfuerzo y altas expectativas.

Las iniciativas innovadoras descritas en estas líneas, como las pantallas digitales o las orientaciones didácticas basadas en la gamificación del currículo, pretenden crear entornos que desde lo tecnológico o lo metodológico inspiren al alumnado a querer saber más y generar conocimiento compartido. El aprendizaje se produce muchas veces tanto por la introspección y el análisis de los comportamientos como a través del ejemplo y la generalización.

Por último reseñar que la Universidad Politécnica Salesiana y Christoffel Blindenmission (CBM) han impulsado la edición de este libro. Este hecho muestra su compromiso solidario y académico con la investigación. Miriam Mariana De Jesús Gallegos, directora de la Maestría de Educación Especial, con ayuda de su equipo de investigación, ha conseguido realizar un excelente trabajo de coordinación y sistemati- 
15

zación al trazar conexiones entre diferentes experiencias. Nos recuerda el libro La vida secreta de los árboles de Peter Wohlleben y las cosas sorprendentes sobre estos vegetales y la vida subterránea de sus raíces que describe en él.

Cuenta este autor cómo forman una sociedad interconectada, y cuándo un árbol está enfermo la gran comunidad de árboles que lo rodea en el bosque lo ayudan a mantenerse vivo por medio de esa red que vibra debajo de la tierra. Así como las raíces permiten a los árboles compartir información y ayudarse, esta publicación consigue el mismo propósito. El lector está invitado a participar de su bosque digital de interconexiones y quizás, como decía Proust, encuentre en él ese instrumento óptico que le permita avivar su percepción sobre las posibilidades que las TIC tienen para proporcionarnos una mejor educación inclusiva.

Rafael Sánchez Montoya Doctor en Métodos de Investigación e Innovación Educativa Universidad de Cádiz. España 



\section{Introducción}

"Las TIC constituyen un punto de partida y en muchas ocasiones supondrán la diferencia entre la exclusión y la inclusión. Desde esta perspectiva, si no utilizamos tecnologías inclusivas en las aulas, es probable que estemos contribuyendo a dicha exclusión" (Soto, 2013, p. 14).

El presente texto ofrece a la comunidad educativa varias experiencias relacionadas al uso de las tecnologías de información y comunicación como recurso de apoyo en la educación de estudiantes con discapacidad, experiencias que surgen como, resultado del proyecto de investigación denominado "Estudio de la Aplicabilidad del Enfoque Ecológico Funcional en la Educación de Estudiantes con Discapacidad en el Ecuador", ejecutado por el Grupo de Investigación de Educación Inclusiva (GEI) de la Universidad Politécnica Salesiana del Ecuador entre enero de 2016 y junio de 2017.

El mencionado proyecto se desarrolló en el marco del curso de formación continua de "Diseño Curricular desde una perspectiva ecológica funcional”, auspiciado por CBM Internacional en el que participaron docentes y directivos de instituciones educativas de todo el país que brindaron su aporte al proyecto como informantes directos y recogiendo información que permitió el análisis del estado de la situación educativa de los estudiantes con discapacidad en el país.

Desarrolló cuatro componentes: el primero relacionado con el análisis de la política pública vigente para la educación de la población con discapacidad; el segundo, con la participación de las familias en la educación; el tercero que consistió en el análisis del proceso de transición a la vida joven adulta; y el cuarto con el uso de tecnología en el aula. 
18

Este último componente es el que permitió la sistematización de experiencias ya que, durante el proceso de investigación se evidenció que, en el país existen varias iniciativas vinculadas a la educación de personas con discapacidad mediadas por la tecnología, las mismas estaban invisibilizadas y poco entendidas por la comunidad educativa, y lo más importante, según los profesionales, son altamente aceptadas por los estudiantes.

Esta situación motivó al equipo de investigación a la identificación y difusión de varias experiencias educativas que se desarrollan en el país colocando a la tecnología digital como un recurso didáctico importante para el aprendizaje. Tales experiencias se pueden considerar como buenas prácticas ya que cumplen con las condiciones que la Unesco reconoce en su programa Management of Social Tranformations; de acuerdo a ello, una buena prática debe ser innovadora, efectiva, sostenible y replicable.

La condición de innovadora de una buena práctica va de la mano de la efectividad, ya que evidencia una actuación exitosa que mejora los procesos educativos y los resultados de aprendizaje de los estudiantes, de la misma manera debe ser replicable y de utilidad para la comunidad. Las prácticas presentadas en este guía, promueven soluciones innovadoras de bajo costo, adaptadas a la realidad ecuatoriana para que los profesionales se motiven en multiplicarlas y desarrollar mayor investigación en el campo.

Varias de estas propuestas nacen como resultado de los conocimientos adquiridos por los docentes en el "Curso de Experto en TIC y Discapacidad”, impartido por Creática Fundación FREE, en convenio con la Universidad Politécnica Salesiana.

El texto está dividido en 14 temas cada uno describe la experiencia de usos de las TIC en diferentes entornos educativos, lo que permite al lector entender el desarrollo de cada experiencia desde el planteamiento de la situación que motivó su ejecución, quiénes fueron los gestores, detalles del desarrollo de las experiencias, hasta los resultados de aprendizaje alcanzados. Para ayudar al lector se colocan evidencias fotográficas, así como gráficos de los recursos tecnológicos empleados. 
En la presente guía colocamos dos testimonios: el uno corresponde a una persona con discapacidad, estudiante de la carrera de Sistemas de la Universidad Politécnica Salesiana que cuenta su historia de vida y el impacto de las TIC en su experiencia personal, social y educativa; el segundo testimonio corresponde al trabajo desarrollado por una madre que asume el rol de corresponsable de la educación de su hijo y plantea su experiencia.

Por otro lado, se presentan prácticas desarrolladas en diferentes niveles de educación inicial, básica, bachillerato y superior. Se sumaron a este proyecto instituciones educativas como: Fundación para la Integración del Niño Especial (FINE), Fundación de Enseñanza Individualizada para Niños, Niñas y Adolescentes (EINA), Fe y Alegría Ecuador, Instituto de Educación Especializada del Azuay, Escuela Normal Víctor Mercante Nivel Superior de la República Argentina, Instituto de Educación Especializada del Norte, Centro Traumatológico Integral (CTI). Instituciones que desarrollan acciones de rehabilitación, como el Consultorio Terapéutico Infantil Integral, Fundación Baja Visión Ecuador, que sin ser instituciones educativas generan procesos de estimulación y rehabilitación que coadyuvan en el proceso educativo de las personas con discapacidad.

La presente guía lleva a la práctica lo manifestado en la "Convención de los Derechos de las Personas con Discapacidad” del año 2008, sobre el derecho a recibir información y apoyos de las nuevas tecnologías, de igual manera el derecho de las personas a recibir educación de acuerdo a sus necesidades en un sistema educativo inclusivo.

Se utiliza un lenguaje positivo e inclusivo y para mayor accesibilidad se describen los gráficos expuestos. Es importante anotar que las aplicaciones y programas utilizados no son de exclusiva utilización de las personas con discapacidad son herramientas de apoyo para todo, de esta manera esta guía constituye un recurso para generar acciones inclusivas en las instituciones educativas.

Las TIC son una importante fuente de recursos para el aprendizaje de los estudiantes con discapacidad, permiten la consolidación de 
un modelo educativo que equipara las oportunidades de aprendizaje, se ha tenido mucho cuidado de que, en las experiencias presentadas la tecnología no se convierta en el fin sino en el medio para lograr objetivos pedagógicos, por tanto las experiencias están vinculadas a un currículo, a una planificación donde se expresan aquellos aprendizajes que se quieren lograr con cada uno de los estudiantes; de esta manera las tecnologías se convierten en un recurso para superar las barreras de acceso a la información y producen un impacto positivo en la educación de las personas con discapacidad.

Sin embargo, hay que tomar en cuenta que el potencial transformador de la incorporación de las TIC en la escuela y el resultado de estos logros no depende de la cantidad ni de la sofisticación del equipamiento,

sino de la capacidad de aprender, planificar y transformar, por esta razón cuando las TIC ingresan en la vida escolar, obligan a los docentes, directivos y padres de familia a tomar decisiones que involucran un cambio en su práctica educativa, innovar y a la vez despertar el espíritu investigador.

La inclusión de las TIC en la escuela habilita variadas estrategias de enseñanza, pone en juego diversos modos de aprender, propone nuevos escenarios educativos y a la vez, permite desarrollar competencias para desenvolverse en el contexto social. En consecuencia es el docente conjuntamente con la familia quien propone y lleva adelante la propuesta que más se ajuste a la realidad escolar y a la de sus estudiantes.

\section{Diagnóstico y problema}

La Constitución de la República del Ecuador 2008 establece el alcance y desarrollo que deben lograr las TIC en el Ecuador de acuerdo el Art. 16 manifiesta que "Todas las personas en forma individual o colectiva, tienen derecho a: "El acceso universal a las tecnologías de información y comunicación” mientras que el Art. 17 señala que:

El Estado fomentará la pluralidad y la diversidad en la comunicación, y al efecto: Facilitará la creación y el fortalecimiento de medios de 


\section{1}

comunicación públicos, privados y comunitarios, así como el acceso universal a las tecnologías de información y comunicación. ${ }^{1}$

Dentro de este marco, que reconoce que únicamente la sociedad que aprende a lo largo de toda la vida es una sociedad que se desarrolla y progresa, uno de los mayores retos es brindar herramientas y oportunidades iguales de aprendizaje, que sean sostenibles a lo largo del tiempo; por ello, es necesaria la inclusión de las TIC en el sistema educativo ecuatoriano, en armonía con los desafíos de la sociedad del conocimiento $y$ fortaleciendo la equidad.

Los datos recogidos por el Grupo de Educación Inclusiva de la Universidad Politécnica Salesiana en la investigación Situación actual del uso de la tecnología como recurso de apoyo en la educación de estudiantes con discapacidad en el Ecuador, son el punto de partida para acercarse al rol que tienen las TIC en la educación y motivar a los docentes a presentar sus experiencias y compartirlas en este texto; a continuación se presentan los principales hallazgos de la investigación antes mencionada:

Figura 1

Beneficio del uso de las TIC en la educación de personas con discapacidad

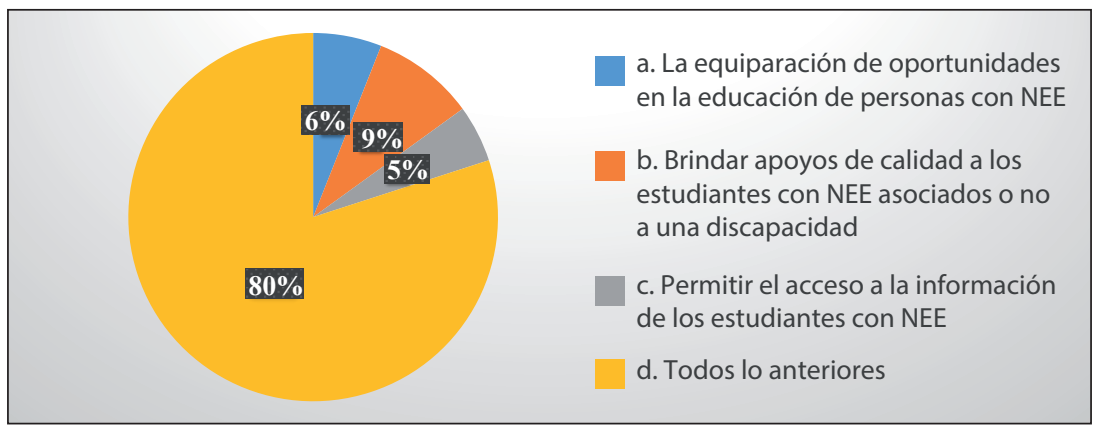

Fuente: Grupo de Investigación de Educación Inclusiva UPS (2016)

1 Constitución de la República del Ecuador. Disponible en: https://bit.ly/2FFdsH9 
Según la figura anterior, el $100 \%$ de docentes encuestados establecen a la tecnología como un medio para brindar mejores oportunidades a estudiantes con Necesidades Específicas de Apoyo Educativo producto de la condición de discapacidad, puesto que es un recurso de acceso a la información y facilita la comunicación.

Figura 2

El costo beneficio del uso de las TIC en la educación de estudiantes con discapacidad

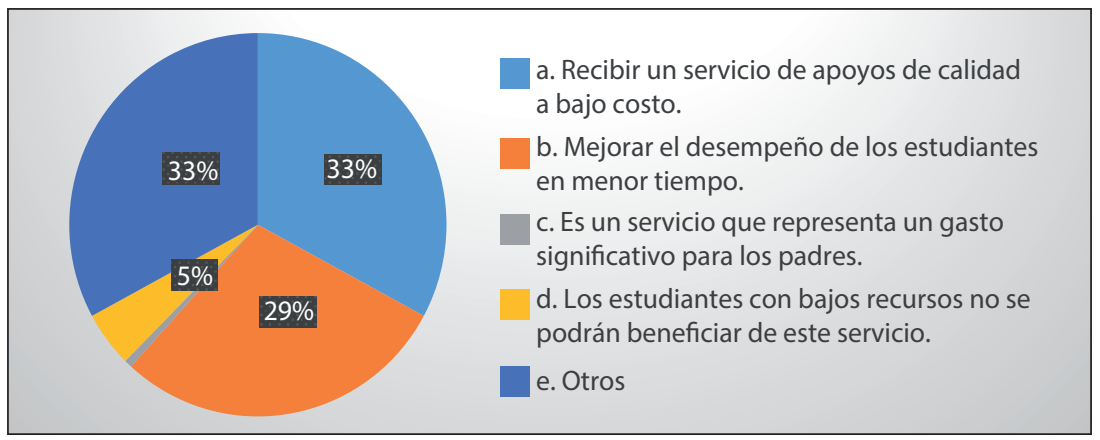

Fuente: Grupo de Investigación de Educación Inclusiva UPS (2016)

Los docentes reconocen la importancia del uso de la tecnología y su capacidad de lograr mayores aprendizajes en menos tiempo y con menos costo; sin embargo, estas reflexiones no forman parte de los proyectos institucionales ni de su vida cotidiana, pues la limitada infraestructura tecnológica con las que cuentan las instituciones educativas es utilizada en primera instancia para actividades administrativas o se limita a ser un recurso audiovisual pero no va más allá ni contribuye en gran medida al aprendizaje.

Pese a los beneficios que los docentes manifiestan en el uso de las TIC, no existen políticas institucionales que favorecen el uso de las mismas; este estudio concluye: que en las instituciones de educación especial no existen políticas institucionales relativas al uso de las TIC como recursos de apoyo en la educación de personas con discapacidad. 
Son escasas o casi nulas las iniciativas enfocadas a proveer de tecnología de apoyo a las instituciones educativas, es importante considerar que los equipos tecnológicos con los que cuentan las instituciones educativas encuestadas son producto de la gestión institucional con el sector privado, donaciones de equipos dados de baja en empresas; en la mayoría de casos la dotación de esta infraestructura básica no vienen acompañadas de mantenimiento, capacitación continua y seguimiento, lo que ha dado como resultado que los equipos sean subutilizados.

La ausencia de conectividad al internet es otra dificultad que se presenta, pues en las instituciones educativas que cuentan con conexión, solo hay cobertura en lugares específicos y usos eminentemente administrativos.

Figura 3

Acceso a internet en las instituciones educativas

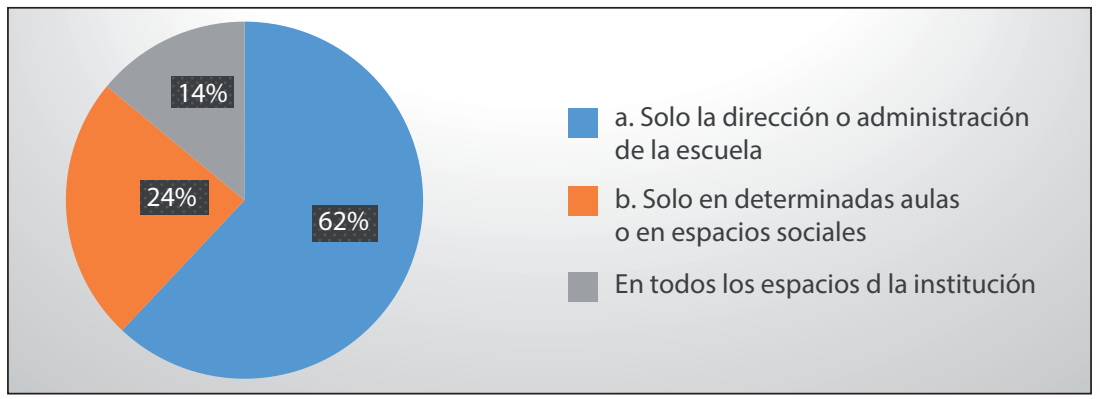

Fuente: Grupo de Investigación de Educación Inclusiva UPS (2016)

Otro importante hallazgo de esta investigación es que el acceso a internet, en su mayoría (62\%), solo se da en la dirección o administración de la escuela, mientras que un $24 \%$ se da endeterminadas aulas o espacios sociales y apenas un 14\% en todos los espacios de la institución. 


\section{4}

Figura 4

¿Es usuario de las TIC en su vida profesional?

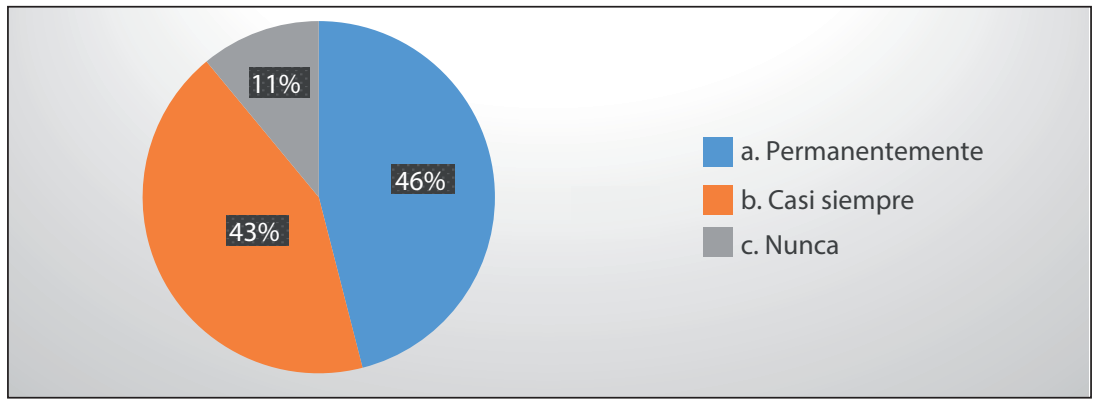

Fuente: Grupo de Investigación de Educación Inclusiva UPS (2016)

Sobre el 50\% de docentes ha adquirido un nivel básico de competencias digitales; los programas más utilizados son el Word, Excel, Power Point, correo electrónico. Gracias a ello, el 46\% de personas es usuario de las TIC permanentemente.

\section{Figura 5}

Uso de programas informáticos por parte de los docentes

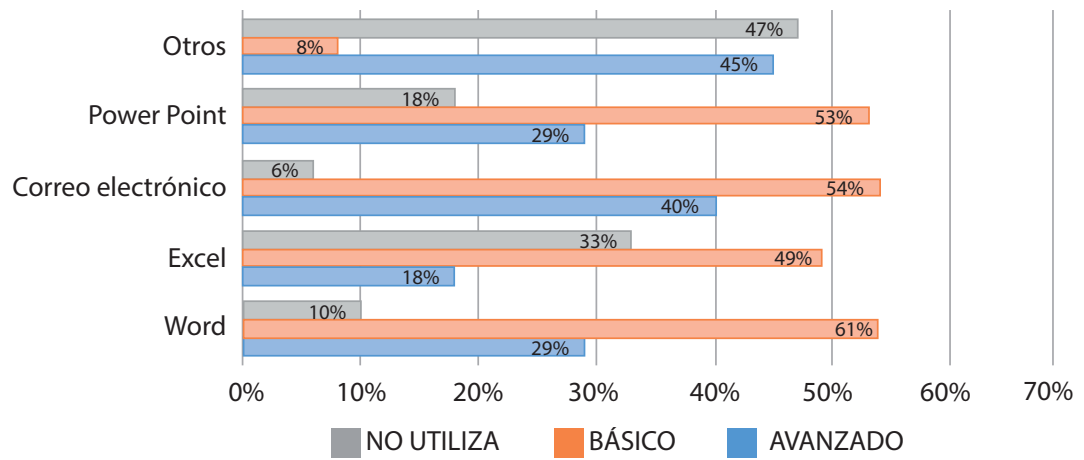

Fuente: Grupo de Investigación de Educación Inclusiva UPS (2016) 
La gran mayoría de docentes menciona la enorme dificultad para utilizar las TIC por falta de formación en el tema, únicamente el 50\% tiene conocimientos de informática básica, mismos que han sido adquiridos por su propia iniciativa. Además, la mitad de docentes utilizan las redes sociales y navegan en internet.

El mismo estudio manifiesta que los docentes no han recibido capacitación para el uso de tecnología a pesar de haber mostrado interés por aprenderlo. Por otro lado la formación en el uso de la tecnología, ha sido por propia iniciativa.

Además, los estudiantes con discapacidad en esta época son usuarios nativos de la tecnología pues la condición de discapacidad no deja de lado esta realidad, sin embargo las instituciones no están respondiendo a este desafío.

Figura 6

Capacitación de los docentes

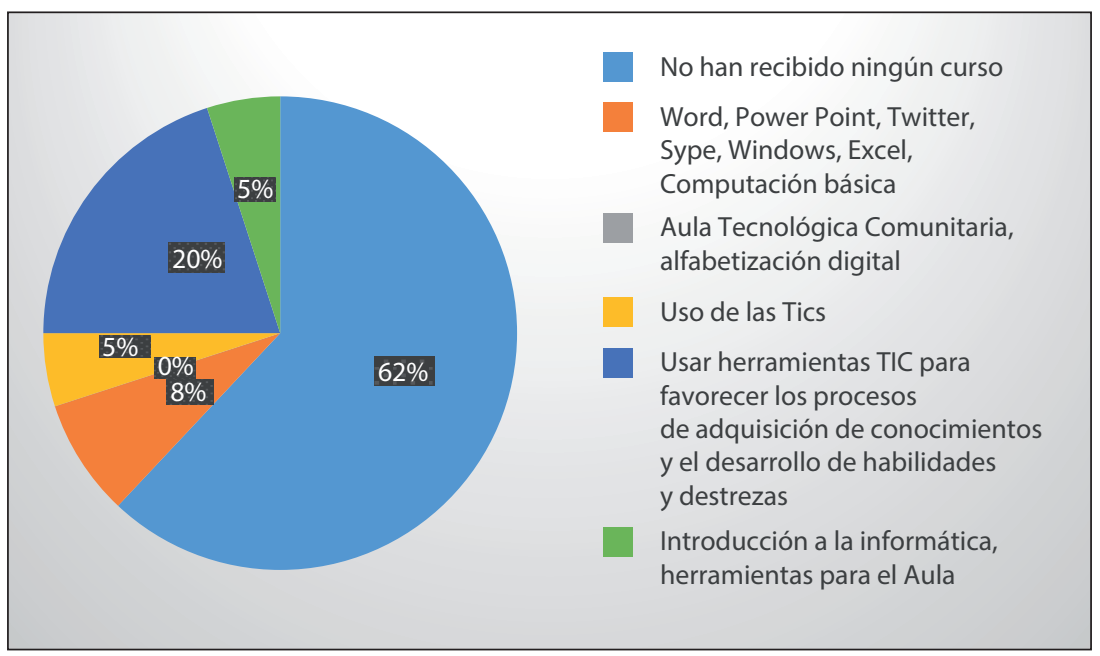

Fuente: Grupo de Investigación de Educación Inclusiva UPS (2016) 


\section{6}

Con relación a los recursos tecnológicos que usan los estudiantes, los resultados son que el $48 \%$ de estudiantes tienen teléfonos celulares y el 58\% cuenta con planes de internet situación que indica que la mitad de estudiantes están usando la tecnología.

En las instituciones educativas que atienden estudiantes con discapacidad cada vez se naturaliza el uso de instrumentos tecnológicos educacionales; sin embargo, no se reconocen ni potencian las capacidades docentes en este tema, ya que se desconocen por ejemplo las posibilidades de comunicación aumentativa que adquieren los estudiantes con el uso de las TIC para que interactúen de manera efectiva en sus entornos sociales, ricos en información y en constante cambio.

Según el 48\% de los docentes encuestados, las redes sociales más utilizadas son: Facebook y WhatsApp, el correo electrónico y Skype son los menos utilizados, sin embargo estos recursos no se utilizan como medio de comunicación con los estudiantes y sus familias.

Tabla 1

Uso de redes sociales como mecanismo de comunicación

\begin{tabular}{|l|c|c|}
\hline & Sí & No \\
\hline Facebook & $42 \%$ & $58 \%$ \\
\hline Correo electrónico & $8 \%$ & $92 \%$ \\
\hline WhatsApp & $45 \%$ & $55 \%$ \\
\hline Skype & $4 \%$ & $96 \%$ \\
\hline Otros & & \\
\hline
\end{tabular}

Fuente: Grupo de Investigación de Educación Inclusiva UPS (2016)

Otro estudio que visibiliza la situación del uso de la tecnología en la educación de personas con discapacidad es el informe sobre el "Uso de las Tecnologías de Información y Comunicación (TIC) en la Educación para Personas con Discapacidad o desarrollado por la UNESCO y 
la fundación Trust For The Américas"2: los resultados de este informe, coinciden con lo anteriormente citado. Uno de los hallazgos es que en la región de Latinoamérica existe falta de docentes capacitados en recursos tecnológicos de apoyo a los estudiantes con discapacidad, esto acompañado del costo de la tecnología y la infraestructura limitada constituye otro punto importante de este estudio y debilidad en la implementación de las políticas de infraestructura tecnológica en las instituciones educativas.

Entre los factores que obstaculizan los avances hacia una sociedad más inclusiva, teniendo en cuenta la inclusión digital, se encuentran el enfoque médico rehabilitador y el desconocimiento sobre la discapacidad en las autoridades y la sociedad. Hay desconocimiento sobre los temas de la discapacidad, el tema de las TIC y las ventajas que conlleva el uso de las mismas para lograr la igualdad de oportunidades en la inclusión de las personas con discapacidad en la educación y otras áreas de la vida.

Para lograr un cambio del enfoque médico rehabilitador, y el desconocimiento sobre la discapacidad, y el tema de las TIC y las TAC (Tecnologías del Aprendizaje y el Conocimiento) los países de la región y las organizaciones que trabajan en torno a este tema deben realizar actividades de promoción y difusión de la Convención sobre los Derechos de las Personas con Discapacidad a todos los niveles, para que a través de sus propósitos, principios y obligaciones generales se garanticen los derechos de este sector. Asimismo recomienda profundizar en cómo facilitar la transición de los centros de educación especial hacia centros de recursos tecnológicos, no solamente de apoyo y asesoría pedagógica.

Una importante recomendación de este estudio es la promoción de alianzas con organismos e instituciones que trabajan con tecnologías, para que se formulen e implementen programas que permitan el acceso y provisionamiento de equipos adaptados que respondan a los retos de las personas con discapacidad. Así como también, definir elementos y

2 Disponible en: https://goo.gl/3XY7ej 


\section{8}

criterios para la identificación de buenas prácticas que se estén generando con respecto al uso de las TIC y TAC (Tecnologías del Aprendizaje y el Conocimiento) en la educación inclusiva de las personas con discapacidad, con el objetivo de difundirlas, multiplicarlas y elevarlas a nivel de programas. Se debe suscitar la integración de prácticas provenientes de la sociedad civil, universidades, instituciones tecnológicas, gobierno, etc., fundamentales para alcanzar la inclusión plena, mediante las Tecnología de la Información y la Comunicación. 


\section{Viaje al centro de las TIC inclusivas}

Rafael Sánchez Montoya

\section{Romper el estigma}

Eduardo tiene 7 años y sus padres no desean mandarlo a una escuela especial; quieren que vaya a una común. No camina, puede mover los brazos y mantener el tronco erguido y, si se le ayuda, da pequeños pasos. Sus padres le han comprado una computadora. Al principio no podía controlar el ratón pero ya puede hacerlo, siempre con mucha dificultad. Vive en una pequeña localidad y ha cursado preescolar. Tiene la suerte de que sus compañeros de clase colaboran con él y no es motivo de bromas. Su problema principal es que no articula ninguna palabra, así que no puede comunicarse oralmente. Los padres consiguen entenderlo gracias a un lenguaje de señas muy particular que se han inventado. Por favor, Eduardo necesitaría con urgencia un programa para que pueda comunicarse con la maestra.

La narración da luces para tratar el tema del uso de TIC por parte de los alumnos que tienen dificultad de comunicación, para aprender a vivir con autonomía o alcanzar las competencias establecidas en los currículos escolares.

Los docentes incluiríamos a Eduardo en el grupo de alumnos con Necesidades Educativas Especiales (NEE) o, como últimamente se hace con mayor precisión, alumnos con Necesidades Específicas de Apoyo Educativo (NEAE).

Si volvemos al correo observaremos a unos padres muy preocupados por el presente y, lógicamente, por el futuro de su hijo. Destaca- 
mos dos deseos que creemos que son paradigmáticos de la situación. En primer lugar, el querer que su hijo consiga un sistema de comunicación que le permita interactuar con los demás de forma legible, con autonomía y calidad. Y en segundo lugar, que realice su proceso de socialización y educación en un centro regular.

Conseguir estos deseos no es tarea fácil y supone luchar contra muchas barreras tanto físicas como mentales. La estigmatización es una de las más difíciles de superar, ya que supone ir contra viejas concepciones estereotipadas que conceptualizan actitudes negativas de la población con respecto a la NEAE. Se suele hablar de alumno discapacitado como un todo, y no de alumno normal que tiene una restricción o ausencia de capacidad para realizar determinadas actividades. Bajo el modelo del estigma es frecuente que algunas personas se refieran a los alumnos sordos como sordomudos, esto es un error pues pueden comunicarse de forma signada, oral o bilingüe. Otras veces se cree que las dificultades para comunicarse, por escrito o de forma oral, que presentan algunas personas con parálisis cerebral se deben a una discapacidad intelectual, cuando no es así e incluso muchas de ellas superan su déficit en el sistema nervioso central para desarrollar sus competencias lingüísticas utilizando un procesador de textos y la síntesis de voz, si su habla es ininteligible.

Recibir a alumnos con NEAE en un centro de educación regular es una de las experiencias más complejas y desafiantes para un docente, ya que supone adaptar la práctica educativa a las necesidades del alumno. El concepto de adaptación tiene un carácter amplio; para llevarla a cabo desearíamos contar con personal calificado que diseñe, si fuera necesario, un plan que permita:

- Modificar los espacios físicos y eliminar las barreras arquitectónicas hasta facilitar la movilidad en silla de ruedas o con bastón de ciego.

- Adaptar el equipamiento con un mobiliario apropiado a las necesidades de los alumnos desde el que resulte fácil acceder al equipo informático. 
- Acomodar el tiempo a los ritmos del alumno.

- Incluir ayudas pedagógicas (actividades complementarias para el aprendizaje del braille, Lenguaje de Señas, recursos TIC, etc.) y seleccionar una metodología que incluya, modifique o excluya los contenidos que se consideren convenientes.

No podemos olvidar que, aunque estamos a favor de la mayor inclusión del alumno. En ocasiones el "Aula abierta" especializada de educación especial ${ }^{3}$ en centros ordinarios es una opción cuando el alumno requiera de una atención individualizada, con adaptaciones significativas que no puedan ser atendidas en el marco del aula ordinaria con apoyos. El alumnado del "Ala abierta" compartirá con el resto de compañeros del centro espacios comunes y tiempos de recreos, así como actividades extraescolares, de acuerdo con las posibilidades planificadas para dichas acciones.

Partiendo de la opinión de Ken Robinson (2015) quien afirma que no sabemos cómo será el futuro para el que estamos educando pero que una de las pocas certezas es que el alumnado vivirá fuertemente condicionado por las TIC. Esta situación obliga a una reconceptualización de la educación especial, no es una tarea fácil pues sabemos que nuestro cerebro es experto en crear patrones de pensamientos rutinarios, casi mecánicos y por ello el advenimiento de las TIC habría que aprovecharlo para adquirir nuevas formas de pensar y actuar dentro del modelo de la Escuela Inclusiva.

3 En España las "Aulas abiertas" se encuentran ubicadas en un centro ordinario para aquellos alumnos que precisan adaptaciones curriculares muy significativas. Es destinatario de esta medida de atención a la diversidad, el alumnado con necesidades educativas graves y permanentes derivadas de: a) Discapacidad psíquica severa. b) Pluridiscapacidad: discapacidad sensorial auditiva y/o visual severa o profunda asociada a discapacidad psíquica; discapacidad motórica grave asociada a discapacidad psíquica, y discapacidad psíquica con alteraciones graves de comunicación. 


\section{2}

\section{Círculo de invisibilidad}

Una de las consecuencias de considerar a la discapacidad como un estigma es que muchas veces las personas son excluidas de las decisiones que les afectan como ciudadanos. Se acuerdan de aspectos muy importantes sobre sus vidas sin contar con ellos, como si fueran invisibles. Es como si estuvieran escondidas en el cuarto de atrás.

Sin duda es injusta la expresión "otra vez nos han dejado fuera" es un sentimiento común en muchos estudiantes con NEAE al ver que sus gobiernos invierten en tecnologías que no pueden utilizar. De todas formas debemos ser optimistas y esperar que, gracias a la toma de conciencia de las entidades y gobiernos implicados, se vayan adoptando medidas para evitar que se perpetúe, en esta era tecnológica, el ciclo de invisibilidad de la discapacidad.

¿Cómo invertir este proceso? Partiendo del diseño del prototipo hasta su fabricación que se hagan visibles las necesidades de las personas con NEAE, es decir, que se tengan en cuenta los principios del Diseño Universal. Aplicar estos principios supone abrir las TIC a todas las personas, sin importar sus aptitudes motoras, sensoriales o cognitivas, $y$ conseguir que el software, el hardware y los aspectos ergonómicos sean amigables y satisfactorios para todos los usuarios. La propuesta es no crear entornos o productos específicos para un usuario medio imaginario, sino fabricar productos desde el punto de vista ecológico en el que se tengan en cuenta las necesidades e intereses de todos los posibles usuarios. Se trata de enfatizar al individuo, facilitar su inclusión, buscar la igualdad y no clasificar a los productos e individuos por déficit.

Un buen ejemplo de Diseño Universal es el software El árbol mágico de las palabras. ${ }^{4}$ Elaborado por profesionales especializados en la atención a niños y jóvenes con ceguera o baja visión. Han hecho un importante esfuerzo por cumplir las normas del Diseño Universal con 
el fin de que pueda ser utilizado por personas videntes. Independientemente de la calidad del software que puede ser debatida, no hay duda que se sitúa dentro de los principios de igualdad de oportunidades de la Escuela Inclusiva para que pueda ser utilizado por todos los alumnos.

\section{Inteligencia ambiental}

Si profundizamos en el deseo de romper el paradigma del déficit y navegar en el barco del diseño para todos, podemos avanzar y tomar un concepto más amplio y complementario para llegar al puerto tecnológico emergente denominado "Inteligencia Ambiental".

Esta concepción implica diseñar las TIC de tal manera que tengan en cuenta la presencia de la persona y la situación en la que se encuentra, adaptándolas y respondiendo a sus necesidades, costumbres y emociones. Consiste en integrar la tecnología en el entorno para que las personas se beneficien de sus funciones sin percibir que la usan, haciendo que sus interacciones sean amigables, fáciles y beneficiosas para todos.

De la Inteligencia Ambiental destacamos tres características:

- Ubicuidad, que le permite acompañar al usuario allá donde esté (hogar, escuela, medio de transporte, hospital, en movimiento por la calle, etc.),

- Invisibilidad por la posibilidad de pasar desapercibida en el medio físico.

- Inteligencia por su capacidad para adaptarse a las preferencias de la persona así como una perspectiva humanista frente al extendido determinismo tecnológico. Estas investigaciones involucran a expertos de diversas áreas de conocimiento como psicología cognitiva, ergonomía, ingeniería de software, filología, inteligencia artificial y otras.

5 Disponible en: https://goo.gl/vRSmHG 
La Inteligencia Ambiental es una bonita utopía que poco a poco va teniendo más presencia en la sociedad aunque realmente, ¿qué beneficios le puede reportar al estudiante?; para explicarlo pensemos en Catalina, que es una joven sin comunicación oral, con parálisis cerebral, que utiliza la computadora prácticamente en todos los entornos cotidianos. Las TIC se han integrado a su silla de ruedas con la misma naturalidad que un bastón de ciego o un audífono a otras personas. Gracias a ella, Catalina ha mejorado su nivel de independencia. Esta situación, sin embargo, sabemos que no es frecuente. Conocemos muchos alumnos que, gracias a su tablet o celular tienen un buen nivel de comunicación e interacción con sus compañeros, maestros en el colegio, familiares y amigos de su entorno; pero ésta se interrumpe cuando sale de los ámbitos mencionados, porque su computadora no cumple todos los principios de la Inteligencia Ambiental, en este caso el de ubicuidad.

\section{Las TIC andamiaje del desarrollo personal}

Utilizamos la metáfora del andamiaje -scaffolding- para explicar el papel de las TIC como estructuras de apoyo para que los alumnos que tienen dificultades dentro del proceso de Inclusión y gracias a las tecnologías son capaces de progresar y mejorar en su comunicación, su aprendizaje, el ocio, el control ambiental o la transición al mundo laboral, entre otras.

El andamiaje es un enfoque sociocultural del constructivismo cognitivo y social que se asienta, entre otras, en la Zona de Desarrollo Próximo de Vygotsky (1978), en la neurociencia (plasticidad, inteligencia y estimulación) y en la Inteligencia Ambiental. Constituye una estructura que, de forma provisional o definitiva, aportan las TIC al alumno como un apoyo para su desarrollo personal. Hay estudiantes que requieren un andamiaje permanente, como los que tienen baja visión, ceguera, sordera, discapacidad intelectual, parálisis cerebral, trastornos del espectro autista, etc. y también otros, alrededor del 25\%, que sólo presentan dificultades temporales de aprendizaje: trastornos de 
atención, dificultades para el desarrollo de la lectura y escritura, dificultades para comunicar las ideas, etc. En estos últimos casos es posible retirar todos o algunos apoyos TIC una vez que el alumno alcanza el nivel requerido.

Las TIC ofrecen novedades y nuevas aplicaciones casi a diario ${ }^{6}$. Sus usos son múltiples y se distribuyen prácticamente en todos los campos de la actividad humana. Veamos algunas de las claves del contexto en el que se desenvuelven para conseguir tener éxito en los siguientes ámbitos: comunicación, educación, transición a la vida laboral, web social y ocio creativo, y control ambiental.

\section{Comunicación}

Alumnos como Eduardo, sin comunicación oral, ¿cómo pueden participar activamente en su clase o en su entorno? ¿Cómo demuestran sus conocimientos? ¿Cómo expresan sus sentimientos y opiniones? Sin duda la carencia de códigos, predominante en los procesos comunicativos como el lenguaje oral, es uno de los motivos principales de exclusión. Por ello es importante el papel del docente formado en TIC para que le ofrezca el andamiaje tecnológico y metodológico necesario.

Desgraciadamente, algunas personas -incluyendo a docentesequiparan la discapacidad para hablar con la incapacidad para pensar. Algunos suelen tener muy bajas expectativas para los chicos que no pueden hablar y le ofrecen muy pocas oportunidades para aprender. Entendemos las prisas de los padres de Eduardo para encontrar un medio de interacción con los demás. Si recordamos, en el e-mail que nos enviaron, nos decían que tiene un sistema de comunicación compartido con sus familiares que otros no pueden entender. Como señala Martha E. Snell (2006) esto es debido a que la comunicación no simbólica es idiosincrásica, es decir, surge por el conjunto de actos y significados que son propios y únicos

6 Recomendamos la consulta de https://goo.gl/36uKDr 


\section{6}

para cada niño. El sistema de comunicación es compartido por los interlocutores que ayudan a definir los significados e introducen y guían a las rutinas con un vocabulario predecible que se puede definir.

Las dificultades de comunicación producen muchas veces frustración y así algunos alumnos autistas o con discapacidad intelectual muestran su malestar con gritos, mordeduras, golpes y conductas de autolesión (Olmos, Cascales, y Alcañiz, 2017).

Para los alumnos con alteraciones en la comunicación y/o lenguaje los Sistemas de Comunicación Aumentativa y/o Alternativa pueden serles útiles como instrumentos para la terapia del lenguaje y el desarrollo del currículo. Su objetivo es proporcionar un conjunto estructurado de códigos no vocales que sirvan para llevar a cabo actos de comunicación (funcional, espontánea y generalizable). Las calificaremos de eficientes si los usuarios construyen competencias que les resulten útiles en su vida cotidiana y, a ser posible, que les ayuden a tener acceso a nuevos contextos lo menos restrictivos posibles.

Esta idea de funcionalidad de la comunicación ha llevado a dos profesoras (Figura 7), a poner en marcha un sistema de videoconferencia entre dos centros de Educación Especial con el fin de facilitar la comunicación y el desarrollo del lenguaje entre sus alumnos que utilizan tablero de Comunicación Aumentativa soportado por la computadora (Martínez, y Ribes, 2008).

Los alumnos que participan en la experiencia tienen una edad similar y no se conocen entre sí. Algunos tienen discapacidad intelectual y otras discapacidades múltiples. Comparten sus ganas de interaccionar con otras personas con intereses similares y la utilización de la Comunicación Aumentativa en sus centros. Utilizaron el programa OOVOO, ${ }^{7}$ similar al Skype pero con la ventaja de que su interfaz permite a los interlocutores verse con un tamaño mayor, lo que resulta de gran ayuda

7 Se puede bajar gratuitamente de: https://goo.gl/HCea9i 


\section{7}

para mantener la atención de los alumnos. También tiene la ventaja de que permite grabar la videoconferencia en la computadora para reproducirla posteriormente.

\section{Figura 7}

Formación de mensajes a través de pictogramas

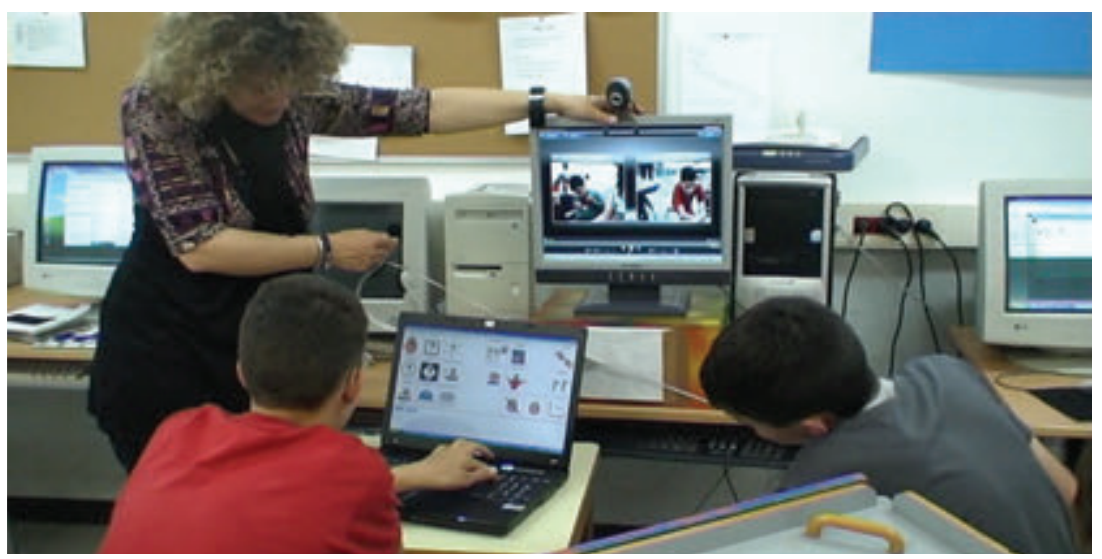

Los alumnos y su maestra seleccionan los pictogramas de la pantalla de la computadora para formar los mensajes en interacción con los alumnos de la otra escuela. La webcam registra sus imágenes. Foto: Rafael Sánchez (2017)

Las docentes se plantearon los siguientes objetivos: a) Reproducir situaciones comunicativas diversas. b) Exponer de forma ordenada hechos y vivencias. c) Iniciar e intervenir en una conversación sin salirse del tema. d) Respetar los turnos de palabra. e) Ampliar el vocabulario. f) Potenciar las diferentes funciones comunicativas. g) Utilizar, cuando fuera necesario, sistemas alternativos de comunicación basados en pictogramas del sistema SPC (Sistema Pictográfico para la Comunicación). ${ }^{8}$

8 Mayer-Jonson https://goo.gl/8JT53p 


\section{Educación}

El derecho fundamental de las personas con NEAE es la educación. Es instrumento primario y principal de inclusión pues de ella depende el pleno desarrollo de su personalidad y el aprendizaje de las competencias que le permitirán acceder, en el futuro, a un empleo adecuado, además de facilitarle o dificultarle su participación activa y responsable en la sociedad.

Muchos docentes encuentran en las TIC un medio ideal para facilitar interacciones positivas y aprendizajes entre los alumnos. La utilización de las TIC en el aula es similar a la de cualquier recurso, y para que sean eficaces es necesario conectarlas con el currículo escolar. Son muchas las investigaciones sobre sus efectos positivos. López-Escribano (2007) constata que la práctica de la lectura repetida con la computadora ayuda a los niños a desarrollar la fluidez, la ortografía y la comprensión lectora.

De forma general Marchesi et al. (2003) atribuyen a las TIC grandes ventajas en los aprendizajes de los alumnos:

- Capacidad para crear contextos de aprendizaje que abren nuevas posibilidades de información y de comunicación y conectan con algunas de las competencias que son necesarias para desenvolverse en el siglo XXI.

- Interactividad. Los estudiantes pueden adentrarse con más facilidad en experiencias de aprendizaje en las que reciben nueva información, están en contacto con otros aprendices, comprueban sus avances y dificultades y pueden ensayar estrategias diferentes para construir sus conocimientos.

- El software informático puede transformar nociones abstractas en modelos figurativos, lo que facilita su comprensión y su aprendizaje.

- La utilización de las TIC aproxima el entorno escolar a otros entornos del alumno (familia, amigos, etc.), lo que facilita la transferencia de los aprendizajes de unos contextos a otros.

- Las TIC pueden ampliar las relaciones de los alumnos y de los profesores con otros docentes y profesionales. 
Es frecuente leer informaciones que destacan que cada vez hay más tablets y computadoras en las escuelas y que se están haciendo importantes inversiones en capacitación pero, salvo experiencias aisladas, se publica poco acerca de los resultados que se obtienen de esas inversiones. Para obtener una información global sobre este hecho, vamos a tomar como referencia el estudio realizado recientemente por la Fundación Telefónica (2008) en más de 800 centros educativos españoles sobre el uso real de las TIC en primaria y secundaria.

El estudio de la Fundación Telefónica (2007) un panorama poco optimista ante las expectativas generadas por la introducción de las TIC como herramienta para innovar y transformar la educación. La opinión de los autores es que el profesorado, en general, se limita a utilizar las TIC en apoyo de las prácticas docentes tradicionales, de carácter transmisivo. Estaríamos lejos de la tipología de impregnación. Los profesores usan a menudo la computadora para preparar las clases, y los alumnos para realizar sus trabajos (tipologías suplementaria, complementaria y en menor medida integración), pero apenas se usan en las aulas de forma que impregne el currículo.

Los docentes tienden a utilizar las TIC de acuerdo con un cálculo racional coste/beneficio y acostumbran a incorporarlas en aquellas situaciones en las que no necesitan hacer grandes cambios en las prácticas preexistentes. Parece que si los gobiernos pretenden impulsar cambios importantes mediante las TIC, deberían replantearse previamente otros muchos factores, por ejemplo, que la mera presencia de los medios informáticos en los centros docentes no desencadena per se procesos de innovación docente.

\section{Transición a la vida laboral}

Los jóvenes con NEAE deberían tener el andamiaje necesario para realizar una transición eficaz de la escuela a la vida laboral adulta. Los centros docentes deberían ser activos y proporcionarles las destrezas 
necesarias para la vida diaria, ofreciéndoles formación en aquéllas que respondan a las demandas y expectativas sociales y comunicativas de la vida adulta (UNESCO, 2015). Los datos actuales revelan que muchas personas con discapacidades carecen de las cualificaciones adecuadas para el trabajo (Oficina Internacional del Trabajo 2008).

En relación a su incorporación al trabajo, casi la tercera parte de la población con discapacidad que accede al mercado de trabajo tiene como máximo dos años de estudios, una situación que necesitará cambiar para que puedan incluirse efectivamente en la sociedad y ocupar los puestos que tienen reservados por ley en las empresas.

CEPAL (2011) estima que en los países de América Latina y el Caribe es aún más seria la brecha doméstica (ciudadanos del mismo país) que la internacional. La falta de acceso a las TIC de la población con discapacidad genera un impacto devastador, incluso en aquellas personas que ya eran parte del sistema y que, por un accidente o por enfermedad, se ven obligadas a retirarse del mercado, en ocasiones de forma definitiva, aún en plena fase productiva de su vida.

Conseguir un empleo es el elemento clave para la independencia personal. El Empleo con Apoyo proporciona empleo dentro de empresas normalizadas a personas con discapacidad que tradicionalmente no han tenido posibilidad de acceso al mercado laboral, mediante la provisión de los apoyos necesarios dentro y fuera del lugar de trabajo, a lo largo de su vida laboral, y en condiciones de empleo lo más similares posibles en trabajo y sueldo a las de otro trabajador sin discapacidad en un puesto equiparable dentro de la misma empresa (Verdugo y Jordán de Urríes, 2001). En estos casos es destacable el papel del preparador laboral, el/la profesional de intervención directa que acompaña a la persona con discapacidad durante el primer periodo de su inserción en la empresa y desempeña su acción no sólo con el sujeto sino también con el entorno laboral.

El hecho de poder realizar parcial o íntegramente tareas de trabajo y estudios desde la vivienda o el trabajo puede facilitar la inserción en 
el mercado laboral de personas con ciertas discapacidades y darles acceso a estudios a los que no podrían haber asistido de otra manera. Para la realización de tareas de teletrabajo y estudios on-line de forma eficaz es fundamental disponer de una zona de trabajo diseñada adecuadamente y de las mejores aplicaciones informáticas posibles. Es necesario realizar una inversión mayor, y no solo económica, en este tipo de políticas activas, en lugar de continuar con la línea emprendida por algunos gobiernos basada en la pensión como máxima aspiración.

\section{Web social y ocio-creativo}

La facilidad con que se utilizan nuevas herramientas en Internet como los blogs, redes sociales, wikis o podcasts, está permitiendo que muchos usuarios, entre ellos los que tienen NEAE, tomen la iniciativa en la Red y no sólo con contenidos basados en sus necesidades e intereses sino también para establecer nuevas relaciones sociales que hasta ahora no parecían posibles. Este fenómeno lleva a la madre de Iago, niño de 9 años con trastornos del espectro autista, a relatarnos en su blog${ }^{9}$ algunos aspectos de la vida de su hijo y los logros que va consiguiendo. Con el apoyo de videos y de materiales de diferente índole, estos relatos son un punto de apoyo para muchas personas interesadas en compartir experiencias e informaciones sobre el autismo.

Los videojuegos también son una opción para el tiempo libre. Existe una opinión bastante generalizada de que no aportan nada bueno al desarrollo psicosocial de los alumnos, pero esto no siempre es así. Muchos de los juicios emitidos sobre el tema carecen de investigaciones rigurosas. ${ }^{10}$

9 Disponible en: https://goo.gl/JC19cw

10 A modo de ejemplo, la Revista Escuela de Salud, en el artículo "Videojuegos con riesgo" afirma: "Según los expertos, si se utilizan diaria y continuamente los videojuegos se facilita el niño la aparición de numerosos trastornos físicos y psicológicos, que pueden llegar a alterar su conducta y a transformarse en graves problemas psicopatológicos". 


\section{2}

Figura 8

Videojuegos que favorecen el movimiento ocular

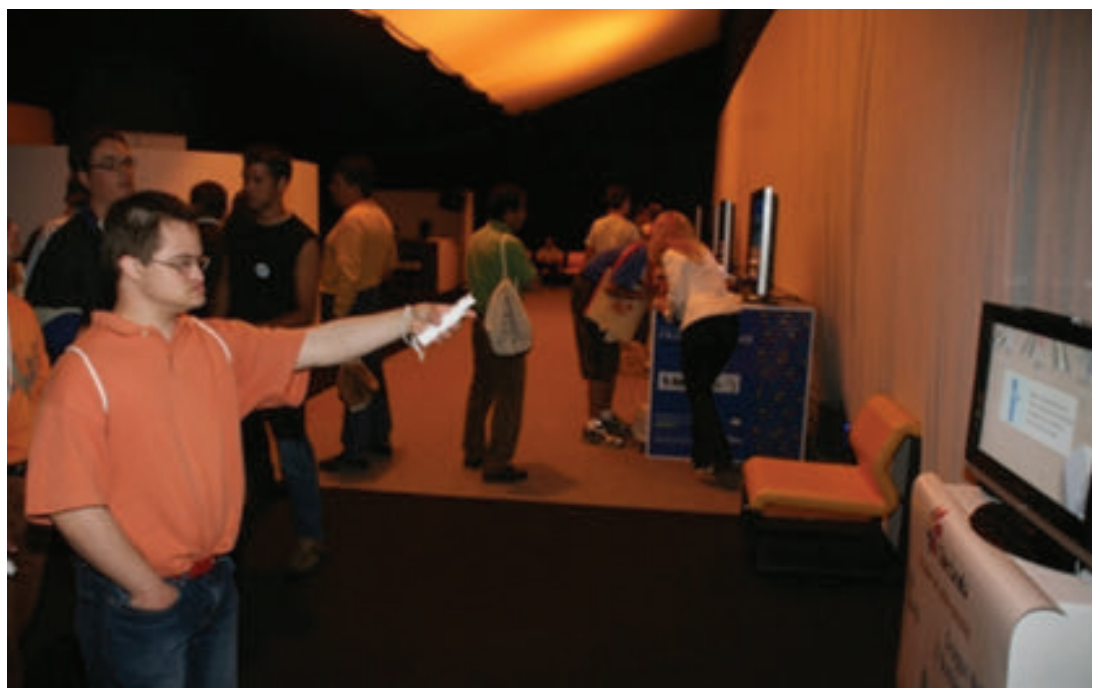

Con los videojuegos el usuario puede reforzar la capacidad de coordinación de sus movimientos oculares con los de pies y manos. Podemos estimular las diversas inteligencias e integrar las actividades del mundo virtual con sus propias habilidades al tener que adaptarse a las circunstancias y desarrollo del juego.

Foto: Fundación FREE. Feria Realidad Virtual, Ocio y Discapacidad. IMSERSO-España (2007)

En apoyo de los videojuegos surge McFarlane del Teachers Evaluating Educational Multimedia, ${ }^{11}$ quien ha investigado cómo se puede aprovechar la afición de muchos niños y jóvenes a este tipo de juegos para mejorar sus aprendizajes. En su trabajo Games in Education (2007), pasó diversos cuestionarios a 700 niños entre 7 y 16 años y obtuvo, entre otras, las siguientes conclusiones:

- Los videojuegos sencillos pueden ser una forma intuitiva de empezar a familiarizarse con la computadora o con un nuevo dispositivo que nos interese conocer.

11 Disponible en: https://goo.gl/1qdLWJ 
- Los videojuegos mejoran la comprensión lectora y las matemáticas.

- Los de simulación y aventura, en los que los jugadores deben crear sociedades y jugar en grupo, ayudan a desarrollar el pensamiento estratégico y de planificación y a relacionarse con otras personas. Se puede jugar en grupo al mismo juego, cada uno con un mando distinto, y además utilizar simultáneamente un chat de texto o de voz.

- A través de los juegos y simulaciones, adquieren un compromiso con el cumplimiento de una misión, la habilidad para desarrollar estrategias complicadas o la capacidad de hacer planes y adelantarse a los acontecimientos.

En la escuela de Yawata, el alumnado dedicó cinco minutos diarios a hacer ejercicios de inglés para mejorar su vocabulario durante un año y medio y sus notas subieron un 10\% de media. Como señalan varios autores su valor pedagógico es grande: resultan muy motivadores para la mayoría de los alumnos, lo que ayuda a crear situaciones de aprendizaje altamente significativas, y constituyen un recurso didáctico muy flexible dado que se pueden utilizar en una asignatura concreta, como taller o como eje transversal. Aportan múltiples posibilidades para el desarrollo de procedimientos tales como la adquisición de destrezas básicas, la autonomía, el razonamiento inductivo y deductivo, la creatividad, las habilidades y estrategias de resolución de problemas... y favorecen, además, el aprendizaje de contenidos que forman parte de las diferentes áreas curriculares (Gros, 2000; Gallego, 2000; Archambault 2000).

\section{Control ambiental}

¿Qué ventajas tiene para mí el uso del control de ambiental? se pregunta Gerardo Barroso, persona con discapacidad motriz en el congreso sobre Domótica, Robótica y Teleasistencia para todos celebrado en Madrid. Continuaba “...la lista sería enorme. Dentro de mi casa me cuesta mucho levantar una persiana, poner la calefacción, abrir determinadas puertas, las ventanas...". 
La idea del hogar digital cada vez la tenemos más cerca: alarmas técnicas para detección de humo, escapes de gas o agua; control de iluminación y persianas, comunicaciones de banda ancha en todas las estancias, servicios de entretenimiento, etc. $y$ todo esto integrado y con posibilidad de control tanto desde el interior mediante pantallas táctiles, una computadora o un mando a distancia a través del televisor, o exteriormente desde cualquier punto mediante Internet o un teléfono móvil.

Los sistemas de domótica, robótica y teleasistencia presentan aún muchos interrogantes que dificultan su implantación generalizada. Uno de ellos es el precio que, aunque está cayendo, todavía es alto.

De forma más modesta, en las escuelas podemos poner en práctica los principios del control ambiental con la micro-robótica para desarrollar competencias de los alumnos con NEAE.

Así lo está haciendo el centro Ca'n Tangram con chicos con trastornos por déficit de atención con hiperactividad (TDAH). Sabemos que la TDAH se caracteriza por la impulsividad que conlleva a serias dificultades del alumno para controlar el procesamiento de la información, con corta latencia, alta tasa de respuesta y elevado número de errores. La presencia en las población infantojuvenil supone entre el 5-7\% a nivel mundial (Fenollar- Cortés, 2015; Montoya-Sánchez y HerreraGutiérrez, 2014) y los síntomas no remiten de forma espontánea y necesitan apoyos.

A partir de la adolescencia, los síntomas fundamentales disminuyen significativamente, sobre todo la actividad motriz, pero no desaparece. Es precisamente en esta edad donde los alumnos del colegio realizan actividades con micro-robots como Lego-MindStorm ${ }^{12}$ que utiliza un lenguaje muy visual e intuitivo que conecta con los intereses del alumnado y le permite desarrollar habilidades cognitivas deficitarias, con el propósito de potenciar las funciones ejecutivas e incrementar la 


\section{5}

autodirección de su comportamiento. Una de las técnicas más utilizada es la de Autoinstrucciones de Meichenbaum y Goodman que resumimos en el cuadro siguiente (Luque y Rodríguez, 2007):

Tabla 2

Resumen de fases

Objetivo: Enseñar a los alumnos con TDAH a hablarse a sí mismos cuando se enfrentan a la resolución de una tarea cognitiva: Comprender la situación, generar estrategias y controlar su comportamiento.

\begin{tabular}{|l|l|}
\hline \multicolumn{1}{|c|}{ Fases } & \multicolumn{1}{c|}{ Guía de pensamiento } \\
\hline - Definición del problema & ¿Qué es lo que tengo que hacer? \\
\hline - Aproximación al problema & ¿Cómo lo voy a hacer? \\
\hline - Focalización de la atención & $\begin{array}{l}\text { Tengo que estar muy atento y ver todas las res- } \\
\text { puestas posibles. ¿Estoy utilizando mi plan? }\end{array}$ \\
\hline - Selección de la respuesta & - ¡Ya está! Creo que la solución es ésta \\
\hline - Autorefuerzo & $\begin{array}{l}\text { ¿Cómo lo he hecho?: ¡Fantástico!, me ha sali- } \\
\text { do bien. } \\
\text { ¡Vaya!, me ha salido mal, ¿por qué?. ¡Ah!, jes por } \\
\text { eso!, la próxima vez me saldrá mejor. }\end{array}$ \\
\hline - Autoevaluación & $\begin{array}{l}\text { No he cometido errores, he seguido los pasos con } \\
\text { cuidado y despacio. } \\
\text { He cometido un error, debo ir con más cuidado y } \\
\text { hacerlo más despacio. }\end{array}$ \\
\hline
\end{tabular}

Fuente: Rafael Sánchez (2017) 



\title{
Experiencias de buenas prácticas
}

\section{Reciclaje de tecnologías de consumo como apoyo a las personas con baja visión}

"Nadie se educa a sí mismo todos se educan en comunidad"

(P. Freire)

\begin{abstract}
Fundación Baja Visión Ecuador
Ecuador

Quito

Responsable: Franklin Aguayo

Gestores de la práctica: La experiencia se desarrolló con los miembros del equipo de optómetras de la institución especializados en el tema de baja visión y se enfoca en poner al alcance de las personas con baja visión ayudas técnicas de bajo costo, que les permita una adecuada inclusión en el ámbito educativo y social.

Para ello se desarrolla una estrategia alternativa de reutilización de dispositivos electrónicos de consumo masivo tales como: teléfonos digitales o tabletas que están a la mano de la mayoría de la población, pero se desconoce que pueden ser utilizarlos como herramientas de apoyo en la rehabilitación visual instalando en ellos varios programas y aplicaciones tecnológicas gratuitas que permiten transformar estos dispositivos en magnificadores electrónicos, que pueden ser introducidos en el ámbito educativo gracias a su versatilidad, convirtiéndose en una herramienta fundamental para para enfocar imágenes tanto de lejos como de cerca.
\end{abstract}

\section{Motivación}

La Fundación Baja Visión Ecuador, es una organización no gubernamental que brinda los servicios de rehabilitación integral a personas con baja visión, busca potencializar la visión funcional de las personas diagnosticadas con baja visión. Una de las acciones constituye la configuración de apoyos visuales de grandes potencias como: lupas, telesco- 
pios, microscopios, lupas electrónicas, circuitos cerrados de televisión, entre otras, las cuales son prescritas luego de la evaluación realizada por el equipo de baja visión conformado por el medico oftalmólogo, optometrista y rehabilitador visual; con los resultados de la evaluación el profesional en rehabilitación visual, ejecuta el proceso de estimulación y/o rehabilitación visual en el cual se enseña a la persona a potenciar su visión a través del uso de la ayuda prescrita.

Una de las principales barreras a las que se enfrenta la población con baja visión en el Ecuador es no contar con las ayudas ópticas y no ópticas necesarias. La mayoría no se producen en el país y su importación las encarece haciéndolos poco accesibles a personas de escasos recursos económicos.

\section{Objetivos}

Potenciar el remanente visual de las personas con baja visión para que puedan desenvolverse con mayor autonomía en las actividades de la vida cotidiana.

\section{Desarrollo de la experiencia}

a. Identificación de tecnologías de consumo: esta actividad consiste en identificar tecnologías de consumo tales como teléfonos móviles o tabletas, que ya no se utilicen y que permitan la adaptación de nuevas funciones que permitan el acceso a la información de las personas con discapacidad visual.

b. Descargar el software gratuito: procedemos a realizar la descarga del software Súper Visión de la siguiente dirección electrónica: https://goo.gl/ZvMgT9; este programa es de uso gratuito. 
Figura 9

Software Super Visión

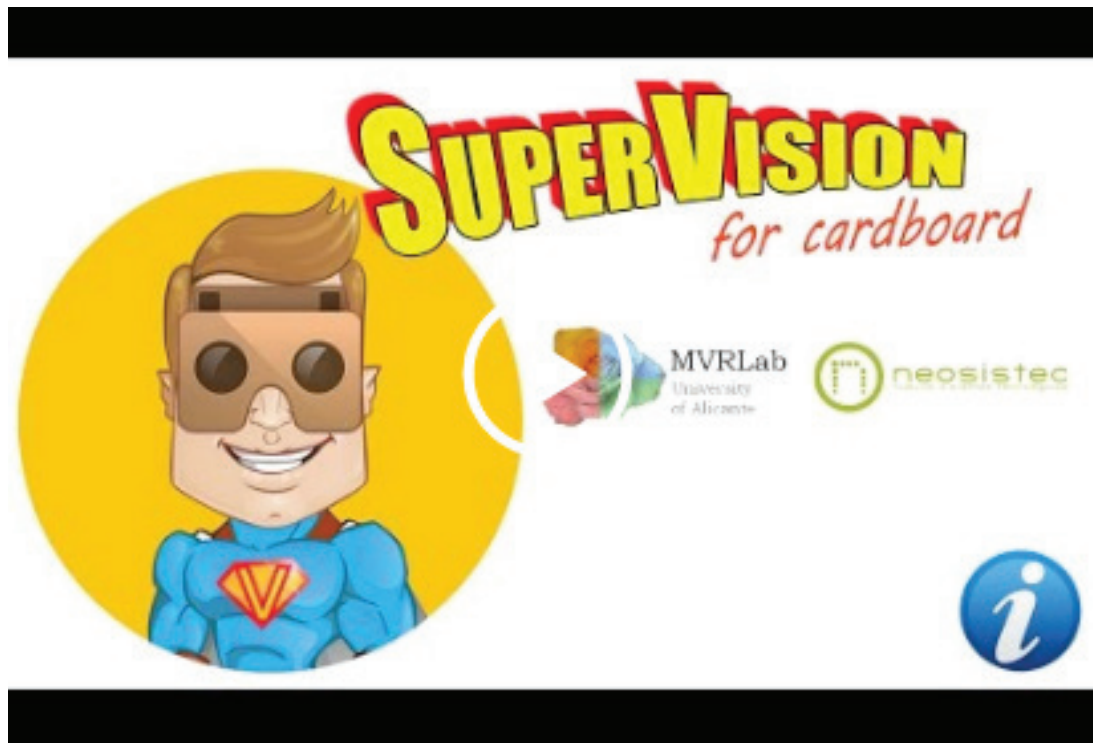

Fuente: SuperVisión mini - Google play. Recuperado de https://goo.gl/TFVozk

c. Una vez instalado el programa el menú principal del dispositivo móvil (Tablet, celular), aparecerá en el menú principal el siguiente icono:

Descargado el software en el teléfono o Tablet, se cuenta con tres posibilidades de aplicación:

- Utilizarlo como lupa electrónica: para ampliación de textos y de imágenes a corta distancia y a su vez para actividades de lectura y escritura, para lo cual dispone de control del zoom, 9 modos de color, puede usarse en entornos de poca iluminación gracias a la activación de flash. 


\section{0}

Figura 10

Uso de software en una Tablet

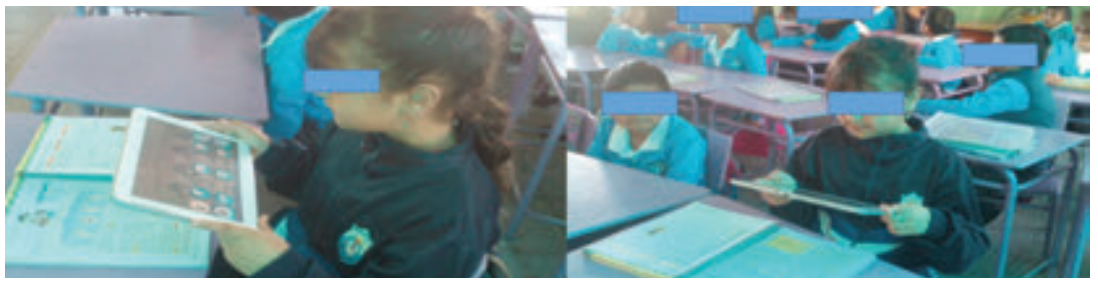

Fotos: Franklin Aguayo (2016)

Figura 11

Menú de Configuración del software

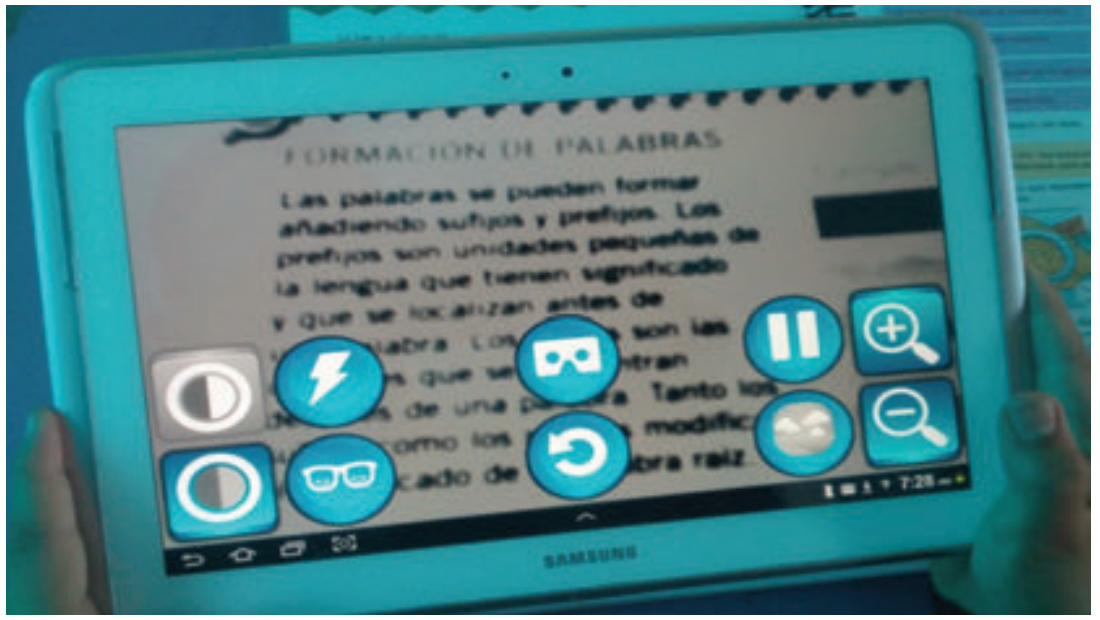

Foto: Franklin Aguayo (2016)

- Utilizarlo como telescopio: para amplificar las imágenes a la distancia, cumpliendo funciones de telescopio electrónico y que puede ser usado para mirar el pizarrón, letreros, direcciones de calles, nombres de autobuses, etc. 


\section{1}

Figura 12

Ejemplo de utilización del software

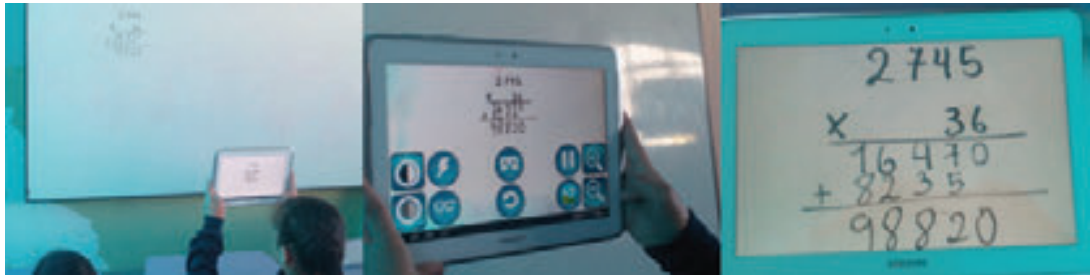

Fotos: Franklin Aguayo (2016)

- Utilizarlo como gafas electrónicas bifocales: para simulación virtual que permite un enfoque tanto de lejos como de cerca con visión estereoscópica simulando una ayuda técnica de visión artificial, gracias a la capacidad de detectar el movimiento de cabeza y el cambio de enfoque a diversas distancias, las diferentes funciones pueden ser controladas por medio de un teclado conectado por bluetooth.

Figura 13

Uso de gafas electrónicas bifocales

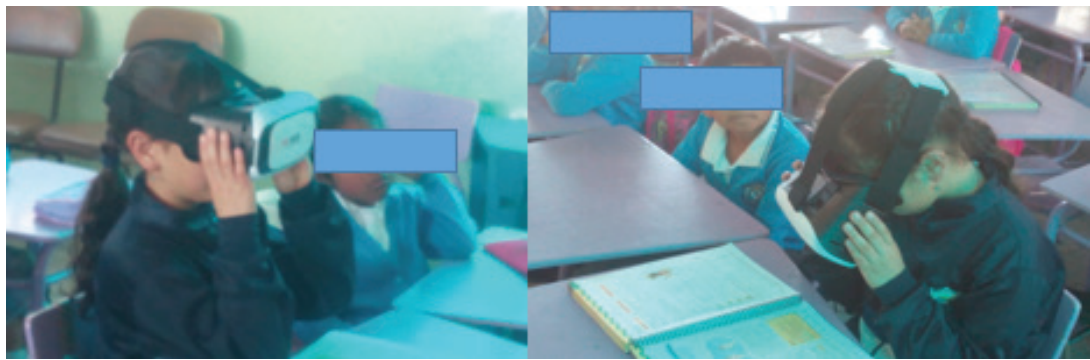

Fotos: Franklin Aguayo (2016)

- Utilizarlo como lector óptico de caracteres: para las personas con discapacidad visual severa, podemos utilizar esta tecnología con un software denominado OCR, (reconocimiento óptico de 


\section{2}

caracteres), que permite al dispositivo transformarse en un escáner y convertir un archivo de imagen (fotografía del texto) a un archivo de texto y este a su vez en un archivo audible que permita escuchar el texto que fue capturado por el dispositivo.

\section{Logros obtenidos}

Para determinar los logros alcanzados en los procesos de rehabilitación visual, se midió la agudeza visual y necesidades del grupo seleccionado antes y después del proceso de rehabilitación; los niños que al inicio tenían agudeza visual desde (AV. 20 /60 e inferiores) hasta discapacidad visual grave, agudezas visuales (20/800) lograron mejorar y llegar a agudezas visuales de 20/30 y 20/100-20/50 respectivamente en visión próxima, es decir, consiguieron una visión suficiente para desenvolverse adecuadamente en el aula de clases y poder continuar con sus estudios en las instituciones de educación regular a las cuales fueron asignados, por otra parte también mejoró su rendimiento académico al finalizar el período escolar respectivo.

La utilización de esta lupa electrónica avanzada de bajo costo, permitió a los estudiantes amplificar la imagen del objeto o texto observado, tanto en visión próxima como en visión lejana, cumpliendo la función de lupa y de telescopio electrónico, versatilidad que ha posibilitado el acceso a la información de libros, folletos, leer etiquetas, precios, firmar, escribir, ver letreros, nombres de autobuses, nombres de calles, entre otras aplicaciones con ciertas limitación producidas por su discapacidad.

Utilizado con una carcasa (Cardboard), ${ }^{13}$ permite adaptar a los ojos a modo de gafas de realidad virtual, controlar los diferentes modos de contraste y la función de zoom la misma que da una apariencia de una gafa bifocal, permitiendo manejar el enfoque de lejos y cerca. Todo esto ha hecho que los estudiantes puedan acceder a la información así

13 Disponible en: https://goo.gl/7jkfPs 
como también adquieran un adecuando desenvolvimiento en actividades de la vida diaria, en actividades escolares esta función permite manejarse adecuadamente en el aula de clase ya que sentado en el pupitre, puede magnificar o ampliar la pizarra y en el caso de bajar la vista al escritorio, el dispositivo cambia automáticamente el enfoque para facilitar la lecto-escritura.

Los estudiantes con baja visión acogieron con mucho entusiasmo el uso de estos apoyos en el aula, se evidenció la colaboración de los docentes para evitar que los equipos sufran daños ya que los estudiantes sentían curiosidad de los mismos. De igual manera las familias están muy contentas con la yuda recibida ya que el rendimiento escolar de sus hijos está al nivel de sus compañeros.

\section{Aplicaciones informáticas para el aprendizaje de inglés en universitarios con discapacidad visual}

"Dime y lo olvido, enséñame y lo recuerdo, involúcrame y lo aprendo" (Benjamín Franklin)

Universidad Politécnica Salesiana

Ecuador

Quito

Responsable: Cristian Castañeda

Gestores de la práctica: Tiflobiblioteca UPS

Esta experiencia presenta estrategias metodológicas para el aprendizaje de una segunda lengua de los estudiantes con discapacidad, con cinco estudiantes con discapacidad visual que cursan diversas carreras en la Universidad Politécnica Salesiana del Ecuador, sede Quito

\section{Motivación}

Para el aprendizaje de una segunda lengua de los estudiantes con discapacidad en la universidad, requieren que los docentes utilicen diferentes estrategias metodológicas en sus clases, para cubrir las expec- 
tativas de aprendizaje en las competencias de hablar, escuchar, escribir y leer en otro idioma, de estas cuatro competencias el hablar y escuchar son fácilmente asimiladas por los estudiantes con discapacidad, por lo que es importante que los docentes puedan realizar ajustes razonables para que a través de nuevas estrategias metodológicas y recursos accesibles se pueda desarrollar las capacidades de escribir y leer, los docentes manifiestan el desconocimiento de las estrategias, así como, la carencia de recursos didácticos ajustados a las necesidades de los estudiantes como: cartillas en sistema braille, vocabulario en audio, expresiones idiomáticas, textos de lectura, material de trabajo en clase, digitalización de textos accesibles en formato Word, pdf y txt, situaciones que se convierten en barreras que limitan las posibilidades de aprendizaje de la lectura y escritura en un contexto de equidad.

La metodología de trabajo que sustenta esta práctica de aprendizaje, es la utilización de herramientas tiflotécnicas ${ }^{14}$ fundamentales utilizadas por estudiantes con discapacidad visual en su vida diaria como: el lector de pantalla Jaws en su versión 17, el convertidor de texto en audio Balabolka ${ }^{15}$ y la herramienta propia del paquete de Office Microsoft Word.

Para la ejecución de la práctica se contó con la participación de docentes del Instituto de Idiomas de la Institución, personas encargadas de la tiflobiblioteca de la UPS, estudiantes de la carrera de Pedagogía, docentes del Grupo de Apoyo a la Inclusión, los tutores participantes en la adaptación de material accesible y los estudiantes con discapacidad visual de la misma Institución.

\section{Objetivo}

Fortalecer el proceso pedagógico de enseñanza del idioma inglés para estudiantes con discapacidad visual, tilizando la tecnología como recurso de apoyo incrementando recursos bibliográficos y opciones de

14 https://goo.gl/vGY2YR

15 https://goo.gl/JgkE8c 


\section{5}

accesibilidad, que faciliten el desempeño académico y la autonomía de los estudiantes.

\section{Desarrollo de la experiencia}

En primer lugar se observó e investigó las necesidades de aprendizaje en la materia de inglés que manifestaban los estudiantes con discapacidad visual. Los resultados de esta investigación permitieron evidenciar la necesidad de proveer recursos didácticos accesibles que mejoren la comprensión y el aprendizaje de la segunda lengua.

En segundo lugar, se realizaron entrevistas con los docentes para conocer, cuál es su criterio y requerimientos con relación a la enseñanza de inglés a estudiantes con discapacidad visual, la información de los docentes estuvo centrada en los temores sobre la falta de herramientas metodológicas y material didáctico empleado en el proceso de formación, lo que limita la participación integral del estudiante, y solicitan además se provea de capacitación en proyectos de formación incluyente.

Actualización constante del inventario de material base y de apoyo disponible para estudiantes con discapacidad visual.

Adaptación del material bibliográfico de aprendizaje del idioma inglés de los Textos de Cambridge ("Interchange") en formato PDF, describiendo gráficos, tablas y cuadros para facilitar la lectura y aprendizaje con las aplicaciones de Word, Jaws ${ }^{16}$ y Balabolka a personas con discapacidad visual.

Validación y puesta en práctica del material adaptado usando el lector de pantalla jaws, convertidor de texto en audio Balabolka.

Capacitación a los docentes en el manejo del material y la forma de trabajo con los estudiantes del Instituto de Idiomas.

16 https://goo.gl/DrZLrb 


\section{6}

Encuesta de impacto y sugerencias frente al proceso de apoyo a los estudiantes con discapacidad visual.

Aplicación estudiantil de la escritura del idioma inglés con los conocimientos impartidos por los docentes.

\section{Recursos utilizados}

\section{Figura 14}

Recursos y materiales con adaptación
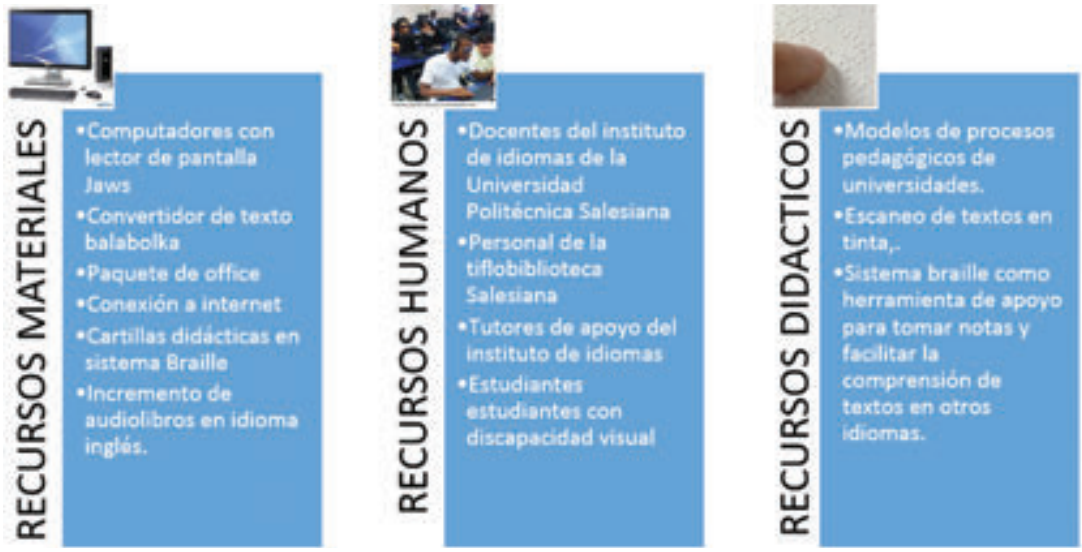

Fuente: Miriam Gallegos (2016)

\section{Logros obtenidos}

Los estudiantes con discapacidad visual:

- Han aprobado los exámenes de inglés para realizar estudios de posgrado.

- Conocen el manejo de páginas y herramientas web en idioma inglés.

- Lectura y escritura académica de textos en idioma inglés. 


\section{7}

\section{Las TIC en tres instituciones educativas de Quito}

"La educación es el gran motor del desarrollo personal. Es a través de la educación como la hija de un campesino puede convertirse en una médica, el hijo de un minero puede convertirse en el jefe de la mina, o el hijo de trabajadores agrícolas puede llegar a ser presidente de una gran nación"

(Nelson Mandela)

Universidad Politécnica Salesiana

Ecuador

Quito

Responsable: Alberto Duchi

Gestores de la práctica: Los estudiantes que realizaron la capitación fueron 12 integrantes del Grupo de Apoyo de Organizaciones Sociales (GAOS) y 2 profesores de la carrera de Ingeniería de Sistemas de la Universidad Politécnica Salesiana

Experiencia desarrollada desde la carrera de Sistemas de la Universidad Politécnica Salesiana sede Quito, con el fin de favorecer la aplicación de los conocimientos adquiridos por los estudiantes del grupo de Apoyo de Organizaciones Sociales (GAOS) y aportar a las necesidades de formación de los docentes de la comunidad.

\section{Motivación}

Partiendo de los resultados de las investigaciones y/o experiencia de los relatos realizados en el VII congreso de Aplicación de Tecnologías de la Información y Comunicaciones Avanzadas (Ática) 2016 y de los resultados indicados en los artículos del grupo Educación Inclusiva (GEI) "Situación actual del uso de la tecnología como recurso de apoyo en la educación de estudiantes con discapacidad", donde se realizan algunas referencias estadísticas sobre el uso de las TIC en la educación de los estudiantes con discapacidad, mostrando las dificultades que tienen los docentes para utilizar la tecnología y el internet, este último su uso se limita solo a labores de tipo administrativas más no pedagógicas; por esta razón, propone se impulse a que los docentes usen la tecnología en el aula, de la misma manera que propone en el documento "El uso 
de las TIC como recurso didáctico de apoyo a los estudiantes con discapacidad del Instituto Fiscal de Discapacidad Motriz de la Ciudad de Quito, año 2015-2016”, se menciona la necesidad de que los docentes creen o utilicen productos que conquisten la atención, con la finalidad estimular el desarrollo cognitivo y competencias de los estudiantes con discapacidad. Así también, los dos documentos resaltan la importancia de las TIC y la necesidad fundamental de contar con una formación continua y periódica sobre las mismas.

Hoy nos enfrentamos a nuevos desafíos. Los problemas del presente exigen soluciones distintas, llenas de imaginación y audacia. Las viejas soluciones no son aceptables. Nunca, como ahora, el país reclama que frente a estos retos, hagamos uso de lo tradicional y hermosa virtud de concordar y luchar juntos por todo aquello que engrandecernos (Ottón Solis Fallas, 2017).

Es por esto, que la Universidad Politécnica Salesiana tiene un rol esencial para que esto suceda, siendo partícipe en apoyar y promover espacios de interacción con el conocimiento a través de ideas innovadoras, para resolver problemas y realizar acciones de responsabilidad social con la búsqueda implementación de nuevas y mejores prácticas orientadas a mejorar la calidad de vida las personas. Para esto, es necesario el compromiso de todos los involucrados para responder de forma positiva a nuevos estilos de aprendizaje que son demandados por la sociedad. Es decir, los docentes apoyan a los estudiantes a que accedan, propicien e intercambien el conocimiento y aprendan a adaptarlo a las experiencias de cada situación.

Es aquí, donde nace la idea de juntar esfuerzos entre el Grupo de Investigación Inclusiva (GEI) y la carrera de Sistemas de la Universidad Politécnica Salesiana, el reto a realizar es un taller de actualización en el uso de las TIC dirigido a los docentes de las instituciones educativas consideradas, con la finalidad de potenciar el uso de las TIC en la preparación de sus clases y ampliación de sus conocimientos en función de sus necesidades de aprendizaje. El fortalecimiento cooperativo y so- 
lidario, entre la universidad y las instituciones permitirá que los docentes de las instituciones educativas y nuestros estudiantes capacitadores compartan experiencias y diferentes estrategias de trabajo para llamar la atención de los estudiantes en el aula.

Los docentes participantes fueron 59 de las instituciones beneficiarias (25 docentes de la escuela Emaús, 22 docentes del Instituto Fiscal de Discapacidad Motriz INSFIDIM, 12 docentes de la Escuela Santa Teresita del Valle de Fe y Alegría).

\section{Objetivo general}

Aportar a los docentes con competencias básicas en el uso de las TIC con el fin brindar estrategias que logren mejorar sus prácticas educativas.

\section{Objetivos específicos}

- Incentivar a los docentes en el uso de las TIC como herramienta de apoyo.

- Elaborar material de apoyo con el uso de las TIC.

- Realizar un acompañamiento y compartir experiencias del uso de las TIC a través dinámicas grupales e individuales.

\section{Desarrollo de la experiencia}

Fase metodológica

El criterio considerado para la definición de la propuesta se basó en:

- Pertinencia: la propuesta responde a las necesidades de los beneficiarios.

- Experiencia transferible: la experiencia constituye un modelo útil para ser replicado.

- Sostenibilidad: la propuesta es sustentable en el tiempo. 


\section{0}

- Participación: se cuenta con la participación de los docentes de las instituciones educativas.

- Cobertura: es aplicable a los docentes de varias instituciones educativas.

Es por esto que se siguió y adaptó el modelo de intermediación M-FREE el cual plantea el seguimiento de cinco pasos $^{17}$ :

Fase 1: Capacidades y competencias múltiples

Fase 2: Propuesta curricular

Fase 3: Correlacionar el software con las competencias,

Fase 4: ¿Necesita adaptaciones?, ¿Rampas digitales? (Paso no utilizado)

Fase 5: Evaluación y plan de mejoras.

Fase 1 evalúa y diagnostica al docente de las instituciones educativas, sus características particulares, para lo cual se consideró los resultados y recomendaciones en los artículos de Miriam Gallegos, Alberto Duchi y las experticias del VII Congreso Internacional sobre Aplicación de Tecnologías de la Información y Comunicaciones Avanzadas, ATICA 2016.

Luego de la participación en el congreso de ATICA 2016 en una reunión del Grupo de Educación Inclusiva GEI se definen y evalúan los criterios indicados en este congreso y se plantea cómo el grupo GEI puede contribuir en el aprendizaje y actualización de nuevos conocimientos partiendo de las necesidades e iniciativas considerados en los resultados de los artículos mencionados inicialmente de las instituciones externas. Estos lineamientos permitieron elaborar una propuesta de capacitación en TIC enmarcados en las políticas colaborativas que maneja la Universidad Politécnica Salesiana.

17 https://goo.gl/f8Nw8D 


\section{1}

Figura 15

Docentes del Grupo de Educación Inclusiva GEI

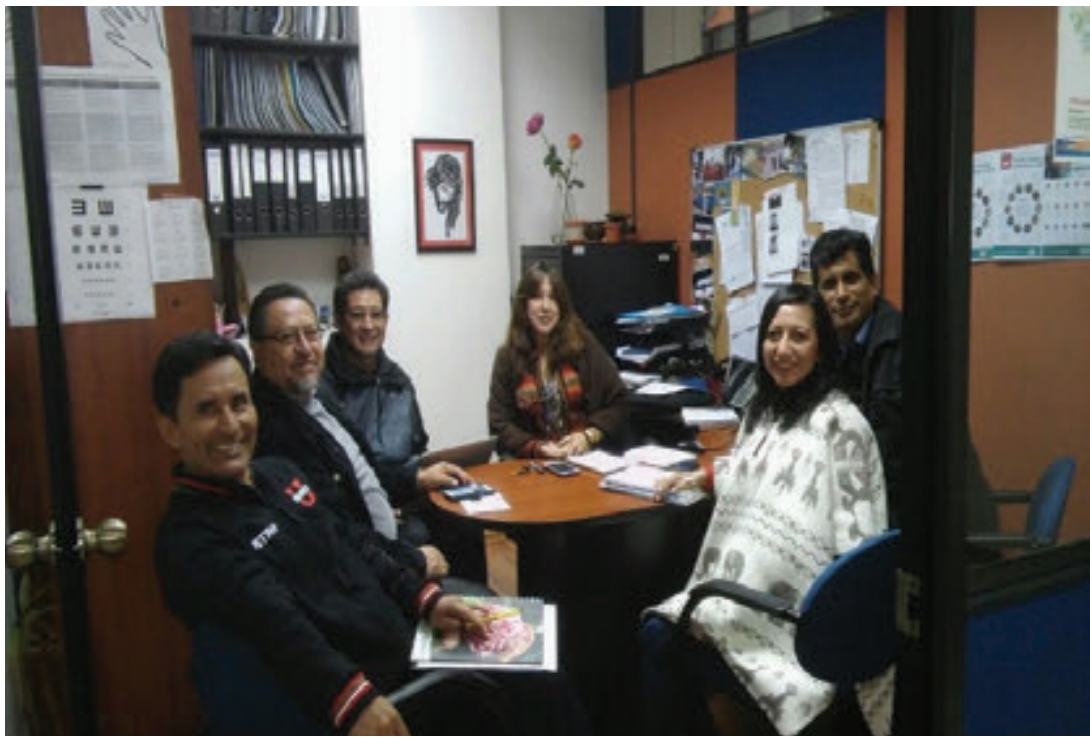

Foto: Grupo de Investigación de Educación Inclusiva UPS (2016)

Una vez definida la idea de la propuesta se realizó un acercamiento con las instituciones educativas, para concretar si existe el interés de participar en esta iniciativa, y especificar algunos temas que serían de su interés, y los días de la semana que pueden participar en el taller.

Dado el interés de las instituciones externaws por medio de los docentes de la carrera de Ingeniería en Sistemas, que son parte del grupo de investigación inclusiva GEI se contactó con el coordinador del grupo de apoyo de organizaciones sociales GAOS (conformado por estudiantes de los últimos niveles perteneciente a la carrera de Ingeniería en Sistemas del campus Sur), para hacerles participe de esta propuesta de capacitación.

Fase 2 y 3 se sugiere una propuesta curricular que ayude al docente a conseguir las competencias partiendo de sus necesidades y se 


\section{2}

correlaciona al software con las competencias que se desea que alcance al final.

El coordinador y estudiantes del grupo GAOS con los días y temas definidos con las instituciones educativas se planteó un cronograma de actividades con el fin de cubrir la temática indicada y se define la fecha de inicio del curso.

Tabla 3

Unidades y temas propuestos

\begin{tabular}{|l|l|}
\hline \multicolumn{2}{|c|}{ Temas } \\
\hline 1. Unidad I: El ordenador o computador & 4. Unidad IV: Diapositivas \\
\hline 1.1. Definiciones básicas & 4.1. Introducción \\
\hline 1.2. Componentes de un computador & 4.2. Partes de una diapositiva \\
\hline Ejercicios & 4.3. Creación de una presentación \\
\hline 1.3. Encender una computadora & 4.4. Guardar una diapositiva \\
\hline 1.4. Cómo ingresar a un computador & Ejercicios \\
\hline \begin{tabular}{l} 
1.5. Los programas \\
\hline 1.6. Ingresar a un programa o aplicación
\end{tabular} & 4.5. Elección de esquema y diseño \\
\hline $\begin{array}{l}\text { 1.7. Como cerrar un programa o una } \\
\text { aplicación }\end{array}$ & 4.7. Imprimir una diapositiva \\
\hline Ejercicios & Ejercicios \\
\hline $\begin{array}{l}\text { 1.8. Cerrar sesión, reiniciar o apagar el } \\
\text { equipo }\end{array}$ & 4.9. Vistas de una diapositiva \\
\hline $\begin{array}{l}\text { 1.9. Manejo de Paint } \\
\text { Ejercicios }\end{array}$ & 4.10. Formato fuente \\
\hline Ejercicios Unidad I & Ejercicios \\
\hline 2. Unidad II: Editor de texto & Ejercicios de la Unidad IV \\
\hline 2.1. Introducción & Animaciones y transiciones \\
\hline
\end{tabular}




\section{3}

\begin{tabular}{|c|c|}
\hline 2.2. Acceso a WORD & 5. Unidad V: Herramientas de internet \\
\hline 2.3. Creación y edición de documentos & 5.1. Introducción \\
\hline 2.4. Elaboración de un escrito sin formato & 5.2. Navegadores \\
\hline 2.5. Guardar un documento & 5.3. URL y direccionamiento \\
\hline Ejercicios & 5.4. Buscadores \\
\hline 2.6. Abrir un documento & Ejercicios \\
\hline 2.7. Imprimir un documento & 5.5. Correo electrónico: Gmail \\
\hline 2.8. Edición de documentos & Ejercicios \\
\hline Ejercicios & 5.6. Redes sociales: Facebook y Twiter \\
\hline 2.9. Vistas de un documento & Ejercicios \\
\hline Ejercicios & Ejercicios Correo y Red social \\
\hline Ejercicios Unidad II & 5.7. Youtube \\
\hline 3. Unidad III: Hojas de cálculo & Ejercicios \\
\hline 3.1. Introducción & 5.8. Whatsapp \\
\hline 3.2. Definiciones & Ejercicios \\
\hline 3.3. Funciones & Ejercicios Unidad V \\
\hline Ejercicios & 6. Unidad VI: Tecnologías de apoyo \\
\hline 3.4. Fórmulas & 6.1 Rampas digitales \\
\hline Ejercicios de fórmulas & 6.2 Hot Potatoes \\
\hline 3.5. Guardar un libro & 6.1 Arazá \\
\hline 3.6. Abrir un libro & 6.1 Picto droid \\
\hline Ejercicios de fórmulas & Ejercicios \\
\hline 3.7. Imprimir una hoja & Ejercicios Unidad VI \\
\hline Ejercicios Unidad III & Evaluación cognitiva \\
\hline
\end{tabular}

Fuente: Grupo de Educacion Inclusiva y Grupo Gaos, A. (2016) 


\section{4}

La propuesta inicial de capacitación fue adaptada a la disponibilidad del tiempo y de acuerdo a la dinámica de cada institución educativa, para lo cual se elaboró un horario de capacitaciones que se detalla a continuación.

Los horarios y capacitadores planteados:

\section{Unidad Educativa Emaús}

Horario: miércoles, jueves y viernes de 13:00 a 15:00

Capacitadores: 3 estudiantes

Fecha de Inicio de la Capacitación: 16 de febrero de 2017

Figura 16

Estudiantes del grupo GAOS que apoyaron en Emaús

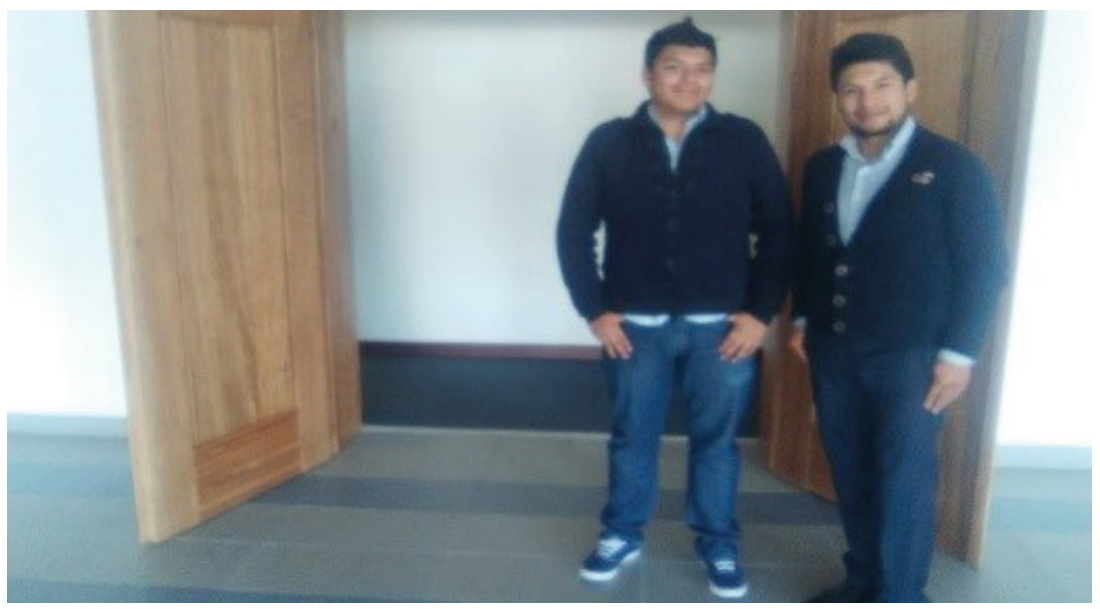

Foto: Alberto Duchi (2016)

\section{Instituto Fiscal de Discapacidad Motriz INSFIDIM}

Horario: Lunes a viernes de 12:00 a 14:00

Capacitadores: 5 estudiantes

Fecha de Inicio de la Capacitación: 13 de febrero de 2017 


\section{5}

\section{Figura 17}

Estudiantes del grupo GAOS que apoyaron en Insfidim

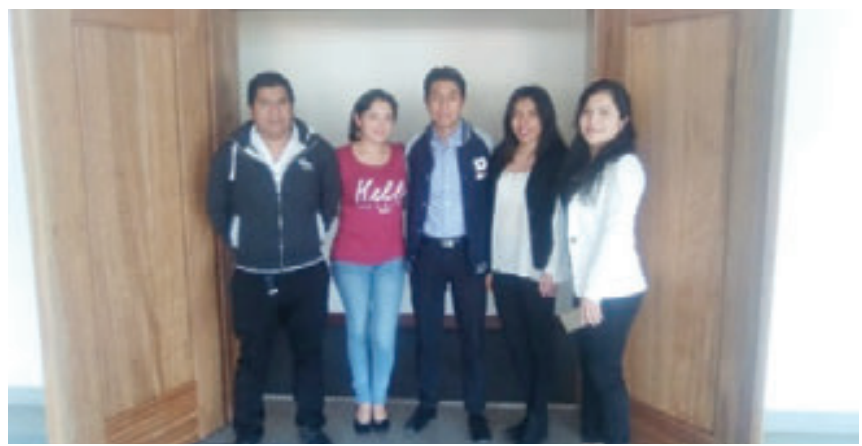

Foto: Alberto Duchi (2016)

\section{Escuela Santa Teresita del Valle de Fe y Alegría}

Horario: lunes y martes de 13:30 a 15:30, miércoles, jueves y viernes de 13:00 a 15:00 horas.

Capacitadores: 4 estudiantes

Fecha de Inicio de la Capacitación: 13 de febrero de 2017

Figura 18

Estudiantes del grupo GAOS que apoyaron en la escuela Santa Teresita

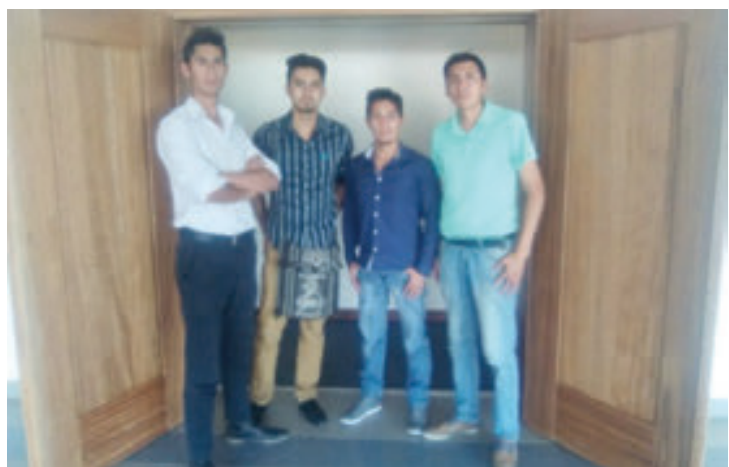

Foto: Alberto Duchi (2016) 


\section{6}

Los temas de cada unidad que se impartieron en los talleres de acuerdo a las necesidades detectadas en los docentes, para poder realizar sus labores cotidianas, y que permitirán el desarrollo de competencias básicas en el uso de las TIC.

Fase 5. Se evalúa las acciones realizadas (competencias conseguidas, en proceso o no conseguidas).

\section{Acciones realizadas a evaluar}

La evaluación de las actividades se realizó en función de los temas tratados y avance realizados en los talleres de capacitación; en algunas instituciones surgió la necesidad de profundizar en algunos temas lo que significa que se mantuvo el criterio de flexibilización durante todo el proceso de formación.

Los participantes desarrollaron las siguientes actividades de evaluación:

Elaboración de recursos didácticos digitales. Los docentes realizaron guías de resumen basados en los temas que manejan en su materia, considerando que los documentos tengan una estructura adecuada y sean llamativos para los estudiantes.

Optimización de gestión pedagógica. Los docentes utilizaron la herramienta de Excel para la recolección de datos en el proceso de evaluación de sus estudiantes.

Búsqueda y uso de sitios educativos. Los docentes realizaron la búsqueda de recursos educativos en internet para que estos sean compartidos con los compañeros y cuenten con recursos educativos para aplicarlos en sus clases.

\section{Criterio de evaluación de las actividades}

Se estableció como instrumento evaluación: a) El nivel de desenvolvimiento de los docentes en el uso de las TIC. b) Impacto de las 


\section{7}

exposiciones considerando la percepción de los participantes. c) La estructura de los trabajos y lo llamativo.

Conforme se fue desenvolviendo el taller se realizó el seguimiento de las actividades, por parte del coordinador de grupo GAOS y el docente del grupo de investigación GEI. Esta actividad se la realizó a través de los informes que emiten los estudiantes capacitadores de cada institución externa, sobre el avance y las actividades participativas realizadas en clase. Así también, se realizó una visita a dos de las instituciones con el fin de evidenciar cómo se ejecuta la dinámica de las clases en los talleres.

Del seguimiento realizado se pudo evidenciar el interés de los docentes de las instituciones externas y el grado de participación en las tareas asignadas. Así también, se notó la afinidad entre los estudiantes capacitadores y los docentes de las instituciones educativas esto ha permitido que la interacción sea dinámica y puedan compartir experiencias que aportan al crecimiento de los estudiantes y docentes.

Figura 19

Capacitación en la escuela Santa Teresita del valle de Fe y Alegría

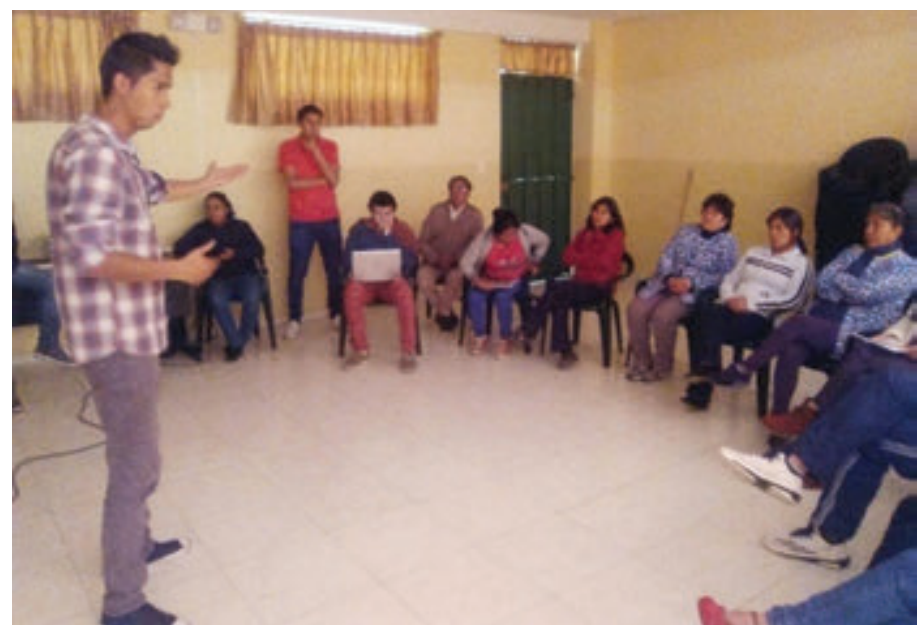

Foto: Alberto Duchi (2016) 


\section{8}

Figura 20

Capacitación en Instituto Fiscal de Discapacidad Motriz INSFIDIM

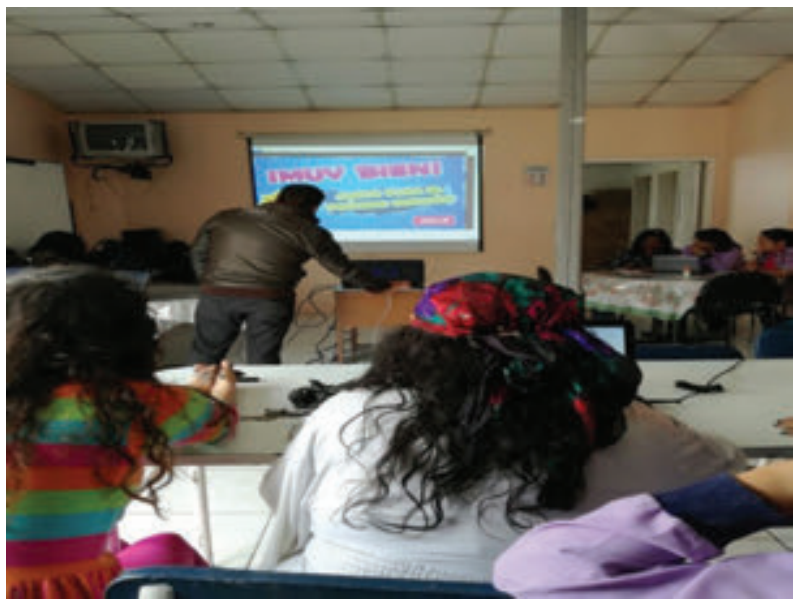

Foto: Grupos Gaos (2016)

Figura 21

Capacitación en la Emaús

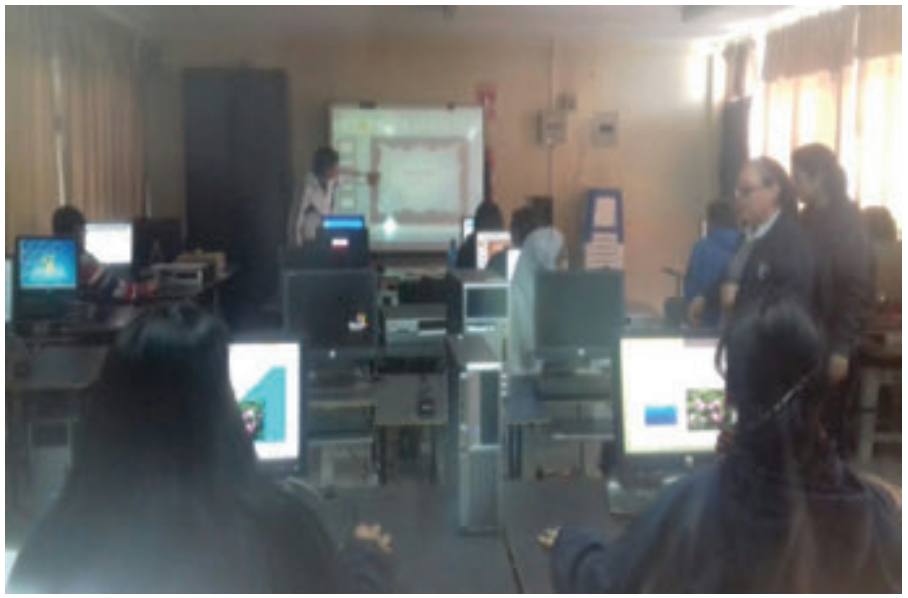

Foto: Grupos Gaos (2016) 


\section{9}

Con el fin de valorar el grado de entendimiento y participación de los docentes de cada institución en el curso se ha realizado: tareas dirigidas y participativas para ser expuestas en el curso ante los profesores estudiantes, parte de estas tareas son la elaboración de material didáctico que fue evaluado al finalizar cada unidad. Durante la realización del taller de las TIC, se visualizó en los docentes participantes un nivel medio y avanzado en conocimiento de los temas tratados.

Figura 22

Participación docente las tareas participativas

Escuela Santa Teresita del Valle de Fe y Alegría

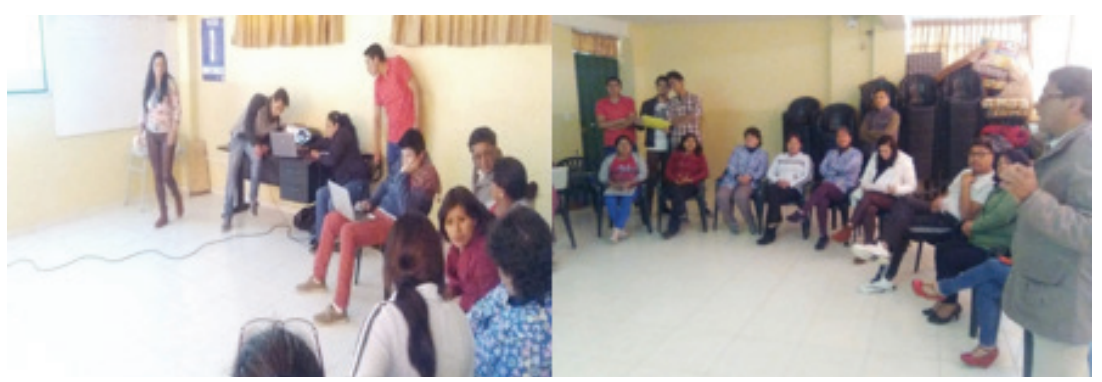

Fotos: Alberto Duchi (2016)

Figura 23

Participación docente en las tareas participativas, Escuela Emaús

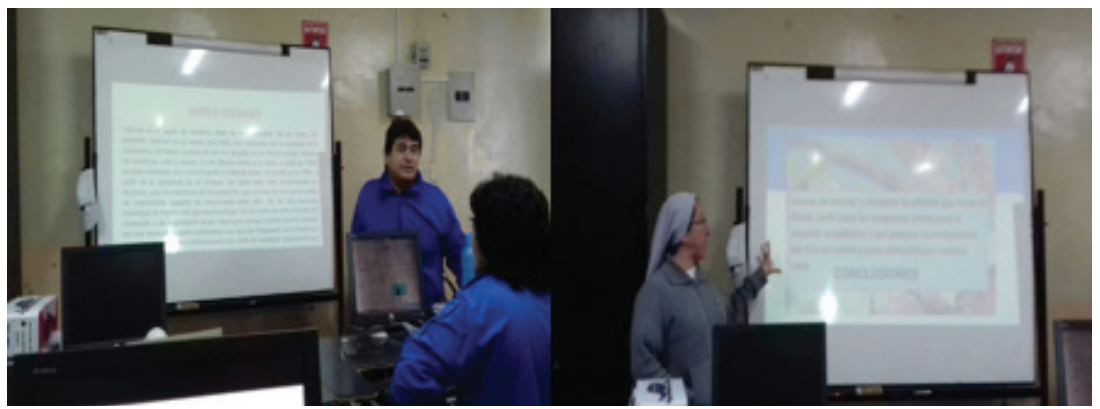

Fotos: Grupo Gaos (2016) 


\section{0}

Al término de las capacitaciones realizadas por los estudiantes en las instituciones, la carrera de Sistemas organizó el evento en el que se entregó certificados de participación en el auditorio 1 de la Universidad Politécnica Salesiana, Sede Quito, Campus Sur, el 6 de abril del 2017.

Figura 24

Palabras de bienvenida y agradecimiento del Coordinador del grupo GAOS

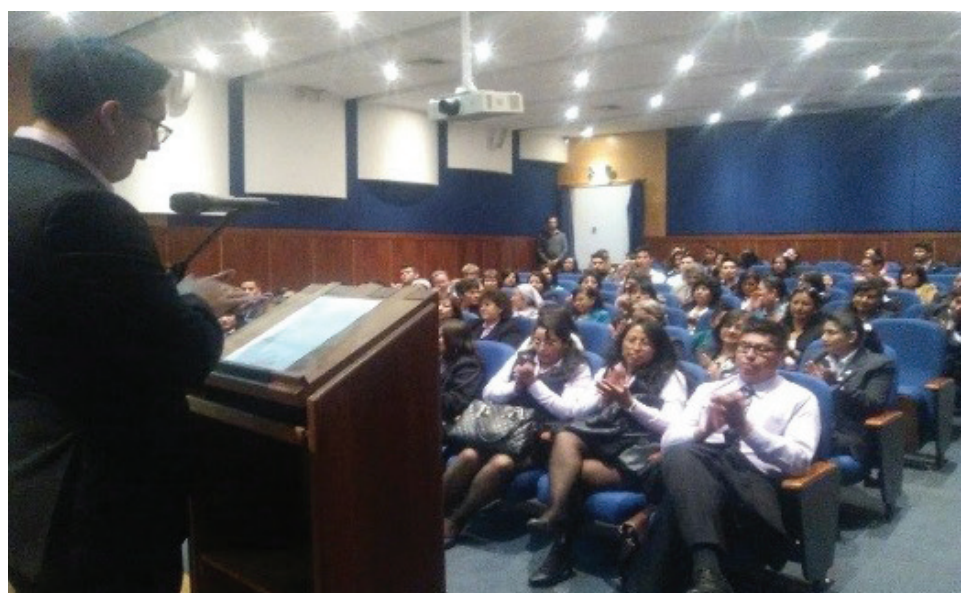

Foto: Alberto Duchi (2016)

Además, estas actividades organizadas por la universidad permiten una interacción con la sociedad, a través de sus estudiantes los cuales ponen en práctica sus conocimientos, motivándolos a participar activamente en vivencias reales, en este caso su objetivo fue brindar apoyo a un grupo prioritario de la sociedad con el fin de mejorar su calidad de vida.

En este evento el coordinador del grupo GAOS dio la bienvenida a los docentes de las instituciones educativas a nombre de la carrera de Sistemas y agradeció el interés y participación activa que tuvieron en el curso e indicó que esta experiencia ha servido de mucho a los estudiantes que realizaron la capacitación. 


\section{1}

\section{Figura 25}

Palabras de agradecimiento del grupo GEI

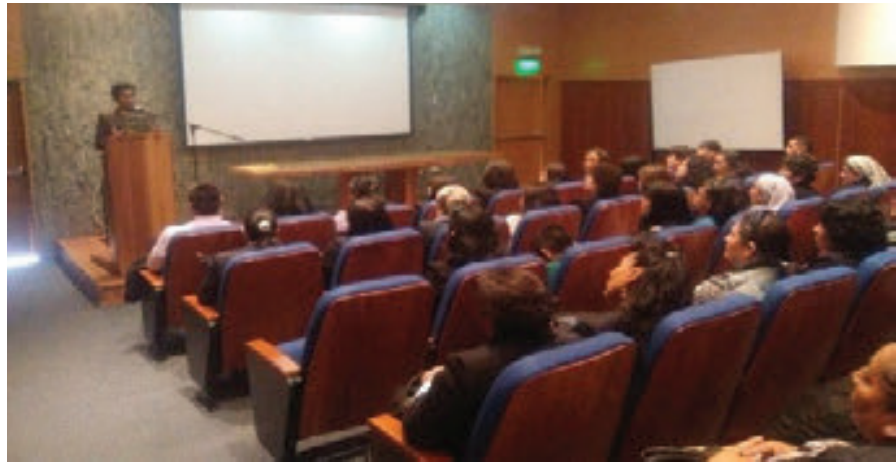

Foto: Alberto Duchi (2016)

Un representante del grupo de educación Inclusiva GEI agradeció por la colaboración y acogida que tuvo la propuesta de capacitación por parte de las instituciones externas y manifiesta la índico la importancia que tienen estas propuestas y el compromiso que tiene la Universidad en apoyar este tipo de proyectos.

Figura 26

Palabras de agradecimiento de los estudiantes, grupo GAOS

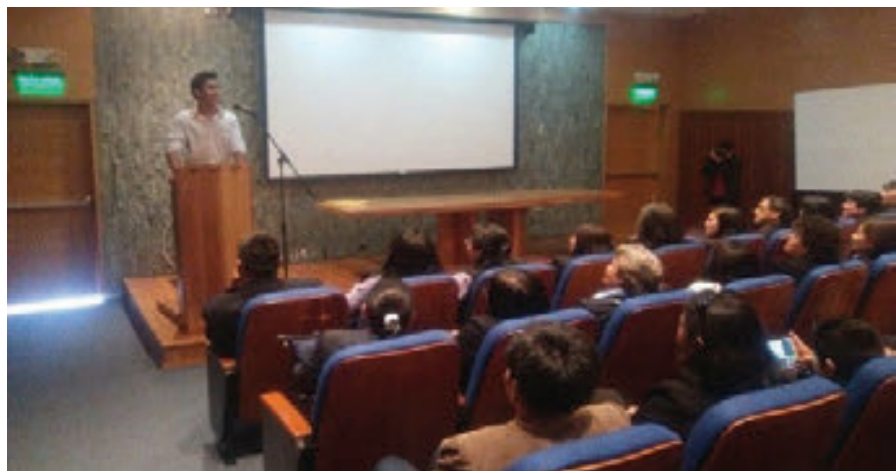

Foto: Alberto Duchi (2016) 


\section{2}

Uno de los estudiantes capacitores agradeció la oportunidad que tuvieron al realizar esta capacitación y dieron a conocer la importancia de que sintieron al ser capacitadores de docentes. Indicó que esta experiencia obligó a poner más de parte con el fin de preparar las clases y conocer el duro trabajo que tienen los docentes.

Figura 27

Entrega de certificados de participación

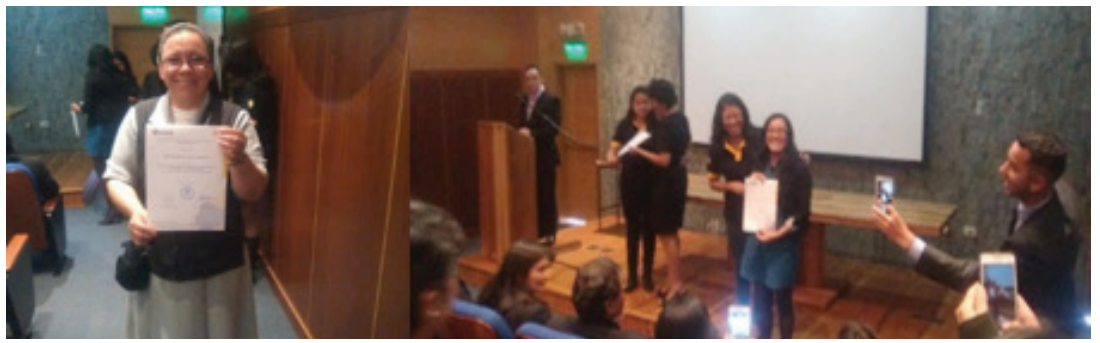

Fotos: Alberto Duchi (2016)

La Hna. Martha García, rectora del centro educativo Emaús, participó de los talleres de capacitación, quien supo manifestar que el taller de capacitación fue de gran ayuda y apoyo para las labores diarias de su trabajo. Así también, resaltó que los estudiantes que participaron en Emaús tienen un alto nivel académico.

Figura 28

Grupo de docentes participantes

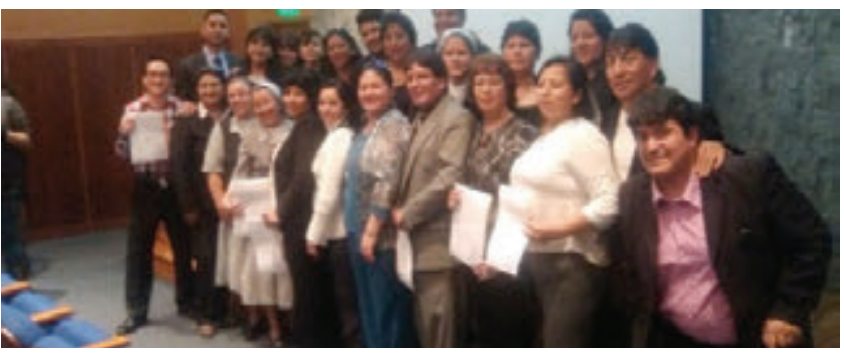

Foto: Alberto Duchi (2016) 


\section{3}

Figura 29

Grupo de docentes y estudiantes capacitadores

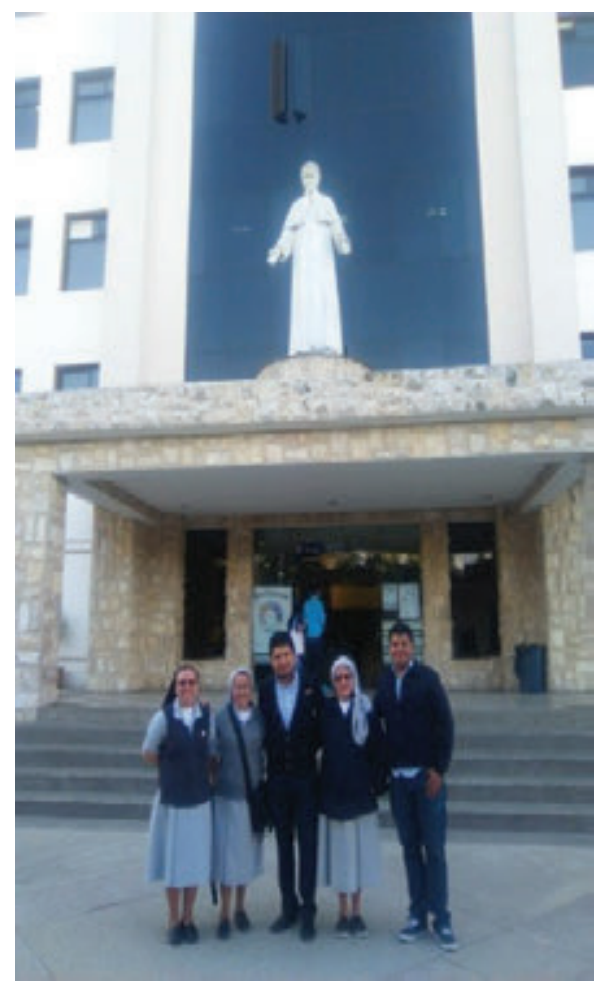

Foto: Alberto Duchi (2016)

\section{Logros obtenidos}

- El uso de las TIC como herramienta de apoyo en el aula de trabajo exige a los docentes redefinir sus habilidades clásicas para fortalecer su protagonismo en el campo educativo, es así como los docentes se interesaron y participaron de forma activa en los talleres de capacitación que les permite potenciar el uso de las TIC en sus actividades como docentes. 


\section{4}

- El uso de las TIC en el aula generó un impacto positivo en el proceso educativo, ya que permitió captar la atención de los docentes-estudiantes y mejorar su aprendizaje.

- Los talleres realizados permitieron a los docentes refrescar criterios y/o actualizarse en el manejo de herramientas de software.

- Se compartieron experiencias y se debatió entre docentes y estudiantes del grupo GAOS sobre la necesidad de crear diferentes estrategias de trabajo para llamar la atención de los estudiantes en el aula.

- Además, se generó una cultura colaborativa para favorecer el uso de las redes sociales como formas de trabajo cooperativo, entre alumnos y docentes.

Una de las funciones que tiene la universidad es buscar espacios de vinculación con la sociedad, esto lo realiza a través de actividades como las que se realizaron en las diferentes instituciones, para lo cual se diseñó una agenda con unidades para capacitar a docentes en el uso de las TIC, para que actualicen sus conocimientos en estos temas, el impacto que se deseaba obtener es que estas herramientas apoyo en la educación. Este proceso fue posible gracias al apoyo de la Universidad, la carrera de Sistemas y el GEI; quienes diseñaron la propuesta capacitación.

Este curso piloto de TIC nace en función de los aportes del congreso Ática 2016, de las necesidades encontradas en el estudio realizado por Miriam Gallegos "Situación actual del uso de la tecnología como recurso de apoyo en la educación de estudiantes con discapacidad", de las recomendaciones de la experiencia "El uso de las TIC como recurso didáctico de apoyo a los estudiantes con discapacidad del Instituto Fiscal de Discapacidad Motriz de la Ciudad de Quito, año 2015-2016” realizado por Alberto Duchi y José Luis Aguayo.

El compromiso colaborativo entre la Universidad Politécnica Salesiana y las instituciones externas permitirá en lo posterior realizar nuevos talleres de capacitación para ampliar las unidades y temas tratados en los mismos, con el fin de ser un referente de apoyo a las instituciones de educación especial. 


\section{5}

\section{Recursos utilizados}

Los recursos utilizados en la realización la propuesta de capacitación son:

- Laboratorio Computacional.

- Software de Ofimática.

- Internet con acceso libre a redes sociales.

- Pizarrón de tiza líquida.

- Marcadores de tiza líquida.

\section{Pantalla digital MIMIO en el área de comunicación con estudiantes con discapacidad intelectual de segundo de básica}

"Todos tenemos la esperanza de que el mundo pueda ser un lugar mejor donde vivir y la tecnología puede colaborar para que ello suceda"

(Tim Berners Lee)

Fundación individualizada para Niños, Niñas y Adolescentes EINA

Ecuador

Quito

Responsable: Adriana Guachamín

Gestores de la práctica: 42 estudiantes de segundo año de Educación Básica con discapacidad intelectual, Director de la institución y 12 docentes

La buena práctica docente giró en torno al desarrollo del plan micro curricular usando varias aplicaciones informáticas motivadoras para los estudiantes, con esta experiencia, se desplegó un gran abanico de posibilidades de estrategias didácticas para trabajar en Matemática, Comprensión Lectora, Ciencias e Historia, desarrollando aprendizajes útiles para los estudiantes.

\section{Motivación}

La Fundación Individualizada Para Niños, Niñas y Adolescentes EINA, es una institución ubicada en el Distrito Metropolitano de Quito sector Pusuqui, es una entidad sin fines de lucro que brinda atención 


\section{6}

personalizada a niños, niñas y jóvenes con discapacidad intelectual, la unidad educativa cuenta con los niveles de educación inicial, básica y formación profesional, su finalidad es la inclusión socio-laboral de sus estudiantes.

La institución ofrece educación individualizada, su propuesta curricular institucional, está basada en la propuesta curricular del Ministerio de Educación, en la misma se incentiva el uso de la tecnología tanto a estudiantes como profesores con miras a potenciar el proceso de aprendizaje de los estudiantes.

El aprendizaje de las personas con discapacidad intelectual, permite a los docentes mejorar su práctica educativa haciendo usos de variadas y creativas formas de enseñar. Los desafíos a los que nos vemos comprometidos los docentes es el de mantener la motivación de los estudiantes y evitar el rechazo y la frustración a ciertos actividades de orden cognitivo.

Por decisión institucional, se colocaron pantallas digitales interactivas "Mimio", como un mecanismo de equiparación de oportunidades de aprendizaje, de esta manera eliminar las barreras del aprendizaje de los estudiantes a través del uso de la dispositivos tecnológicos.

\section{Objetivo}

Apoyar el aprendizaje de los estudiantes en las diferentes áreas curriculares a través de la utilización de recursos didácticos y tecnológicos.

\section{Objetivos específicos}

- Elaborar una micro planificación curricular que responda a las necesidades del estudiante incorporando el uso de las TIC.

- Transformar la hora de clase tradicional en un espacio lúdico y divertido mediante el uso de recursos tecnológicos interactivos.

- Involucrar a los padres de familia en el uso de herramientas tecnológicas para que exista un refuerzo académico en el hogar. 


\section{7}

\section{Desarrollo de la experiencia}

Esta experiencia dio inicio con la familiarización por parte de los docentes en el uso y beneficios de varias herramientas tecnológicas y software Mimio Teach, posteriormente se desarrolló un proceso de capacitación a las familias para informarles de las estrategias de aprendizaje a desarrollar para que de esta manera apoyen a sus hijos en el hogar.

Un punto importante fue el proceso de planificación microcurricular a través de las destrezas con criterio de desempeño que den respuesta a la diversidad de ritmos y estilos de aprendizaje, intereses, entre otros; que potencien al máximo las habilidades personales.

Durante la prueba de manejo de la pizarra interactiva, se observó el entusiasmo de los estudiantes por aprender poco a poco, se evidenció mayor disposición para el aprendizaje de las matemáticas, estudios sociales y comunicación.

La pantalla digital Mimio es un producto muy flexible y permite a los docentes elaborar sus propios recursos didácticos y formar parte de una red de profesores que comparten infinidad de recursos, es una plataforma para trabajar en paralelo con otros programas. El kid Mimio funciona con un computador, un proyector, un pizarrón que sirva de pantalla, un marcador óptico con su receptor y el software Mimio Studio. Estos equipos permiten que el docente proyecte sobre el pizarrón la clase que previamente planificó y que tanto él, como los estudiantes puedan trabajar sobre la proyección con el lápiz óptico que es a la vez un marcador tradicional y un mouse inalámbrico.

Si bien, dichos equipos presentan muchas bondades, son el trabajo y la creatividad del docente los que hacen de esta herramienta una posibilidad sin límites para innovar en la enseñanza día a día. 


\section{8}

Figura 30

Pantalla Mimio

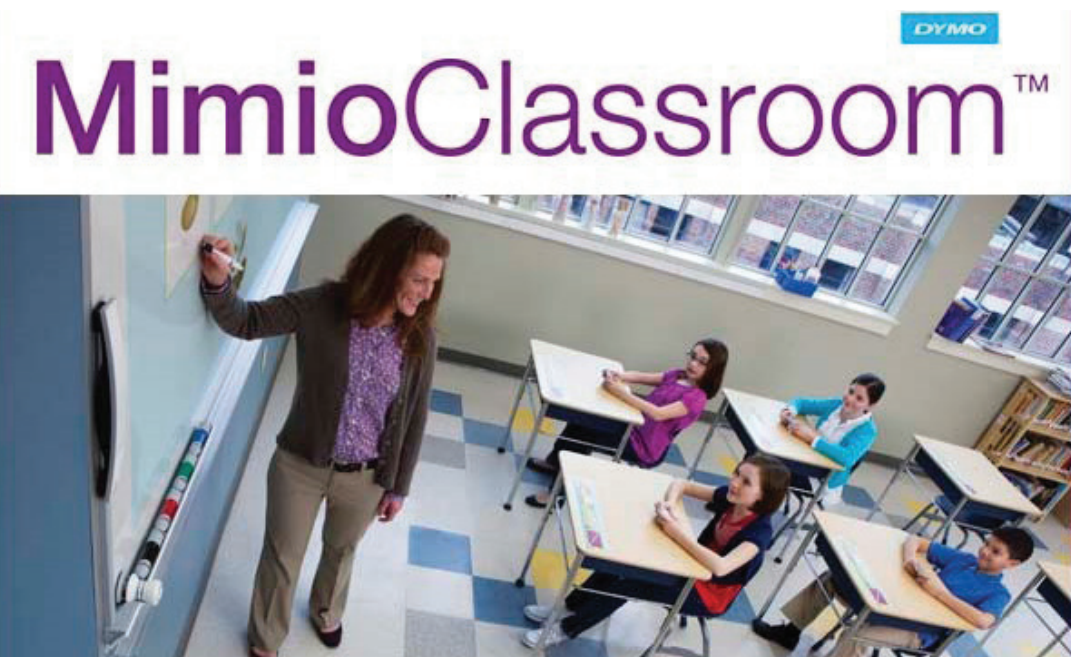

Fuente: MimioClassroom. Recuperado de https://goo.gl/N4uaVV

Figura 31

Utilitarios Pantalla Mimio

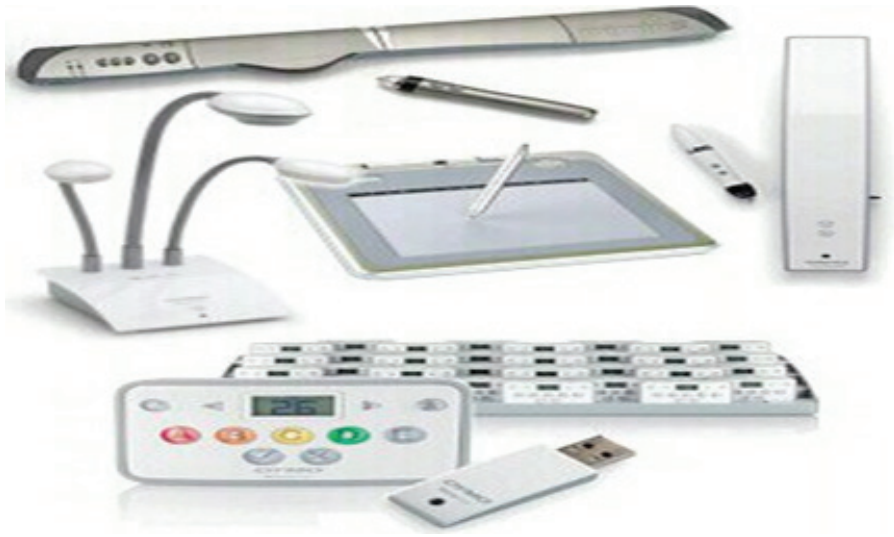

Fuente: TecnoEdu. Recuperado de https://goo.gl/LSczZ9 
Los programas utilizados como apoyo al aprendizaje de las diferentes asignaturas en la plataforma de la pantalla fueron:

Sebran's ABC. Es un programa gratuito que cuenta con doce juegos para que los más pequeños, de 4 a 9 años que se diviertan mientras aprenden. Incluye juegos muy variados y entretenidos, juegos de memoria, de palabras, de matemáticas, de abecedario. Las actividades que se presentan son lúcidas las cuales llaman la atención del niño, haciendo un aprendizaje divertido.

Figura 32

Software Sebran

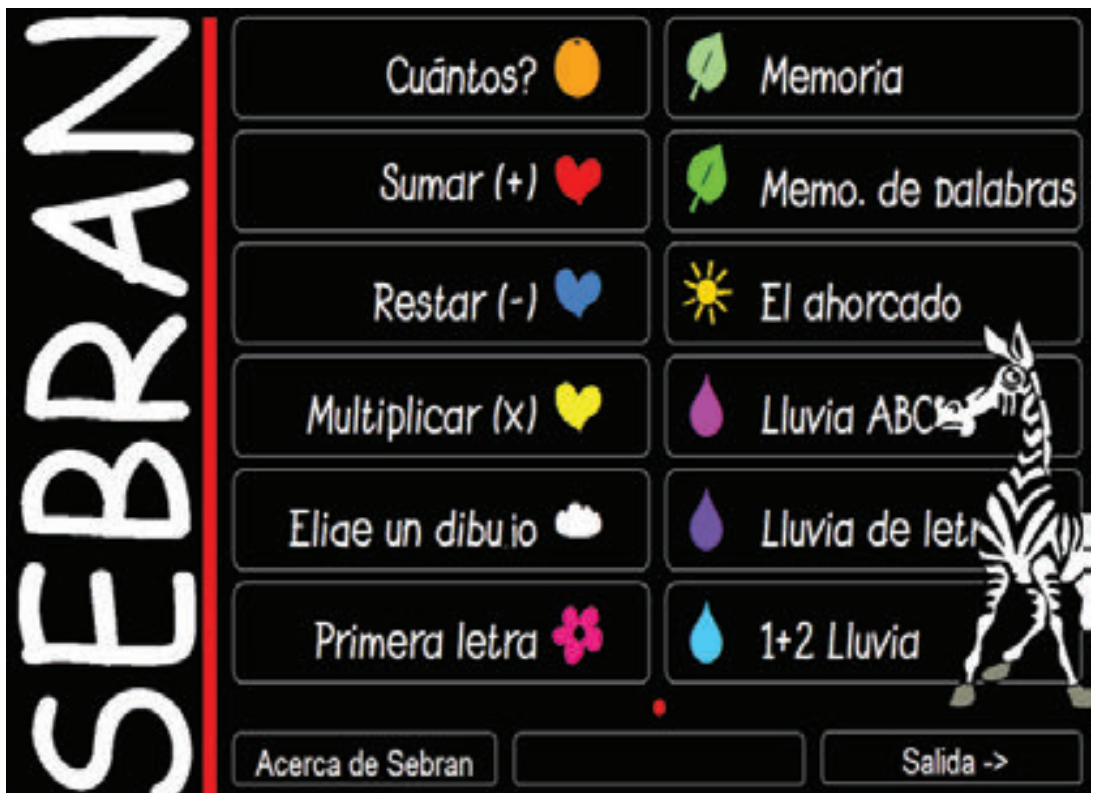

Fuente: Potal Programas. Recuperado de: https://goo.gl/8kDrtZ

Mini Sebran. Es un programa de juegos educativos para niños de 2 a 6 años. Incluye ocho actividades diversas, entre las que propone ejer- 


\section{0}

cicios con siluetas, juegos sencillos para familiarizarse con los colores, los números y las letras.

Minisebran, es una colección de ocho juegos muy sencillitos para que niños pequeños, aprendan mientras se entretienen. Los juegos, o mejor dicho ejercicios, están orientados a que el niño descubra los números, las letras y aprenda a usar el teclado y el ratón.

Figura 33

Software Mini Sebran

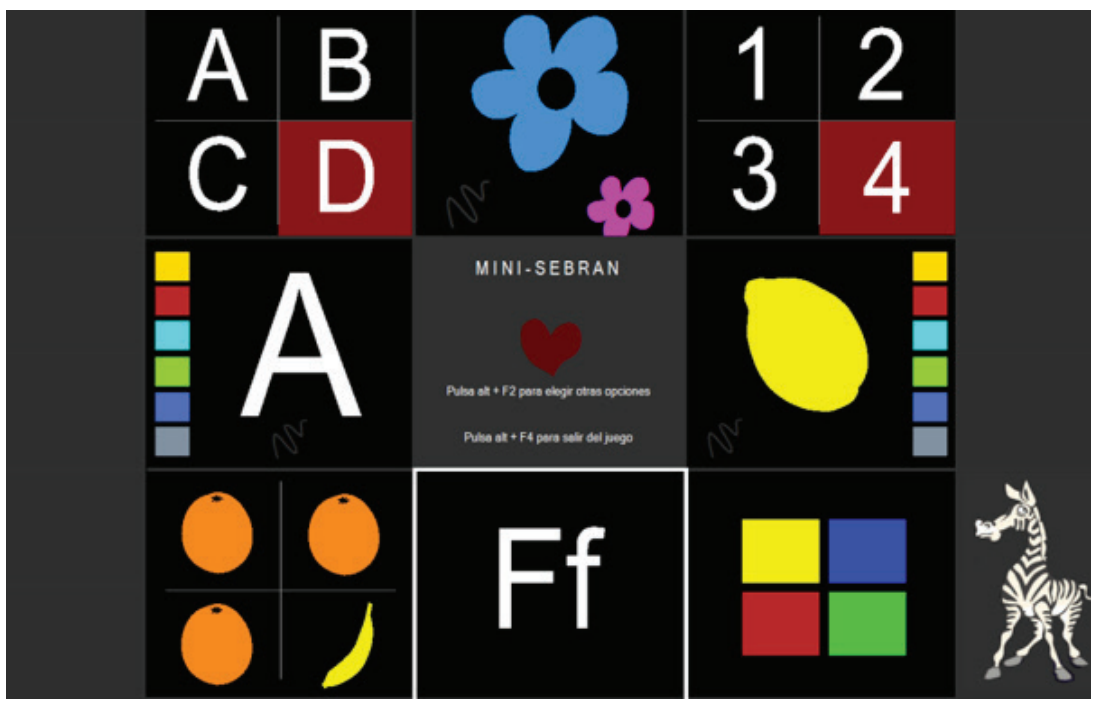

Fuente: Seterra. Recuperado de https://goo.gl/XndV8z

Proyecto Aprender. Presenta variadas e interesantes actividades relacionadas a diferentes temáticas curriculares.

Canta Letras. Es un software educativo para la enseñanza de la lectura y escritura.

El Toque Mágico. Este programa tiene por objeto el desarrollo de nociones y conceptos previos a la escolarización, tales como el lenguaje, 


\section{1}

los números, la orientación espacial y temporal; de manera entretenida para el niño.

Figura 34

Ejemplo de Software de Proyecto Aprender

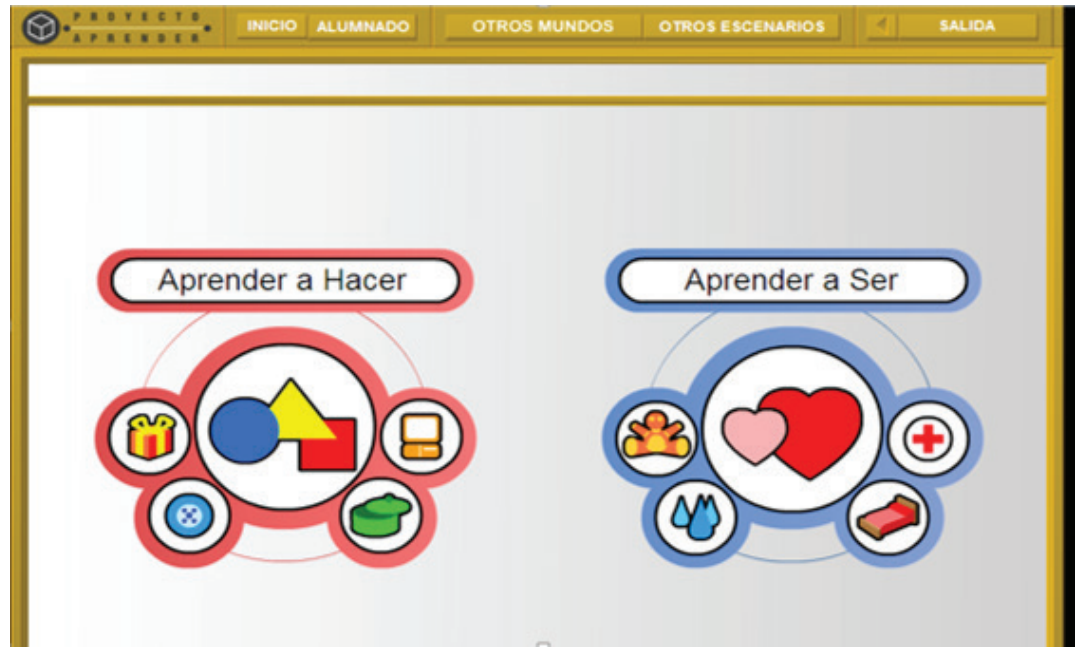

Fuente: Informática para educación especial. Recuperado de https:/goo.gl/d9FWEi

Los diferentes programas se utilizaron para reforzar los siguientes contenidos académicos:

- Funciones básicas: lateralidad, temporalidad, espacialidad.

- Colores, formas, tamaños.

- Números, operaciones básicas.

- Vocales, abecedario, sílabas, palabras

Si bien todas las actividades desarrolladas con los programas antes mencionados forman parte de la planificación microcurricular también, se las refuerza en el plan individualizada de esta manera también se incentiva su uso en el hogar. 


\section{2}

\section{Figura 35}

\section{Estudiantes trabajando con la pantalla Interactiva Mimio}
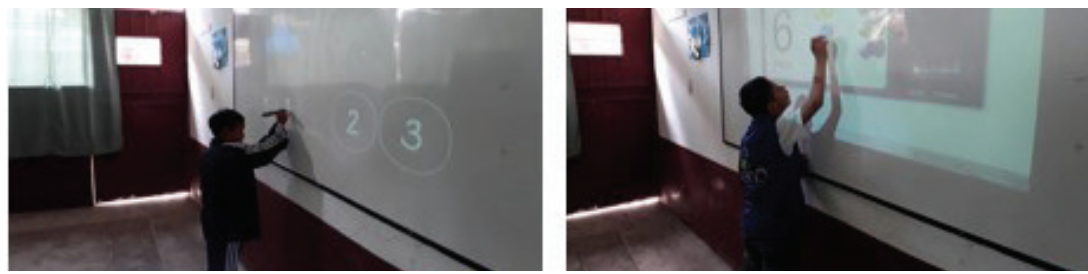

Foto: Adriana Guachamín (2016)

\section{Logros obtenidos}

Los resultados alcanzados en esta experiencia nos arrojan datos sobre los avances en la comprensión y memoria presentan además mayor motivación para el aprendizaje.

\section{Tabla 4 \\ Logros obtenidos}

Con esta metodología lúdica se logró que los estudiantes aprendan con facilidad y que no tengan a participar de manera espontánea.

\begin{tabular}{|l|l|}
\hline \multicolumn{1}{|c|}{ Áreas } & \multicolumn{1}{c|}{ Logros } \\
\hline Matemáticas & $\begin{array}{l}\text { Jugar con los conjuntos y los números lo hacen de una for- } \\
\text { ma divertida. } \\
\text { Reconocimiento de colores y tamaños en los objetos trabaja- } \\
\text { dos durante la planificación. } \\
\text { Ubicación espacial y temporal, lateralidades y nocio- } \\
\text { nes básicas. }\end{array}$ \\
\hline $\begin{array}{l}\text { En lenguaje y } \\
\text { comunicación }\end{array}$ & $\begin{array}{l}\text { Lectura de pictogramas. } \\
\text { Reconocimiento de secuencias comprensiva, reconocen soni- } \\
\text { dos con la vocal y el significado, etc. } \\
\text { Comunicación dialogo es más espontáneo. }\end{array}$ \\
\hline Estudios sociales & Reconocimiento de las regiones del país, división política. \\
\hline Ciencias Naturales & Conozcan la flora y fauna del Ecuador \\
\hline
\end{tabular}

Fuente: Adriana Guachamín (2016) 


\section{3}

Cuantitativamente el uso de las herramientas tecnológicas ha permitido que actualmente 42 estudiantes de segundo año de básica logren establecer un aprendizaje significativo por medio de la utilización de las pantallas digitales.

Los estudiantes a través de la pantalla digital se sienten motivados y se logra captar y extender sus períodos de atención debido a los sonidos, imágenes en movimiento y otros elementos. Las actividades que deben ejecutar en cada programa les permite desarrollar determinada destreza hasta lograr un objetivo, para luego pasar a otro que representa un reto mayor; de esta forma van de lo simple a lo complejo.

Por otra parte, un aporte muy significativo es que además de ayudar a desarrollar o mejorar destrezas en diferentes niveles y áreas; está el hecho de que disfrutan de la actividad y desarrollan un nivel de competencia y valía a través de los logros que ellos experimentan al superar los retos que se les plantea, esto sin duda, aporta a su bienestar emocional y su autoestima.

El uso del Mimio y los programas nos ha permitido observar no solo resultados medibles sino que ha logrado generar un ambiente diferente en el entorno escolar ya que ha motivado a los docentes a la investigación y uso de herramientas tecnológicas, a la innovación constante de los contenidos y metodologías de enseñanza y una mayor motivación por parte de los estudiantes.

Adicionalmente se ha evidenciado una reducción en el tiempo promedio de adquisición de la lecto-escritura básica y operaciones matemáticas de suma y resta en los estudiantes con discapacidad intelectual que tuvieron el apoyo de Mimio en este proceso. 


\section{4}

Figura 36

Tiempo promedio de adquisición de la lecto escritura básica y operaciones matemáticas de suma y resta

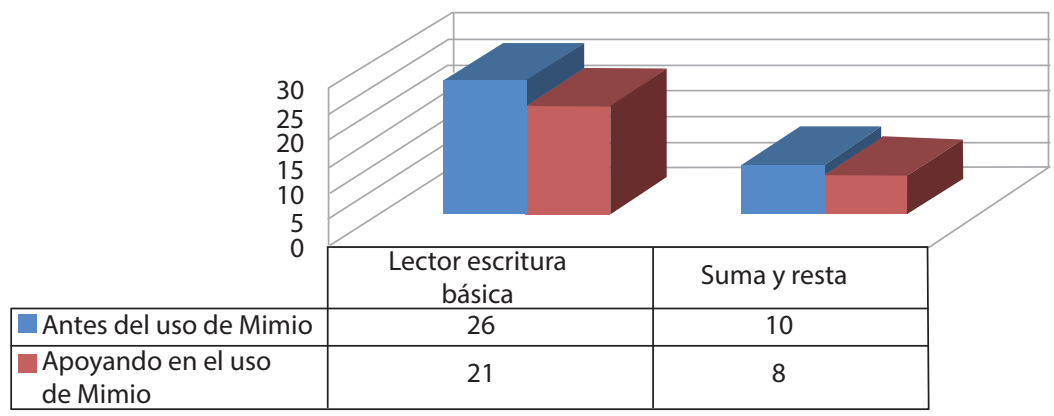

Fuente: Adriana Guachamín (2016)

Otro resultado obtenido es el incremento en el gusto de los estudiantes por las materias consideradas de más difícil comprensión y el alto índice de aceptación y gusto de la hora de Mimio. Este resultado más allá de expresarse cuantitativamente se aprecia en el deseo diario de los estudiantes por aprender.

Figura 37

Agrado por acudir a cada asignatura/10

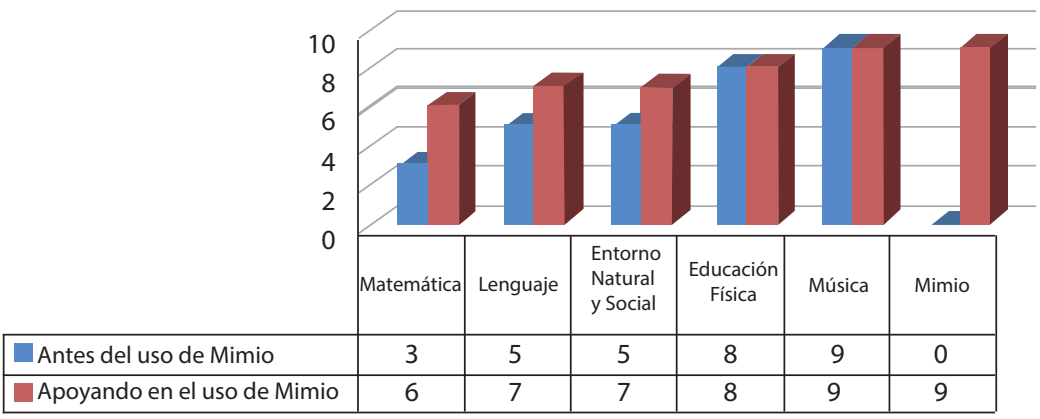

Fuente: Adriana Guachamín (2016) 
En la figura anterior se observa hay un incremento en el sentimiento de agrado por las materias que anteriormente eran rechazadas por los estudiantes.

\section{5. ¿Estudiantes aburridos o propuesta pedagógica poco motivadora? - Experiencia de inclusión significativa de las TIC en los procesos de enseñanza y aprendizaje}

"La verdadera educación consiste en obtener lo mejor de uno mismo. ¿Qué otro libro se puede estudiar mejor que el de la Humanidad?"

(P. Freire)

Escuela Normal Víctor Mercante -Nivel Superior

Argentina

Córdoba

Responsable: Lamberti Evelina Mariel

Gestores de la práctica: equipo directivo de la institución educativa, compuesto por: Prof. Petrucci Marcela - Directora y Lic. Tesan Luciana - Vicedirectora

Para enfrentar las necesidades de aprendizaje de un grupo de estudiantes ( 4 estudiantes con discapacidad intelectual 1 estudiante con Síndrome de West) esta práctica resalta dos aspectos de la dinámica pedagógica. En ese sentido, la práctica docente buscó promover y estimular en los estudiantes la resolución de problemas en el contexto real, así como, mejorar su capacidad de expresión oral, y la comprensión lectora a través del uso de varios dispositivos tecnológicos que se constituyeron en apoyos efectivos en el logro de los objetivos propuestos.

\section{Motivación}

De acuerdo a lo que establece la Ley de Educación Nacional, en el art 41: La Educación Especial es la modalidad del Sistema Educativo destinada a asegurar el derecho a la educación de las personas con discapacidades, temporales o permanentes, en todos los niveles y modalidades del Sistema. Se rige por el principio de inclusión y brinda atención educativa a todas aquellas problemáticas específicas que no puedan ser abordadas por la educación común (Congreso de la Nación Argentina, 2006, p. 9). 


\section{6}

En este sentido, y en pos de garantizar la formación integral de los estudiantes a través del acceso, en igualdad de condiciones, a una educación de calidad, establece en el Artículo 88 que "el acceso y dominio de las tecnologías de la información y la comunicación formarán parte de los contenidos curriculares indispensables para la inclusión en la sociedad del conocimiento" (Congreso de la Nación Argentina, 2006, p.18). Bajo estos lineamientos el docente a cargo de la presente experiencia, luego de la identificación de las competencias y necesidades del grupo de estudiantes, diseñó y llevó a la práctica una oferta formativa con inclusión de las TIC. Para ello, con el apoyo del equipo directivo de la institución educativa, se dio origen a un taller específico para el desarrollo de competencias digitales y se incluyeron diversos recursos de forma transversal en los distintos espacios curriculares, tales como Lengua, Matemática y Ciencias.

El principal desafío que se le presentó al docente, era diseñar una propuesta que atendiera a la diversidad del grupo fortaleciendo los vínculos entre ellos. El mismo estaba compuesto por tres estudiantes varones y dos mujeres, cuatro de ellos con discapacidad intelectual y uno con Síndrome de West. La característica en común de todos ellos, fue la necesidad de un ambiente de enseñanza altamente estructurado y la puesta clara de límites, para evitar problemas de conducta. Incluso debido a sus cortos niveles atencionales y baja autoestima, requerían de actividades cortas y motivadoras, para evitar el abandono de la propuesta. De esta manera y bajo el impulso de la formación recibida dentro del experto en TIC, dictado en la ciudad de Córdoba durante el periodo 2016-2017, el docente implementó diversas configuraciones de apoyo para transformar la propuesta educativa, tornándola más atractiva para los estudiantes. Para los cuales, el principal desafío se centró en la adquisición de nuevas competencias, principalmente digitales, para manejar los diversos recursos propuestos.

De esta forma, las diferencias individuales de cada uno de los estudiantes, fueron concebidas por el docente no como obstáculos sino 


\section{7}

como, oportunidades para enriquecer la enseñanza y el aprendizaje, a través del uso de las TIC.

\section{Objetivos}

- Desarrollar las competencias necesarias para el desarrollo integral en el contexto de la cultura digital.

- Mejorar sus problemas de conducta, niveles atencionales, inclusión social y autoestima. Que el docente sea capaz de: incluir las TIC de forma significativa y gradual, en el diseño de la oferta educativa.

\section{Desarrollo de la experiencia}

Debido a que, en la provincia de Córdoba, no se dispone de un Diseño Curricular que oriente el uso de las TIC en nivel primario, el docente a cargo de la experiencia, recurrió para determinar objetivos y competencias, al Anexo Curricular de la Ciudad de Buenos Aires. En el mismo Ripani (2014) establece algunos de los objetivos que a continuación se mencionan y que fueron desarrollados en la presente experiencia.

Las actividades previas que se gestionaron antes de la implementación de la buena práctica fueron:

Detección de necesidades, intereses y competencias individuales, respetando las cinco fases del modelo $\mathrm{M}$-free.

Diseño de proyectos transversalizados por diversos recursos TIC. Los mismos pertenecieron a las áreas curriculares de Lengua, Matemática, Ciencias Sociales y Ciencias Naturales. Las actividades propuestas en los diversos espacios invitaron a los alumnos a apropiarse significativamente de los contenidos propuestos.

Búsqueda, investigación y conocimiento de diversos recursos TIC adecuados al contenido a abordar y a las competencias a desarrollar en los estudiantes. 
Diseño de una matriz de evaluación de competencias con el fin de incluir en las propuestas de enseñanza y aprendizaje los ajustes necesarios.

En la presente experiencia las actividades se desarrollaron en tres momentos, que, si bien a continuación se presentan de forma separada, se ejecutaron de forma simultánea y/o complementaria. Incluso se mencionan solo algunos de los recursos TIC implementados, a modo de ejemplo, puesto que los mismos se especifican en su totalidad en el apartado de recursos utilizados.

1) Desarrollo de las propuestas de enseñanza y aprendizaje diseñadas en las diversas áreas curriculares.

Dentro de cada espacio curricular se desarrolló una secuencia didáctica mediada por diversos recursos TIC, los cuales fueron utilizados como disparadores de un tema, como evaluación o a modo de profundización de lo estudiado y/o trabajado. En consecuencia, los recursos seleccionados por el docente, estaban íntimamente relacionados con los objetivos y contenidos a desarrollar durante una determinada secuencia, así como también a las competencias, necesidades y estilos de aprendizaje de cada estudiante. Lográndose de esta forma la individualización de la enseñanza.

Los recursos utilizados en este sentido fueron en su mayoría, la aplicación AURASMA y los libros interactivos EDILIM.

A este respecto, es importante mencionar que, al incluirse las TIC dentro de la oferta de enseñanza y aprendizaje, los estudiantes participaron activamente en la producción y construcción de saberes. Proceso en el cual el docente actuó como guía, mediando el proceso individual de cada uno de ellos. 
Figura 38

Fabián, descubriendo y conociendo diversos seres vivos con la aplicación AURASMA

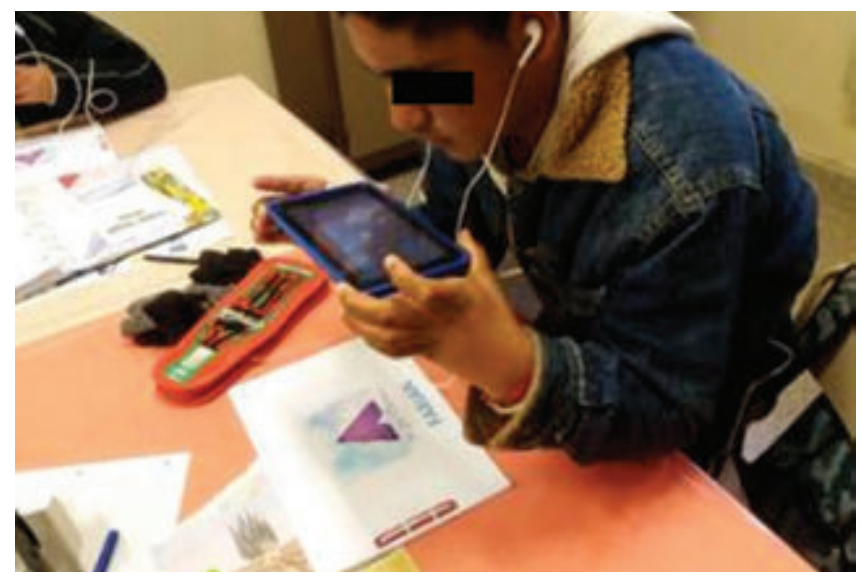

Foto: Lamberti Evelina Mariel (2016)

Figura 39

Jeremías resolviendo una evaluación de Geometría en EDILIM

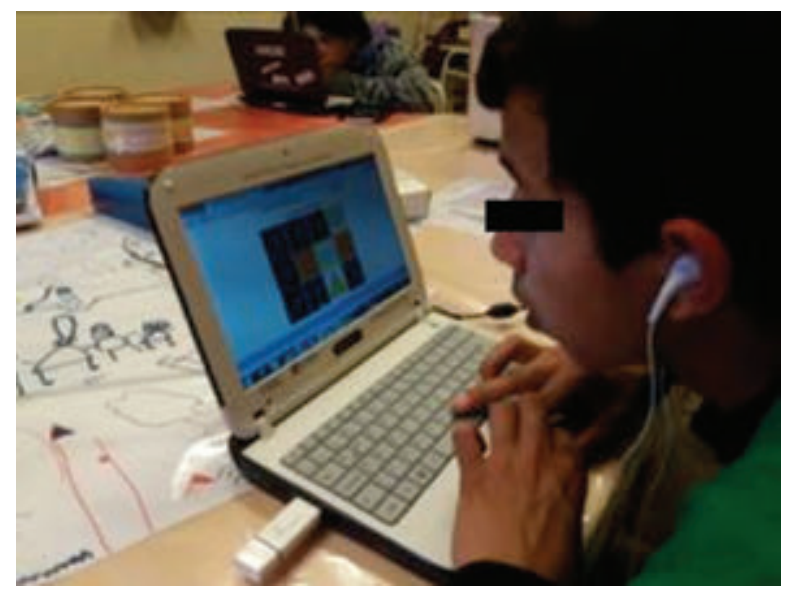

Foto: Lamberti Evelina Mariel (2016) 


\section{0}

De esta manera, al contemplarse las necesidades de cada estudiante el juego, como recursos de enseñanza, adquirió un rol protagónico "no solo porque permite a los alumnos elaborar modos complejos de simbolización y acceso al conocimiento, sino también porque es una poderosa fuente de motivación” (Ripani, 2014, p. 21). Para ello dentro de las propuestas de enseñanza se experimentó con la robótica y la programación. Así, como también se promovió el uso de diversas aplicaciones, que dentro de un entorno lúdico permitían abordar los contenidos/temas estudiados; tales como Scratch JR, Mat Ninja, Mat Duel, entre otros.

Figura 40

Lucas programando al robot DASH con la aplicación GO!

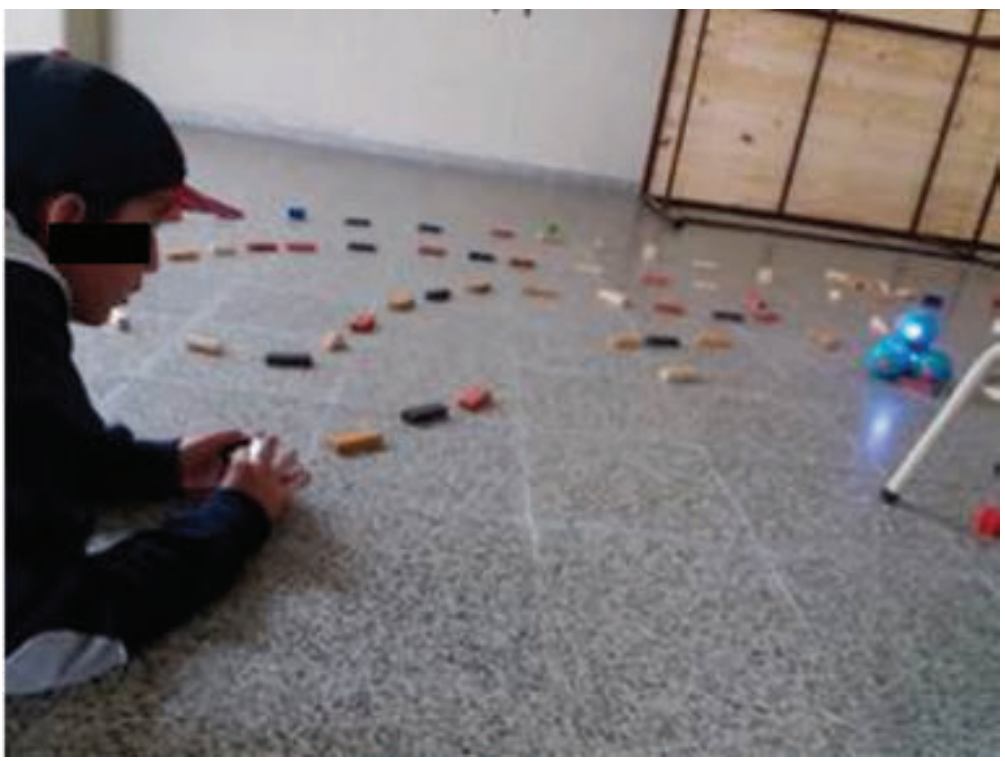

Lucas programando al robot DASH, mediante el uso de la aplicación GO!, para que realice diversos trayectos creados en forma previa

Foto: Lamberti Evelina Mariel (2016) 
Figura 41

Estimulación multisensorial por el robot DOT con la aplicación GO!

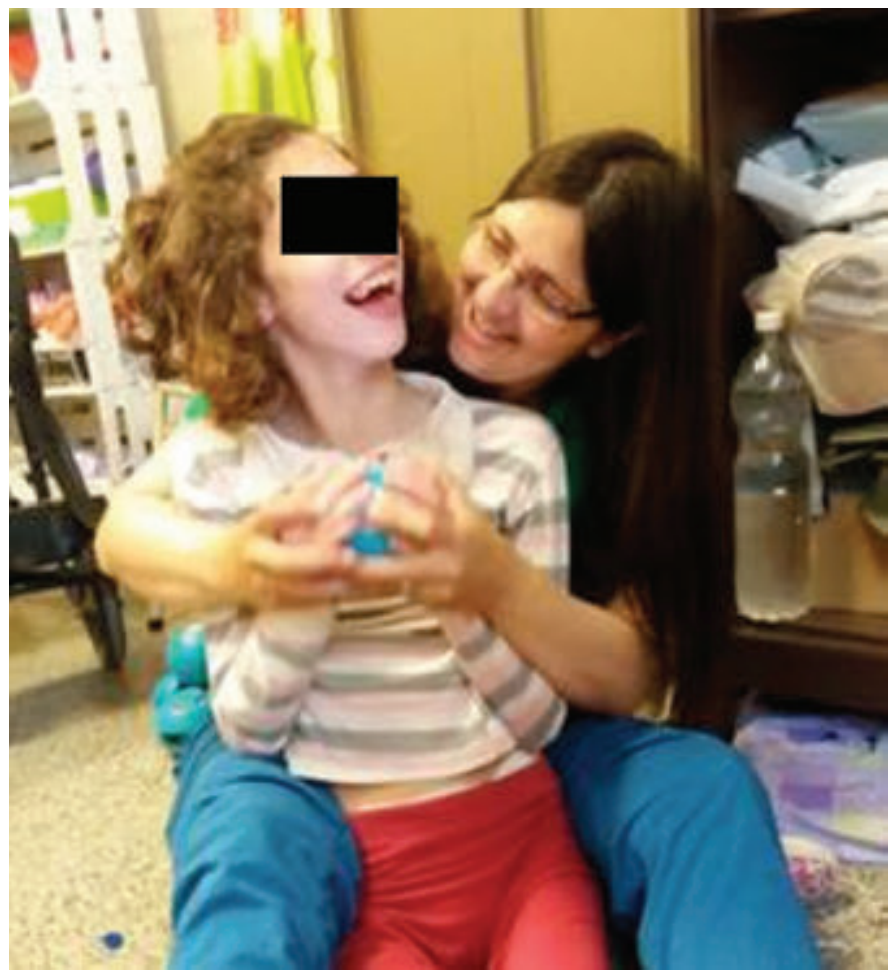

Micaela disfrutando de la estimulación multisensorial brindada por el robot DOT, programado por sus compañeros mediante el uso de la aplicación GO!

Foto: Lamberti Evelina Mariel (2016)

Otros de los recursos implementados fueron: páginas de Internet (sin conexión a la red), Microsoft Word, Microsoft Publisher, visualizador de imágenes, Webcam, Paint, entre otros. 


\section{2}

Figura 42

Jeremías, escribiendo créditos en una fotonovela, utilizando Microsoft Publisher

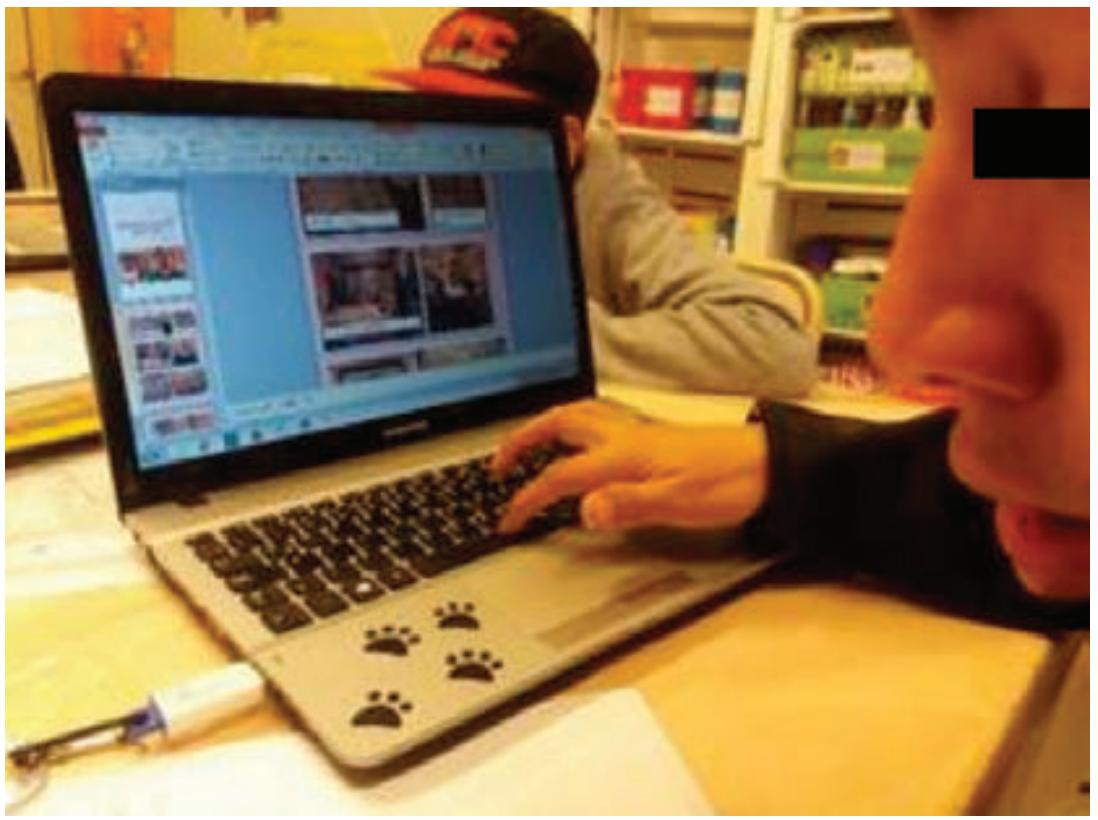

Foto: Lamberti Evelina Mariel (2016)

La mayoría de los recursos que se implementaron, se generalizaron a distintas situaciones tanto dentro de la institución, en los diversos espacios curriculares, como fuera de ella, al promover el docente la participación del grupo de estudiantes en competencias zonales y provinciales vinculadas al uso de las TIC. Así, del grupo de estudiantes, uno de ellos pasó a instancia provincial en la cual, mediante el uso del Paint debía realizar un dibujo vinculado al tema asignado. 
Figura 43

Candela, participando en las Olimpiadas de Informática, Instancia provincial llevada a cabo en la ciudad de Córdoba, Argentina

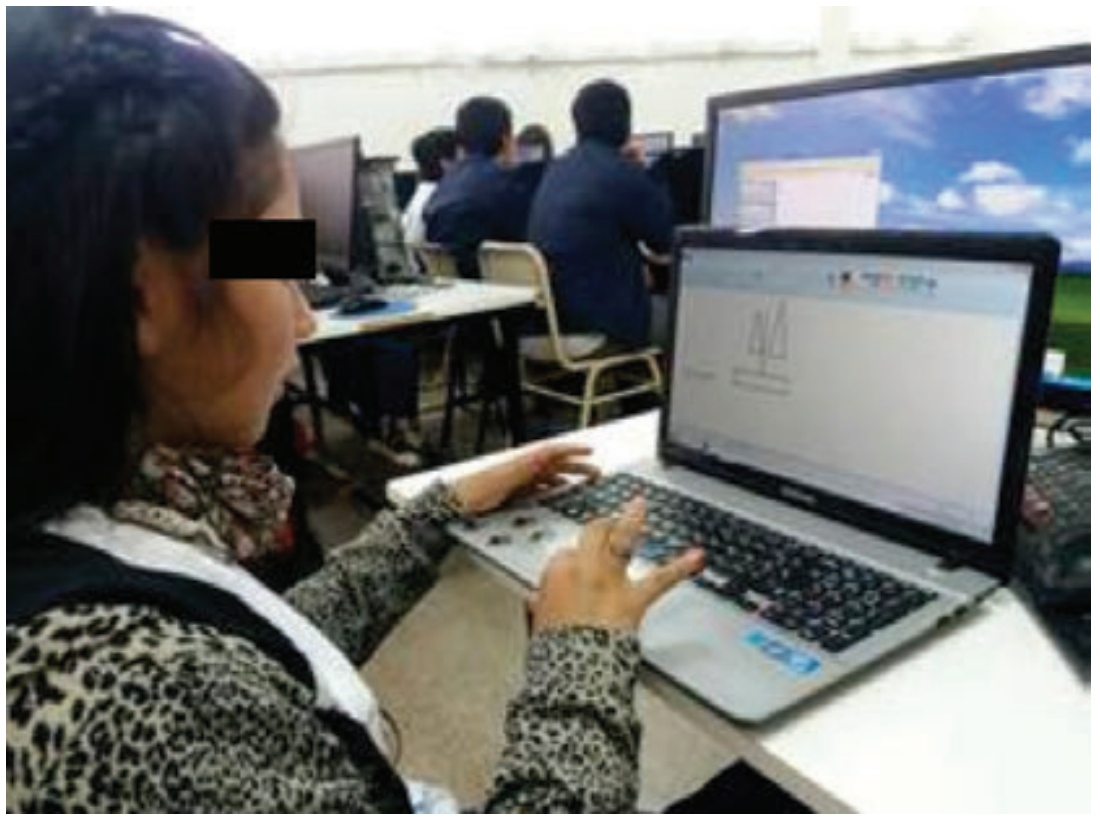

Foto: Lamberti Evelina Mariel (2016)

Por último, se menciona que al inicio de cada jornada escolar se trabajó con el PLAPHOONS para organizar las actividades por hora, asociando la imagen acompañada de la voz del docente, quien especificaba su nombre y espacio curricular a cargo. De esta manera se logró en el grupo, pero principalmente en la estudiante con Síndrome de West la anticipación y organización ante el desarrollo de las diversas propuestas, así como también se estimuló y favoreció su intencionalidad comunicativa.

La realización de ajustes durante el desarrollo de los diversos proyectos fue en función de nuevas necesidades o competencias detectadas 
en los estudiantes. Los cambios realizados por el docente se vincularon a la posibilidad de generalizar una aplicación a todo el grupo de estudiantes, debido a la complejidad o la posibilidad de un uso intuitivo en todos ellos. Así como también, en respuesta a la demanda del grupo, quienes le planteaban al docente realizar las mismas actividades que su compañera con Síndrome de West; la cual, debido a sus necesidades y competencias, requería no solo de la intervención personalizada del docente, sino también de recursos con un gran atractivo visual, en respuesta a su estilo de aprendizaje.

En cuanto a la evaluación, se caracterizó por ser de proceso durante el desarrollo de las diversas secuencias de enseñanza y aprendizaje para realizarse los ajustes antes mencionados, al finalizar las mismas, el docente de forma individual completaba una grilla de evaluación, compuesta por diversos indicadores, que detallaban los contenidos abordados y los siguientes criterios de valoración: AV (a veces), SI/NO, EP (en proceso de ser adquirido), I (independiente), CV (con ayuda verbal) y CC (con ayuda corporal). Resultados que significaban nuevos cambios en siguientes propuestas de enseñanza y aprendizaje.

Búsqueda, investigación y conocimiento de nuevos recursos TIC para superar las barreras que generaban en los estudiantes los que actualmente se estaban implementando. Las principales necesidades detectadas en los estudiantes, y que se le plantearon al docente como desafíos al momento de buscar los recursos necesarios, se relacionaban con:

- La alfabetización, ya que, para comprender aquello que debían realizar, requerían que la información sea visual y auditiva, además de gráfica, en las distintas apps y software a implementar.

- Las apps debían desarrollarse dentro de un entorno atractivo y lúdico, para evitar que abandonen la actividad propuesta, argumentando estar aburridos.

- Las apps debían promover un uso intuitivo en la mayoría de los estudiantes, para que el docente pudiera atender todas las demandas, principalmente a aquellos que requerían de interven- 


\section{5}

ción personalizada y para promover el trabajo colaborativo entre ellos, es decir entre quienes manifestaban un fácil dominio de uso de las TIC y aquellos que requerían de mayor tiempo, explicaciones y práctica para familiarizarse con el recurso.

- Las apps no solo debían ser adecuadas al contenido y objetivos de enseñanza, sino también acordes a la edad e intereses de los estudiantes, para evitar la infantilización y en consecuencia la negación, de parte de los destinatarios frente a la utilización de las mismas.

\section{Evaluación}

La evaluación se caracterizó por ser de proceso, y llevarse a cabo de forma continua a lo largo del desarrollo de las diversas propuestas de enseñanza y aprendizaje, en función de los resultados obtenidos. Para ello el docente:

Completó la matriz de evaluación, diseñada específicamente para cada proyecto.

Realizó sobre las actividades los ajustes necesarios, en función de necesidades y competencias detectadas en los estudiantes.

Reflexionó sobre la propia práctica de enseñanza.

Revisó los registros audiovisuales, capturados durante la ejecución de las diversas propuestas de enseñanza y aprendizaje, para complementar la matriz de evaluación.

\section{Logros obtenidos}

Los estudiantes se apropiaron significativamente de las TIC.

El docente logró progresiva y gradualmente integrar diversos recursos TIC en sus propuestas de enseñanza y aprendizaje. 


\section{6}

Los estudiantes lograron trabajar colaborativa y cooperativamente entre ellos.

El docente logró adaptar las propuestas de enseñanza y aprendizaje a las necesidades y competencias de cada estudiante, mediante la inclusión de diversos recursos para producir textos, gráficos, videos, etc.

Los estudiantes desarrollaron diversas competencias digitales, tales como prender y apagar los dispositivos (tableta, netbook), manejar teclas de desplazamiento, identificar y seleccionar accesos directos/iconos en el escritorio, reconocer el entorno de trabajo del procesador de texto, crear un documento nuevo, abrir un documento ya creado, crear, y organizar diapositivas en programas de presentación, entre otras.

Los estudiantes emplearon su creatividad y expresión en sus distintos lenguajes (corporal, verbal, gestual). Los estudiantes participaron activamente, en la construcción de actividades lúdicas, mediadas por el uso de las TIC. Los estudiantes lograron crear, comunicar y compartir temas estudiados a través de múltiples lenguajes de representación. Los estudiantes lograron resolver problemas con diversos recursos. Los estudiantes lograron transferir conocimientos previos para aprender a usar nuevos recursos. Por ejemplo, participaron por primera vez en las Olimpiadas de Informática, logrando uno de ellos pasar a la instancia provincial, llevada a cabo en la ciudad de Córdoba.

El docente a través de la inclusión de las TIC en sus propuestas de enseñanza logró facilitar el aprendizaje de todos los estudiantes, mediante la gestión de un proceso de retroalimentación en el cual ambos actores aprendieron mutuamente.

Los padres de los estudiantes se interesaron por la metodología de trabajo, solicitando al docente la enseñanza de los diversos recursos TIC para ser utilizados en sus hogares.

La propuesta de enseñanza y aprendizaje mediada por las TIC generó curiosidad e interés en otros docentes. 


\section{7}

Los estudiantes lograron respetar normas de trabajo y uso de los diversos dispositivos (tableta, netbook, celular) y de las aplicaciones o recursos TIC propuestos por el docente.

Los estudiantes lograron regular su comportamiento, mediante la evaluación y reflexión de la propia conducta, a través de la aplicación CLASS DOJO. Esto fue el logro más importante y gratificante para el docente, ya que muchas propuestas, antes del uso de las TIC, eran consideradas aburridas por los estudiantes, generando en consecuencia problemas de conducta.

Los estudiantes lograron interactuar entre ellos, asignando y respetando roles, así como también necesidades dentro de actividades lúdicas y juegos mediados por las TIC.

El uso del Sistema de Comunicación Aumentativa, creado en el Plaphoons, incremento la comunicación y/o expresión de la estudiante con Síndrome de West.

\section{Recursos utilizados}

Dentro de cada espacio curricular se diseñaron proyectos con actividades que incluyeron diversos recursos TIC, a fin de promover en los estudiantes el aprendizaje, el conocimiento, el juego, el pensamiento, la comunicación, la creación y el trabajo colaborativo. En todos ellos se utilizaron tabletas o las netbook entregadas por el gobierno, con recursos que no necesitaran de conexión a internet, ya que la institución educativa no dispone del mismo. Solo en algunas ocasiones se recurrió al uso del celular personal del docente para utilizar algunas aplicaciones que así lo requerían. Este último dispositivo también se implementó a la hora de programar y resolver situaciones con los robots Dot y Dash.

A continuación, se detallan las aplicaciones implementadas, con algunos de los usos que se les dio en el aula. Por último, se comparten enlaces para visualizar las producciones de los estudiantes: 
Movie Maker, ${ }^{18}$ para crear videos utilizando capturas realizadas por los estudiantes o brindas por el docente.

Visualizador de imágenes de Windows, utilizado para ver imágenes y favorecer el análisis de las mismas.

Reproductor de Windows media, para proyectar videos utilizados como disparador de un tema o para profundizar el mismo.

WebCam utilizada para capturar videos o fotografías durante la realización de una salida/visita y para registrar diversas entrevistas (material que luego, a través de su proyección favoreció la reconstrucción de las actividades realizadas).

Microsoft Word para favorecer el proceso de escritura de diversos enunciados y/o textos.

Microsoft Publisher, para crear folletos informativos.

Páginas web (sin conexión a internet) para investigar y conocer sobre un tema de estudio y para estimular el proceso de alfabetización inicial.

Libros interactivos (EdiLim), utilizados como: disparador de un nuevo tema, para indagar saberes previos, para profundizar un tema de estudio o para evaluar lo aprendido.

Aplicación: Trasportador - ON PROTACTOR: utilizando para que los estudiantes midan ángulos en objetos reales, utilizando la cámara de las tabletas. ${ }^{19}$

Aplicación: "Math Duel”, utilizada para estimular en los estudiantes el cálculo mental, y la resolución de operaciones básicas (adición, sustracción, multiplicación y división $)^{20}$.

18 Programa para editar vídeos. Link de descarga: https://goo.gl/xkmRPC

19 Disponible en: https://goo.gl/6YG1Re

20 Disponible en: https://goo.gl/cre5Ug 


\section{9}

Aplicación: "Mat Ninja", utilizada para que los estudiantes aprendan las tablas de multiplicación. ${ }^{21}$

Aplicación: "Lupa y microscopio", utilizada para observar resultados de experimentos realizados junto a los estudiantes en el área de Ciencias Naturales. ${ }^{22}$

Aplicación: "Ciencias Naturales", utilizada junto a los estudiantes para acceder a información sobre seres vivos e inertes. Esta aplicación es totalmente accesible ya que posee un lector que en voz alta lee y marca la información disponible en la página, a medida que se avanza en la lectura, y acompaña los textos con imágenes reales. ${ }^{23}$

Aplicación: "Calculadora que habla": utilizada para que los estudiantes reconozcan números de diversa cantidad de cifras, y realicen las cuatro operaciones básicas (adición, sustracción, multiplicación y división). ${ }^{24}$

Aplicación: "AURASMA" utilizada por el docente, como disparador de un contenido a trabajar. ${ }^{25}$

Aplicación: "Geoplano Digital”, utilizado para crear diversas figuras geométricas, así como también para calcular el área y perímetro de las mismas. ${ }^{26}$

Aplicación: “@voice”, utilizada para que los estudiantes escuchen atentamente información del tema estudiado y logren por ejemplo clasificar seres vivos siguiendo un criterio propio o determinado por el docente. Esta aplicación permitió también que los estudiantes sigan una lectura, ya que marca el progreso de la misma en el texto. ${ }^{27}$

\footnotetext{
21 Disponible en: https://goo.gl/Q62ia8

22 Disponible en: https://goo.gl/Ev4yYe

23 Disponible en: https://goo.gl/FHs9nk

24 Disponible en: https://goo.gl/uXfhvz

25 Disponible en: https://goo.gl/GUKiZv

26 Disponible en: https://goo.gl/S8X3hr

27 Disponible en: https://goo.gl/2YbQW7
} 
100

Google Earth y Google Maps, utilizados junto a los estudiantes para ubicar geográficamente un lugar, para trazar un trayecto o recorrido a realizar. ${ }^{28}$

Aplicaciones: Drawing, Scribmaster y Boceto, para que los estudiantes realicen dibujos con diferentes propósitos y los guarden en formato imagen. ${ }^{29}$

Aplicación Voz-Texto y Texto-Voz, para que los estudiantes transformen mensajes orales en oraciones y textos y luego los escuchen por párrafos o el texto completo. ${ }^{30}$

Aplicaciones: Scratch JR, Lightbot y BIT BY BIT, utilizados para iniciar a los estudiantes en el lenguaje de la programación, en el trabajo colaborativo, la resolución de problemas, etc. ${ }^{31}$

Robots DOT y DASH y sus aplicaciones: GO!, WONDER, BLOCKY, PATH Y XILO, utilizados por los estudiantes para programar los robots y resolver diversas situaciones propuestas por el docente o creadas por ellos mismos. ${ }^{32}$

Videos juegos de Family, utilizados para promover en los estudiantes el trabajo colaborativo, el desarrollo de competencias digitales y el juego. Para promover la participación de todos los estudiantes, los juegos se realizaron con el uso del dispositivo Makey Makey.

Aplicación: CLASS DOJO, utilizado junto a los estudiantes para evaluar su comportamiento y acordar estrategias o normas para su mejora. ${ }^{33}$

28 Disponible en: https://goo.gl/JXbKww

29 Disponibles en: https://goo.gl/JrclKN; https://goo.gl/7Pk7D8; https://goo.gl/aJkVjz

30 Disponible en: https://goo.gl/1rinPd

31 Disponibles en: https://goo.gl/6gjvS9; https://goo.gl/VRGnc); https:/goo.gl/2GUopg

32 Disponible en: https://goo.gl/5X5CPz; https:/goo.gl/tMkHUj; https:/goo.gl/ QdeR7F; https://goo.gl/SbSdtm; https://goo.gl/xwMSLM 


\section{1}

Programa PLAPHOONS, utilizado para crear un comunicador personalizado para que uno de los estudiantes trabaje el calendario, es decir para anticipar las actividades a realizar dentro de la jornada escolar. ${ }^{34}$

Programa: SÍGUEME, utilizado para trabajar la atención. ${ }^{35}$

Programa: BLUESTACKS, utilizado para instalar en la computadora las mismas aplicaciones que se disponían en la tablet, con el objetivo de que la estudiante con Síndrome de West pudiera participar en las actividades en igualdad de condiciones que sus pares. ${ }^{36}$

\section{Producciones de los estudiantes}

Área: Ciencias Sociales, producción audiovisual efeméride 20 de junio-Día de la bandera. ${ }^{37}$

Área: Lengua: producción audiovisual de noticias locas creadas a partir de un cuento. ${ }^{38}$

Área: Lengua, uso del Plaphoons para anticipar las actividades de la jornada escolar. ${ }^{39}$

Área: Lengua, uso de la aplicación BOCETO para aprender a escribir el nombre propio. ${ }^{40}$

Área: Ciencias Naturales: uso de la aplicación AURASMA para descubrir y conocer seres vivos. ${ }^{41}$

34 Disponible en: https://goo.gl/jNiKeH

35 Disponible en: https://goo.gl/VmLWDH

36 Disponible en: https://goo.gl/yzfgE1

37 Disponible en: https://goo.gl/cCjmnv

38 Disponible en: https://goo.gl/YZkGpx

39 Disponible en: https://goo.gl/XKbe74

40 Disponible en: https://goo.gl/UxBaZY

41 Disponible en: https://goo.gl/3qpWvR 
102

Área: Ciudadanía y Participación, producción audiovisual: fotonovela "Historia de un amor exagerado", trabajo sobre respeto a la diversidad y derechos del niño. Realización de entrevistas a cargo de los estudiantes. ${ }^{42}$

Área: Taller de TIC, uso del programa "Sigueme" para trabajar atención. ${ }^{43}$

Área: Taller de TIC, programación con los robots DOT y DASH..$^{44}$

Área: Taller de TIC, uso de videojuegos de Family con el dispositivo Makey Makey. ${ }^{45}$

\section{Aclaraciones}

El docente se encargó no solo de la búsqueda de los diversos recursos, sino también de su instalación previa, en los diversos dispositivos de trabajo, para poder ser utilizados en el aula.

En caso de no visualizar los recursos audiovisuales de las producciones de los estudiantes, solicitar acceso al siguiente correo: evelinamlamberti@gmail.com

Los estudiantes que participaron de la propuesta cuentan con la debida autorización de sus familiares, para que sus imágenes sean publicadas y utilizadas en presentaciones con fines educativos.

Los recursos implementados, tales como las tabletas, el dispositivo Makey y los robots Dot y Dash fueron comprados por el docente, ya que la institución educativa, al ser pública, no cuenta con los recursos económicos necesarios para realizar tales inversiones.

El uso de las aplicaciones varió en cada estudiante, en función de sus necesidades, competencias y estilo de aprendizaje. Lo que significa que no todos utilizaron la totalidad de las aplicaciones anteriormente descriptas.

\footnotetext{
42 Disponible en: https://goo.gl/GZQw4N

43 Disponible en: https://goo.gl/dd3VPf

44 Disponible en: https://goo.gl/r4UUNw

45 Disponible en: https://goo.gl/ZmqcFh
} 


\section{La incorporación de las TIC en el aprendizaje. Mejoramiento de la calidad de vida (testimonio)}

"La ciencia y la tecnología, en la sociedad revolucionaria, deben estar al servicio de la liberación permanente de la Humanización del hombre" (P. Freire)

Universidad Politécnica Salesiana

Ecuador

Quito

Responsable: Pablo Laverde

En esta experiencia presento mi testimonio personal en el que se deja establecido el hecho de que la tecnología se vuelve una aliada para la superión personal

\section{Motivación}

La condición de discapacaidad, no impede desarrollar sueños personales como es el de escribir y transmitir a través de sus textos, el pensamiento propio, logrando así objetivos personales y profesionales.

Figura 44

Pablo Laverde, "Programador Matemático"

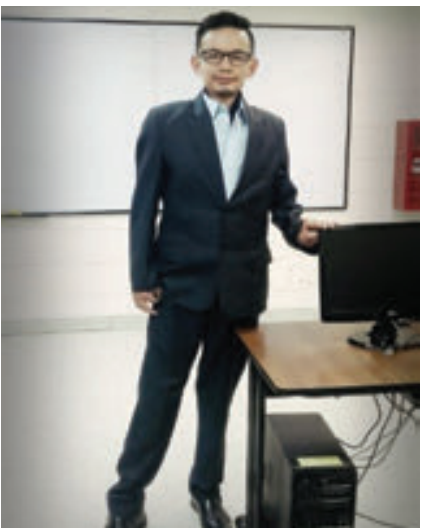

Foto: Pablo Laverde (2016) 
104

En mi condición de persona con discapacidad física producto de una distrofia muscular, el acceso a la información y comunicación a través de recursos tecnológicos constituyen mi principal apoyo para potenciar mi aprendizaje y mis actividades cotidianas; mi computadora se ha convertido en mi amiga permanente ya que gracias a ella plasmo toda mi producción intelectual con mayor facilidad en menos tiempo; me gusta escribir con el fin de influir en el pensamiento de los jóvenes para que encuentren sentido a su vida, además, disfruto liderando grupos de juveniles, y gracias al internet puedo investigar y ampliar mi conocimientos y llegar más allá de lo que mis limitaciones físicas me lo permiten. La práctica cuenta con la participación de mis padres, mi persona y mis treinta compañeros de clase.

\section{Desarrollo de la experiencia}

En pequeños recuerdos que bordean mi pensamiento, están presentes aquellos días en los cuales mi querida madre con lágrimas en los ojos en un hospital escuchaba el diagnóstico de un doctor que decía con una segura precisión; su hijo tiene una discapacidad física, no podrá llevar una vida normal y le queda poco tiempo de vida, siendo un niño de 5 años no sabía a lo que se refería, solo estaba preocupado porque no podía jugar fútbol con mis primos o correr para alcanzar a mis compañeros de la escuela, quería ir rápido a casa para jugar con mi mascota, pero seguíamos escuchando al doctor y en palabras de médico contaba que 1 de cada 1000 niños en el mundo nacen con una discapacidad como la de su hijo y el 90\% fallece a la edad de 12 años, recomendó fisioterapia para aumentar de alguna manera la masa muscular, su recetario estaba vacío ya que dijo que no existía medicina para curar esta enfermedad.

Con el pasar del tiempo en mi escuela la solidaridad de mis compañeros se hacía presente brindándome un espacio de inclusión social, estaban dispuestos a ayudarme a movilizarme en los diferentes espacios de la institución, también jugaban y estaban conmigo en todo momento sin dejarme solo. Esto me ayudó a darme cuenta que no hay limitacio- 


\section{5}

nes para compartir las experiencias de la vida con las personas que estaban pendientes de mí, que de alguna manera cuando caía me ayudaban a levantarme y mantenerme firme con mis propósitos.

\section{Figura 45}

Apoyo incondicional de la madre

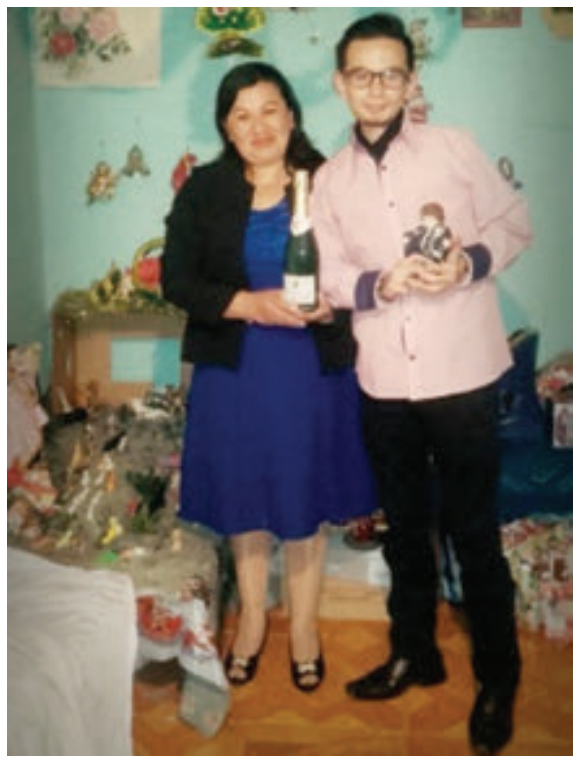

Foto: Pablo Laverde (2016)

Mi madre, constantemente decía que tenga cuidado ya que caía de vez en cuando y mis rodillas se raspaban, pero en mi mente estaban presentes las ganas de seguir con la misma actividad. Sus cuidados hasta el día de hoy son permanentes, no permitía que haga cosas que provoquen daños en mi persona; durante toda mi vida ella ha sido el pilar fundamental de las acciones que realizaba, solía repetirme que piense antes de hacer las cosas y que todo en la vida pasa por algo; una persona tan religiosa como ella determinaba que Dios era el que definía dos caminos nuestro destino y que nosotros solo somos quienes decidimos cual de los dos tomar, el 
106

fácil, sin nada de represión ni sufrimiento y el difícil, en el cual existen barreras y distintos riesgos a tomar para seguirlo; con tan solo 8 años de edad solo entendía que si tomaba el camino fácil no lograría nada en la vida, pero si me portaba valiente y seguía el difícil algún día después de tantos obstáculos tendría nuevas metas para seguir adelante.

Mis profesores llegaron a tenerme aprecio, me veían como un buen estudiante que salía adelante y perseguía sus sueños sin importar la condición en la que estaba expuesto. Sin embargo, mis pasos con el tiempo se fueron haciendo más pesados y en mi mente seguía viva la imagen de aquel doctor que expuso el periodo corto de vida que tenía; además, que en poco tiempo necesitaría una silla de ruedas para poder movilizarme siempre, yo no hacía más que pensar que sentado para siempre en una silla de ruedas la vida a la que estaba acostumbrado cambiaría radicalmente y mis sueños que perseguía con anhelo se verían afectados, eran aquellos pensamientos que tenía cuando era niño y que con el tiempo llegando a la madurez irían cambiando.

Figura 46

Gusto por la Literatura

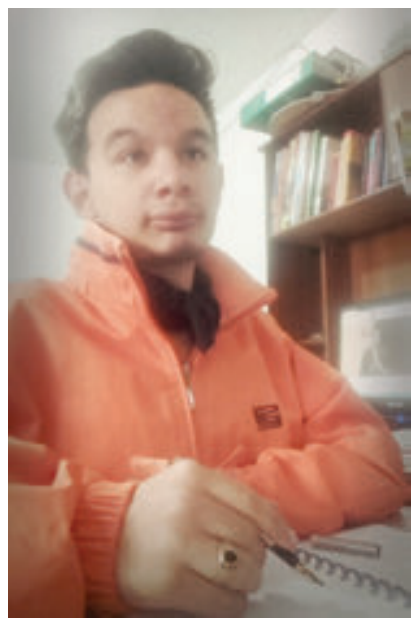


Cuando mis manos apretaban el lápiz y tenía una hoja en mi mesa me sentía poderoso ya que las tareas eran lo más simple en mi vida, terminaba rápido y buscaba seguir escribiendo o dibujando, me sentía muy bien porque expresaba lo que sentía en lo que hacía en esos momentos, me inundaba la felicidad ya que redactando me olvidaba de la silla de ruedas, me concentraba en hacer desde unas simples sumas hasta complejas divisiones que en la escuela me enseñaban; cuando me ponía triste no había nada más que me pusiera de buen humor guardar muy bien mis apuntes, como un tesoro escondido en una isla misteriosa, parecía que algún día esos papeles me harían mucha falta; y fue así, cada vez que me insistían que tenía que estar en una silla de ruedas los leía y salía caminando a jugar con mis primos, jugar definitivamente me hacía bien y después me sentía más fuerte e inevitablemente quería seguir escribiendo lo que sentía.

Con el pasar del tiempo constantemente en la primaria subía de nivel con buenas notas, las felicitaciones de mi familia y maestros no se hacían esperar, eres un muy buen niño, decían y lo repetían cuando me veían triste por algo que no podía hacer o cuando con mis pocas fuerzas me sentía desalentado y sin ganas de continuar.

Llegaron los niveles altos en la escuela y conocí algo tan bonito llamado computadora, eran unas máquinas donadas por el Ministerio de Educación y tenían juegos interactivos que ayudaban en la educación de los estudiantes, lo que más me llamaba la atención fue cuando mi maestro de computación me indicó que existía un programa para escribir cualquier cosa, el famoso Word, en mi mente solo estaba la idea de escribir algo bonito para una niña que me gustaba, procedí a prender la computadora y con el puntero del mouse abrí el programa en su versión 2003 una hoja en blanco y unas opciones en la parte de arriba eran las características de aquel programa lo que más me llamó la atención era que tecleando las letras, estas aparecían en la hoja en blanco y con las herramientas de la parte superior podía cambiar de color las letras o elegir el tipo de las mismas a mi gusto; fue entonces cuando comencé a realizar la carta para aquella niña por la cual sentía algo especial cuando la veía. 
La moda de las computadoras crecía, y los profesores comenzaban a enviar deberes en computadora, fue entonces cuando al no contar con una computadora en casa tenía que ir al centro de cómputo más cercano para poder hacer las tareas encomendadas, la afición que sentía al manejar aquella máquina crecía y las ganas de seguir aprendiendo eran persistentes; además, Word ya no me llamaba la atención ya que nos habían enseñado todo sobre aquel programa y quería aprender cosas nuevas.

Una clase de computación de dos horas en un día como cualquiera marcó la diferencia, el maestro indicó que ya no manejaríamos Word ni Excel ya que con los conocimientos que teníamos era suficiente para hacer cualquier tipo de documento, pidió que prendamos la computadora y hagamos doble clic en el ícono Internet Explorer al abrir aquel programa de internet unas letras grandes y coloridas que decían Google y más abajo una parte para escribir algo apareció, el maestro indicó que este es un navegador y que se puede buscar cualquier cosa, en ese instante me invadió la duda de cómo funciona el programa, y procedí a escribir la palabra juegos, de repente se desplegó una página con algunos títulos de color azul, el profesor indicó que haciendo clic en cualquiera de los títulos se desprende información o algo en específico de lo que buscábamos, el profesor nos dio una hora para hacer un documento en Word sobre algún tema en especial no lo pensé mucho y escogí distrofia muscular espinal muchos textos hablaban sobre esta enfermedad, se presentaban imágenes de niños en sillas de ruedas niños postrados en camas con cables y tubos de respiración; mirando estas imágenes me inundó un sentimiento de angustia, pero tenía que hacer la tarea propuesta, de repente al leer un artículo sobre la enfermedad una imagen me llamó mucho la atención era un señor sentado en una silla de ruedas con la mirada al piso y algunas malformaciones en su cuerpo, se trataba de un científico reconocido mundialmente por su aportes a la ciencia, Steven Hawking, leer su vida y logros cambiaron mi enfoque de la discapacidad y me ayudó a vencer mis miedos para ser como aquel científico cuya incapacidad lo llevó a ser quien es ahora. 
Continué con mis estudios con tranquilidad y afición, hasta que a la edad de 11 años en un mes de mayo una semana después de celebrar el sacramento de la Primera Comunión una triste situación invadió a mi familia, mi hermano mayor de 24 años falleció en un accidente, fue tan lamentable la noticia que mi madre sentía que una parte de su corazón se arrancaba dolorosamente y lo sepultaba en un frío cementerio, por mi parte solo sentía que ya no compartiría los más grandiosos momentos de alegría y juegos con el hermano que estaba conmigo en todo momento, tenía otro hermano mayor que vivía lejos y casi no lo veía al ver tan dolorosa situación se mudó con nosotros hasta que la tormenta pase.

El tiempo pasaba, los tristes sentimientos que tenía por la muerte de mi hermano comenzaron a ser menos constantes. En mi pensamiento permanecían vigentes recuerdos de lo que pasó, pero no podía dejar de lado mis estudios. Me convertí en aquella persona que no deja de lado algo que quiere hacer y hace hasta lo imposible por lograrlo. Mi hermano descansaba en paz, mi madre se recuperaba con psicólogos, mi otro hermano hacía planes de viaje y mi padre se alejó de nosotros, la única manera de dejar de lado esas situaciones fue haciendo lo que tenía que hacer, continuar mis estudios.

Felicitaciones, siga adelante; mis cuadernos de primaria se llenaban de aquellos sellos tan agraciados de caritas felices o tristes de profesores de mi escuelita percibía una gran satisfacción cuando mis notas eran sobresalientes cuando por alguna razón, las notas bajaban me angustiaba un poco pero me llenaba de fuerza y recuperaba aquellas notas ejercitando mi mente y volviendo a intentarlo, como algunas situaciones en la vida en el segundo intento recuperaba lo que deseaba y mi pensamiento ya no se ocupaba de las cosas que no podía hacer por mi enfermedad, sino por las que puedo lograr con mis estudios.

Una computadora en mi casa con internet me permitía hacer tareas e investigaciones que me ayudaban a entender el contexto de mis estudios y lo que pasaba alrededor del mundo; un adolescente es atraído 


\section{0}

por la música y videos que distraían su mente, yo no me quedaba atrás; tomaba momentos para todo y organizaba cada tarea que debía hacer, eso ayudaba a que mis estudios sobre las matemáticas surjan, escribía algunos ensayos que describían la importancia de las matemáticas en los estudios y cuando podía redactaba algunos poemas que afloraban los sentimientos de adolescente.

\section{Logros obtenidos}

Figura 47

Discursos presidenciales

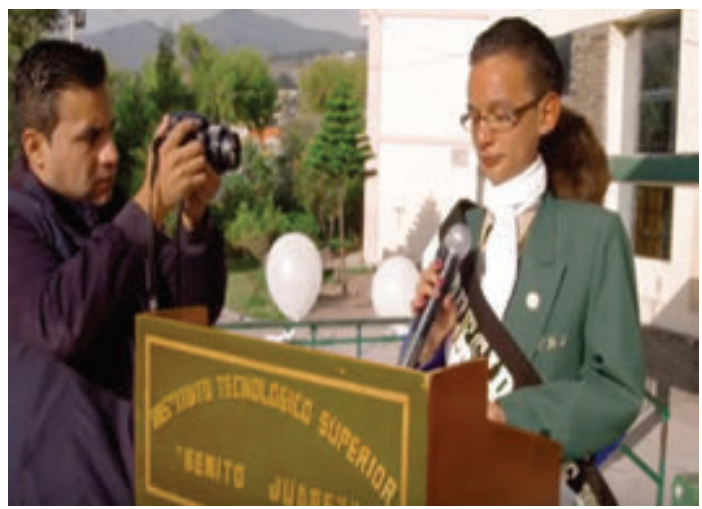

Foto: Pablo Laverde (2016)

El gusto de toda mi familia fue cuando en décimo año de educación básica, fui proclamado abanderado. Me alegré mucho cuando por primera vez en mi vida con mis pocas fuerzas pude levantar la bandera. De repente me sentía feliz y en un discurso agradecí a Dios, a mi madre, a mi familia, a mis amigos y a quienes hicieron realidad este sueño. No había logrado tanto éxito sin el apoyo de todos ellos. La maestra de matemáticas que había sido mi docente durante tres años consecutivos se acercó a felicitarme y de repente vi una lágrima que corría por su mejilla, le pregunté, ¿Por qué estaba triste? y me respondió, llevo 10 años 
siendo maestra en este colegio y es la primera vez que tengo a un alumno como tú, lamentablemente por situaciones personales tengo que ir a trabajar en otro colegio. En mi mente estaba por decirle que no se fuera porque era la persona que más me apoyaba, pero solo pude responder al abrazo, entonces me contestó; sigue siendo como eres, no cambies.

Era un arduo trabajo ser estudiante y líder de más de 3000 estudiantes, pero tuve un apoyo incondicional del Consejo Nacional Electoral quién en una ceremonia me reconoció como el mejor líder estudiantil; me apasionaba el hecho de participar en todo tipo de reuniones y eventos que contribuían al desarrollo de la educación, fue entonces cuando al momento de realizar mi monografía, redacté un capítulo de la belleza y elegancia de las matemáticas. Era el momento de implementar de manera más eficiente el desarrollo tecnológico, entonces comencé con un gusto por la programación y el diseño de proyectos en programas que permitían que mis ideales sean reconocidos, es por eso que implemente el tema de Belleza y elegancia de las Matemáticas, un conjunto de escritos que gracias a la práctica en computadoras y dispositivos los ponía a disposición de las personas interesadas en conocer sobre el tema; uno de los escritos refería que:

La matemática es elegante, una noble ciencia que ayuda a la comprensión de la razón del ser y el existir; es dotada de gracia, su resolución mueve al mundo por conseguir resultados sobre sus problemas, algo que resulta grandioso, ya que unifica pueblos y naciones, que resuelven conflictos con números y letras; es sencilla, para su resolución solo basta un conocimiento pleno, sobre sus fundamentos, relacionándola con las demás ciencias, es la más detallada, infalible, rigurosa, precisa, exacta y comprobada (Laverde, 2015).

Basándome en aquella pasión por escribir lo que tenía en mente tuve la oportunidad de seguir adelante con mis estudios en la educación superior. 


\section{2}

Figura 48

Inicios en la Universidad

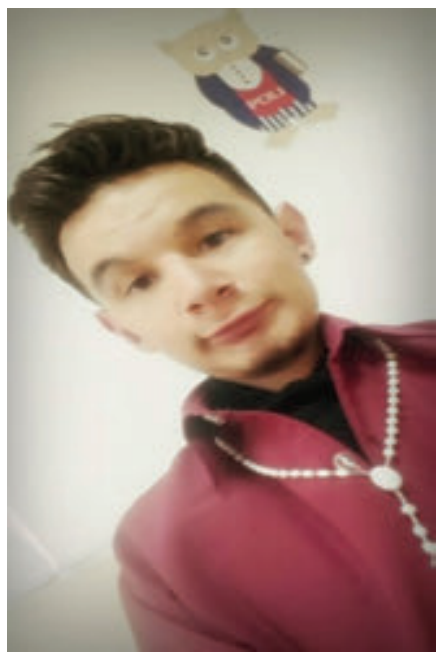

Foto: Pablo Laverde (2016)

El siguiente paso de la educación fue la universidad, en las pruebas de la Secretaría de Educación Superior, Ciencia, Tecnología e innovación (SENESCYT) fui admitido en la Escuela Politécnica Nacional, en la carrera de Ingeniería Matemática, ahí durante dos semestres aprendí a demostrar varios teoremas que pasan desapercibidos en el Estudio de las Matemáticas. Por diferentes situaciones comprendí que para desarrollar a plenitud estos estudios es necesario aprender primero a formalizar una ciencia que busque promover nuevas tendencias en el presente y futuro; la Ingeniería en Ciencias de la Computación sería la base fundamental, así que tomé la decisión de estudiar aquella carrera para seguir adquiriendo conocimiento científico y llegar a la meta planificada.

Sin duda la universidad es un nuevo espacio de creación de conocimiento, en donde los jóvenes aprendemos que las metas propuestas por uno mismo son aquellas que se logran con esfuerzo y dedica- 
ción; mi propuesta hacia la educación superior radica en el servicio a los demás y el compartir mis experiencias como ser humano hacia el mundo, sin dejar de lado la teoría de la capacidad de cada persona para seguir adelante con sus sueños, además, un joven con determinación es el factor clave para dar solución por lo menos a algún problema en el mundo; me encaminé a cambiar el mundo paso a paso, en la universidad fundamentando mis conocimientos y aprendiendo cada día a saber demostrarlos en un futuro próximo, la razón de estudiar una carrera tan compleja como la Ingeniería es por demostrar a la sociedad que no hay barreras que impidan seguir cultivando sueños y cosechando éxitos que valen la pena.

El ambiente universitario está más definido en lo que se hace para aprobar la carrera, la institución brinda los soportes necesarios para continuar, entonces hay que aprovecharlos al máximo si una persona con discapacidad se encuentra con estos; las rampas digitales se hacen presentes y son de mucha ayuda al momento de hacer un trabajo que tenga una gran dificultad, para quienes tenemos discapacidad motriz la ayuda de programas como: Técnica de Estudio, un software de refuerzo para mejorar actividades como: concentración, ambiente de estudio, actitud, técnicas, memoria y razonamiento; In-Tic, un programa que tiene como objetivo ayudar a mejorar la autonomía personal creando entornos personalizados para un acceso simplificado a computadoras y a celulares, además, de funcionar como un comunicador dinámico; entre otros, son de gran importancia para enfrentarse con las distintas situaciones que surgen al momento de cursar una carrera, en lo personal me han ayudado a tener mayor capacidad de comunicación.

Según la Unesco:

Las TIC no abarcan sólo dispositivos como computadoras, radios, teléfonos celulares y conectividad, sino que también remiten a la posibilidad que se abre a las personas de crear, compartir y adquirir conocimientos. Para colmar la "brecha digital" se hacía hincapié inicialmente en la instalación de equipos e infraestructura informáticos y la garantía 
114

del acceso y la conectividad. Sin embargo, la UNESCO siempre ha subrayado la importancia de los componentes "intangibles" de las TIC, es decir las dimensiones del contenido, las políticas y el desarrollo de capacidades, que son igualmente fundamentales para colmar esa brecha (Unesco, 2012).

Una situación de la vida actual está caracterizada en lo que haces, para qué lo haces y para quiénes lo haces, ya sea con herramientas tan sutiles como el manejo de computadoras y otros dispositivos que permiten la interacción del ser humano con la tecnología y la ciencia, únicamente en un sentido ético, queda por decir, que la tecnología es de gran importancia para desarrollar las habilidades de personas que pudieran quedarse en el olvido por una discapacidad que lo marcó de por vida.

La importancia de las TIC en la discapacidad es una solución a aquellas situaciones en las cuales las personas quieren ver sus sueños hechos realidad, pero, no solo se trata de computadoras que trabajan al ritmo de la situación en la que se vive para salir adelante, en efecto el mundo de la tecnología en el cual estamos viviendo da a conocer las diferentes soluciones hechas por programadores y personas que están trabajando a diario por la implementación de un mundo incluyente para todos. Ahora bien, si hablamos de la inclusión es necesario debatir el tema de la capacidad de las personas para hacer diferentes actividades y aquellas actividades que no son posibles de realizar pero que se pueden implementar de manera efectiva. No sólo es el hecho significativo de hacer tecnología que apoye al descubrimiento de capacidades y la ayuda con respecto a la discapacidad, sino también es necesario conocer la manera efectiva de presentar aquella tecnología con fundamentos esenciales para toda persona, independiente de que pueda o no manejar tecnología.

Vivir los sueños de un joven con discapacidad motriz, cuyas metas están encaminadas al servicio social es una ligera ilusión vista a los ojos de quienes tienen todas sus capacidades y no las aprovechan y no es el hecho de que los impedimentos físicos determinen la falta de las 
ganas de luchar por conseguir de alguna manera aquel sueño, al parecer el poder del ser humano radica esencialmente en lo que se propone hacer, y hablando en un plano más antropológico la esencia pura de sus dimensiones al realizar sus actividades como acostumbra; generalmente nos vemos en la situación de impotencia ante lo difícil que se presenta en la vida, pero qué sería del mundo si la impotencia hubiese ganado a aquellos científicos, investigadores o artistas que no se dejaron llevar por las dificultades y dieron al mundo grandes innovaciones que permitieron el desarrollo de la sociedad, algo increíble ¿verdad?, y fue aquel pensamiento el que me permitió ir más allá de mis límites y hacer algo que promueva el sentido de amor a lo que hago cada día y la gratitud con los demás por permitirme enfocarme en nuevas visiones a través de la tecnología.

De cierta forma los recursos tecnológicos enfocados para la discapacidad motriz como gadgets, software especializado, sillas de ruedas electrónicas, recursos digitales con precisión para realizar tareas cotidianas, entre otros; ayudan de manera efectiva a que la persona que utiliza estos implementos lleve una vida parcialmente normal; en mi caso estos recursos serán indispensables a medida que se eleve el grado de dificultad para realizar acciones; no obstante, como ya lo había mencionado el uso del computador con herramientas que ayudan a la realización de programas e implementos que ayuden de alguna manera a la inclusión de personas con discapacidad en todos los ámbitos de la vida, ahí uno de mis objetivos. Queda claro que la tecnología en mi vida se ha presentado como el instrumento de gran utilidad para erradicar el pensamiento de impotencia y elevar aquellas facultades escondidas del ser humano y seguir una evolución continua con éxito y perseverancia.

Ahora bien, es necesario que estos implementos sean determinados con el estudio de determinadas ciencias que son parte fundamental de la tecnología, es por eso que durante mis estudios universitarios como en las investigaciones que estoy llevando a cabo, iré descubriendo nuevos métodos que ayuden con los objetivos propuestos, además, inte- 
resado por la literatura y el arte de creación de conciencia hacia aquellas personas que necesiten de apoyo emocional "No descansaré de escribir hasta que mis palabras se plasmen en la vida de los jóvenes" quienes serán los que seguirán apoyando la inclusión y las ganas inevitables de seguir siempre adelante a pesar de cualquier dificultad.

\section{Proyecto "Sígueme" una iniciativa para apoyar a estudiantes con Trastornos del Espectro Autista}

"El trabajo del maestro no consiste tanto en enseñar todo lo aprendible, como en producir en el alumno amor y estima por el conocimiento"

(John Locke)

Instituto de Educación Especial del Norte

Ecuador

Quito

Responsable: Giovanna Bedoya Navas

Gestores : Área Psicológica de la institución

Con la ejecución de este proyecto innovador se promueve el desarrollo de habilidades sociales de los estudiantes con Trastornos del Espectro Autista (TEA) de bajo funcionamiento que acuden a la institución, instaurando con la ayuda de programas informáticos rutinas de trabajo que comprometen la necesidad de compartir con otros y fomentando la interrelación social.

\section{Motivación}

Esta práctica se desarrolla en el Instituto de Educación Especial del Norte en la ciudad de Quito, con estudiantes con Trastorno del Espectro Autista de bajo funcionamiento, cuyas barreras en la comunicación limitan el logro de aprendizajes académicos y sociales.

Los docentes de la institución manifiestan la dificultad que tienen para controlar la conducta de los estudiantes en el aula, por lo tanto los remiten al servicio de psicología para que reciban los apoyos correspondientes. 


\section{7}

En la observación de los estudiantes en sus ambientes naturales y en la escuela se estableció que, cuando utilizaban la tecnología mostraban signos de interés por comunicarse y colaborar en las actividades propuestas esto motivó a potenciar su uso para desarrollar la comunicación de los estudiantes.

\section{Sujetos de aprendizaje}

Los estudiantes beneficiarios de este proyecto son:

Tabla 5

Beneficiarios del proyecto

\begin{tabular}{|l|c|c|c|c|c|c|c|c|}
\hline & \multicolumn{7}{|c|}{ Estudiante } \\
\hline & $\mathbf{1}$ & $\mathbf{2}$ & $\mathbf{3}$ & $\mathbf{4}$ & $\mathbf{5}$ & $\mathbf{6}$ & $\mathbf{7}$ & $\mathbf{8}$ \\
\hline Trastorno del Espectro Autista & $\mathrm{x}$ & $\mathrm{x}$ & $\mathrm{x}$ & $\mathrm{x}$ & $\mathrm{x}$ & $\mathrm{x}$ & $\mathrm{x}$ & $\mathrm{x}$ \\
\hline Baja Visión & $\mathrm{x}$ & & & & & & & \\
\hline Parálisis Cerebral Infantil & $\mathrm{x}$ & & & & $\mathrm{x}$ & & & \\
\hline Trastorno de Ansiedad & $\mathrm{x}$ & & $\mathrm{x}$ & & & & & $\mathrm{x}$ \\
\hline Epilepsia & & $\mathrm{x}$ & & $\mathrm{x}$ & $\mathrm{x}$ & & & \\
\hline Hipoacusia & & $\mathrm{x}$ & & & & & & \\
\hline Trastorno Conductual Severo & & $\mathrm{x}$ & & & & & & \\
\hline Hipoacusia bilateral leve & & & $\mathrm{x}$ & & & & & \\
\hline Síndrome Lennox Gastaut & & & & $\mathrm{x}$ & $\mathrm{x}$ & & & \\
\hline Trastorno Conductual & & & & $\mathrm{x}$ & & $\mathrm{x}$ & & \\
\hline Trastorno del Lenguaje & & & & & & $\mathrm{x}$ & & \\
\hline Síndrome X Frágil vs Síndrome Opitz & & & & & & & & \\
\hline Frías & & & & & & & $\mathrm{x}$ & \\
\hline Baja Visión Leve & & & & & & & $\mathrm{x}$ & \\
\hline Hipoacusia Bilateral Leve & & & & & & & $\mathrm{x}$ & \\
\hline Síndrome Damp & & & & & & & & $\mathrm{x}$ \\
\hline
\end{tabular}

Fuente: Giovanna Bedoya Navas (2016) 


\section{Desarrollo de la experiencia}

Las actividades previas a la práctica consistieron en:

- Investigar sobre programas gratuitos que no requieran ser utilizados a través de la red de internet orientados a desarrollar procesos de atención y comunicación, la aplicación que brindaba mayor respuesta a las competencias a alcanzar por parte de los estudiantes fue el "Proyecto Sígueme".

- Familiarización por parte de los docentes y estudiantes con la aplicación a través de ejercicios de simulación y verificación de los contenidos del mismo.

- Socialización con los padres de los estudiantes para solicitar su colaboración en el hogar.

- Registro anecdótico de las conductas observadas en los estudiantes tanto en el aula como fuera de ella y se identifican las competencias sociales y comunicativas a trabajar con cada uno de los estudiantes.

- Las actividades se desarrollaron en un primer momento de forma individual ya que así lo establece la estrategia de atención personalizada y también por que únicamente se contaba con una tableta, de esta manera el estudiante se familiariza con la aplicación.

- Se establecen acuerdos de colaboración con la maestra del aula para el cumplimiento de ciertas rutinas que permitan la aceptación del estudiante de las nuevas actividades entre las rutinas que se requiere apoyar es la del desplazamiento a la sala psicología todos los días a la misma hora, para lo cual la docente integra esta actividad en el calendario personal de cada estudiante, y acompaña en el desarrollo de la misma hasta que lo realice por sí mismo.

- Como actividades de inicio de clase realizan actividades de relajación acompañadas de luces y sonidos tenues que captan el interés de los estudiantes. 


\section{9}

Figura 49

Actividades de relajación

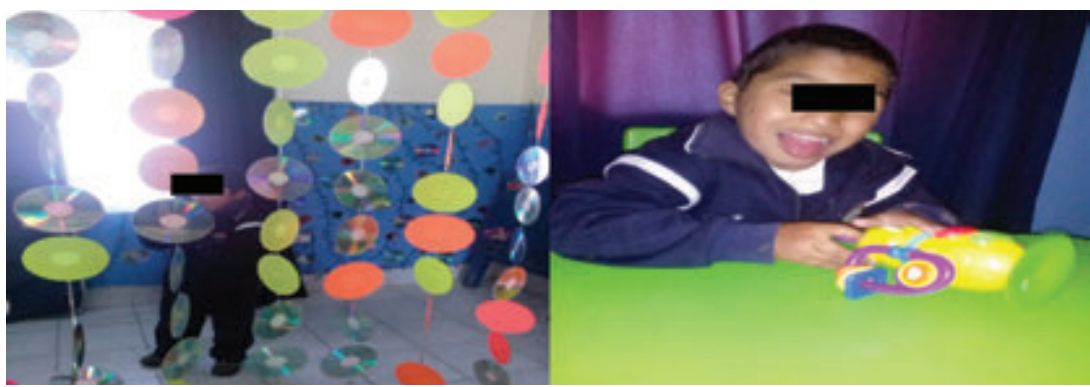

Fotos: Giovanna Bedoya Navas (2016)

Una vez que el estudiante se siente cómodo con el ambiente creado se le ofrece un juguete invitándole a sentarse en la mesa de trabajo.

Cuando el niño se encuentra sentado se le va presentando la tableta motivando a captar su atención.

Figura 50

Captar atención

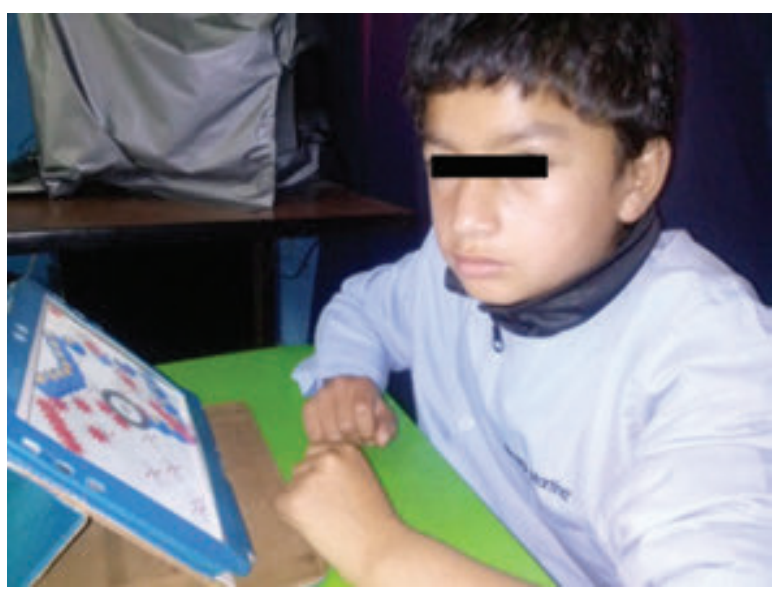

Foto: Giovanna Bedoya Navas (2016) 
120

Una vez captada la atención del niño se le indica el programa "proyecto sígueme", el cual le motiva a mirar y topar la pantalla demostrándole que obtenemos un efecto, lo que incita al niño a tomar la mano del terapeuta en "grúa".

\section{Figura 51}

Motivar a mirar y topar la pantalla

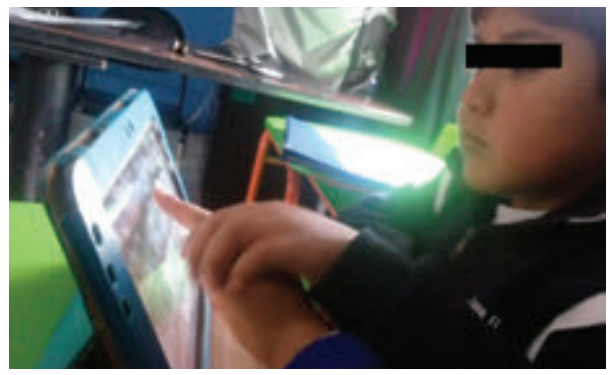

Foto: Giovanna Bedoya Navas (2016)

Paulatinamente se va introduciendo al niño a que mire la pantalla, esperando una respuesta de tipo visual al regresar a verla, esbozando una sonrisa o estableciendo contacto visual; convirtiéndose en el indicador para poder dirigir su mano, sacando su dedo índice hacia la tableta, mientras se le enseña a controlar la presión para dañar la pantalla.

Figura 52

Manejo de pantalla

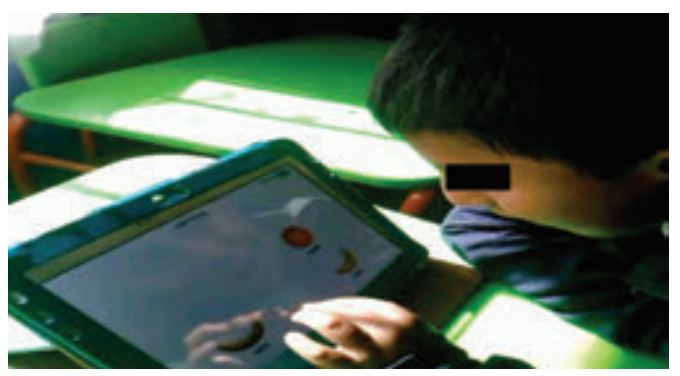

Foto: Giovanna Bedoya Navas (2016) 
Cada vez que el niño admite que su mano sea dirigida, se debe motivarle a que lo intente y una vez ejecutado por él, se lo anima a continuar por medio de aplausos o expresiones verbales que lo incentiven como: "Muy bien", "Bravo", iniciando así la fase de trabajo autónomo por parte del niño.

A medida que se van realizando las diferentes fases del programa, los ejercicios se acompañan con objetos y material concreto lo cual favoreció la relación y adquisición de conocimientos, vinculando la imagen que observa con la realidad que puede tener en sus manos o en su entorno.

\section{Figura 53}

Favorecer la relación y adquisición de conocimientos

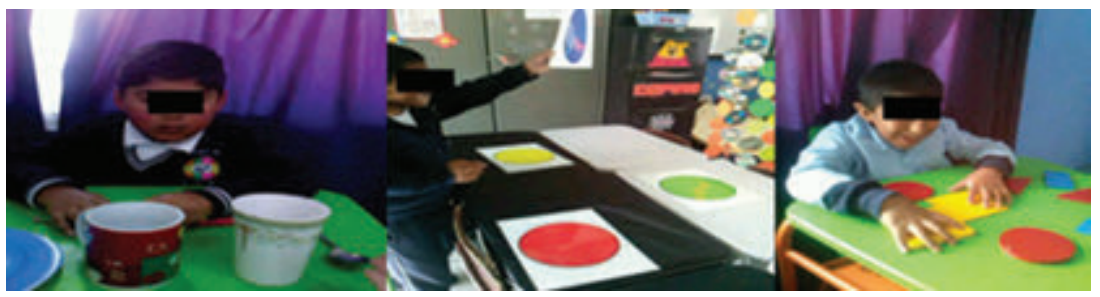

Fotos: Giovanna Bedoya Navas (2016)

Una vez finalizadas las seis fases incrementales del Proyecto Sígueme, se elabora un tablero de comunicación personalizado que responda a las necesidades comunicativas de cada estudiante.

A través de las hojas de seguimiento y valoración establecidas por el mismo programa se registró el progreso del estudiante en las seis fases desarrolladas que van desde la estimulación basal a la adquisición de significado por medio de vídeos, dibujos, pictogramas y fotografías así como el uso de categorizaciones y asociaciones.

De igual manera a través de la ficha de observación creada por el departamento de psicología se evidenció los siguientes logros: 
- Atención visual: fijación, captación, seguimiento visual y atención.

- Conductas: disminuye estereotipias, baja nivel de deambulación, decrecen berrinches, seguimiento de órdenes simples, tolerancia a sonidos, finalización de tareas.

- Conocimientos: identifica visualmente el objeto en pantalla, identifica el objeto concreto e identifica el objeto en lámina.

- Lenguaje: verbaliza.

- Ficha de Observación Proyecto "Sígueme" Área Psicología se adjunta al final, al igual que hojas de seguimiento y valoración del proyecto.

\section{Recursos utilizados}

Tabla 6

Recursos utilizados Proyecto Sígueme

\begin{tabular}{|c|c|}
\hline Recursos materiales & Recursos humanos \\
\hline Tableta con aplicación proyecto sígueme & \multirow{8}{*}{$\begin{array}{l}\text { Psicóloga y estudiantes del } \\
\text { IEEN }\end{array}$} \\
\hline Aula de Estimulación Visual y Psicológica & \\
\hline Mesas de trabajo & \\
\hline Objetos con luces y sonidos & \\
\hline Luces, linternas. & \\
\hline $\begin{array}{l}\text { Objetos varios vinculados con el vocabulario a } \\
\text { desarrollar }\end{array}$ & \\
\hline Láminas & \\
\hline Fichas u hojas de registro, etc. & \\
\hline
\end{tabular}

Fuente: Giovanna Bedoya Navas (2016)

\section{Logros obtenidos}

El uso de la aplicación "Proyecto Sígueme" permitió obtener logros tanto de tipo cuantitativo, como cualitativo en los estudiantes en los que fue aplicado, aspecto que se puede visualizar en los siguientes cuadros de evaluación inicial y final: 
Figura 54

Evaluación Inicial Atención visual

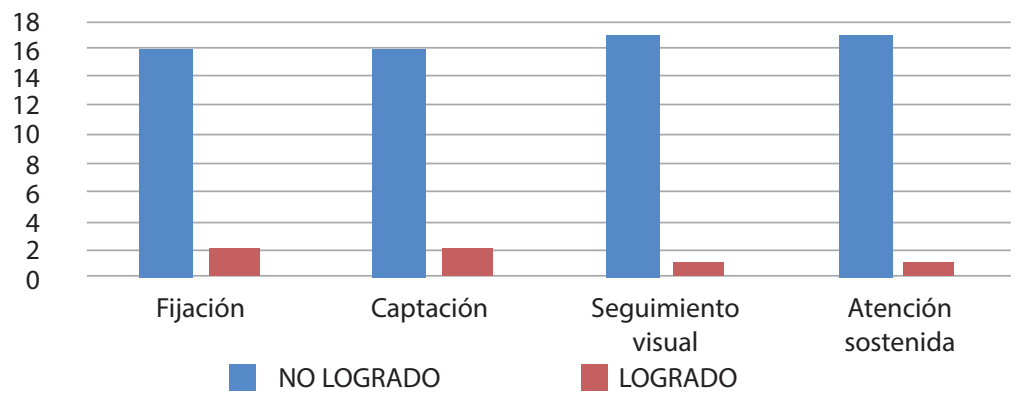

Fuente: Giovanna Bedoya Navas (2016)

Figura 55

Evaluación Final Atención visual

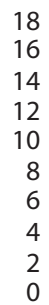

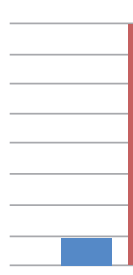

Fijación

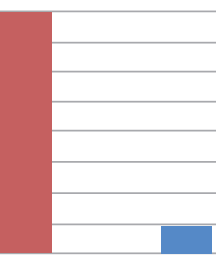

Captación

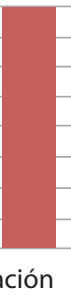

NO LOGRADO

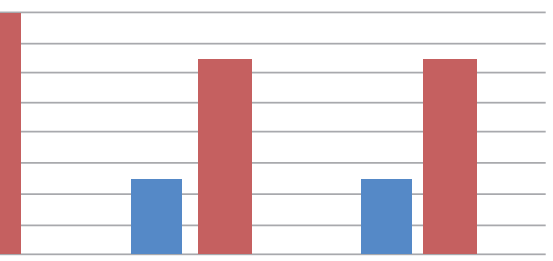

Seguimiento visual Atención sostenida

Fuente: Giovanna Bedoya Navas (2016)

Inicialmente la atención visual general de los niños con TEA es deficiente, partiendo que 16 estudiantes tienen dificultad en fijar y captar visualmente un estímulo, 17 no realizan un seguimiento visual como atencional, teniendo dificultad en cumplirse con el parámetro inicial solicitado por el de cuatro segundos, como se observa en la figura 54 . 
Luego del uso de técnicas que captaron su interés en este grupo de niños, se obtiene como evaluación final periodos de fijación y captación visual en 16 niños, seguimiento visual y atención sostenida en 13, lográndose una atención visual de 30 minutos hasta dos horas de trabajo continuo (Ver figura 55).

Figura 56

Evaluación Inicial Adquisición de conocimientos

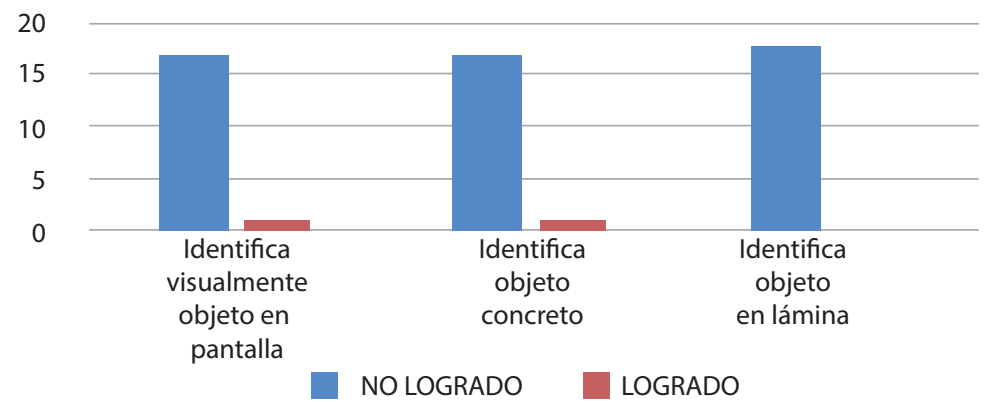

Fuente: Giovanna Bedoya Navas (2016)

Figura 57

Evaluación Final Adquisición de conocimientos

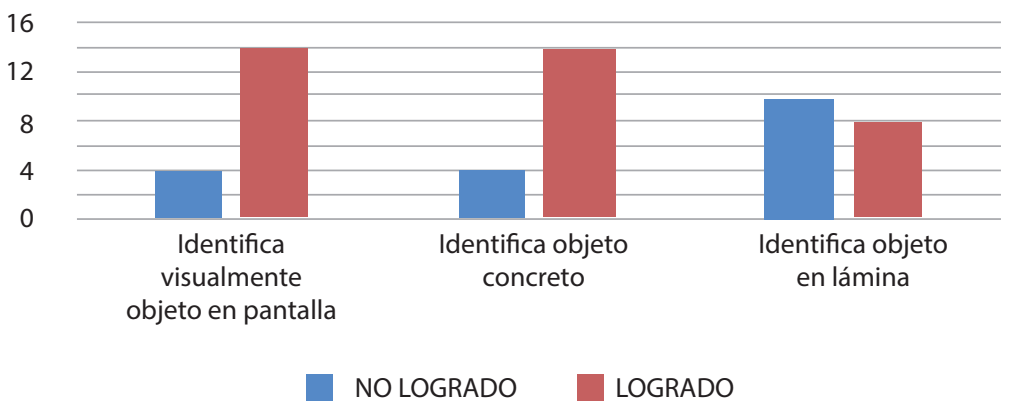

Fuente: Giovanna Bedoya Navas (2016) 


\section{5}

En la figura 56 se puede contemplar que 17 niños no pueden identificar visualmente un objeto en la pantalla de la tableta e identificar objetos concretos, y el grupo completo de aplicación no identifica objetos en láminas.

Después del uso del "Proyecto Sígueme" se observa en la figura 57 de evaluación final, que los estudiantes logran identificar objetos tanto en la pantalla como de forma concreta 14 niños y 8 en lámina de forma autónoma; este último indicador se adiciona al "Proyecto Sígueme" considerando la posibilidad de trabajo en hoja con los niños tanto en el área psicológica como del salón de clases.

\section{Figura 58}

\section{Evaluación Inicial Conducta}

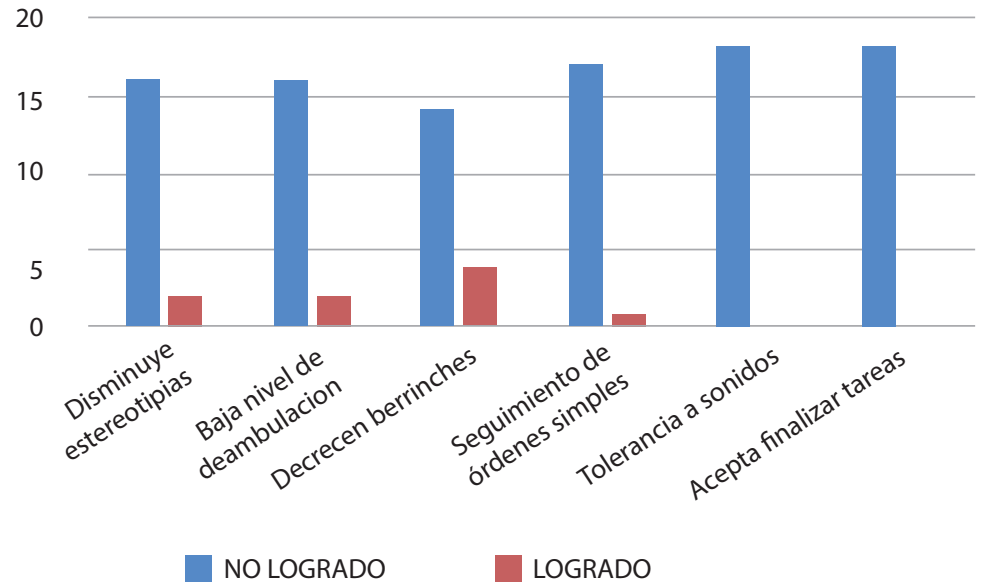

Fuente: Giovanna Bedoya Navas (2016) 


\section{6}

Figura 59

Evaluación Final Conducta

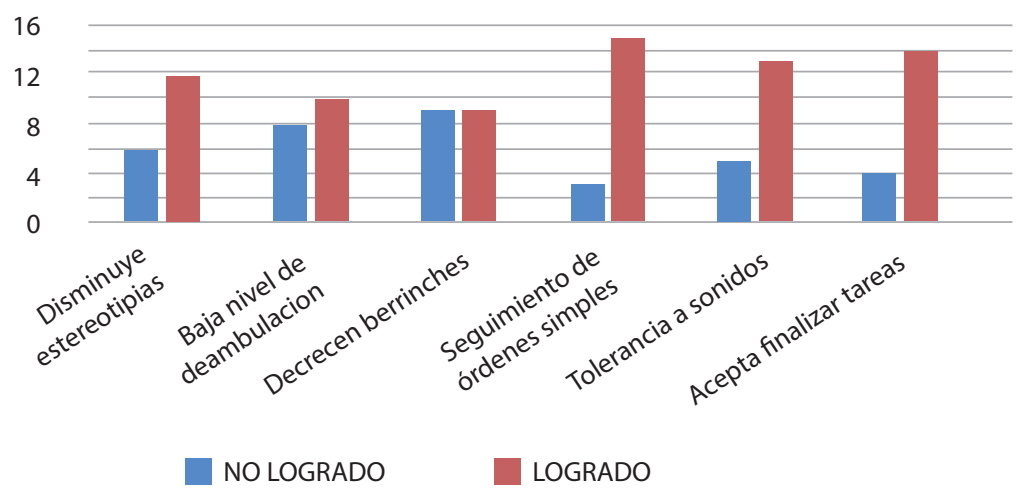

Fuente: Giovanna Bedoya Navas (2016)

Con relación a la evaluación inicial de tipo conductual, la figura 58 demuestra que 16 niños muestran estereotipias, 14 berrinches, 17 niños no realizan seguimiento de órdenes simples, 18 no toleran sonidos ni finalizaban tareas.

En la figura 59 se puede comprobar que hay un cambio favorecedor a nivel conductual en los niños con TEA, dado que la presencia de estereotipias en 12 niños decrece, en 10 bajan su nivel de deambulación, en 9 dejan de hacer berrinches, en 15 niños hay un seguimiento de órdenes simples, 13 toleran los sonidos que en un inicio los alteraban y 14 pueden aceptar la finalización de una tarea sin presentar crisis conductuales.

Como adicionales al programa se contempló los siguientes indicadores: disminución de estereotipias deambulación, tolerancia a sonidos y aceptación de finalización de tareas, como parámetros de importancia en el campo psicológico. 


\section{7}

Figura 60

Evaluación Inicial Adquisición de lenguaje

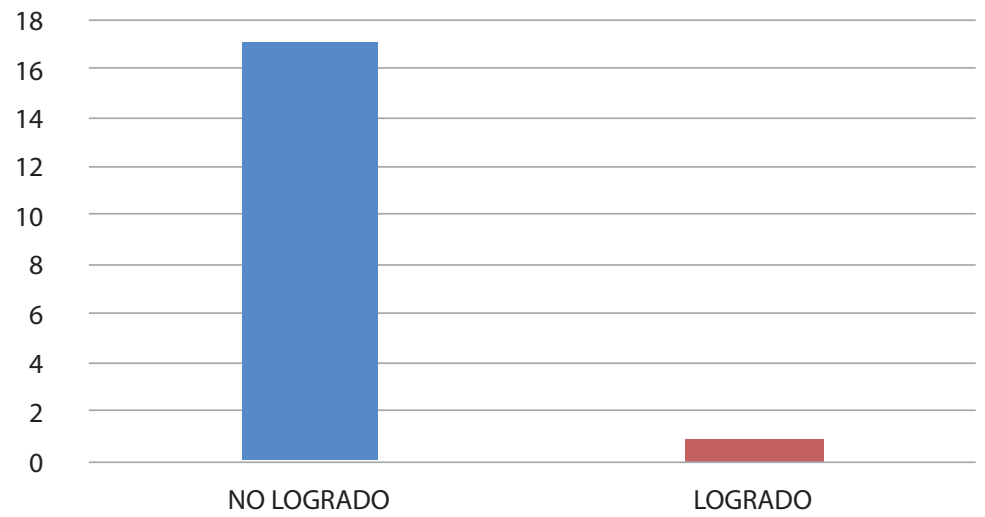

Fuente: Giovanna Bedoya Navas (2016)

Figura 61

Evaluación Final Adquisición de lenguaje

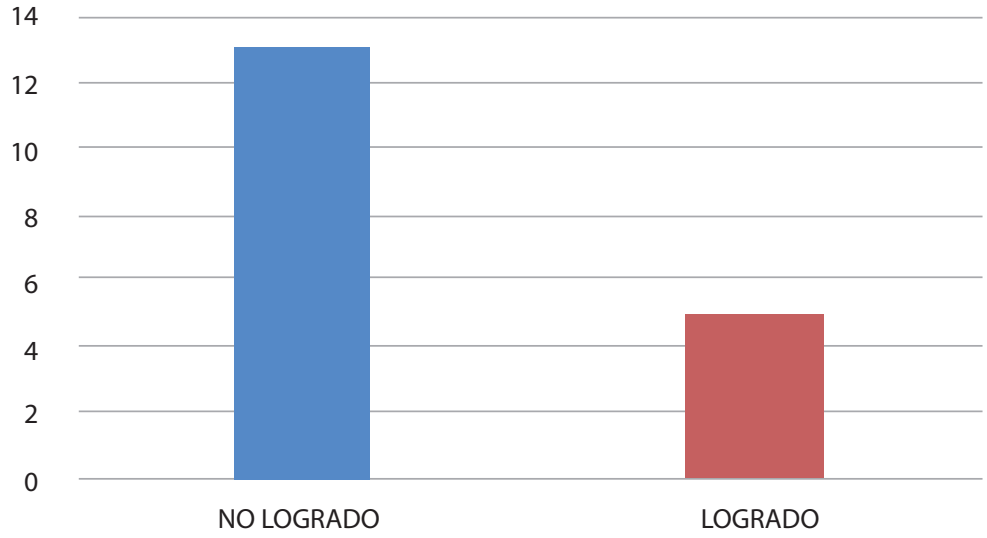

Fuente: Giovanna Bedoya Navas (2016) 
Con relación a la adquisición de lenguaje se visualiza en la figura 60, que 17 niños no verbalizan palabra alguna solo emiten ciertos sonidos y que al finalizar la administración del "Proyecto Sígueme" (figura 61), verbalizan 5 niños todos los objetos que les presenta el programa.

\section{Fortalecimiento de las funciones cognitivas en adultos mayores con discapacidad}

"La educación ayuda a la persona a aprender a ser lo que es capaz de ser"

(Hesíodo)

Fundación para la Integración del Niño Especial FINE

Ecuador

Quito

Responsable: Yolanda Ortiz

Gestores de la práctica: Yolanda Ortiz Directora, equipo educativo (Terapista de Lenguaje, Docentes Terapista física Psicorehabilitador y familia)

Ante la necesidad de brindar a los adultos estrategias para evitar el deterioro cognitivo asociado a la edad, se plantea una serie de actividades mediadas por las TIC que ayudan a la resolución de las situaciones de la vida diaria. Esta experiencia se enmarca en el ámbito de la educación de adultos.

\section{Motivación}

La Fundación para la Integración del Niño Especial FINE, es una entidad cuyo objetivo se centra mejorar la calidad de vida de personas adultas con discapacidad múltiple, lograr los mayores niveles de autonomía en sus actividades cotidianas, para lo cual la institución cuenta con los servicios de capacitación pre laboral, laboral, inserción laboral y seguimiento.

Las necesidades de apoyo de los estudiantes que asisten a nuestra institución son múltiples lo que constituye para los docentes un desafío permanente para mejorar la práctica educativa, esto implica una búsqueda constante de recursos y estrategias que permitan consolidar los aprendizajes. 
La población con la que contamos viene de diferentes contextos, así:

- Un primer grupo viene del sistema de educación especial, esta población pertenece a una condición económica media y media baja.

- Un segundo grupo nunca tuvo escolarización vienen de su casa, al morir sus padres los hermanos los traen a la institución. Como es de esperarse en este grupo tenemos que provienen de familias de escasos recursos económicos, los padres no contaron con los recursos suficientes para incluirlos en una escuela y tampoco estuvieron convencidos de que era lo mejor. Dentro de este grupo hay un par de casos particulares que son personas indigentes que están acogidos en una institución religiosa con la que FINE mantiene un convenio para que estas personas puedan capacitarse.

- Un tercer grupo son personas que vienen del proceso de inclusión de la educación regular. Ellos también cuentan con una condición económica media y media baja.

Por el lado de los docentes, una de las preocupaciones es la de contar con herramientas tecnológicas, que permitan mantener y desarrollar las funciones cognitivas de los estudiantes como la memoria, la atención, el lenguaje, y que las mismas permitan una mejor comunicación y desempeño en sus actividades laborales.

Tabla 7

Uso de la tecnología

\begin{tabular}{|l|c|c|c|c|}
\hline No. de estudiantes & Teléfono celular & Tablet & Computador & ninguno \\
\hline 7 & $\mathrm{X}$ & & & \\
\hline 39 & & & $\mathrm{x}$ & \\
\hline 6 & & & & $\mathrm{X}$ \\
\hline
\end{tabular}

Fuente: Yolanda Ortiz (2016) 
Como se observa en la tabla anterior, la mayoría de estudiantes está familiarizada con el uso de la tecnología especialmente el celular y la computadora, es evidente la motivación, el interés y curiosidad que estos recursos despiertan en los estudiantes.

Por otro lado, las múltiples necesidades de los usuarios, obligan a mantener una búsqueda permanente de nuevas posibilidades que potencien sus funciones cognitivas en las actividades de la vida cotidiana, las mismas que pueden verse afectadas debido a la frágil salud que la mayoría de los estudiantes presentan. En esa búsqueda permanente desde hace cuatro años se introdujo el uso de las TIC como una herramienta que complementa la atención integral que brinda la institución.

La población que se atiende en la fundación son personas con discapacidad múltiple (Síndrome de Down con Alzheimer, personas con discapacidad intelectual y trastornos del espectro del autista, personas con parálisis cerebral, con Síndrome de Apert) la mayoría de salud frágil.

\section{Objetivos}

Disminuir las barreras para la accesibilidad cognitiva de las personas con discapacidad múltiple a través del uso de tecnología de alto y bajo impacto.

\section{Desarrollo de la experiencia}

La experiencia consistió en la planificación y ejecución de un proyecto integral que permita naturalizar el uso de las TIC en todas las actividades de la institución, para lo cual se partió de un estudio de viabilidad (económica, infraestructura tecnológica), de la identificación de las necesidades del recurso humano (docentes y estudiantes), de la capacidad de gestionar redes de apoyo externas (universidades, varias organizaciones de la sociedad civil). 
Contando con los resultados de las necesidades de aprendizaje y de los objetivos curriculares propuestos para cada estudiante, se investigó la pertinencia de los recursos tecnológicos a utilizar y la formación de los docentes en el uso de estos recursos.

Como política institucional, se utilizó en todos los servicios la técnica de aprendizaje lúdica llamada también "Gamificación” lo que facilitó el uso de recursos tecnológicos ya que, esta técnica según lo expresa Gaitán (2013) “traslada la mecánica de los juegos al ámbito educativo con el fin de conseguir mejores resultados ya sea para absorber mejor algunos conocimientos, mejorar alguna habilidad, o bien recompensar acciones concretas, entre otros muchos objetivos" (p. 32) de esta manera, se recompensa al estudiante por los logros alcanzados, lo que provocó en los mismos una actitud positiva frente a la actividades propuestas.

Por otro lado, el uso de la técnica de la gamificación, a través de recursos tecnológicos, aportó en el desarrollo de la educación emocional logrando mejores niveles de concentración, esfuerzo y compromiso con la tarea. De igual manera permitió que la parte física (el cuerpo) de los estudiantes interactúe de forma lúdica para expresar diferentes situaciones de su vida afectiva; es decir, condujo a los estudiantes a una auto-percepción o un autoconocimiento de sí mismos.

En la figura 62 se puede observar las técnicas de gamificación que más se utilizaron.

Para eliminar las barreras de acceso a la información de la población con parálisis cerebral través de las TIC, se adaptaron los ratones de los computadores a las condiciones físicas y de movilidad de cada estudiante, con esta rampa digital acceden a todos los procesos de igual manera que el resto de la población. 


\section{2}

\section{Figura 62}

\section{Algunas técnicas de gamificación}

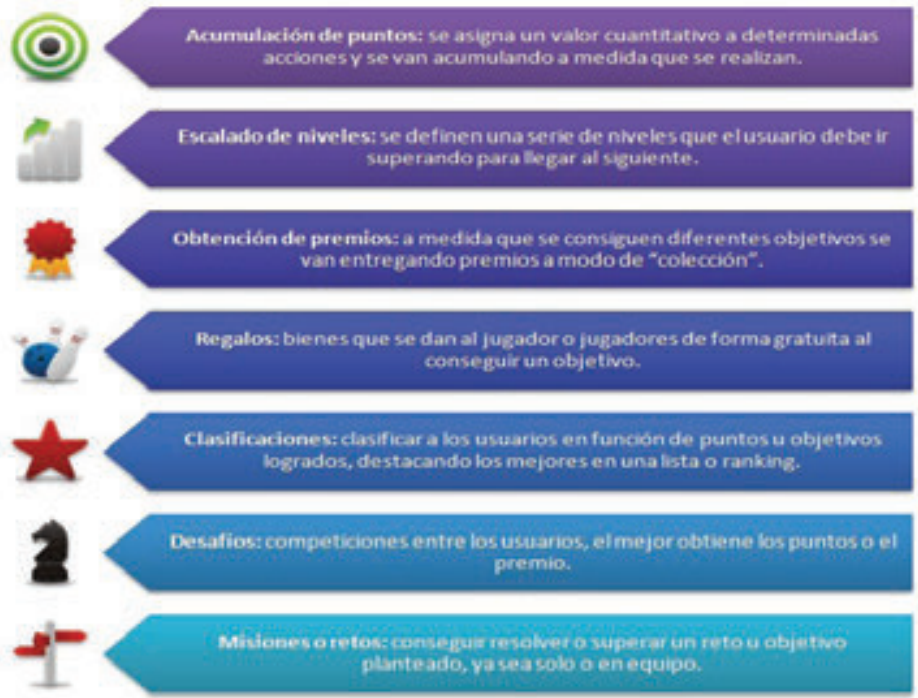

Fuente: Gamificación: el aprendizaje divertido. Recuperado de https://goo.gl/Jc5FrS

\section{Figura 63}

\section{Estudiante haciendo uso de ratón}

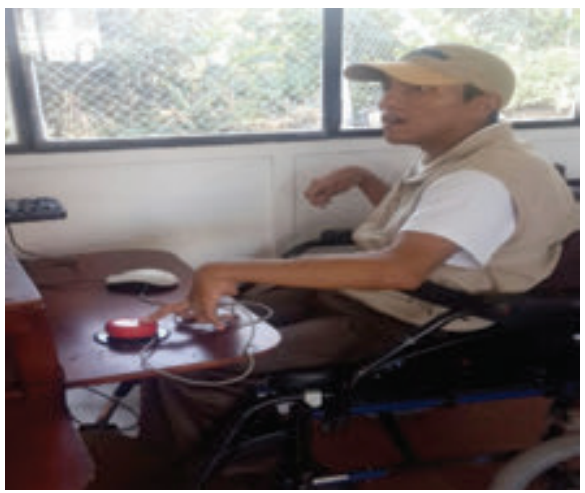

Foto: Yolanda Ortiz (2016) 
133

Para facilitar la comunicación se utilizó el software Pikto Plus, cuyas licencias para su uso fueron donadas, de igual forma se capacitó a los docentes en el uso de este software. De esta manera se construyeron con tableros de comunicación para los estudiantes.

\section{Figura 64}

Estudiante usando su tablero de comunicación en el sistema Pikto Plus

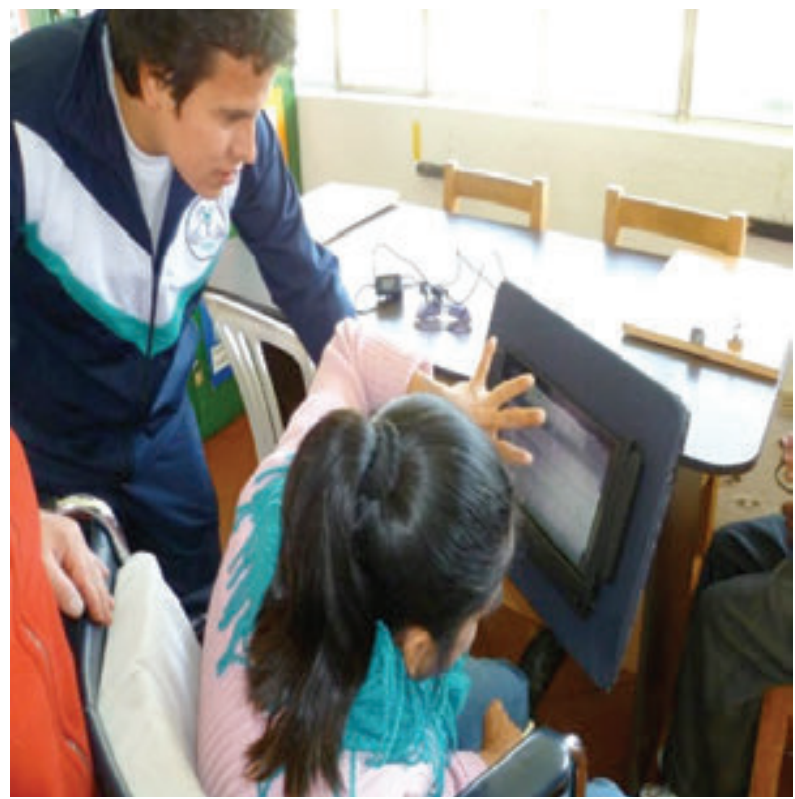

Foto: Yolanda Ortiz (2016)

El programa contribuyó a incrementar los niveles de comunicación de varios estudiantes principalmente aquellos con múltiples desafíos cognitivos y físicos, en el caso de la estudiante de la fotografía anterior, con la ayuda del software, comunica asertivamente sus necesidades mediante los tableros creados para ella; los tableros de comunicación y calendarios, los mismos que se construyen con imágenes personalizadas acompañadas de sonidos. 
134

Otro programa que se utilizó con mucho éxito fue: "Sistema Informático de Entrenamiento Visual para Personas con Deficiencia Visual (EVO)", este programa permitió las estimulación de las funciones visuales de los estudiantes y de esta manera mejorar sus habilidades cognitivas y de reconocimiento visual.

El Pictogram Room, programa que se utilizó con todos los estudiantes para atender los diferentes requerimientos en varias áreas del desarrollo como la comunicación, la atención el esquema corporal y la imitación. Los apoyos visuales y musicales de este programa que le ayudan a encontrar sus puntos fuertes para el uso de su propio cuerpo.

\section{Figura 65}

Utilización de Pictogram Room

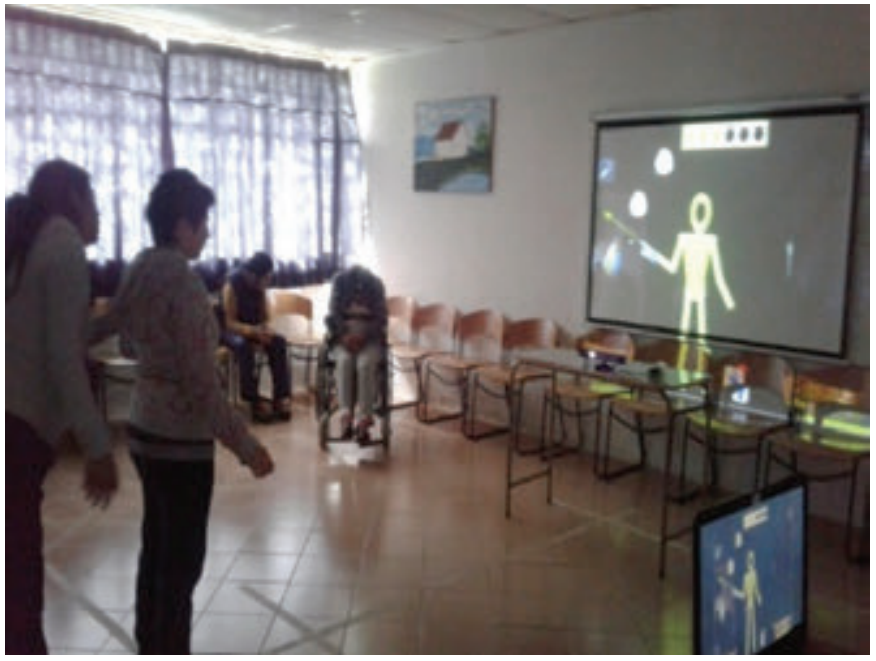

Foto: Yolanda Ortiz (2016)

En la foto anterior se pude observar a una estudiante haciendo uso del pictogram room, lo cual le ayudó a imitar los movimientos del muñeco en la pantalla. 
Este programa se utilizó con los estudiantes con discapacidad motriz quienes demostraron su gran interés y motivación en participar. En los casos de estudiantes hiperkinéticos vimos que las rampas de barrido, apoyaban y favorecían los tiempos de atención.

Figura 66

Estudiante trabajando con Pictogram Room

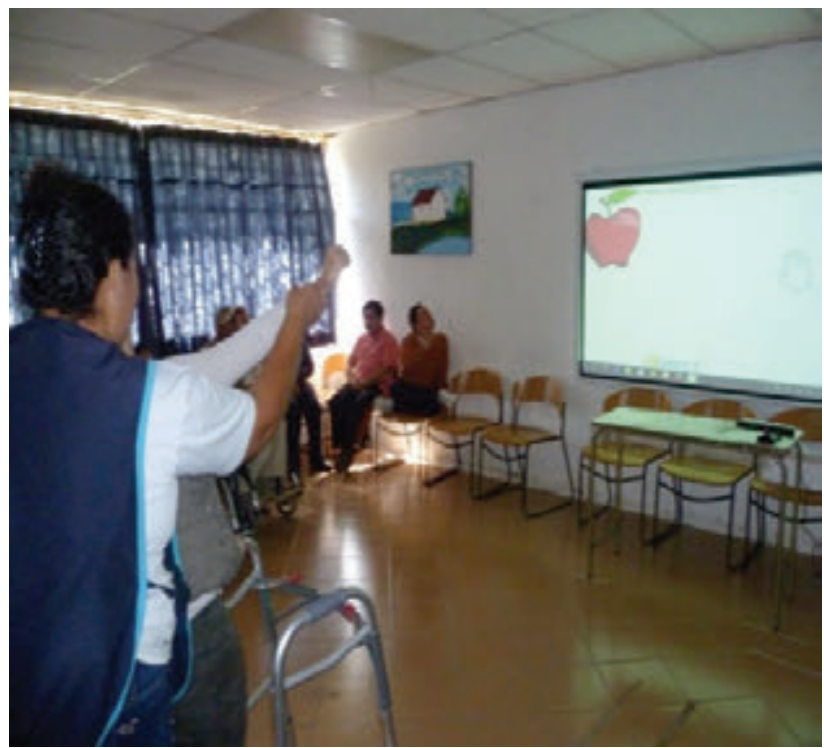

Foto: Yolanda Ortiz (2016)

En este caso el estudiante está recibiendo apoyo físico, para aprender las rutinas del juego, rápidamente ellos se involucran y por efecto de la repetición van adquiriendo nuevas destrezas con su cuerpo y la comprensión del lenguaje corporal, en esta actividad se observó mejores resultados con los estudiantes con TEA.

Los estudiantes dentro del espectro del autismo tienen dificultades en entender el significado de pictogramas, la más pequeña variación dificulta su reconocimiento el pictogram room facilita la conexión entre 
la imagen real y pictograma en tiempo real; los ejercicios se realizan en varias etapas, el trabajo en espejo con la imagen del estudiante, el trabajo en la pantalla con un pictograma de la figura humana sobre puesto a la imagen del estudiante y un pictograma que simula los todos los movimientos del estudiante.

El programa Abrapalabra ${ }^{\circledR}$ se utilizó con todos los estudiantes para fortalecer la comprensión lectora el conjunto de ejercicios utilizados con este fin, lograron captar en mejor la atención y el aprendizaje con actividades apropiadas a la edad cronológica de los estudiantes.

Los estudiantes mejoraron en destrezas cognitivas así: memoria visual, auditiva y la fijación aumentó notablemente la atención.

El trabajo con Snoezelen nos permitió mejorar los procesos de comunicación no verbal de los estudiantes utilizando de manera organizada los cuatro componentes en los que fundamenta este programa: el ocio, la relajación, la atención individualizada y a la estimulación sensorial.

\section{Figura 67}

Estudiantes recibiendo aromaterapia, estimulación visual, auditiva, vestibular, y propioceptiva

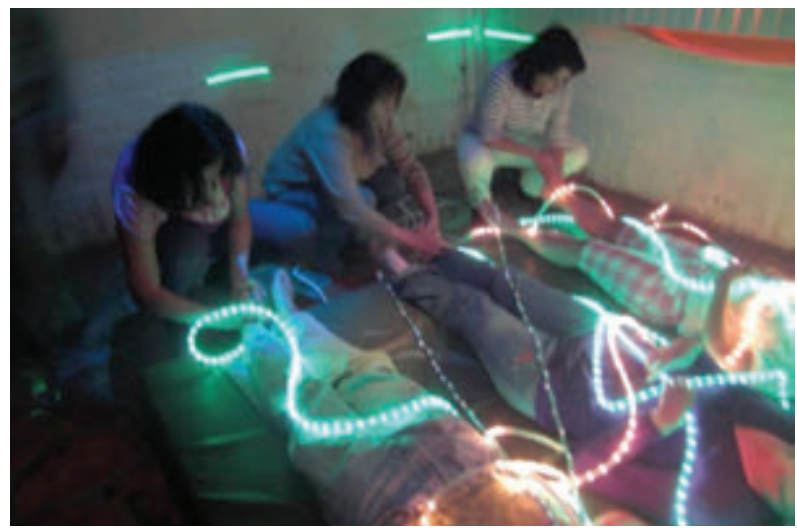

Un trabajo enriquecedor para cualquier persona.

Foto: Yolanda Ortiz (2016) 
Los recursos utilizados para la estimulación sensorial se resumen en la siguiente tabla:

Tabla 8

Recursos de las aulas multisensoriales

\begin{tabular}{|c|c|c|c|}
\hline Estímulos visuales & Estímulos táctiles & $\begin{array}{l}\text { Estímulos } \\
\text { auditivos }\end{array}$ & $\begin{array}{c}\text { Estímulos } \\
\text { olfativos }\end{array}$ \\
\hline $\begin{array}{l}\text { Fibra óptica } \\
\text { Rueda de efectos } \\
\text { Columnas de aire, } \\
\text { de burbujas } \\
\text { Pintura fluorescente } \\
\text { Luz negra, linternas } \\
\text { Paneles de pared } \\
\text { con efectos de luz } \\
\text { Proyector de luz, } \\
\text { dibujos }\end{array}$ & $\begin{array}{l}\text { Piscina de bolas } \\
\text { Columnas } \\
\text { de burbujas } \\
\text { (Vibración) } \\
\text { Fibra óptica } \\
\text { (suavidad) } \\
\text { Paneles táctiles } \\
\text { Cojín táctil } \\
\text { Material } \\
\text { vibratorio }\end{array}$ & $\begin{array}{l}\text { Panel de } \\
\text { sonidos } \\
\text { Columnas de } \\
\text { aire } \\
\text { Equipo de } \\
\text { música } \\
\text { Silla musical }\end{array}$ & $\begin{array}{l}\text { Olores rela- } \\
\text { cionados con } \\
\text { rutinas diarias } \\
\text { Difusor de } \\
\text { aromas } \\
\text { Pelotas de olor } \\
\text { Juegos de } \\
\text { aromas } \\
\text { Perfume de los } \\
\text { padres }\end{array}$ \\
\hline
\end{tabular}

Fuente: Yolanda Ortiz (2016)

\section{Logros obtenidos}

La institución cuenta con un sistema informativo que registra el avance del cumplimiento de los objetivos planteados en la planificación individual, de esta manera los avances ingresan de manera automática al sistema y permiten contar con un perfil actualizado de los logros de cada en las áreas cognitivas: memoria, atención, discriminación visual, discriminación auditiva, comprensión, percepción y su aplicación de estos procesos en las habilidades de la vida diaria.

Para la implementación de esta experiencia contamos con el apoyo de los estudiantes de la carrera de Ingeniería de Sistemas de la Universidad Politécnica Salesiana de Quito, gracias a su apoyo se superaron las dificultades de instalación de programas, actualización de equipos y capacitación de los docentes en el desarrollo de competencias básicas y manejo de los programas informáticos que se utilizaron desarrollan- 
do un trabajo colaborativo interdisciplinario que tenga como centro el aprendizaje de todos nuestros estudiantes.

De igual manera fueron instalados los programas en los hogares de los estudiantes e involucrando en este proceso. Situaciones que han permitido que la comunidad educativa se comprometa con la mejora constante de la calidad y la innovación. Con esto hemos conseguido una comunidad educativa más empoderada y proactiva que busca siempre la innovación y el enriquecimiento de la oferta curricular de la institución con experiencias cognitivas de implementadas de manera lúdica:

Crear un entorno de aprendizaje accesible para personas con discapacidades múltiples a través del uso de la tecnología.

A partir de esta experiencia se elaboró un manual para el apoyo de la gestión del aprendizaje de los docentes. Actualmente la institución recibe a muchos estudiantes de varias universidades que se encuentran formándose para ejercer la docencia; en la gestión directiva. Las familias manifiestan que ha mejorado la comunicación de ellos mantienen con sus hijos, situación que les llena de esperanza de una mejor calidad de vida para ellos. Se han consolidado las políticas institucionales de accesibilidad cognitiva gestión directiva.

\section{Recursos utilizados}

Evo: es un software desarrollado para la estimulación visual, permite realizar actividades concretas para buscar la mejora en el funcionamiento visual estructurado por áreas perceptivas teniendo un entrenamiento global o específico.

Abrapalabra: Es un software para aprender a leer, escribir y mejorar la pronunciación.

Piktoplus: Es una aplicación desarrollada para dispositivos con sistema operativo Android especialmente tabletas, mantiene un amplio 
conjunto de pictogramas que permite la construcción y programación de tableros gráficos.

El Pictogram Room: Es un programa que reúne un conjunto de actividades diseñadas para dar respuesta a una serie de necesidades de las personas con Trastorno del Espectro del Autismo (TEA). Dificultades en la comprensión del lenguaje corporal, el reconocimiento de uno mismo, la imitación o la atención conjunta.

Las salas de estimulación sensorial-Snoezelen: Constituyen un recurso para la estimulación multisensorial de todas las personas en todas las edades y condiciones mejora las respuestas sensoriales, y costa de varios espacios físicos que cuentan con una riqueza de estímulos sensoriales controlados que favorecen la percepción por medio del descubrimiento, así como el desarrollo integral y armónico de cada persona.

\section{MIMIO: herramienta de interaprendizaje en personas con discapacidad intelectual}

"La educación es el movimiento de la oscuridad a la luz" (Allan Bloom)

Fundación de Enseñanza Individualizada (EINA)

Ecuador

Quito

Responsable: Daniel Salas

Gestores de la práctica: Equipo directivo de la institución, docentes y familias

La propuesta surgió desde la gestión directiva de la institución, de resolver las necesidades de los estudiantes, quienes en las aulas se mostraban distraídos, inquietos, desinteresados, aburridos y olvidaban fácilmente lo aprendido debido a la metodología pasiva, repetitiva y basada en contenidos abstractos.

Esta situación motivó a los directivos de la institución a la utilización de metodologías activo-participativas, centradas en el aprendizaje, y la utilización de recursos tecnológicos y materiales educativos concretos y diversos, pertinentes para que el estudiante construya sus aprendizajes efectivos con interés, alegría y naturalidad. 
140

\section{Motivación}

Fundación EINA a lo largo de sus 37 años de vida institucional ha buscado la equidad como principio rector de su política institucional orientada a propiciar experiencias significativas que permitan mejorar los procesos de aprendizaje de la población con discapacidad intelectual y asegurar el dominio de los mismos en los estudiantes. Estos propósitos obligan a desarrollar una gestión institucional eficiente en la que los directivos, docentes y padres de familia que cumplen un papel fundamental para contar con las mejores estrategias metodológicas para que sus estudiantes con discapacidad intelectual logren el desarrollo máximo de sus habilidades.

La formación permanente de los docentes y la dotación de herramientas didácticas asequibles constituyen una estrategia para lograr los objetivos institucionales, la búsqueda permanente de nuevos referentes educativos nos ratifica la postura de que el aprendizaje debe ser lúdico, centrado en las necesidades del estudiante, apalancado en los requerimientos sociales para la vida diaria y apoyada en la tecnología. De estos cuatro pilares el que cuenta con un desarrollo más vertiginoso es el tecnológico por lo que en el año 2012 decidimos realizar una inversión en esta área e iniciamos por evaluar las herramientas disponibles y revisar sus resultados en nuestro medio y en la región.

Repetidamente encontrábamos como respuesta la utilización de Pizarrones Digitales Interactivos, los mismos están compuestos por un pizarrón o pantalla, computador, proyector, equipo de audio y un sistema de captura de óptica de movimiento que transforma el marcador para pizarrón en un mouse. Sin embargo, la herramienta por sí misma no genera ningún cambio por lo que hay que complementarla con el Software adecuado que explote la capacidad del sistema y docentes preparados y dispuestos para generar los ajustes necesarios para incluir las herramientas en su planificación. 
141

Bajo estos hallazgos iniciamos el trabajo piloto con un set de pantalla digital interactiva "MIMIO", el mismo que en esta etapa era usado por cada grupo de estudiantes durante dos horas clase semanales. Esta constituyó la primera experiencia documentada de su uso en la educación de estudiantes con discapacidad y el primer intento de sistematización de sus resultados.

El piloto fue exitoso y los resultados alentadores, esto nos llevó a profundizar y ampliar su uso, lo cual creemos ampliamente se convirtió en una práctica innovadora, efectiva, eficaz y que vale la pena ser replicada por otras instituciones da características similares. Nuestros resultados son ratificados año a año y seguimos viendo la expansión de esta herramienta en educación regular e inclusiva con magníficos resultados también.

\section{Figura 68}

Uso de herramientas didácticas

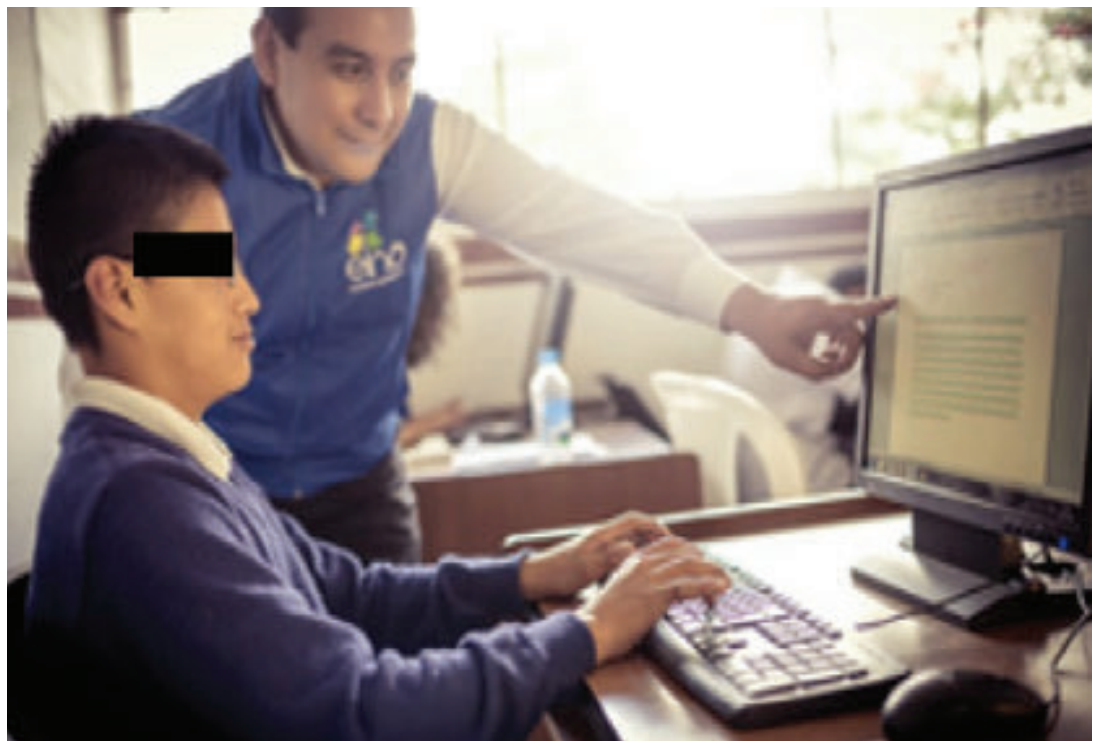

Foto: Daniel Salas (2016) 
142

\section{Objetivos}

Mejorar el aprendizaje de los estudiantes mediante la introducción de pantallas digitales interactivas "MIMIO" como recurso pedagógico.

\section{Objetivos específicos}

- Capacitar a los docentes en el uso de herramientas tecnológicas y software Mimio Teach.

- Incorporar el uso de MIMIO como política institucional mediante su incorporación en los documentos de planificación institucional como el Proyecto Educativo Institucional (PEI) y el Proyecto Curricular Institucional (PCI).

- Involucrar a los padres de familia en el uso de las herramientas tecnológicas para mejorar el refuerzo y apoyo pedagógico en el hogar.

\section{Desarrollo de la experiencia}

Luego del proceso de detección de la necesidad de mejorar la metodología de enseñanza para nuestro grupo de estudiantes, empezamos por valorar las diferentes opciones de recursos tecnológicos disponibles, ninguno de ellos contaba con estudios o experiencias previas de trabajo en educación especializada por lo que nos decidimos por la incorporación de las plataformas MIMIO por ser las que mejores características presentaban.

Figura 69

Estudiantes de EINA

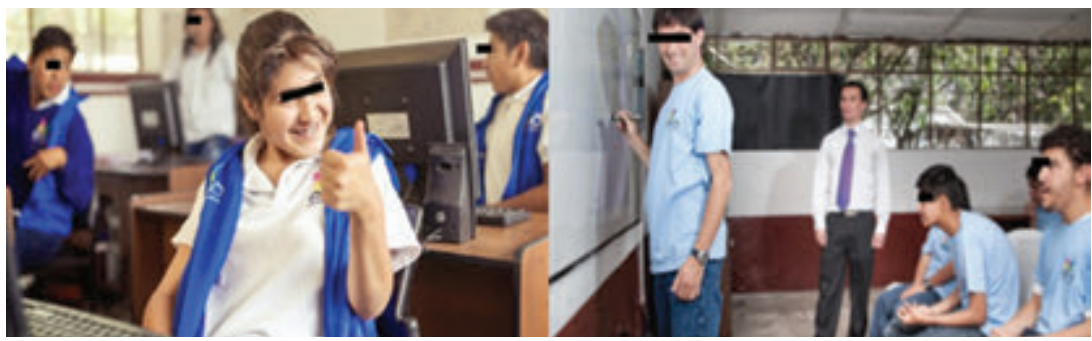

Foto: Daniel Salas (2016) 
Para que el proyecto tuviera éxito y teniendo en cuenta que la sola presencia del recurso tecnológico no generaría el cambio deseado determinamos que antes de su inicio todos los docentes deberían contar con un conocimiento básico de informática, por lo se coordinó varias posibilidades para ellos:

- Curso básico obligatorio ofrecido por el docente de informática de la institución o su respectiva validación de conocimientos.

- Curso complementario gratuito en la plataforma de COURSERA.

- Curso complementario gratuito ofrecido por Escuela Politécnica Nacional.

- Cursos avanzados cofinanciados por la institución.

Con esta medida garantizamos que los docentes hablen un lenguaje común y estén listos para el aprendizaje de la plataforma y software que MIMIO trae con sus productos. Adicionalmente la dirección se encargó de brindar charlas sobre las implicaciones e importancia de los entornos digitales de aprendizaje.

Posteriormente, los docentes tomaron un curso de utilización básica del software MIMIO Teach que permite la creación de lecciones interactivas con facilidad y la plataforma MimioConnect que es una red de docentes que utilizan el software y un repositorio de actividades desarrolladas para todas las áreas básicas y niveles de aprendizaje, lo que facilita la adaptación y el proceso de intercambio.

Una vez que los docentes estuvieron listos se dio inicio a un piloto durante tres meses con un solo equipo MIMIO, esto nos permitía que cada grupo de estudiantes (entre 6 y 12) acceda durante dos horas clase a la semana. Se determinó que en estas horas no se llevaría ningún material complementario, que solo se reforzarían conocimientos (no nuevos temas), que se daría prioridad a las áreas de lenguaje y matemáticas, que se utilizaría elementos lúdicos y que las clases debían estar previamente creadas y probadas por el docente. 
144

Los resultados preliminares demostraron que los estudiantes paulatinamente se sintieron más motivados debido a la naturaleza lúdica de las actividades, adicionalmente el periodo de atención y concentración empezó a demostrar incrementos significativos, el tiempo de aprendizaje de contenidos específicos mejoró y la predisposición de las estuaciones por las materias de lenguaje y matemáticas mejoró tanto en la hora de uso de la herramienta como en la clase regular.

Con estos alentadores resultados se decidió dar inicio al proyecto con una escala institucional y adquirió tres equipos completos que aumentan la capacidad hasta en seis horas clase a la semana, lo que implica un $20 \%$ del total de horas clase.

Figura 70

Estudiantes en Educación Física de EINA

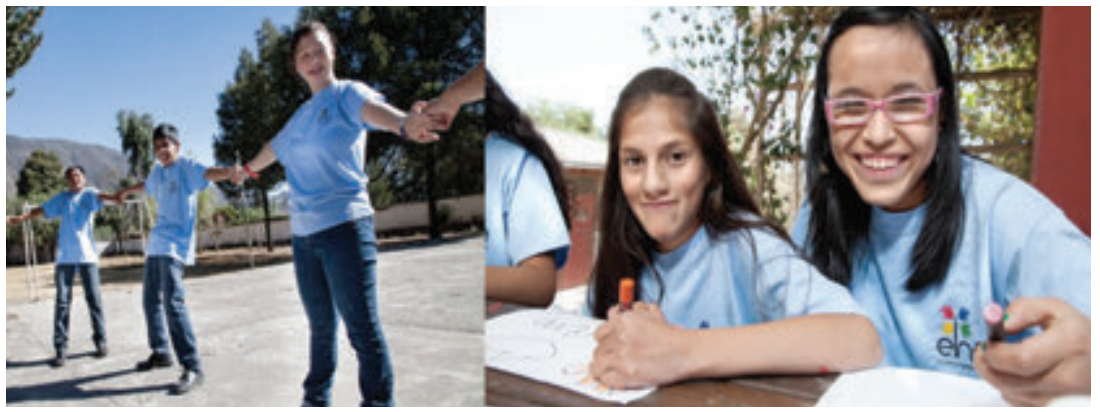

Fotos: Daniel Salas (2016)

Al ser ya una actividad que pasaba de ser eventual (una vez a la semana por dos horas) a ser una actividad permanente (entre una y dos horas diarias) el proceso inició con la familiarización de la plataforma para los estudiantes mediante juegos y proyección de contenido educativo, posteriormente se introdujeron contenidos de las materias que menos resistencia generaban (ciencias naturales, estudios sociales, cultura estética), una vez iniciado el uso académico de los equipos y los estudiantes familiarizados con los mismos iniciamos la incorporación 
de contenidos académicos de las áreas de mayor resistencia (lenguaje y matemáticas) siempre manteniendo un esquema lúdico.

Adicionalmente se capacitó a los padres que contaban con computador en casa para el uso del programa Mimio Studio y los docentes empezaron a mandar actividades de refuerzo a ese grupo, sin embargo, hay que señalar que este grupo es una minoría. Ellos han demostrado un avance más significativo y consideramos que sería la forma ideal de aplicación.

Los padres recibieron una inducción al software y acceso al contenido de las clases por lo que están en capacidad de repetir la actividad realizada en la escuela, adicionalmente y para evitar inconvenientes producto del uso de la tecnología para actividades nocivas no relacionadas al desarrollo pedagógico recibieron capacitan y licencias para el uso de programas de control parental.

A nivel administrativo se realizó la incorporación del uso de MI$\mathrm{MIO}$ al Proyecto Educativo Institucional (PEI), como un plan de mejora en respuesta a problemas pedagógicos detectados en los estudiantes, posteriormente en la actualización de este documento y en base a los resultados obtenidos se incluyó al uso de la tecnología como un elemento transversal en nuestra propuesta educativa al colocarlo como un elemento de nuestro ideario y propuesta curricular.

Adicionalmente los Planes Operativos Anuales (POA) han incluido desde el año 2014 como proyectos institucionales la creación de la base de datos de actividades MIMIO y la sistematización de los resultados obtenidos. También, y con el objetivo de volverlo una práctica común en la tarea diaria se solicita a los docentes incluir dentro de su plan de clase y planificación de bloque la utilización de la herramienta. Esto permite a la dirección estar constantemente informada de las actividades MIMIO desarrolladas y apoyar en su mejora constante.

Posteriormente se detectó que la herramienta podía adaptarse sin complicaciones a otros paquetes de software educativo, razón por 
146

la cual se invirtió en la capacitación de un grupo de docentes y directivos en el programa de formación "Experto en TIC, inclusión y discapacidad”, esto permitió descubrir nuevas formas de hacer las clases más interactivas y accesibles. De este proceso se pueden destacar iniciativas de los docentes con el uso de programas como Sebran, Mini Sebran, Katamotz y Mito.

Actualmente todos los estudiantes, docentes y padres de familia saben del manejo de la herramienta y se ha vuelto parte del movimiento cotidiano de la institución.

\section{Logros alcanzados}

Con el fin de evaluar y sistematizar el proceso se propusieron áreas puntuales que evidencien la mejoría del aprendizaje de los estudiantes, se priorizó las siguientes:

- Tiempos promedio de atención sostenida.

- Tiempos promedio de adquisición de lecto escritura.

- Tiempos promedios de adquisición de suma y resta.

- Preferencia de asignaturas.

Se ha realizado una toma inicial de los indicadores antes de iniciar el proceso y se repitió luego de uno y dos años de implementación, de esta manera fue posible detectar el impacto del proyecto.

Adicionalmente, se ha realizado una evaluación con docentes, estudiantes y padres de familia para conocer la percepción e incidencia del uso de los equipos en la comunidad educativa.

El proyecto ha permitido observar no solo resultados medibles, sino que ha logrado generar un ambiente diferente en el entorno escolar, ya que, ha motivado a los docentes a la investigación y uso de herramientas tecnológicas, a la innovación constante de los contenidos y metodologías de enseñanza y una mayor motivación por parte de los estudiantes. 
Es importante señalar que en el año 2015 el proyecto fue presentado al panel internacional de jurados del concurso de excelencia educativa organizado por la Fundación Para la Integración y Desarrollo de América Latina (FIDAL), dentro del proceso de evaluación el proyecto fue visitado y recibimos la distinción de ser considerados como un proyecto finalista.

\section{Figura 71}

Estudiantes de EINA utilizando el lápiz digital de la pantalla MIMIO

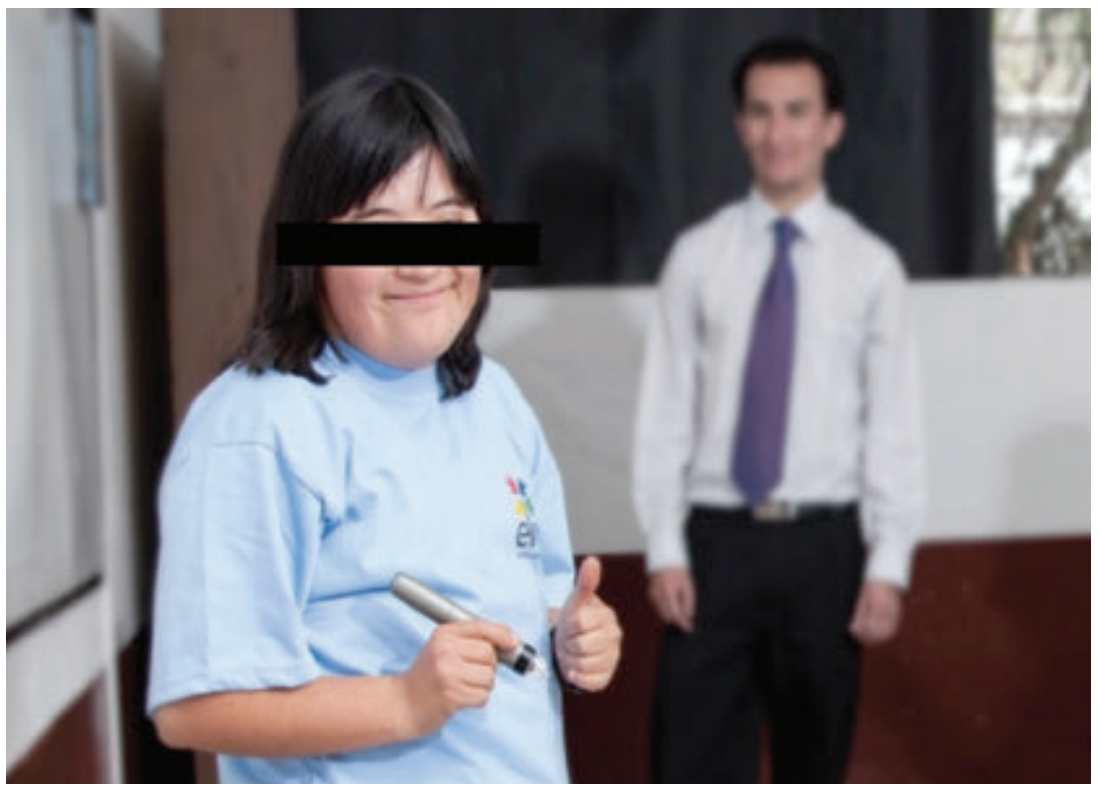

Foto: Daniel Salas (2016)

\section{La familia asume el uso de las TIC como apoyo al aprendizaje}

“Tan solo por la educación puede el hombre llegar a ser hombre. El hombre no es más que lo que la educación hace de él" (Immanuel Kant) 


\section{8}

\section{Ecuador}

Quito

Responsable: Silvania Salazar

Gestores de la práctica: la familia comparte del equipo de apoyo

La presente experiencia constituye un relato de trascendencia ya que involucra el trabajo de apoyo que desarrollan las familias cuando en el seno de ellas existe un miembro con discapacidad, es menester reconocer que la experticia que desarrollan las familias en este caso en particular el deseo de una madre de lograr que su hijo cumpla con los sueños y metas que toda familia para sus hijos se convierte en la motivación para desarrollar un colaborativo con los maestros.

\section{Motivación}

Silvania la protagonista de este testimonio es madre de Jorge Sebastián, quien hoy es un joven de 21 años que tiene una condición de discapacidad intelectual leve a consecuencia de una agenesia del cuerpo calloso (ACC) y al síndrome de Angelman, debido a los apoyos recibidos desde edades tempranas ha superado muchas de sus necesidades personales y de aprendizaje, y actualmente se desempeña como un adulto independiente.

En este proceso, su madre profesora de profesión, asumió el desafío de ser la primera maestra de Sebastián y superar con mucha fuerza el impacto del diagnóstico médico centrado en todas las debilidades y/o problemas que su condición de discapacidad genera, nunca se le informó de todas las fortalezas, y potencialidades que ella descubriría cada momento en su hijo.

Con esta visión centrada en los "problemas del niño" inició el largo camino de las terapias con el objetivo de mejorar los posibles trastornos motores y del aprendizaje que puedan aparecer a lo largo de su desarrollo.

\section{Cuenta Silvania:}

Cuando inicia su proceso educativo desde los 5 años, empiezo a utilizar las TIC, para incentivar en mi hijo el proceso de adaptación a la institución educativa ya que en la Fundación de Enseñanza Individualizada 
149

para Niños, Niñas y Jóvenes con Discapacidad Intelectual (EINA), Escuela el Parvulario y Colegio Ciclo Básico Popular Horizontes utilizan herramientas tecnológicas para apoyar el aprendizaje en los estudiantes con discapacidad intelectual.

Figura 72

Jorge Sebastián de 2 años empieza su proceso de formación

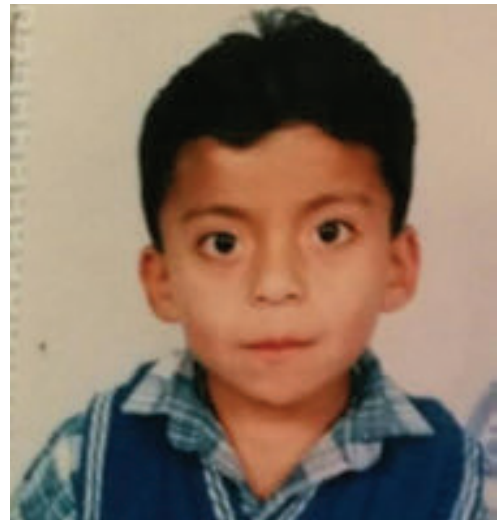

Foto: Silvania Salazar (2016)

Figura 73

Fundación EINA

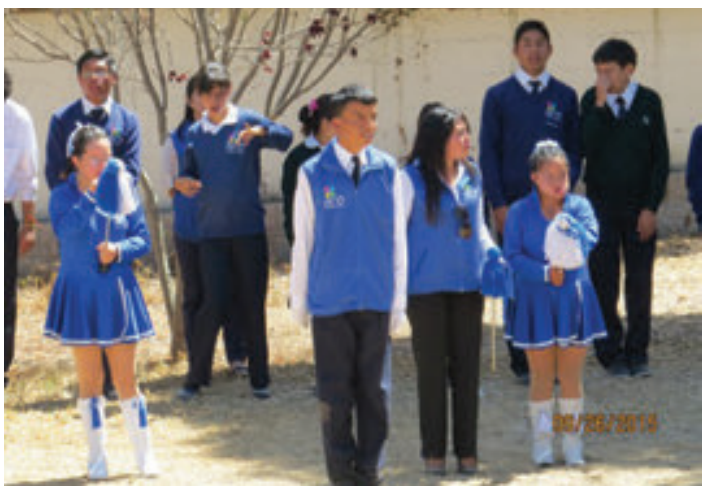

Foto: Silvania Salazar (2016) 
150

Gracias a la experiencia como docente que tiene esta madre relata la experiencia de aprendizaje de su hijo y las describe según las etapas de desarrollo evolutivo planteadas por Piaget, como ella lo manifiesta fueron la guía para desarrollar su trabajo que lo expresa de la siguiente manera:

\section{Etapa sensorio-motriz}

Edad desde el nacimiento hasta 2 años: el desarrollo cognitivo se articula mediante juegos de experimentación, muchas veces involuntarios en un inicio, en los que se asocian ciertas experiencias con interacciones con objetos, personas y animales cercanos.

Durante este período permitía que Sebastián, explore y juegue con varios programas interactivos de la computadora como: Pipo, Colorea 4.0, Nuestro cuerpo, Educapeques, Videos musicales, juegos en las máquinas, entre otras, espacios que le permitían observar figuras, colores y escuchar diversos sonidos.

\section{Etapa pre-operacional}

Edad de 2 a 7 años: empiezan a ganar la capacidad de ponerse en el lugar de los demás, actuar y jugar siguiendo roles ficticios y utilizar objetos de carácter simbólico.

Empecé con enseñarle el equipo de computación en la casa, como funciona para que se vaya adaptando a su uso.

Los programas interactivos fueron de gran ayuda para que asimile y comprenda lo enseñado.

Para mejorar su razonamiento numérico utilice juegos, como el ábaco, agrupar semillas, canicas, diseños de figuras para que coloree indicándole muchos y pocos para desarrollar el proceso matemático. Escuchar cuentos para mejorar su lenguaje y comprensión lectora. 


\section{1}

Figura 74

Jorge Sebastián con los juegos interactivos

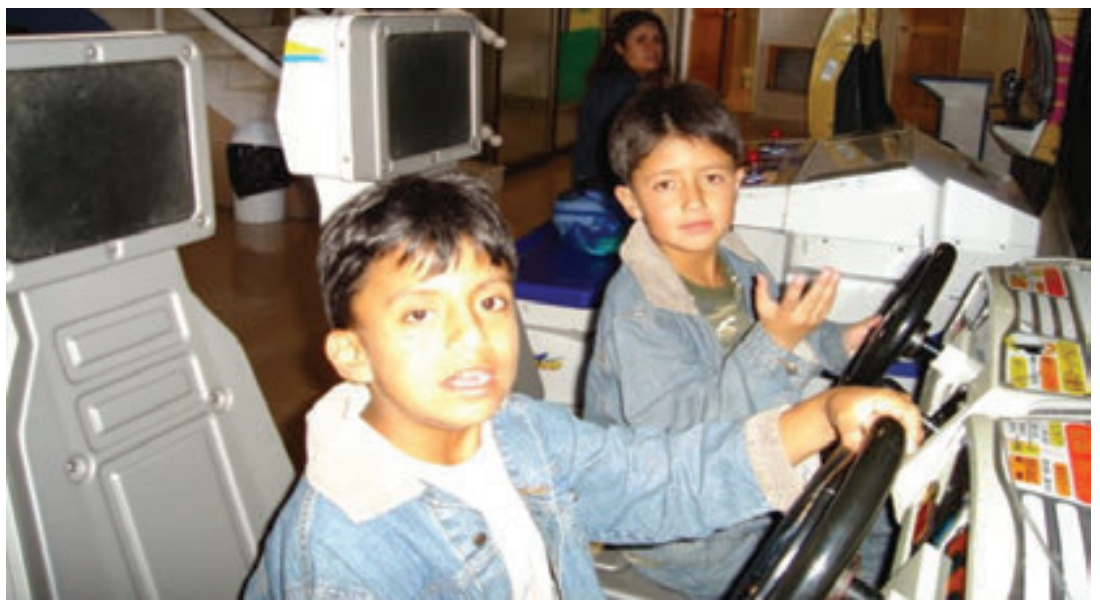

Foto: Silvania Salazar (2016)

\section{Etapa de las operaciones concretas}

Edad de 7 a 12 años: desarrollo cognitivo en el que empieza a usarse la lógica para llegar a conclusiones válidas, siempre y cuando las premisas desde las que se parte tengan que ver con situaciones concretas y no abstractas.

En este período se entrena en varios programas que le permitieron semejanzas, diferencias entre objetos, sopas de letras, crucigramas simples; empezó a elaborar diseños, figuras geométricas y personajes utilizando colores.

Se introdujo el uso de la calculadora del computador para realizar ejercicios simples de las cuatro operaciones matemáticas. 


\section{2}

\section{Figura 75}

Escuela El Parvulario de la Fundación EINA

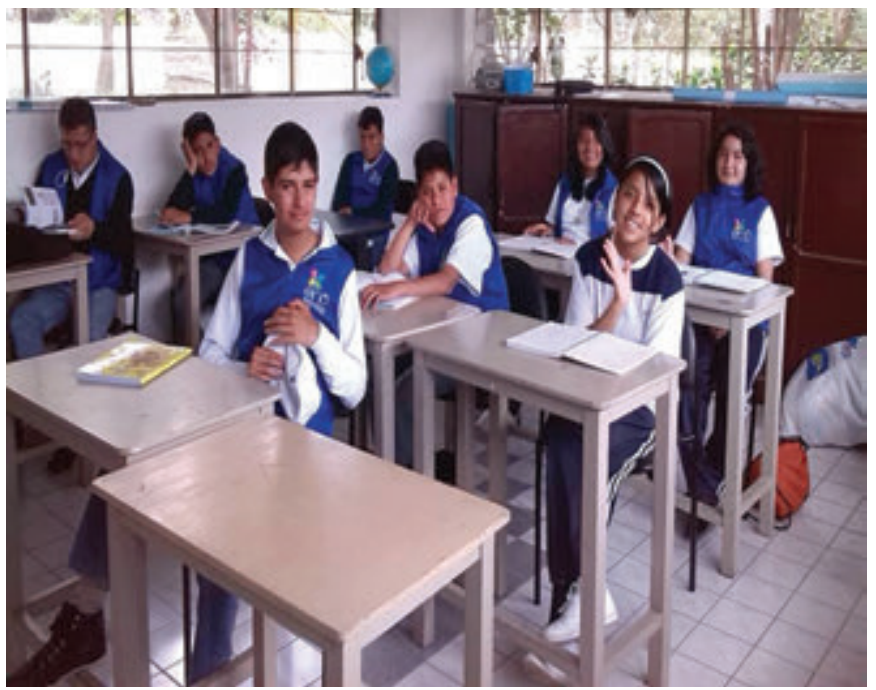

Foto: Silvania Salazar (2016)

\section{Etapa de las operaciones formales}

Edad de 12 años en adelante: la capacidad para utilizar la lógica para llegar a conclusiones abstractas ${ }^{46}$ que no están ligadas a casos concretos que se han experimentado de primera mano.

Jorge Sebastián no alcanza a potenciar el aprendizaje en esta etapa, ya que su nivel de desarrollo intelectual limita el desarrollo de procesos lógicos y abstractos, sin embargo equilibra su aprendizaje con el desarrollo de habilidades mecánicas y funcionales como el uso de la computadora, teléfonos móviles, y redes sociales.

46 El pensamiento abstracto: supone la capacidad de asumir un marco mental de forma voluntaria. Esto implica la posibilidad de cambiar, a voluntad, de una situación a otra, de descomponer el todo en partes y de analizar de forma simultánea distintos aspectos de una misma realidad. 
153

Figura 76

Clase de computación

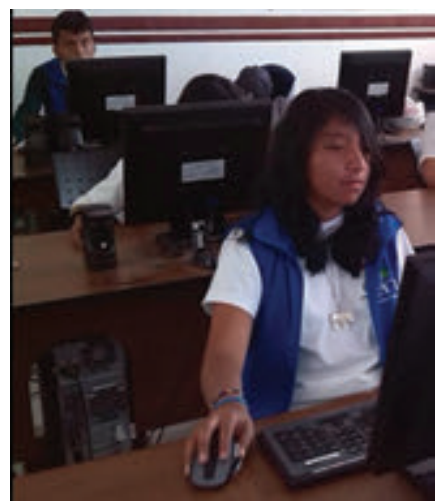

Foto: Silvania Salazar (2016)

Los logros alcanzados por Sebastián en la actualidad son innumerables, la mediación tecnológica recibida le ha permitido alcanzar mayores niveles de autonomía, busca información y prepara presentación sobre temáticas de su interés.

Figura 77

Defensa de tesis

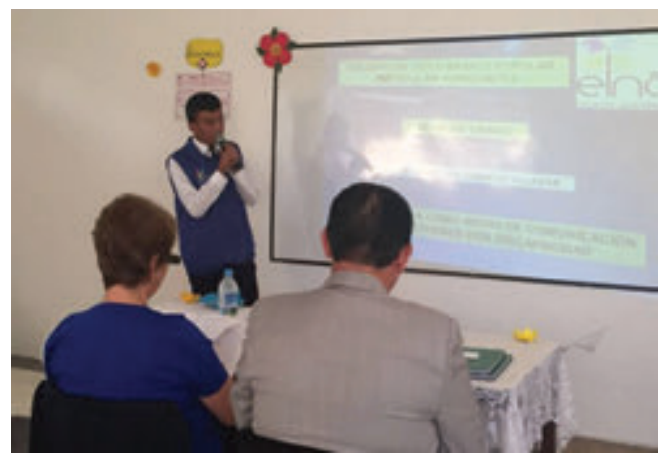

Tema tesis: La danza como medio de comunicación de los jóvenes con discapacidad. Foto: Silvania Salazar (2016) 
154

Luego de revisar la trayectoria educativa de Sebastián se observa que desde tempranas edades tuvo contacto con varios dispositivos tecnológicos.

En el momento actual su madre da testimonio de los logros alcanzados y los resume en los siguientes puntos:

- Le facilitó la adquisición de bases teóricas y destrezas operativas que las utiliza su práctica profesional como Auxiliar de Oficina.

- Sentirse motivado utilizando las herramientas TIC puesto que le permiten aprender las materias de forma más atractiva, amena, divertida, investigando de una forma sencilla.

- Utiliza las TIC en el desempeño diario, personal.

- Utiliza las TIC para mejorar su forma de comunicarse e intercambiar experiencias con los demás enriqueciendo en gran medida su aprendizaje.

Finalmente, considero que hay que buscar las oportunidades de ayuda o de mejora en la educación explorando las posibilidades educativas de la utilización de las TIC en las personas con discapacidad.

Figura 78

Incorporación y presentación de su trabajo académico

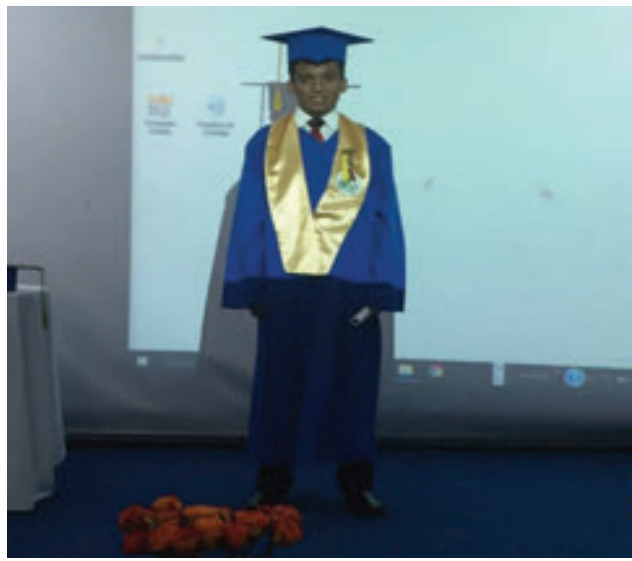

Foto: Silvania Salazar (2016) 
155

Figura 79

Uso de información digital en su entrevista de trabajo

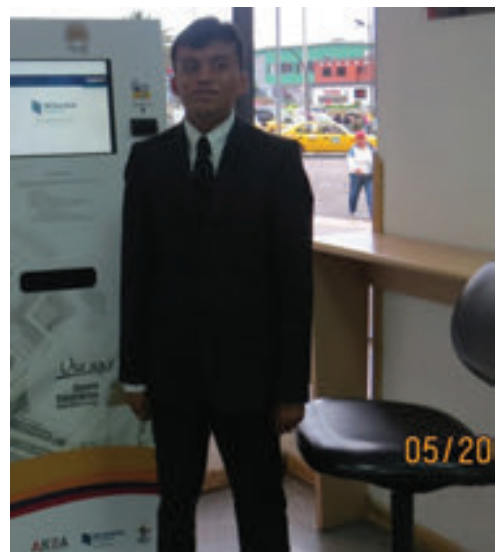

Foto: Silvania Salazar (2016)

\section{Apoyos para garantizar el acceso al aprendizaje de los estudiantes con discapacidad en el nivel superior}

"Los apoyos son recursos y estrategias cuyo objetivo es promover el desarrollo, la educación, los intereses y el bienestar personal de una persona y que mejoran el funcionamiento individual”

(Luckasson)

Universidad Politécnica Salesiana

Ecuador

Quito

Responsable: Mauricio Suárez y Andrés Jaramillo

Gestores de la práctica: Mara Tamayo Directora de la Biblioteca de la UPS

Garantizar la inclusión de estudiantes con discapacidad es un desafío para las instituciones de educación superior. La inclusión educativa tiene que enfocarse en la apropiación de aprendizajes que permitan a los estudiantes alcanzar el perfil de salida planteado para las diferentes carreras, de esta manera en la Universidad Politécnica Salesiana se cuenta con un espacio específico para la adaptación de recursos bibliográficos en formatos accesibles. 
156

\section{Motivación}

La Tiflobiblioteca de la Universidad Politécnica Salesiana, forma parte de la biblioteca de la Universidad, es un servicio creado hace diez años con el fin de apoyar académicamente a los estudiantes con discapacidad visual y a la comunidad en general cumple con la función de elaborar recursos bibliográficos accesibles.

Existe un alto número de estudiantes con discapacidad visual que al iniciar la etapa universitaria, no cuentan con la preparación adecuada para el uso del internet o que no tienen acceso a internet desde sus hogares situación que limita su acceso al conocimiento en igualdad de condiciones que el resto de los estudiantes.

\section{Objetivos}

- Facilitar la accesibilidad de los estudiantes con discapacidad visual a recursos didácticos accesibles.

- Capacitar a los estudiantes con discapacidad visual al uso de entonarnos virtuales y herramientas de comunicación y consulta.

\section{Desarrollo de la experiencia}

En concordancia con las necesidades y objetivos planteados, la atención a las necesidades de los estudiantes se da en dos etapas: accesibilidad a textos escritos y capacitación para el uso de las TIC.

\section{Accesibilidad a textos en tinta y digitales}

La tiflobiblioteca cuenta con un espacio físico equipado con once computadores y un escáner de alta resolución, dispositivos Víctor Reader producto de la gestión del grupo de investigación de Educación Inclusiva GEI. A este espacio asisten docentes, estudiantes y personas de la comunidad. 
157

Figura 80

Uso de la tiflobiblioteca

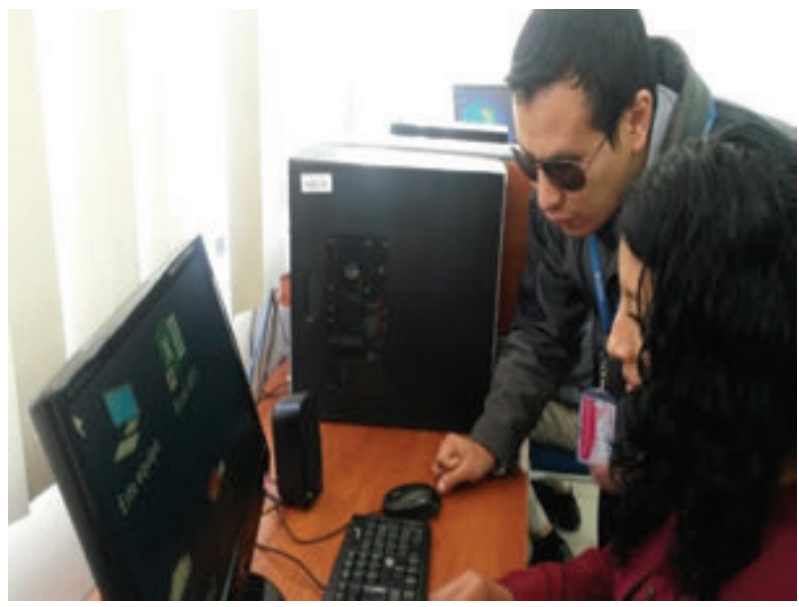

Foto: Miriam Gallego (2017)

La ruta a seguir por parte de los usuarios (docentes, estudiantes con discapacidad no solo de la universidad sino de la comunidad) para la elaboración de recursos bibliográficos accesibles se resume en los siguientes pasos:

- Solicita el servicio de digitalización del material según sus necesidades, generalmente los usuarios traen con sí, ejemplares originales, copias o archivos digitales que permitan ser transformados a imagen a texto. Para ello se cuenta con el apoyo de un escáner de alta resolución, con el cual se puede obtener un texto en formato Word, que luego, puede ser leído en la computadora o se lo transforma en audio para que pueda ser escuchado en algún reproductor de sonido.

- Búsqueda de información en el repositorio bibliográfico. La Tiflobiblioteca cuenta con 18000 títulos recopilados generados a partir ésta experiencia. 
158

- Si el material solicitado se encuentra en el repositorio bibliográfico se procede a ser entregado inmediatamente al usuario.

- Una vez concluido con el proceso de digitalización, y si el usuario necesita, se procede a la capacitación en el manejo del lector de pantalla JAWS, así como de los programas que vayan a emplear para cumplir con sus objetivos.

Es importante indicar que el uso de dispositivos móviles como el "Víctor Reader" permiten a la persona con discapacidad visual o cualquier persona que desee escuchar libros en diversos formatos, escuchar documentos de textos, música y libros en formato mp3; este dispositivo incluye una grabadora digital integrada para registrar notas de voz. En pocas palabras este recurso se convierte en una biblioteca móvil de gran apoyo para los estudiantes.

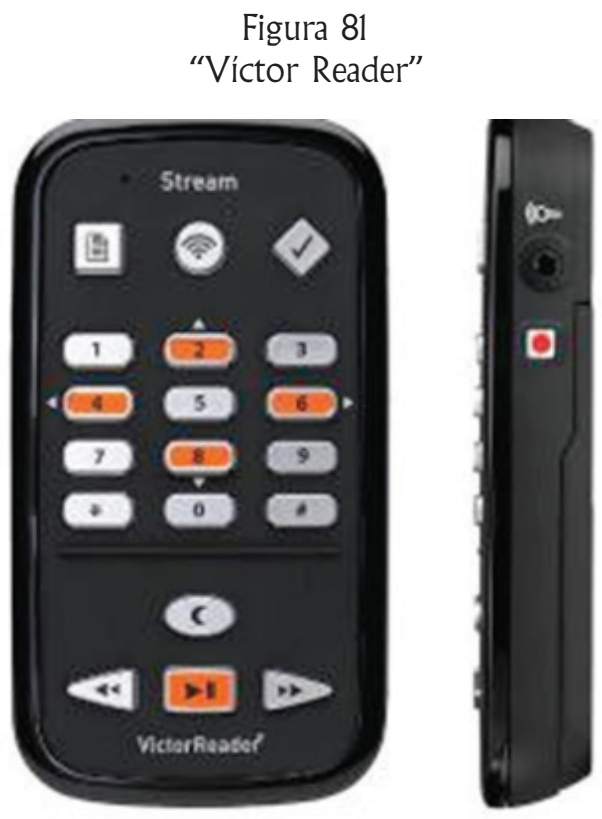

Fuente: Compartolid.es. Recuperado de https://goo.gl/gBNsjH 
159

Al igual que los lectores de pantalla el Víctor Reader es un dispositivo que permite la accesibilidad, autonomía e igualdad de oportunidades a los estudiantes con discapacidad visual.

\section{Capacitación para el uso de las TIC}

La capacitación a los estudiantes con discapacidad visual en el uso de las TIC se fundamenta en el conocimiento de lectores de pantalla como el programa Jaws y el NVDA.

La capacitación al uso del lector de pantalla Jaws se desarrolla bajo un ciclo de aprendizaje que conjuga la teoría con la práctica y permite el dominio de esta herramienta para acceso a la información y al cocimiento.

Figura 82

Ciclo de aprendizaje del programa Jaws

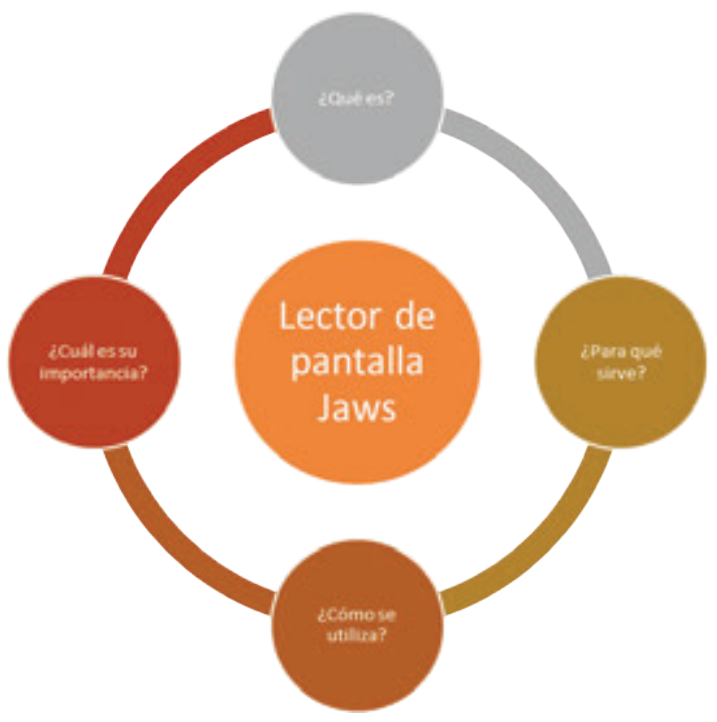

Fuente: Miriam Gallegos (2017) 
160

Figura 83

Uso del Software Jaws

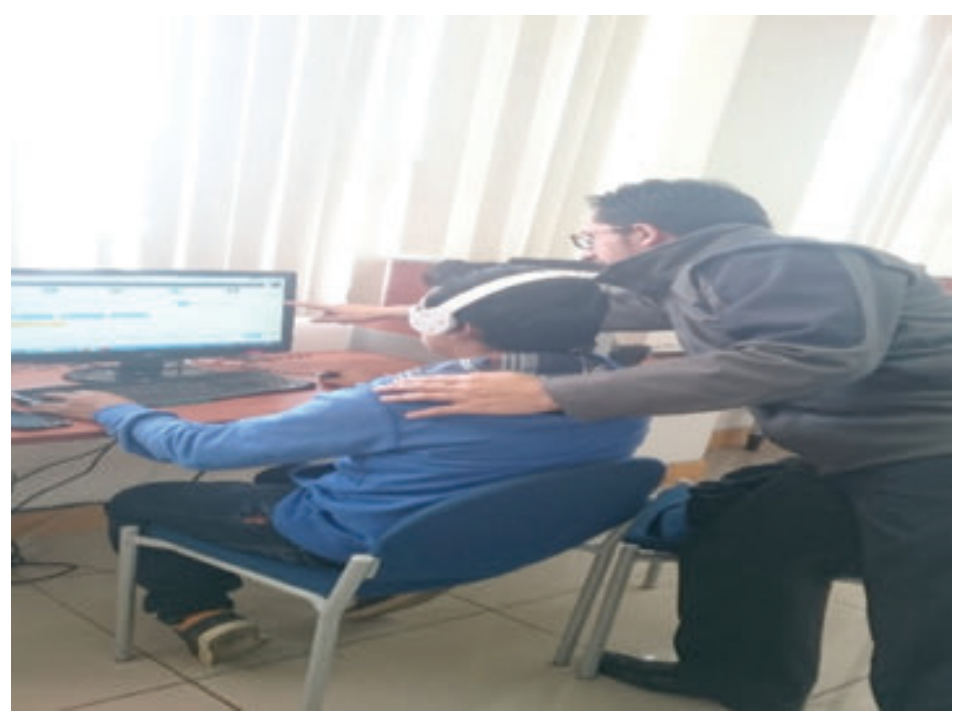

Foto: Andrés Jaramillo (2017)

Para conseguir este propósito, el programa convierte el contenido de la pantalla en sonido de manera que el estudiante pude acceder a todos las funciones del computador y navegar en internet. Para un eficiente manejo del programa Jaws, se requiere, que el modulador de voz sea regulado tanto en volumen como en velocidad de reproducción de acuerdo al manejo del mismo.

En el caso de estudiantes que se están iniciando en el uso del programa, fue necesaria una reproducción más pausada para que comprendan la acción que estaban realizando. Cuando el usuario adquiriere mayor experiencia en el manejo del computador mediante el Jaws, se aumenta el nivel de velocidad de reproducción de la voz y las acciones y comandos que se estén ejecutando en el computador se realizan con mayor rapidez. 


\section{1}

Figura 84

Lectores de pantalla

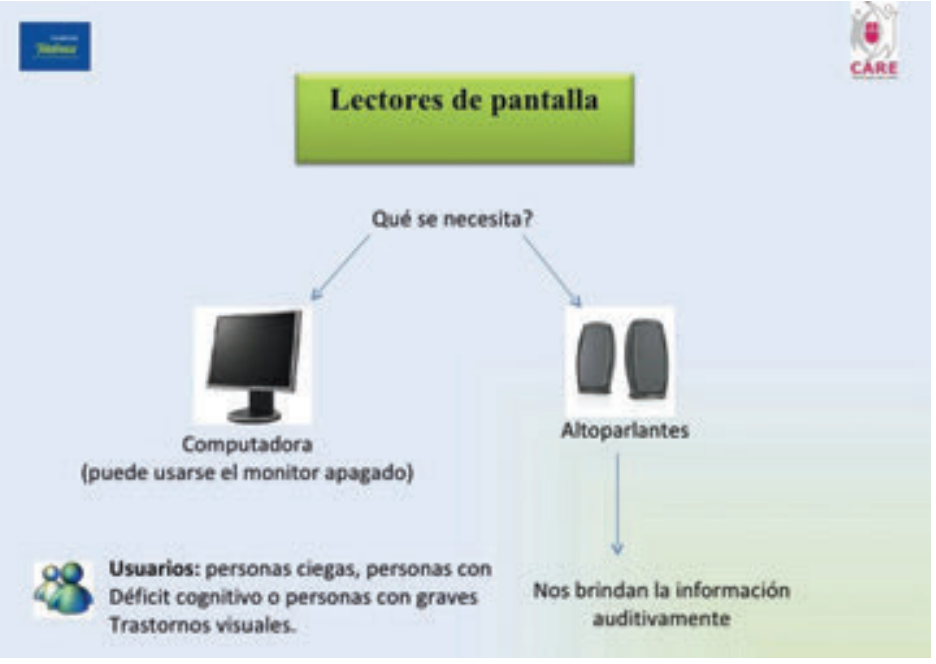

Fuente: Lectores de Pantalla y Accesibilidad Web. Recuperado de https://goo.gl/fMWa1V

\section{Figura 85}

Usuarios de la Tiflobiblioteca

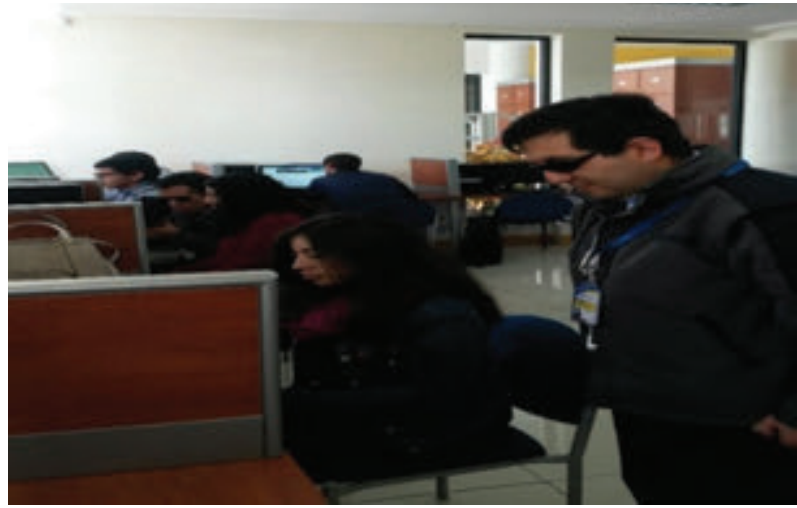

Foto: Miriam Gallego (2017) 
A los usuarios de la Tiflobiblioteca se los capacita en el manejo de correos electrónicos con mayor compatibilidad con Jaws. Se les enseña el manejo del Outlook (Personal e institucional) y Gmail. El servidor Gmail es el más accesible para las personas con discapacidad visual, en él se puede modificar la vista estándar a una vista básica, aunque, por un lado pierde características como plug-ins, imágenes y acceso ilimitado a videos, por otro lado permite resaltar el fácil acceso y manejo de la información textual.

Una herramienta importante para el aprendizaje universitario en los estudiantes con discapacidad visual son los dispositivos móviles (Smartphone). Los estudiantes reciben una clase introductoria para el uso de lectores de pantalla para estos dispositivos. En algunos casos se instalan moduladores de voz para dispositivos móviles, como Google Talkback para Android o VoiceOver para IOS.

Las actividades del proceso de formación son eminentemente prácticas entre las más relevantes constan las siguientes:

Figura 86

Actividades del proceso de formación

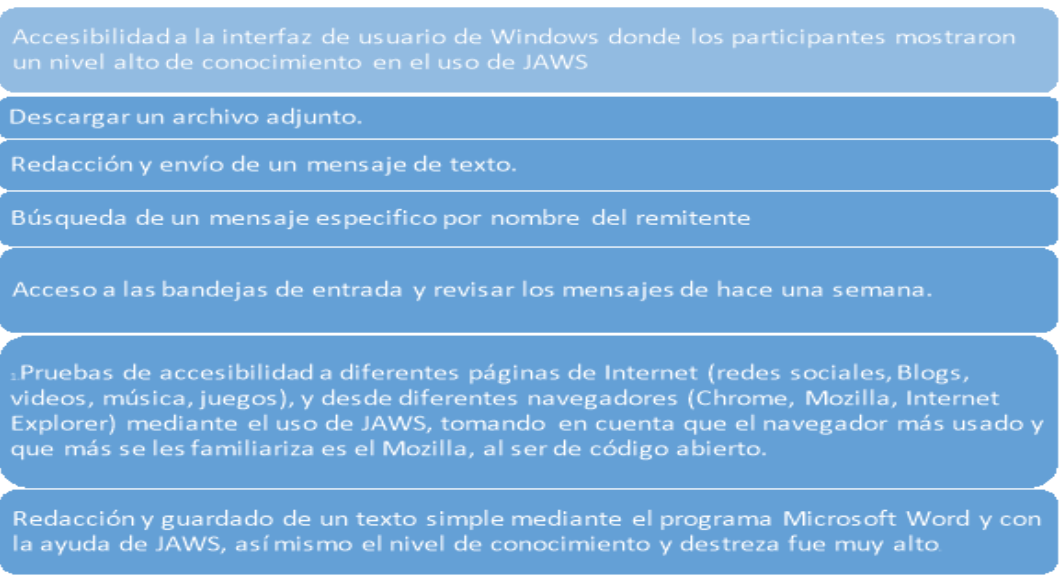

Fuente: Miriam Gallego (2017) 


\section{3}

\section{Logros obtenidos}

Dentro de los resultados alcanzados se presentan los estudiantes:

- Mayor accesibilidad a la interfaz del correo electrónico al usar la versión básica que Gmail proporciona a los usuarios. Los estudiantes demuestran mayor acceso a los mensajes recibidos.

- Capacidad para encontrar un documento y en algunos casos a modificar el nombre y a adjuntarlo al correo electrónico.

- Acceso a información y a textos escritos tanto académicos como de interés personal con mayor rapidez.

- Facilidad de comunicación e interacción con la información de la universidad.

- Mayor de independencia en las actividades académicas.

Con los conocimientos adquiridos se procede a elaborar una lista de cotejo con las actividades antes descritas como instrumento de evaluación para medir los logros obtenidos en los participantes, con resultados similares en cuanto a la práctica desarrollada.

Es importante resaltar que el aprendizaje es evaluado mediante la práctica constante del uso de las herramientas, los encargados de la evaluación los encargados de la Tiflobiblioteca quienes desempeñan el rol de tutores.

\section{Recursos utilizados}

- Computadores del departamento de Tiflobiblioteca.

- Programa JAWS v.17: Es un software lector de pantalla para ciegos o personas con visión reducida.

- Internet (redes sociales, correo electrónico, blogs, videos, música): es un conjunto descentralizado de redes de comunicación interconectadas entre sí.

- Dispositivos Víctor Reader. 


\section{Desarrollo de funciones básicas mediante un diseño de intermediación cognitiva}

"La enseñanza que deja huella no es la que se hace de cabeza a cabeza, sino de corazón a corazón”

(Howard G. Hendricks)

Instituto de Educación Especial del Azuay

Ecuador

Quito

Responsable: Gloria Sánchez

Gestores de la práctica: Líder institucional, docente, pasante de la UPS, alumnos, padres de familia y profesionales de la institución.

Esta experiencia se desarrolló con los estudiantes con discapacidad múltiple del Instituto de Piloto de Educación Especial del Azuay.

La utilización del Diseño de intermediación como un auxiliar de aprendizaje para el desarrollo de sus habilidades como: raciocinio, pensamiento abstracto, resolución de problemas, autonomía habilidades de motricidad fina; reconocimiento de esquema corporal, y el desarrollo de habilidades de comunicación funcional tanto expresiva como comprensiva constituye una valiosa herramienta para el aprendizaje.

\section{Motivación}

Esta experiencia surge de la necesidad de contar con estrategias pedagógicas como alternativa en la educación de los estudiantes que por su condición de discapacidad presentan períodos cortos de atención y concentración y requieren del desarrollo de actividades funcionales significativas que se facilitan con el uso de recursos tecnológicos como un apoyo pedagógico dentro del aula; los recursos tecnológicos permitieron estimular las áreas de comunicación e interacción social.

Para la implementación de recursos tecnológicos se contó con el apoyo de los estudiantes de la carrera de Sistemas de la Universidad Politécnica Salesiana quienes luego crean software de acuerdo a las necesidades de los estudiantes estos programas no representan gastos para las familias. 


\section{5}

\section{Objetivo}

Favorecer el aprendizaje de los estudiantes con discapacidad, utilizando un Diseño de Intermediación formado por secuencias de actividades con soporte digital que generan un informe del desempeño realizado por los estudiantes.

\section{Desarrollo de la experiencia}

El proceso de implementación de esta experiencia inició con la valoración de las posibilidades de aprendizaje de los estudiantes y el análisis de las causas por las cuales los estudiantes tienen dificultad en permanecer dentro del aula y cumplir tareas planificadas.

A continuación, conjuntamente con los pasantes de la Universidad, se elaboró las secuencias de aprendizaje de conceptos, selección e implementación de los diferentes materiales en el espacio determinado dentro del aula, considerando la accesibilidad y la posibilidad de que puedan ser manipulados por los estudiantes sin dificultad.

El desarrollo del diseño de intermediación se inicia con la implementación de un programa de computación que puede ser controlado por el docente mediante la utilización de varias plantillas que contienen la información de las diferentes secuencias de aprendizajes programadas para ser ejecutadas en los diferentes paneles, plantillas en las cuales se anotan los aciertos y errores de cada estudiante lo que permite conocer el nivel de avance al mismo tiempo que practicar una actividad hasta lograr el mayor número de aciertos.

Los paneles están programados de tal manera que cuando el estudiante cumple con una tarea puede recibir inmediatamente retroinformación para continuar o corregir la actividad realizada, está la recibe mediante luces de colores o palabras de aprobación.

A medida que el estudiante trabaja en cada uno de los paneles el docente puede revisar la información que se va registrando en la plan- 


\section{6}

tilla correspondiente lo que le permite continuar a reprogramar su propuesta educativa.

Cada uno de los módulos tiene una función específica por ejemplo "Simón Dice" para el desarrollo del lenguaje comprensivo y expresivo mediante la utilización de tarjetas de diferentes categorías, alimentos, vestido, animales, etc. En el desarrollo de esta actividad el estudiante puede seleccionar una tarjeta y colocarla en el casillero correspondiente o decir el nombre en voz alta dependiendo de su capacidad.

\section{Figura 87}

Panel "Simón Dice"

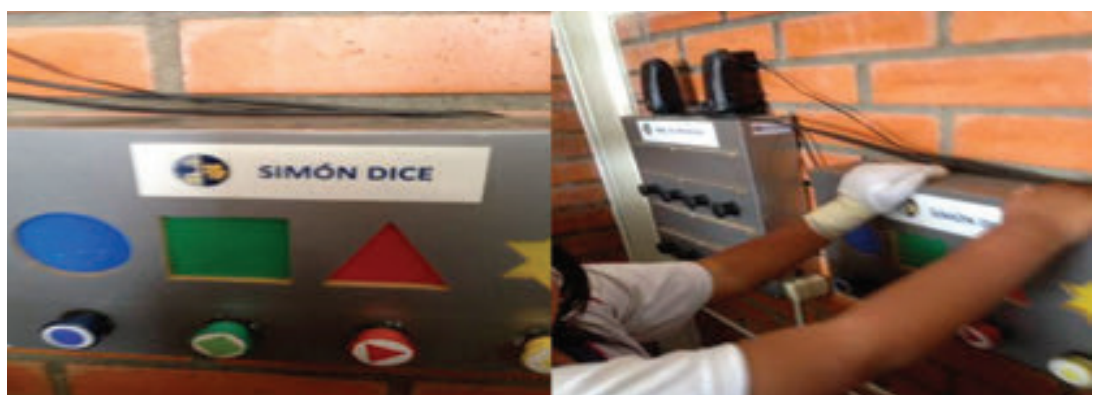

Fotos: Gloria Sánchez (2016)

En la realización de cada tarea en el módulo que se le asigne al estudiante, este tiene la posibilidad de manipular el material, identificar su color, forma tamaño, textura para cumplir con la consigna de la maestra.

Las actividades programadas están graduadas en su nivel de nivel dificultad y tiempo requerido para cada una de ellas tomando en consideración el ritmo de aprendizaje de cada niño-a. La variedad de las actividades programadas y la utilización de diferentes tipos de materiales didácticos hace posible lograr un mayor nivel de atención y concentración, y trabajar con más de un estudiante en forma individualizada. 


\section{7}

Una vez que cada estudiante haya cumplido con la realización de las tareas programadas la maestra puede tener un informe del nivel de desempeño en cada una de las áreas y de manera general en relación con el desarrollo de las funciones básicas para el aprendizaje.

Una vez implementado el software de intermediación y los panales necesarios para cada actividad, se procede a trabajar con los estudiantes en un inicio con actividades demostrativas, para que luego cada estudiante ejecute la orden correspondiente con apoyo constante de la maestra.

Cuando los estudiantes han adquirido la destreza de manipular y colocar las tarjeta en el panel correspondiente se retira gradualmente el apoyo y se inicia la tarea: 1) Escuchar la orden. 2) Ubicar el panel donde realizar la actividad. 3) Realizar la actividad.4) Comprobar si es correcta o no. 5) Si es positiva pasar a la siguiente tarea, caso contario repetirla, teniendo la posibilidad de hacerlo hasta tres veces. 6) Concluida la secuencia de actividades se genera un reporte de aciertos y errores lo que permite al docente conocer las áreas en las que debe intervenir.

El trabajo se genera en los siguientes espacios: Tubo confeti, Panel de lectura, Panel de figuras geométricas y de colores, Piano de sonidos y texturas. En este panel se desarrollan actividades que solicitan al estudiante asociar, colores, tamaños, formas pulsando para ello los botones correspondientes siguiendo consignas; esta actividad permite el desarrollo de destrezas motoras finas, lenguaje expresivo y comprensivo y lograr un mayor nivel de atención.

El estudiante trabaja en forma independiente seleccionando tarjetas de diferentes categorías y las coloca en la rejilla correspondiente, utilizando por ejemplo animales él puede producir sonidos, nombrarlos. Como los paneles son diferentes se pude utilizar para trabajar con más de un estudiante como un entrenamiento previo a la realización de todas las actividades para obtener un informe del desarrollo en general. 


\section{8}

\section{Figura 88}

Panel del lenguaje

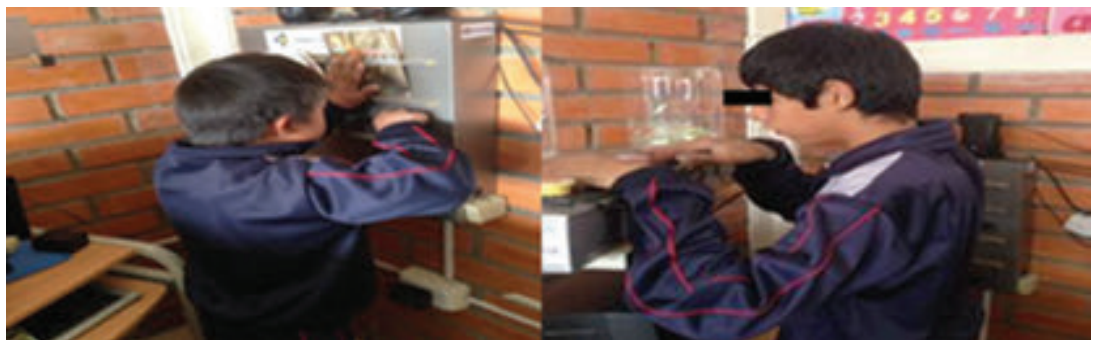

Fotos: Gloria Sánchez (2016)

Una vez completado el proceso mediante la realización de las diferentes actividades propuestas en cada panel de aprendizajes, se permite al estudiante trabajar en forma independiente siendo él quien elige la actividad a realizar de acuerdo con su interés y motivación. La evaluación del proceso se realiza mediante la observación de las plantillas de realización de cada una de las actividades de los diferentes paneles, plantillas en las que se utilizan listas de cotejo. Estas plantillas que se van guardando en el casillero de reporte de cada estudiante nos permiten conocer los progresos que realizan, en número de errores y aciertos así con el tiempo que requiere cada uno de ellos para cumplir con el proceso; de la misma manera estos datos nos permiten elaborar cuadros estadísticos y gráficos comparativos para realizar las correspondientes adaptaciones y reprogramar acciones.

\section{Logros alcanzados}

Los recursos tecnológicos al servicio de los estudiantes con discapacidad favorecen el aprendizaje en las diferentes áreas:

Debemos destacar el hecho de que siempre los docentes debemos tener capacitación y estar preparados para utilizar los diferentes recursos tecnológicos que faciliten nuestra tarea cuando los usamos para el desarrollo integral de los estudiantes en nuestras aulas. 
Observar el nivel de desempeño de cada niño/a al realizar su tarea motiva a los docentes para buscar nuevas metodologías, al mismo tiempo que nos permite reconocer que cuando se utilizan correctamente los recursos en función de los alumnos es posible desarrollar destrezas y habilidades que les permiten trabajar y utilizar nuevas tecnologías de información y comunicación.

Es importante anotar que con la implementación de este programa hemos logrado motivar a los estudiantes por lo novedoso de las actividades a realizar, ya que estas implican la utilización de la parte sonora, visual y auditiva con acciones y movimientos constantes.

- El hecho de ubicar los objetos, señalar las figuras, seleccionar, colocar las tarjetas en el panel permite un mayor desarrollo de la coordinación viso motora, estimula el desarrollo de la motricidad fina.

- La selección de figuras, sonidos formas, tamaños, secuencias ha permitido el desarrollo de habilidades de discriminación visual y auditiva básicas para el aprendizaje.

- La motivación, por lo diferente de la actividad permite que el nivel de concentración al realizar la tarea sea mayor, mejora su nivel de lenguaje comprensivo y expresiva, así como su nivel de satisfacción lo que incide en su desarrollo emocional y por ende en su interrelación con las personas de su entorno.

Participaron en este proceso seis estudiantes tres de ellos con autismo y tres con Multiretos, la variedad de actividades que se propone en cada panel y el nivel de dificultad que implica la ejecución de cada una, ha hecho posible que se pueda trabajar con cada estudiante a su ritmo y respetando su estilo de aprendizaje; por lo tanto podemos decir que se cumplieron en gran medida los objetivos propuesto al inicio del proceso y que cada alumno trabajo en un inicio con apoyo y guía, y que gradualmente han ido realizando las tareas en forma independiente de manera satisfactoria; existiendo dos alumnos que por su nivel de discapacidad siempre necesitaron apoyo y guía constante como el caso de uno de ellos que presenta baja visión. 
170

Para concluir podemos decir que todos los estudiantes trabajaron con estos recursos, aprendieron a utilizarlos, les resultaron motivantes y les ayudaron en su proceso de enseñanza aprendizaje. Los logros obtenidos pueden ser medidos mediante:

- Informe del desarrollo que se genera automáticamente como parte del programa, en este nos da cuenta del número de aciertos y errores, las áreas de mayor fortaleza y las áreas que requieren de una intervención para cumplir los objetivos.

- También mediante la observación directa podemos conocer el nivel de desempeño en el área de motricidad fina, por la precisión al manipular las figuras y botones de los tableros, así como el nivel de concentración y el tiempo en el que pueden ejecutar una tarea en forma independiente.

\section{Recursos utilizados}

Los recursos tecnológicos deben estar en función de los alumnos y ajustados de tal manera que puedan ser utilizados por cada uno de ellos para cumplir con el propósito de generar aprendizajes motivadores $\mathrm{y}$ funcionales.

Figura 89

Recursos utilizados

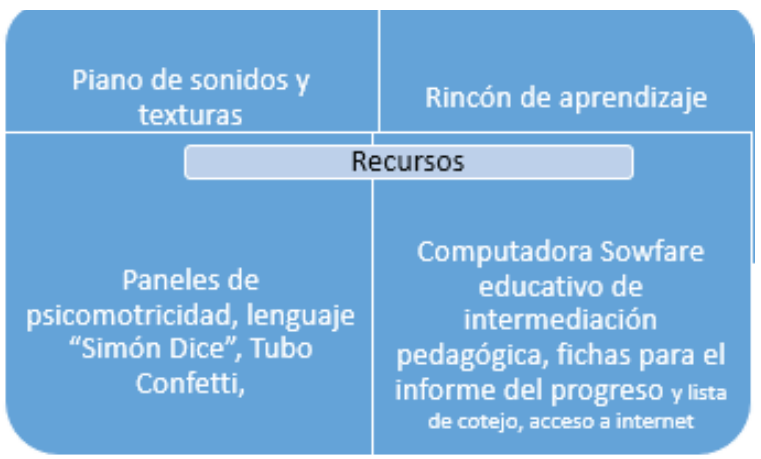

Fuente: Gloria Sánchez (2016) 


\section{3. iMis manos enseñan, tus ojos aprenden! Fotografía y producción de video en la educación de personas sordas ${ }^{47}$}

"La primera tarea de la educación es agitar la vida, pero dejarla libre para que se desarrolle”

(María Montessori)

Fe y Alegría Ecuador

Ecuador

Quito

Responsable: Jaime Sarmiento

Gestores de la práctica: Para la realización de la práctica se contó con la participación de las siguientes personas: Estudiantes sordos: Damaris Lituma, Karen Mora y Yulissa Veintimilla (Presentadoras), Micaela Pazmiño, Evelyn Ordoñez, Anderson Franco y Rosario Álvarez (Realización), Paola Acosta y Daniel Navarrete (Camarógrafos), William López (Mimo) y Jonathan Araujo (Postproducción), 11 estudiantes con discapacidad auditiva, Docentes de la Unidad de Educación Especial Fe y Alegría de Santo Domingo,( Jaime Sarmiento, coordinador de proyecto, Leonardo Llumiquinga, facilitador del proceso de formación y asesor especialista en producción audiovisual) y con la participación de José Pico, coordinador del equipo y facilitador del proceso. Génesis Limaico, Silvia Núñez, Soledad Montalván, Pablo Quezada y Jonathan Zambrano.

El uso de tecnología en la dinámica cotidiana del aula (radio, televisión, internet), permite la construcción de la opinión autónoma de los estudiantes sordos, convirtiéndolos en agentes participativos y responsables del proceso de aprendizaje.

Esta experiencia muestra con claridad la inclusión del carácter lúdico en la experiencia de aprendizaje y el respeto a las diversas formas de comunicación de los estudiantes, lo que permite que se establezca un diálogo intercultural cualificando y mejorando los aprendizajes del conjunto de actores comprometidos (docentes familias y estudiantes). Esta experiencia se constituye en ejemplo de emprendimiento en la que los conocimientos del aula se transfieren en beneficio de la comunidad.

47 Para poner énfasis en un lenguaje positivo y adecuado al referirse a las personas con discapacidad, es necesario resaltar que las personas sordas tienen una lengua propia y pueden comunicarse, por tanto no es correcto referirse a las personas sordas como sordomudas, son simplemente sordas. 
172

\section{Motivación}

A partir de un contexto de exclusión, de una oferta educativa bajo un enfoque clínico que históricamente ha limitado el desarrollo integral de las personas sordas y de una serie de condiciones que han limitado la práctica de los derechos lingüísticos y comunicaciones de las personas sordas, la práctica educativa de Fe y Alegría, desarrollada desde un enfoque bilingüe bicultural, partiendo de un proceso de formación, busca diseñar e implementar un producto educativo y comunicacional que permita abrir a la sociedad en general, una ventana al mundo de las personas sordas con el apoyo de las TIC. El proceso de formación se convirtió en un ejercicio de transferencia de conocimientos para que sean los estudiantes sordos quienes creen la propuesta de comunicación, y a partir de ella, difundan su lengua y la forma en que ven y viven sus problemas, sueños e intereses. Entre otros motivos, esta propuesta surgió porque: ${ }^{48}$

- Existe una limitada oferta de los medios tradicionales de comunicación para la población sorda. La oferta se limita a la interpretación en lengua de señas (realizada por intérpretes oyentes) de algunas noticias, en ciertos canales de televisión.

48 Véase también: Asociación Fe y Alegría Ecuador. (2013). La Educación Especial en Fe y Alegría Ecuador. Quito: Fe y Alegría. Asociación Fe y Alegría Ecuador. (2014). Proyecto Mejora de la Calidad Educativa e Inclusión de estudiantes con discapacidad auditiva con la participación de familias, escuela y comunidad. Quito: Fe y Alegría. Asociación Fe y Alegría Ecuador. (2015). Guía para la Inclusión de Estudiantes Sordos en la Educación Regular. Quito: Fe y Alegría. Asociación Fe y Alegría Ecuador. (2016). Análisis de las fortalezas, retos y prácticas alineadas al Modelo Bilingüe Bicultural de 5 instituciones para estudiantes sordos. Informe de Análisis y Recolección de Información. Quito: Fe y Alegría. CONADIS. (2013). Agenda Nacional para la Igualdad en Discapacidades 2013-2017. Quito: Consejo Nacional de Igualdad de Discapacidades. INEC. (2010). Población por condición de discapacidad, según provincia, cantón, parroquia y área de empadronamiento. Quito: Instituto Nacional de Estadísticas y Censos. 


\section{3}

- No existe la presencia de la persona sorda en los medios, no se evidencian sus problemas, necesidades, expresiones o sueños. Cuando temas relacionados con las personas sordas aparecen en los medios tradicionales, éstos se limitan a la interpretación de los oyentes sobre la realidad de la persona sorda.

- Existe una limitada producción de información, notas, material educativo, contenidos artísticos o comunicacionales desde la comunidad sorda. En los medios tradicionales esta producción es prácticamente nula y en medios alternativos, como sitios web para compartir videos, la producción que aparece se limita a informar de temas de actualidad. Adicionalmente, esta producción carece de un trabajo profesional y de la presencia de jóvenes sordos.

- Hay una demanda limitada por parte de la comunidad sorda, que si bien exige su derecho a la libre expresión y al acceso a la información, por un lado se limita a exigir lo que ya hacen los medios tradicionales, como es la interpretación en lengua de señas de las noticias, y por otro lado no hace uso de las herramientas disponibles para producir información desde medios alternativos.

- Por otro lado, se evidencia un problema de baja autoestima, inseguridad y retraimiento que si bien puede ser una condición común en todo adolescente o joven en algunos contextos, se profundiza en adolescentes sordos, producto de la exclusión y discriminación que afectan a esta población. Esto hace muy difícil que un adolescente se enfrente a una cámara y a la exposición pública. Se requiere un trabajo sostenido en el desarrollo de su identidad como persona sorda y en la autovaloración para vencer los temores y afrontar nuevos retos, como el que plantea la propuesta de comunicación desarrollada por Fe y Alegría. 
174

Figura 90

Trabajo sostenido en Fe y Alegría

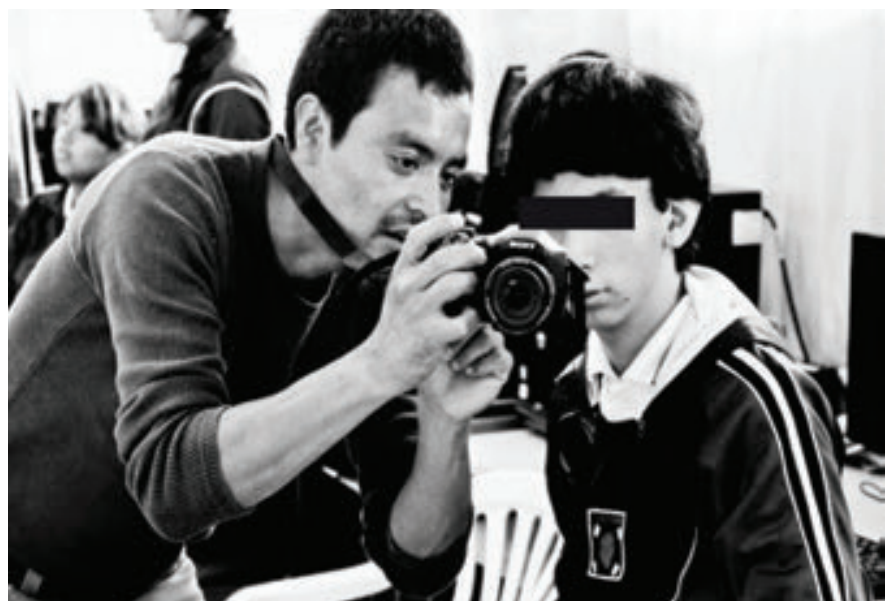

Foto: Jaime Sarmiento (2017)

\section{Objetivos}

Objetivo general

Implementar una propuesta educativa, comunicacional y de sensibilización sobre los derechos de las personas sordas con el apoyo de las tecnologías de la información y comunicación, en donde estudiantes sordos ejecuten todas las fases de pre y post producción de los contenidos.

Objetivos específicos

- Alentar una oferta informativa inclusiva en los medios de comunicación y diversificar la producción de información, notas, contenidos artísticos y comunicacionales desde la comunidad sorda.

- Contribuir al ejercicio de la libertad de expresión y al acceso a información de las personas sordas en Ecuador. 
- Articular la propuesta al proceso educativo de estudiantes sordos, fortaleciendo sus capacidades en el uso de las TIC y en la lectoescritura.

\section{Desarrollo de la experiencia}

Ante la exclusión y subvaloración del rol de las personas con discapacidad, muchas personas y organizaciones han optado por usar las tecnologías de la información y comunicación (en adelante TIC) para llenar el vacío de contenidos o para difundir información relativa a los intereses de las personas sordas.

Siguiendo el ejemplo de la comunidad sorda, a inicios del 2013, Fe y Alegría Ecuador ${ }^{49}$ se planteó desarrollar una propuesta de comunicación para la promoción de los derechos de las personas sordas, mediante el uso de las TIC. Esta propuesta se viene desarrollando en la Unidad de Educación Especial Fe y Alegría (En adelante UEEFA) de la ciudad de Santo Domingo. La UEEFA se creó en 1984 y es la única institución de educación especial de la Provincia de Santo Domingo de los Tsáchilas. En esta institución se ofrecen servicios de estimulación temprana, rehabilitación física, terapia de lenguaje, educación inicial y educación general básica a 150 niñas, niños, adolescentes y jóvenes con discapacidad auditiva e intelectual.

Formación en fotografía. Para la materialización de esta propuesta de comunicación, se inició con un programa especial de formación en fotografía. Por medio de este proceso de formación se logró usar

49 Fe y Alegría es una institución de carácter privado, sin fines de lucro, que brinda servicios de educación y promoción social con énfasis en los sectores y grupos poblacionales tradicionalmente excluidos. Está presente en 14 provincias de Ecuador, principalmente en áreas urbano-marginales y rurales donde atiende las necesidades de educación de más de 29000 niños y jóvenes, a través de sus 77 centros y servicios educativos. Su oferta abarca la educación formal con servicios de educación inicial, educación general básica, bachillerato, educación especial, así como servicios de educación no formal. 
la fotografía como una herramienta de comunicación para transmitir los puntos de vista personales y la percepción del contexto que rodea a jóvenes sordos de la ciudad de Santo Domingo. Luego del proceso de formación se seleccionó una muestra fotográfica, misma que se ha presentado en varios espacios, encuentros y eventos para promocionar los derechos de las personas sordas, como por ejemplo en la Semana Internacional de la Persona Sorda. ${ }^{50}$ De este proceso educativo surgió la exposición "Fotografía para la Inclusión” la cual reúne una serie de fotografías de un grupo de estudiantes sordos de Fe y Alegría. Esta muestra fotográfica permitió apreciar el talento particular de estudiantes sordos, su especial sensibilidad y su potencial en el campo de la fotografía.

Figura 91

Formación en fotografía en Fe y Alegría

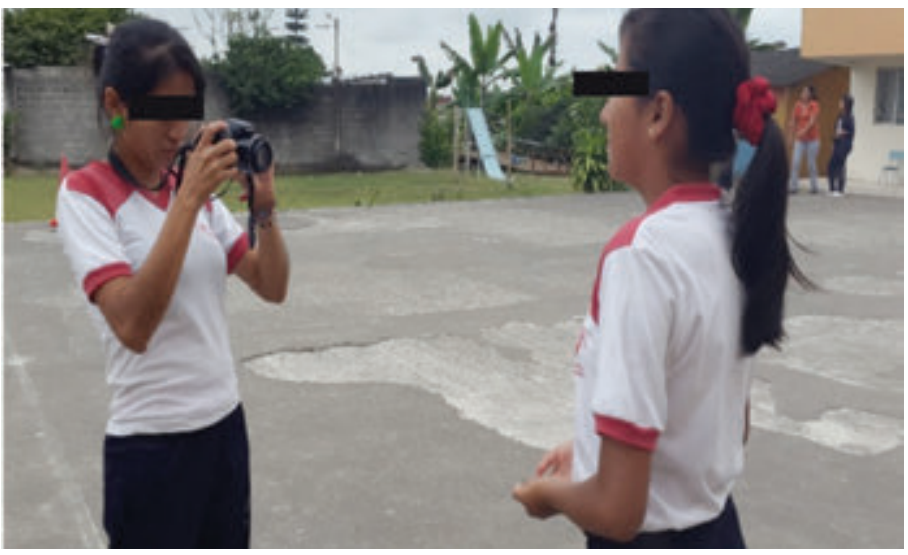

Foto: Jaime Sarmiento (2017)

Formación en producción audiovisual. Posteriormente, se desarrolló un proceso de formación en producción audiovisual, dirigido a un

50 La Semana Internacional de las Personas Sordas comenzó a celebrarse el 28 de septiembre de 1958 para conmemorar el primer Congreso Mundial de la Federación Mundial de Personas Sordas que se celebró en septiembre de 1951, por lo que se celebra durante la última semana completa de septiembre. 
grupo de 11 jóvenes sordos y 5 docentes de la UEEFA. Durante la realización de este programa de formación se concretó la producción de la revista televisiva para sordos y oyentes denominada "Mis manos enseñan, tus ojos aprenden". El producto del proceso de formación fue la edición y publicación en Internet de la revista televisiva, bajo una metodología activa de formación. En el proceso de construcción de la propuesta, se definió que la temática a abordar en la revista, partiría de las vivencias y distintas visiones del entono social que tiene la juventud sorda, con sus personajes, sus temas de interés y en continuo intercambio con otros actores institucionales y sociales. La revista se definió así como una producción educativa y de comunicación diseñada, filmada y editada por estudiantes sordos, con el apoyo de docentes de la UEEFA y la asesoría de Leonardo Llumiquinga, consultor experto en producción audiovisual.

\section{Figura 92}

Formación en producción audiovisual en Fe y Alegría

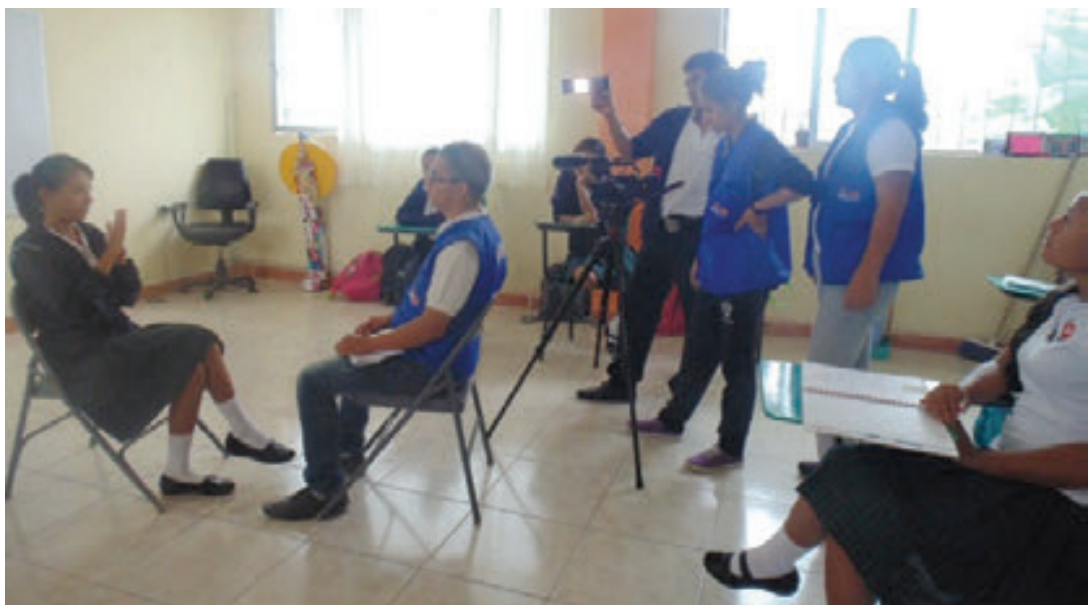

Foto: Jaime Sarmiento (2017)

La metodología desarrollada, como se resume en la Figura 101, consistió en: 
- Formación teórico-práctica sobre producción audiovisual.

- Acompañamiento y seguimiento.

- Publicación de la revista en Internet.

- Difusión de la revista en eventos y redes sociales.

Figura 93

Metodología de la propuesta

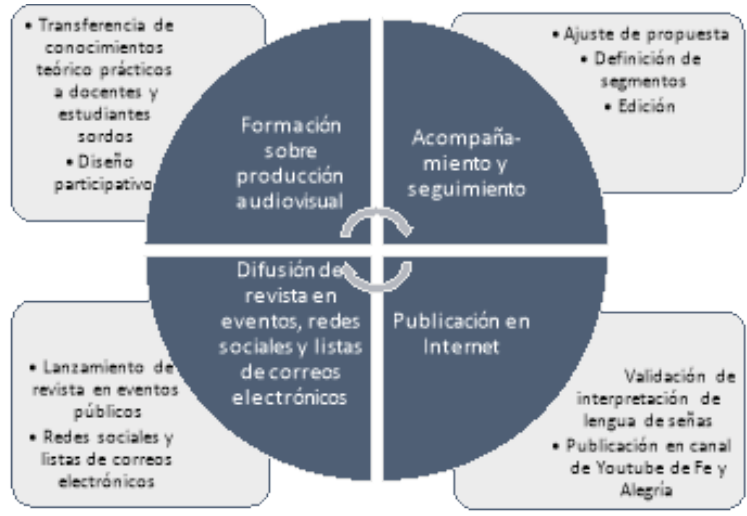

Fuente: Jaime Sarmiento (2017)

Para la elaboración de este producto comunicacional y educativo, se inició con un taller sobre producción audiovisual con una duración de dos meses, en sesiones de trabajo consecutivo, de cuatro días por semana y 4 horas diarias de formación. Esta fase de transferencia de conocimientos estuvo a cargo de Leonardo Llumiquinga, consultor especialista en producción audiovisual y en formación en el ámbito de la comunicación y uso de equipos de filmación, edición y TIC para la comunicación social..$^{51}$

La formación inició con la revisión del marco teórico sobre la organización del equipo de trabajo, la labor del equipo de dirección y del equipo de producción, formato y género de programas audiovisuales, es-

51 El consultor especialista en TIC y comunicación social, Leonardo Llumiquinga preparó todos los contenidos, tutoriales y recursos para este programa de formación. 
tructura narrativa y recursos narrativos. Para esta primera fase se utilizaron tutoriales digitales y métodos activos para llevar la teoría a la práctica, para conocer el manejo de una cámara profesional de video y para crear en equipo la propuesta de comunicación.. En el desarrollo de los talleres, se definió que la revista audiovisual saldría al aire de forma periódica, pero sujeta a la dinámica de la UEEFA y a las facilidades para la edición del material grabado. El programa de formación inició con un grupo de docentes para asegurar la permanencia de los conocimientos y contenidos y para facilitar la incorporación de esta propuesta en la malla curricular de la UEEFA. Esta primera instancia sirvió además para fortalecer el monitoreo a jóvenes sordos en el taller de producción audiovisual subsiguiente.

La segunda etapa de la propuesta consistió en la formación a jóvenes sordos, en donde se combinó la teoría y la práctica en producción audiovisual, con narrativa cinematográfica y con el apoyo de la lengua de señas ecuatoriana. Finalmente, se trabajó con jóvenes y docentes, en la producción de la revista audiovisual hasta ubicarla en un sitio web de reproducción de videos. De esta manera, la experticia surgida en la realización de estos insumos se concatenó, facilitando los procesos y el sostenimiento en la producción para realizar una revista audiovisual de contenido y con estándares de calidad.

Es necesario resaltar que durante todo el proceso de producción, mediante una metodología de lluvia de ideas, junto a los estudiantes se fueron creando tanto la estructura narrativa del programa, como los reportajes y las temáticas a tratar. Incluso el nombre de la revista surgió de una de las estudiantes sordas. Fue así que la revista pasó a llamarse "Mis manos enseñan, tus ojos aprenden", título que revela la intencionalidad de la propuesta, la interacción entre el mundo sordo y oyente, la relevancia de la lengua de señas y el enfoque educativo de la propuesta.

\section{Logros obtenidos}

La revista "Mis manos enseñan, tus ojos aprenden", está articulada al proceso educativo de jóvenes sordos, potenciando las capacidades 
para la redacción, la planificación, el trabajo en equipo, el uso de las TIC y la promoción de los derechos de comunicación, derechos lingüísticos, libertad de expresión e identidad de las personas sordas.

Una vez finalizada la primera edición, la revista se definió como un producto educativo, comunicacional, inclusivo y de innovación social, que muestra de qué forma se pueden desarrollar contenidos inclusivos en donde oyentes y sordos compartan y aprendan juntos, más allá de las barreras y limitaciones de los medios tradicionales de comunicación y de los estigmas sociales. Adicionalmente, se convirtió en una muestra del potencial que tienen jóvenes sordos para producir contenidos de calidad que pueden ser aprovechados como material educativo desde un enfoque bilingüe bicultural.

La revista audiovisual abre las puertas al mundo de las personas sordas, refuerza la identidad de la persona sorda mediante la preeminencia de la lengua de señas ecuatoriana (En adelante LSEC) por sobre la comunicación oral y busca posicionar el protagonismo de jóvenes sordos, sin olvidar el diálogo intergeneracional e intercultural con el mundo de los oyentes.

Producto de esta experiencia, actualmente se cuenta con una metodología de formación en producción audiovisual para estudiantes sordos, cuatro revistas audiovisuales producidas por estudiantes sordos y cinco mini documentales sobre una propuesta de mejora de la calidad de la educación para personas sordas. Adicionalmente, se cuenta con un equipo de tres docentes y un equipo de once estudiantes sordos formados en producción audiovisual.

Tras la difusión de las revistas en el canal de YouTube de Fe y Alegría y en eventos de lanzamiento realizados en la ciudad de Santo Domingo, se ha alcanzado una importante difusión de la misma, alcanzando rápidamente más de 3000 visitas luego de su publicación.

La realización de la revista ha creado nuevas expectativas y proyecciones profesionales en los participantes, ligadas al campo de la producción 
audiovisual, el periodismo y la fotografía. Esto se ha evidenciado a través del seguimiento de la coordinación, al equipo de producción de la revista.

Finalmente, se cuenta con cuatro revistas audiovisuales ${ }^{52}$ producidas por estudiantes sordos, con el apoyo de sus docentes, como material de sensibilización, educación y promoción de la lengua de señas y de los derechos de las personas sordas.

\section{La teoría del Neuroaprendizaje a través de las TIC en personas que asisten al servicio de rehabilitación}

"El primer movimiento de la pequeña mano hacia las cosas, el impulso de este movimiento, representa el esfuerzo del yo por penetrar en el mundo"

(María Montessori)

Centro de Rehabilitación

Ecuador

Quito

Responsable: Juan Carlos Guachamín

Gestores de la práctica: Esta experiencia se desarrolló con los miembros del equipo de rehabilitación (terapista físico, terapista del lenguaje).

Esta buena práctica gira en torno a actividades cotidianas desarrolladas a través de diferentes software los cuales aplicados de acuerdo a los intereses y necesidades de cada niño.

Se desarrollaron con una metodología altamente participativa, los profesionales utilizaron un gran abanico de posibilidades de estrategias didácticas para trabajar en varias áreas del conocimiento como pre matemática, funciones básicas, lenguaje, vocabulario, comprensión lectora.

La presente experiencia permite maximizar los resultados de la rehabilitación de los niños, niñas con trastornos neurológicos. Mediante el trabajo colaborativo con el equipo multimodal de la institución conformado por los profesionales en Terapia Física, Terapia de Lenguaje y Psicología Clínica. El entrenamiento neurocognitivo mediado por las TIC permite la modificación de las funciones cerebrales de manera temporal o permanente, así como de la conducta de los niños y niñas con trastornos neurológicos.

52 Estas revistas están disponibles a través del enlace al canal de YouTube de Fe y Alegría: https://goo.gl/qF2ynm 
182

\section{Motivación}

En todas las etapas de nuestra vida es posible modificar y cambiar la capacidad del cerebro, las experiencias de la vida le van moldeando, pero hay que tomar en cuenta que el momento de mayor plasticidad y donde se producen los mayores y más rápidos cambios es en la infancia.

El aprendizaje es la capacidad que tiene nuestro cerebro de adaptación a los requerimientos ambientales, el cerebro se desarrolla desde que nacemos hasta que morimos, Las experiencias que vivimos en nuestra niñez tienen un impacto decisivo en la "arquitectura" de nuestro cerebro. El cerebro de un niño/a de 3 años es dos veces más activo que el cerebro de un adulto con una elevada actividad intelectual. Por eso es fundamental ayudar a los niños/as en su desarrollo cerebral para que optimicen todas sus posibilidades a través del juego y del respeto a su identidad.

La maduración neurológica es diferente en cada niño/a, hay que respetar sus ritmos de maduración para ayudarles a desarrollarse y crecer con seguridad en sí mismos. En la edad adulta nuestro cerebro también cambia, tal y como lo usemos así se irá configurando.

A través del neuroaprendizaje se puede optimizar el funcionamiento del cerebro para potenciar los procesos de: atención, memoria, lenguaje, lectura, escritura, razonamiento y emociones.

\section{Objetivos}

Mejorar los niveles de comunicación y aprendizaje con la aplicación de las TIC y la participación activa de los padres de familia, de manera que se mitiguen las desventajas cognitivas a causa de las condiciones neurológicas de los niños que asisten al centro de rehabilitación.

\section{Desarrollo de la experiencia}

Consentimiento de todo el equipo de todo el equipo de trabajo (Terapia Física, Terapia de Lenguaje y Psicología Clínica,) con relación al uso de las TIC en la rehabilitación integral. 
Selección de la población beneficiaria a través de estudio de caso para conocer las potencialidades de cada persona.

Reunión con los padres de familia, asesorándoles sobre los beneficios de la terapia mediada por las TIC.

Ejecución del plan terapéutico individual, siguiendo los siguientes pasos:

Figura 94

Plan terapéutico individual
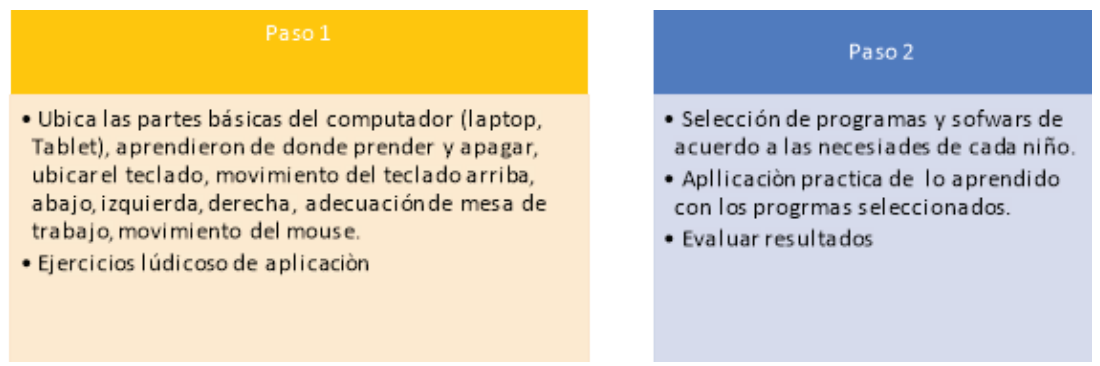

Fuente: Juan Carlos Guachamín (2017)

La fase terapéutica se desarrolla en dos momentos uno grupal y otro individual, los niños acuden a terapia tres días a la semana de los cuales se emplea 30 minutos de cada día en la aplicación de las TIC, donde se trabaja diferentes competencias con los software seleccionados que a continuación se detallan:

- Bouncy Balls

- Aplicaciones en la Tablet con Forge of neón

- Art of glow

- Kaleidoo, actividades causa-efecto 
184

Figura 95

Bouncy Balls

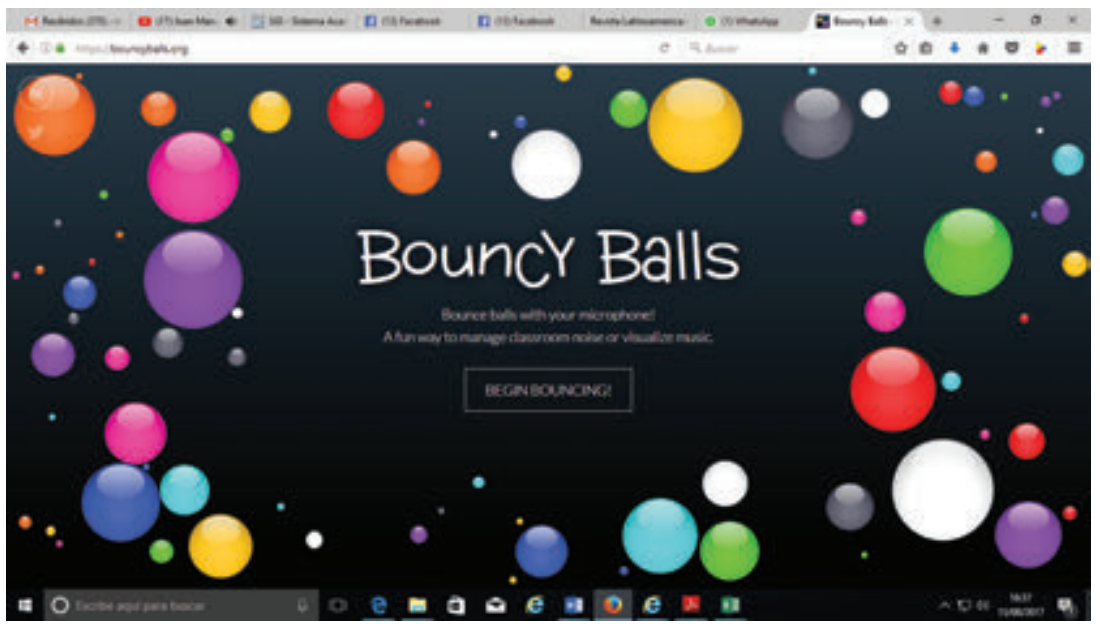

Fuente: Bouncy Balls

Recuperado de https://goo.gl/oT5T31

Posteriormente se aplica las TIC de manera individual respondiendo a las necesidades propias de condición neurológica, sus gustos, habilidades y nivel cognitivo.

Con Violeta y Sebastián, debido a su nivel cognitivo se prioriza el trabajo en el área de comunicación y matemáticas, con el siguiente software, los mismos que se pueden descargar de manera gratuita en los siguientes links: https://goo.gl/LvzycK; https:/goo.gl/uraqCr; https:// goo.gl/WdTzyk

Los software antes mencionados, permite trabajar las habilidades de comprensión lectora a través de la lectura con imagen y texto así como mediante emparejamiento de letras y nombres, actividades que se realizan en colaboración con la terapeuta de lenguaje. En cuanto a matemáticas (pre-matemáticas), el conocimiento de colores, formas, 
avanzamos hacia conocer números, contar, formar cantidades, y posteriormente a operaciones básicas suma y resta.

Figura 96

Ejemplos de uso del software
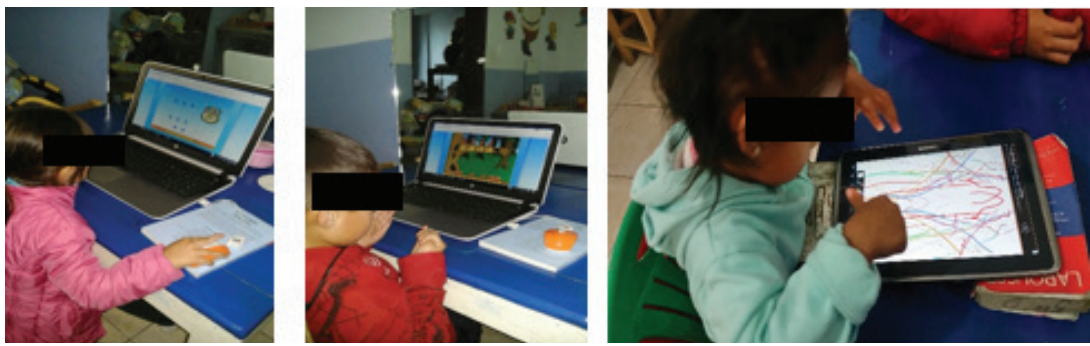

Fotos: Juan Carlos Guachamín (2017)

Por otro lado con Sofía, se adaptó un interruptor por presión, y uno de palanca para facilitar la manipulación del ratón, de igual manera se trabajó en Tablet para facilitar movimientos voluntarios de los dedos especialmente del índice y medio que posteriormente serán esenciales en la prensión de lápiz para la escritura.

Figura 97

Dispositivos adaptados
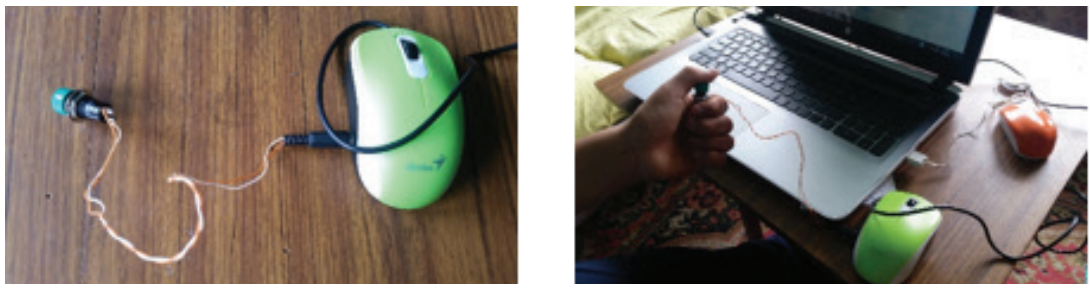

Fotos: Juan Carlos Guachamín (2017)

Para alcanzar el control cefálico de Sofía se utilizó el visor en 3D, se descarga la aplicación VR Ocean Aquarium 3D en el celular y posteriormente ubicarlo en el visor. VR Ocean Aquarium 3D es una apli- 
cación que trata sobre vida marina para lo cual se tiene que mover la cabeza, girando hacia arriba, abajo, a los lados y en forma circular poder ubicar a los peces que se encuentran a su alrededor, con este logramos movimientos voluntarios que fortalecerán por repetición los músculos del cuello. Una vez que mejoró en el control cefálico se la incorpora a trabajar pasturada adecuadamente en mesa facilitando actividades de aprendizaje y terapéuticas en mesa. Una vez pasturada en mesa, trabajamos autonomía y sensomotricidad, con el uso de audífonos, buscamos que discrimine sonidos, onomatopéyicos de animales domésticos, salvajes, medios de transporte, partes del cuerpo humano, apoyados con el profesional terapeuta de lenguaje. Las actividades que se realizó con Sofía en mesa son multisensoriales, y la finalidad es que al realizar una actividad motriz o táctil a la par participen otros sentidos como los visuales y auditivos, para esto se incorpora en el sentido auditivo la música bineural que solo es percibida por los oídos atreves de audífonos y su objetivo es que mediante notas musicales de alta vibración estimule las ondas cerebrales y mejore las conexiones nerviosas entre los hemisferios cerebrales, alcanzando estados de relajación, mejoramiento de la memoria, mayor grado de conciencia y vigilia, excelente grado de atención y concentración. La música bineural se la puede descargar en mp3 y tendrá su efecto solo con el uso de audífonos.

Figura 98

Sofía usando El visor 3D (segundo mes)
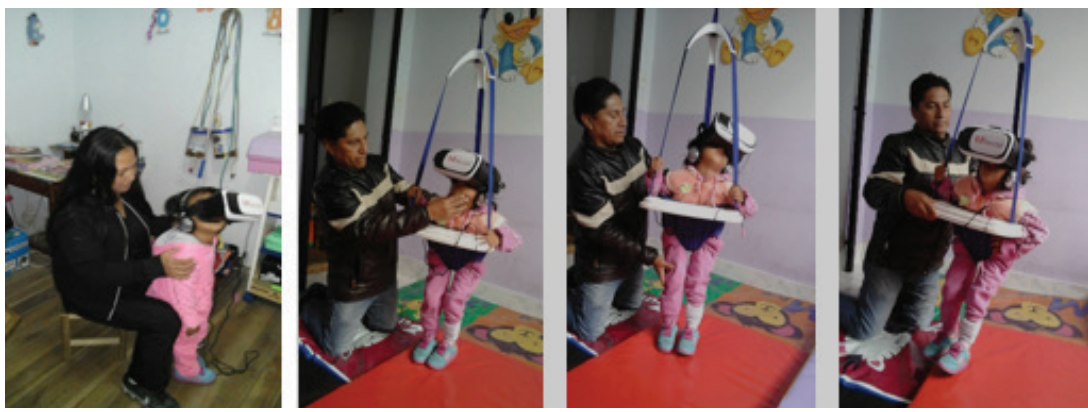

Fotos: Juan Carlos Guachamín (2017) 
VR. Ocean Aquarium 3D-Aplicando la música bineural
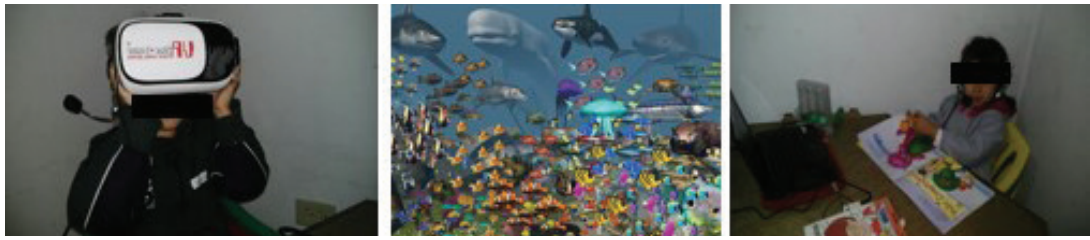

Fotos: Juan Carlos Guachamín (2017)

\section{Logros obtenidos}

Para la obtención de resultados fue necesario interpretarla mediante una metodología cuantitativa y cualitativa, pues de esa forma se detallan el progreso de cada niño (a) y sobre todo el desarrollo cognitivo a través de test y ejecución de programas adaptados. Cabe anotar que el test de inteligencia WIPPSI en este caso constituye una herramienta para la elaboración del plan de apoyo terapéutico.

\section{Interpretación cuantitativa}

Los resultados alcanzados en la aplicación del Test de Wechsler para menores de 6 años WPPSI a Violeta y Sebastián fueron:

\section{Tabla 9}

Resultados del diagnóstico inicial

\begin{tabular}{|c|c|c|c|}
\hline & Violeta 4 años 8 meses & $\begin{array}{l}\text { Sebastián } \\
\text { Edad de } 8 \text { años } 4 \text { meses }\end{array}$ & $\begin{array}{l}\text { Sofía } \\
\text { Edad } 3 \text { años } 2 \text { meses }\end{array}$ \\
\hline Verbal & $\begin{array}{l}22 \text { equivalente a } 65 \\
\text { Deficiente mental leve }\end{array}$ & $\begin{array}{l}19 \text { Equivalente a } 61 \\
\text { Deficiente mental leve }\end{array}$ & \multirow{3}{*}{$\begin{array}{l}\text { Test de Desarrollo de } \\
\text { Brunet -Lezine. Edad de } \\
\text { Desarrollo }\end{array}$} \\
\hline Ejecuciön & $\begin{array}{l}27 \text { equivalente a } 69 \\
\text { Deficiente mental Leve }\end{array}$ & $\begin{array}{l}39 \text { Equivalente a } \\
85 \text { Normal Torpe }\end{array}$ & \\
\hline Total & 49 equivalente a 63 & 58 Equivalente a 70 & \\
\hline C.I. & Deficiente mental leve & C.I. Limítrofe & $\begin{array}{l}\text { E.C }=38 \text { meses (Edad } \\
\text { Cronológica } \\
\text { E.D }=20 \text { meses (edad } \\
\text { de Desarrollo) }\end{array}$ \\
\hline
\end{tabular}

Fuente: Juan Carlos Guachamín (2017) 
Luego de 8 meses de recibir terapias, 3 veces a la semana, una hora diaria y de esta hora dedicarle 30 minutos en el Consultorio Terapéutico Infantil a la aplicación de las TIC; lo resultados tuvieron una mejoría considerable pues a continuación se detallas los resultados que obtuvieron los niños:

Tabla 10

Cuadro resumen de logros con relación al Coeficiente Intelectual

\begin{tabular}{|l|l|l|l|}
\hline Verbal & $\begin{array}{l}\text { Violeta } \\
4 \text { años } 8 \text { meses }\end{array}$ & $\begin{array}{l}\text { Sebastián } \\
\text { Edad d 8 años 4 meses } \\
\text { (Limítrofe) }\end{array}$ & $\begin{array}{l}\text { Sofía } \\
\text { Edad 3 años 2 meses }\end{array}$ \\
\hline Ejecución & $\begin{array}{l}36 \text { Equivalente a } \\
81 \text { (Normal Torpe) }\end{array}$ & $\begin{array}{l}\text { 29 Equivalente a } 74 \\
\text { (Limítrofe) }\end{array}$ & $\begin{array}{l}\text { Test de Desarrollo de } \\
\text { Brunet -Lezine. }\end{array}$ \\
\hline \multirow{2}{*}{ Total } & $\begin{array}{l}\text { 69 Equivalente a 91 } \\
\text { Coeficiente } \\
\text { Intelectual } \\
\text { Limítrofe }\end{array}$ & $\begin{array}{l}\text { E.C }=38 \text { meses } \\
\text { Coeficiente Intelectual } \\
\text { (Edad Cronológica) }\end{array}$ \\
\hline
\end{tabular}

Fuente: Juan Carlos Guachamín (2017)

Tabla 11

Cuadro resumen

\begin{tabular}{|l|l|l|l|}
\hline \multirow{3}{*}{ Antes } & $\begin{array}{l}\text { Violeta } \\
4 \text { años } 8 \text { meses }\end{array}$ & $\begin{array}{l}\text { Sebastián } \\
\text { Edad } 8 \text { años 4 meses }\end{array}$ & $\begin{array}{l}\text { Sofía } \\
\text { Edad 3 años 2 meses }\end{array}$ \\
\hline $\begin{array}{l}\text { Deficiente mental } \\
\text { leve }\end{array}$ & $\begin{array}{l}\text { 58 Equivalente a 70 } \\
\text { C.I. Limítrofe }\end{array}$ & $\begin{array}{l}\text { E.C=38 meses (Edad } \\
\text { Cronológica } \\
\text { E.D }=20 \text { meses (edad } \\
\text { de Desarrollo }\end{array}$ \\
\hline Después & $\begin{array}{l}\text { 69 Equivalente a 78 } \\
\text { Coeficiente }\end{array}$ & $\begin{array}{l}\text { 72 Equivalente a 80 } \\
\text { Coeficiente } \\
\text { Intelectual } \\
\text { Limítrofe }\end{array}$ & $\begin{array}{l}\text { E.C }=38 \text { meses (Edad } \\
\text { Cronológica } \\
\text { E.D }=26 \text { meses (Edad } \\
\text { de Desarrollo) }\end{array}$ \\
\hline
\end{tabular}

Fuente: Juan Carlos Guachamín (2017) 
189

\section{Interpretación cualitativa}

Los evaluados presentan un coeficiente mejor al inicial, lo que indica que al adaptarse al trabajo terapéutico a través de aplicación de las TIC. Demuestra un desarrollo relevante en sus capacidades ejecutivas en relación a las verbales, posee un CI global superior a la inicial, debido a destrezas en determinadas sub pruebas, demostrando mejor capacidad de comprensión, memoria a largo plazo, formación de conceptos, interés en el medio social y esfuerzo intelectual. Además de las funciones ejecutivas como mejor capacidad de percepción, visual, orientación espacial, usos de conceptos abstractos.

Indudablemente el trabajo profesional del equipo multimodal, Terapeuta de Lenguaje, Terapeuta Físico y Psicólogo Clínico, así como el apoyo de los padres de familia que creyeron en la propuesta de la aplicación de las TIC y ser testigos del progreso integral y rápido de sus hijos e hijas con trastornos neurológicos fue determinante para alcanzar los objetivos trazados.

La satisfacción de los padres de incluir a sus hijos e hijas a la escuela con las herramientas necesarias ha sido la mejor recompensa para el equipo profesional. Los resultados positivos alcanzados en esta experiencia profesional nos conducen a trabajar con otras personas con alteraciones neurológicas similares a la vez nos motiva compartir esta labor con otros profesionales o instituciones interesadas.

No se puede pasar por alto la ayuda profesional de los tutores que siempre estuvieron prestos para orientarnos, guiarnos especialmente sobre la aplicación de las tics adecuadas en cada caso. 
190

\title{
Recursos utilizados
}

\author{
Figura 100
}

Recursos utilizados en experiencia según el neuroaprendizaje

\section{RECURSOS HUMANOS}

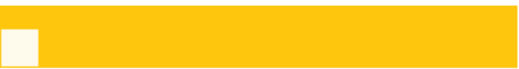

Equipos profesional

Niños niñas

familia
RECURSOS

MATERIALES

computador con pantalla táctil

tablet, VISOR 3D, Audífonos, sillas

correctivas, celular android

Fuente: Juan Carlos Guachamín (2017) 


\section{Conclusiones}

El uso de las TIC constituye un gran aporte para lograr la inclusión en la educación que debe ir de la mano de una buena actitud por parte de la comunidad educativa; puesto que los cambios generados por la integración de la tecnología a la enseñanza están en constante avance y requieren la preparación de los docentes. Asimismo, es imprescindible que los mismos comprendan el significado de la diversidad y la posicionen como un valor y una oportunidad de mejorar y enriquecer su enseñanza mas no como un problema o amenaza a su trabajo (Ávila \& Esquivel, 2009).

Las TIC no deben convertirse en un fin como se ha visto mayoritariamente o usarlos por usar, sino que deben ser el medio a través del cual un docente facilita el aprendizaje de sus estudiantes. De acuerdo con Fonoll (2004), al usar este medio con personas con diversidad funcional, el docente debe asegurarse de que el mencionado evite la discriminación social, sirva de ayuda técnica de las discapacidades, permita atención individualizada y posibilite la aplicación de estrategias nuevas e innovadoras.

En cuanto a la normativa y los requerimientos del sistema educativo, otro beneficio de usar las TIC en las instituciones educativas es que los estudiantes pueden capacitarse, aprender a usarlas de manera correcta y así mejorar su aprendizaje. El educador requiere estar preparado para contribuir en este proceso pues tiene un rol fundamental al ayudar a sus educandos en el camino para alcanzar dichas capacidades. Además, el docente tiene que generar un ambiente adecuado en el salón de clase que facilite la utilización de las TIC y brinde oportunidades a los estudiantes para aprender y comunicarse gracias a ellas (UNESCO, 2008).

El uso de TIC no es solo para sofisticar el proceso de enseñanza pues su principal función radica en facilitar el aprendizaje de estudiantes 
192

cuya diversidad funcional aún se trata como una desventaja. Para que esto cambie, la tecnología debe dar opciones distintas para que los docentes evalúen a este grupo de estudiantes y en base a los resultados puedan mejorar su metodología ya que "una evaluación que parte de que todos los alumnos son iguales (es lo que se sobreentiende fácilmente cuando se evalúa del mismo modo a todos), nunca favorecerá la atención a la diversidad ni estimulará la educación inclusiva” (Casanova, 2011, p. 82).

Los aportes de las buenas prácticas presentadas en esta guía, muestran que el uso de la tecnología en la dinámica cotidiana de la escuela genera alta motivación en los estudiantes hacia el aprendizaje de igual manera la dinámica y el clima institucional de la escuela cambian positivamente creando una nueva relación entre el docente y el estudiante.

Un aspecto relevante a considerar en la educación inclusiva es la evaluación puesto que, al ser el instrumento que permite determinar el aprendizaje de los estudiantes, debe considerar las individualidades de los mismos y adaptarse a las diferencias mas no resaltarlas y a su vez generar actitudes discriminatorias y más desigualdad (Murillo \& Duk, 2012). Para esto, también se debe integrar las TIC, ya que su uso facilitará la elaboración de una evaluación inclusiva que atienda la diversidad y verdaderamente retroalimente al estudiante en lugar de excluirlo. Por esa razón, es fundamental una evaluación que siga los principios de la inclusión; es decir, que sea apta para que todos puedan acceder a ella y realizarla con tecnología de apoyo. Es pertinente tener en cuenta que un instrumento evaluativo no debe cuantificar a los estudiantes sino dar pautas al docente para mejorar su proceso de enseñanza y estrategias en función de contribuir al aprendizaje de los estudiantes sin dejar de lado a aquellos con diversidad funcional (Duk \& Blanco, 2012).

Otro aporte importante es la desvinculación del uso de las TIC de la asignatura de computación ya que su uso está ligado a un proceso de interaprendizaje. Por esa razón, en todas las experiencias presentadas se las incorpora como recurso didáctico y responde a una planificación microcurricular que cubre las necesidades e intereses de los estudiantes 
193

y sus familias, poniendo énfasis en el desarrollo de habilidades comunicativas que permitan a los estudiantes interactuar en su contexto social y familiar con mayores herramientas de esta manera, los estudiantes fortalecen su capacidad de resolver problemas, mejora su autoestima.

Un efecto de la innovación de las buenas prácticas se expresa en la gestión directiva abierta a trabajar en redes de apoyo con organizaciones de la comunidad, universidades, fundaciones para de esta manera afrontar la carencia de recursos y desarrollar infraestructura tecnológica y formación docente. La contextualización del aprendizaje resulta también una característica de las experiencias presentadas.

Con esta publicación, se reconoce y valora el esfuerzo de los docentes protagonistas de estas experiencias pedagógicas, ya que este esfuerzo además de ser producto de la motivación personal, constituye un esfuerzo permanente por reflexionar, diagnosticar, registrar, evaluar y sistematizar su práctica pedagógica diaria. La presente guía es una forma de revalorizar el trabajo docente, difundirlo y aportar en el desarrollo de capacidades de los educadores. 



\section{Bibliografía}

Ávila, A., y Esquivel, V. (2009). Educación Inclusiva en nuestras aulas. San José: Coordinación Educativa y Cultural Centroamericana, CECC/SICA.

Casanova, M. A. (2011). Evaluación para la Inclusión Educativa. Revista Iberoamericana de Evaluación Educativa, 4(1), 78-89.

Chisvert, M.J., Ros, A. y Giménez, E. (2013). Estado de la cuestión de la acreditación de la experiencia profesional. En Ruiz, C. et al. (Grupo CIFO). Formación para el trabajo en tiempos de crisis. Balance y prospectiva (Actas de congreso). CD. Barcelona: Tornapunta Ediciones.

Comisión Económica para América Latina y el Caribe (2011). Las personas con discapacidad en América Latina: del reconocimiento jurídico a la desigualdad real. Santiago de Chile: CEPAL.

Congreso de la Nación Argentina (2006). Ley de Educación Nacional 26.206. Recuperado de: https://goo.gl/LRJiiS

Duk, C., y Blanco, R. (2012). Documento de Estudio curso de formación "Estrategias de Diversificación de la Enseñanza”. Ministerio de Educación de Chile.

Fenollar-Cortés, J. (2015) Una aproximación heurística a la heterogeneidad del TDAH. Revista de Psicología Clínica con Niños y Adolescentes, 2(2), $115-120$

Fonoll, J. (2004). Nuevos periféricos utilizados como ayudas técnicas para personas con discapacidad. En: Tecnología, educación y diversidad: retos y realidades de la inclusión digital. Actas del III Congreso Nacional de Tecnología, Educación y Diversidad (TECNONEET). Murcia: Consejería de Educación y Cultura.

Gaitán, V. (2013). Gamificación: el aprendizaje divertido. Recuperado de: https://goo.gl/21DPH5

Laverde, P. (2015). Estudio del Conocimiento. Quito: Instituto Tecnológico Superior Benito Juárez.

López-Escribano C. (2007). Contribuciones de la neurociencia al diagnóstico y tratamiento educativo de la dislexia del desarrollo. Revista Neurología, 44(03), 173-180. 
196

Luque D. J. y Rodríguez G. (2007). Consideraciones en la intervención psicopedagógica en el alumnado universitario on discapacidad. Revista Universidad Castilla La Mancha, 16, enero/diciembre. 2a Época. Número (versión impresa).

Marchesi, A., Martín, E., Casas, A., Ibáñez, I., Monguillot, V., y Rivièrey, F. (2003). Tecnología y aprendizaje. Investigación sobre el impacto del ordenador en el aula. Madrid: Editorial SM.

Martínez L. y Ribes A. (2008). Videollamadas entre centros. Madrid: Ministerio de Educación y Ciencia.

Montoya-Sánchez, E. y Herrera-Gutiérrez, E. (2014). Manifestaciones del TDAH en la etapa de educación infantil y cómo afrontarlas. En: Á. Calvo (Coord.), Claves para una educación diversa. Murcia: Consejería de Educación

Murillo, J., \& Duk, C. (2012). Una evaluación inclusiva para una educación inclusiva. Revista Latinoamericana de Educación Inclusiva, 6(1), 11-13.

Oficina Internacional del Trabajo (2008). Análisis del empleo y del trabajo. Directrices para identificar empleos para personas con discapacidades. Ginebra: OIT.

Olmos, E., Cascales, A. y Alcañiz, M. (2017). Estimulación sensorial en entornos virtuales inmersivos (EVI) para niños con trastorno del espectro autista. En: P. Arnaiz, Ma D. Gracia, y F.J. Soto (Coords.), Tecnología accesible e inclusiva: logros, resistencias y desafíos. Murcia: Consejería de Educación, Juventud y Deportes.

Ripani, M. (2014). Anexo curricular de educación digital nivel primario. Ciudad Autónoma de Buenos Aires: Secretaría de Gobierno de la Ciudad de Buenos Aires.

Robinson, K. (2015). Escuelas creativas. Barcelona: Grijalbo

Snell, E. (2006). Materiales para el desarrollo de la comunicación y el apoyo al alumnado con discapacidad. Sevilla: Junta de Andalucía.

Soto, F. (2013). Promoviendo el uso de tecnologías inclusivas en contextos educativos diversos. Entera 2.0. Revista Digital, (1), 14-22.

UNESCO (2008). Estándares de competencias en TIC para docentes. Recuperado de: https://goo.gl/dkzSKX

(2012). Informe sobre el Uso de las Tecnologías de Información y Comunicación (TIC) en la Educación para Personas con Discapacidad. Recuperado de: https://goo.gl/V3hZji

(2015). Transformar nuestro mundo: Agenda 2030 para el Desarrollo Sostenible. Nueva York: Organismos Internacionales. 


\section{7}

(2015). Declaración de Nueva Delhi sobre TIC inclusivas al servicio de las personas con discapacidad: hacer del empoderamiento una realidad. Recuperado de: https://goo.gl/NDCusi

Verdugo, M.A. y Jordán de Urríes, B. (Coords.) (2001). Apoyos, autodeterminación y calidad de vida. Salamanca: Amarú.

Vygotsky, L.S. (1978). Pensamiento y lenguaje. Madrid: Paidos. 



\section{Informantes}

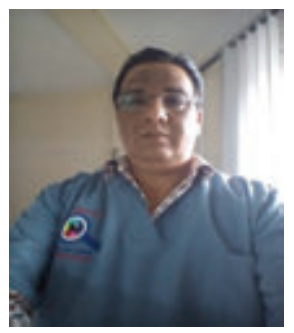

\section{Franklin Aguayo}

Optómetra Universidad San Francisco de Quito. Especialista en Baja Visión y Rehabilitación de Personas con Discapacidad Visual. Director de Fundación Baja Visión Ecuador

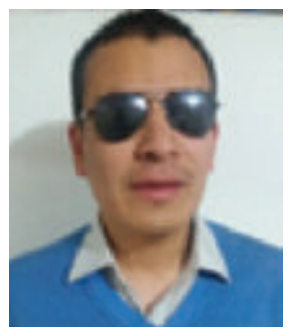

\section{Christian Paúl Castañeda Bravo}

Psicólogo Clínico, con experiencia y formación en musicoterapia. Director de asuntos sociales en la sociedad de ciegos de Pichincha Luis Braille. Maneja talleres de capacitación en proyectos de familia, inclusión laboral y manejo de herramientas tiflotécnicas en el campo de la discapacidad visual en la Consultora C \& Q consultores. Trabaja en la tiflobiblioteca de la Universidad Politécnica Salesiana en el área de accesibilidad, navegación y transformación de textos en formatos legibles para personas con discapacidad visual.

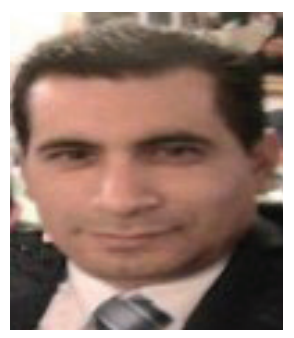

\section{Alberto Duchi Bastidas}

Estudios: Ingeniero Informático Universidad Central del Ecuador. Magister en Gerencia de Sistemas Escuela Politécnica del Ejército. Master en Seguridad Informática Universidad Abierta de Cataluña. Funciones Actuales: Docente de la Carrera de Ingeniería de Sistemas - UPS. Docente Investigador de Grupo de Educación Inclusiva - UPS 


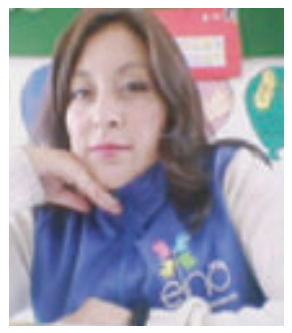

\section{Adriana Cecilia Guachamín Moso}

Licenciada en Ciencias de la Educación, con experiencia laboral con niños, niñas y jóvenes con discapacidad intelectual; actualmente terminando de cursar el Experto en TIC en Discapacidad, trabajo en la Fundación Individualizada para niños, niñas y adolescentes E.I.N.A en el área de educación básica.

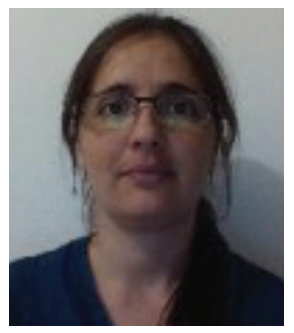

\section{Evelina Mariel Lamberti}

Licenciada y Profesora en Educación Especial, Especialista Docente de Nivel Superior en Educación y TIC y Diplomada en Gestión Escolar para la Inclusión Educativa. Actualmente terminando de cursar el Experto en TIC, inclusión y discapacidad. Es Profesora titular en Escuela Normal Víctor Mercante -Nivel Superior -, en el dictado de la asignatura "Historia y Perspectivas de la Educación Especial" y del seminario "Perspectivas Sociopolíticas de la Educación Especial”, dentro del Profesorado en Educación Especial con Orientación en Discapacidad Intelectual. Es Maestra de Grado titular, en segundo ciclo, en Escuela Especial Pablo VI.

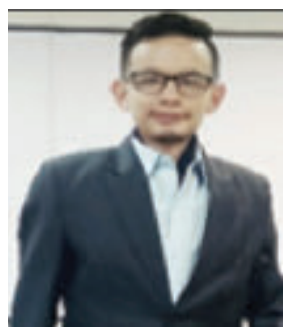

\section{Pablo Andrés Laverde Collaguazo}

Bachiller Físico Matemático, expresidente del consejo estudiantil de su colegio, inspirado en la búsqueda de la belleza y elegancia matemática sigue su camino estudiando una Ingeniería. Pese a su discapacidad ha sabido llevar a cabo sus labores en todo sentido.

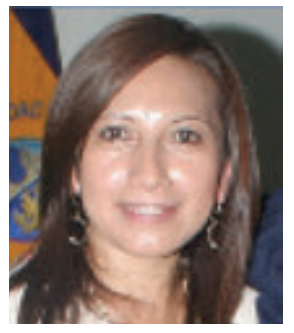

\section{Miriam Bernarda Gallego Condoy}

Docente de la Universidad Politécnica Salesiana. Dra. Ciencias de la Educación. Master en Necesidades Educativas Especiales. Docente de la Universidad Politécnica Salesiana Ecuador. Miembro del Grupo de Investigación de Educación Inclusiva (GEI). Cátedra UNESCO - UPS 

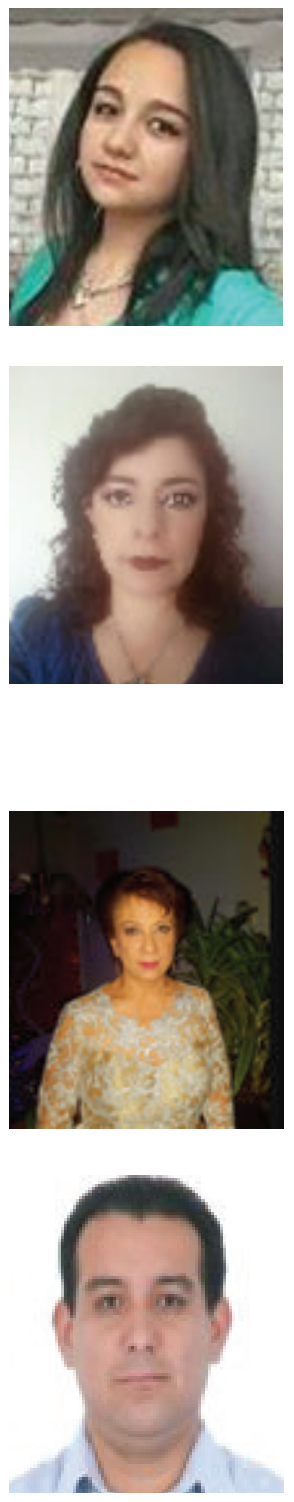

\section{Jessica Jazmín Rivadeneira Peñafiel}

Bachiller en Ciencias Generales, estudiante de Licenciatura en Ciencias de la Educación Básica en la Universidad Politécnica Salesiana. Ayudante de Investigación del Grupo de Educación Inclusiva (GEI) en la Universidad Politécnica Salesiana. Tesorera de la directiva de la carrera de Educación Básica, parte de la Federación de Estudiantes de la Universidad Politécnica Salesiana (FEUPS).

\section{Marcia Giovanna Bedoya Navas}

Doctora en Psicología Infantil y Psico rehabilitación de la Universidad Central del Ecuador. Magister en Educación Especial con mención en Personas con Discapacidad Visual de la Universidad Politécnica Salesiana. Coordinadora Técnica y Psicóloga Rehabilitadora en el Instituto de Educación Especial del Norte de la ciudad de Quito. Rectora del Colegio Montpellier International. Experiencia de 21 años en Rehabilitación Visual, Discapacidad Intelectual, Discapacidad Motriz, Baja Visión, Autismo, Multidiscapacidad y Retos Múltiples.

\section{Yolanda Ortiz}

Master en Educación Infantil y Especial, cursa las carreras de Terapia de lenguaje y Ciencias de la Educación. Galardonada durante el Congreso Nacional en el día de la mujer por la labor que viene realizando desde hace 25 años al formar el programa y los proyectos de la Fundación FINE. Tiene experiencia en discapacidad intelectual y múltiple con programas de Cuidado diario. Vida independiente: Proyecto respiro ganadora del premio nido 2013 y ganadora del premio duende Soñador.

\section{Daniel Salas Rodríguez}

Psicólogo Clínico con amplia experiencia y formación para la atención integral de las personas con Discapacidad Intelectual y del desarrollo. Ha sido galardonado con el premio NOUS a la Excelencia Educativa 2014 por el desarrollo e DESARROLLO DE LA EXPERIENCIA del Programa de Vida Independiente para Personas con Discapacidad Intelectual Moderada de Fundación EINA. Asesor y conferencista internacional para FEPAPDEM, RIADIS, EINA, BEST BUDDIES entre otros. 

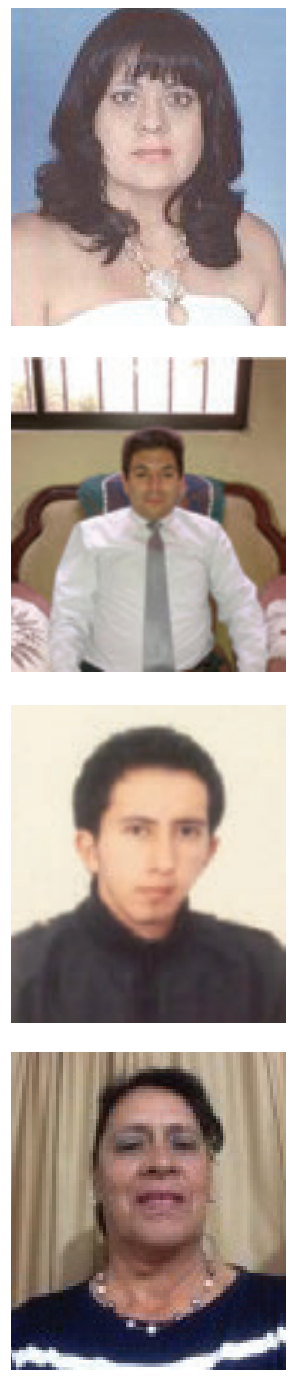

\section{Elsa Silvania Salazar Escobar}

Madre de un joven con discapacidad intelectual, responsable de proveer cuidado físico, recursos económicos, seguridad, salud, afectividad, educación e inserción laboral y con la preocupación por el futuro de Jorge Sebastián. Docente de la Universidad Politécnica Salesiana. Magister en Educación Inicial, Diplomado Superior en Investigación Socioeducativa, Licenciada en Parvularia.

\section{Mauricio Andrés Suárez Rojas}

Máster en Comunicación estratégica y Comunicador social. Se desempeña como colaborador de la Universidad Politécnica Salesiana, en el área de biblioteca en la sección para personas con discapacidad visual, espacio donde contribuye en el manejo de lectores de pantalla y en el soporte académico en diversas ramas del conocimiento.

\section{Andrés Steve Jaramillo Buitrón}

Licenciado en Ciencias de la Educación mención Informática en la Universidad Central del Ecuador. Diplomado de Experto en TIC, Inclusión y Discapacidad por parte de la Universidad Politécnica Salesiana. Master Universitario en E-learning y Redes Sociales en la Universidad Internacional de la Rioja (UNIR), Rioja - España. Auxiliar de Biblioteca de la Universidad Politécnica Salesiana.

\section{Gloria Esperanza Sánchez Cedillo}

Magister en Educación Especial/.Lcda. En Educación Primaria/ Experta Universitaria en atención a la diversidad. LABORAL: Función actual Docente de la Unidad Educativa especial del Azuay.

EXPERIENCIA. Cuarenta años de docencia en Educación Especial con las diferentes aéreas de discapacidad, FUNCIONES. Directora/ Líder Institucional. /Facilitadora de procesos de capacitación/ Asesora en Proyectos de Intervención Social. 

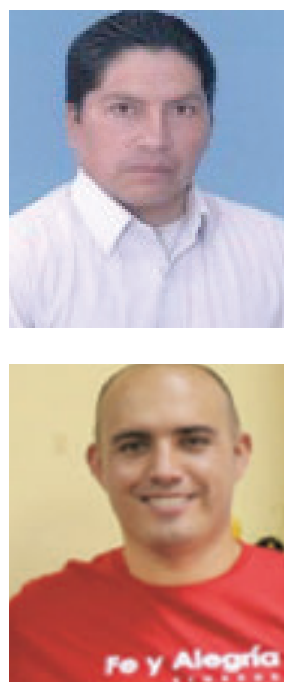

\section{Juan Carlos Guachamín Chalco}

Dr. en Psicología Clínica, Coordinador pedagógico y director de proyectos en el Centro de Niños Especiales "Santiago Saltos", Director del Centro de Niños y Niñas con Discapacidad Intelectual Severa "ASOMAD", Director del Centro Particular "C.T.I." Consultorio Terapéutico Infantil Integral. Actualmente finalice el Diplomado "Experto en TIC, Inclusión y Discapacidad".

\section{Jaime Sarmiento}

Ingeniero en Gerencia y Liderazgo (2007)

Magíster en Desarrollo Local con mención en Formulación y Evaluación de Proyectos de Desarrollo Endógeno (2015) por la Universidad Politécnica Salesiana, Sede Quito - Ecuador. Sus principales áreas de estudio son los proyectos sociales, la violencia intrafamiliar, los derechos humanos y la inclusión educativa.

Ex docente de Proyectos Sociales en la Universidad Politécnica Salesiana, con más de 10 años de experiencia en la formulación y gestión de proyectos de desarrollo con énfasis en educación, derechos humanos, inclusión, discapacidad y TIC, actualmente se desempeña como Gerente del Proyecto Tecnología para la Inclusión en Fe y Alegría Ecuador. Es socio del Colectivo Pro Derechos Humanos desde el 2005 y ha formado parte de importantes coaliciones por los derechos de la juventud. Ha participado en varios congresos, encuentros y talleres a nivel nacional e internacional, presentando la sistematización de experiencias exitosas desarrolladas en proyectos educativos, especialmente en el campo de los derechos humanos, la atención a la diversidad y la inclusión educativa de personas con discapacidad. Ha colaborado en la coordinación general del Diseño del Modelo Nacional de Educación Bilingüe Bicultural para Personas Sordas, del Modelo Nacional de Gestión y Atención para Instituciones de Educación Especial y del Modelo de Inclusión Educativa de Fe y Alegría. 
